\title{
Peripheral arterial occlusive disease : prevalence and diagnostic management in general practice
}

Citation for published version (APA):

Stoffers, H. E. J. H. (1995). Peripheral arterial occlusive disease : prevalence and diagnostic management in general practice. [Doctoral Thesis, Maastricht University]. Datawyse / Universitaire Pers Maastricht. https://doi.org/10.26481/dis.19950601hs

Document status and date:

Published: 01/01/1995

DOI:

10.26481/dis.19950601hs

Document Version:

Publisher's PDF, also known as Version of record

\section{Please check the document version of this publication:}

- A submitted manuscript is the version of the article upon submission and before peer-review. There can be important differences between the submitted version and the official published version of record. People interested in the research are advised to contact the author for the final version of the publication, or visit the DOI to the publisher's website.

- The final author version and the galley proof are versions of the publication after peer review.

- The final published version features the final layout of the paper including the volume, issue and page numbers.

Link to publication

\footnotetext{
General rights rights.

- You may freely distribute the URL identifying the publication in the public portal. please follow below link for the End User Agreement:

www.umlib.nl/taverne-license

Take down policy

If you believe that this document breaches copyright please contact us at:

repository@maastrichtuniversity.nl

providing details and we will investigate your claim.
}

Copyright and moral rights for the publications made accessible in the public portal are retained by the authors and/or other copyright owners and it is a condition of accessing publications that users recognise and abide by the legal requirements associated with these

- Users may download and print one copy of any publication from the public portal for the purpose of private study or research.

- You may not further distribute the material or use it for any profit-making activity or commercial gain

If the publication is distributed under the terms of Article $25 \mathrm{fa}$ of the Dutch Copyright Act, indicated by the "Taverne" license above, 
Peripheral arterial occlusive disease:

prevalence and diagnostic management in general practice 


\section{CIP-DATA KONINKLIJKE BIBLIOTHEEK, DEN HAAG}

Stolfers, Henri Elise Johannes Hubertus

Periplical arterial occlusive disease: prevalence and diagnostic management in general practice/Henri Elise Johannes Hubertus Stoffers. * Maastricht: Universitaire Pers Maastricht. - Ill.

Thesis Rijksuniversiteit Limburg Mastricht. - With ref. - With summary in Dutch. ISBN 90-5278-1869

Subject headings: peripheral arterial occlusive disease / epidemiology / general practice

Henri EJH Stoffers, Maastriche 1995

All rights reserved. No pare of this book may be reproduced or transmitred in any form or by any means "lectronic or mechanical, including photocopying, recording, or by any information storage and retricval system whou written permission from the publisher, except for the inclusion of brief quotations in an revicw.

Publisher Datawyse | Universinatre Pers Maastricht $(+31 \times(0) 43-473460)$

Printed by Krips Repro, Meppel

The photograph used on the front cover (The dorsalis pedis pulse') was reproduced with permission from the publisher from: Barbara Bates. A guide to physical examination and bistory taking. fith ed. Philadelpbia: 1. B. Lippincoti Comprany, 1987 (figure 3 on page 416 ). 


\title{
Peripheral arterial occlusive disease: prevalence and diagnostic management in general practice
}

\author{
PROEFSCHRIFT
}

ter verkriijging van de graad van doctor aan de Rijksuniversiteit Limburg te Maastricht, op gezag van de Rector Magnificus, Prof. Mr. M.J. Cohen, volgens het besluit van het College van Dekanen, in het openbaar te verdedigen op donderdag 1 juni 1995 om 14.00 uur

door 


\section{Promotoren}

Prof. Dr. J.A. Knotnerus

Prof. Dr. P.J.E.H.M. Kitslaar

Beoordelingscommissie

Prof. Dr. P. Pop (voorzitter)

Dr. A.P.M. Gorgels

Prof. Dr. P.G. Knipschild

Prof. Dr. J.A. Rauwerda (Vrije Universiteit Amsterdam)

Prof. Dr. C. van Weel (Katholieke Universiteit Nijmegen)

This study was frnanced by the Netherlands Organization for Scientific Research (number 900-715.154) and the "Praeventiefonds' (28-1323). Doppler devices were donated by ASTA Medica B.V., Diemen.

The publication of this book was made possible by grants from:

Hoechst Holland N.V., Amsterdam,

Abbot B.W. Amstelveen

E. Merck Nederland B.V., Amsterdan

Pfozer B. V., Capelle a/d IIssel

ASTA Medica B.V., Diemen

Ciba-Geigy B. ., Arnhem

This support is gratetully acknowledged. 


\section{Preface}

The origin of the Limburg PAOD Study lies with an experienced general practitioner who had become interested in the prevention and treatment of cardiovascular diseases. After a surgeon friend had explained to him the possibilities of the pocket Doppler device for the diagnosis of peripheral arterial occlusive disease (PAOD), he gained experience using this instrument in his own practice. He realised that its use could have important implications for the diagnosis and treatment of patients with PAOD by the general practitioner. It would be easier than before to identify PAOD in patients presenting with leg problems and follow up of treated patients would be more objective. Furthermore, identification of patients with PAOD would imply identification of patients with increased risk for ischemic heart disease and cerebrovascular disease.

This physician worked part-time as a staff member of the Vocational Training programme of the Department of General. Practice of the University of Limburg in Maastricht. As the department regularly held conferences on general practice performance, he could discuss his ideas with others. These discussions resulted in a publication on the management of PAOD and in a proposal to the "Protocol Project" of the cooperating Dutch university departments of general practice.' The 'Praeventiefonds', which was asked to finance this project, recommended that a research proposal with respect to PAOD be submitted. With the cooperation of varions experts a research project on the natural course and the treatment of PAOD was finally instigated ('Praeventiefonds', 1986).

Given the infrastructure that would have to be developed for this research project, it seemed expedient to develop a complementary study on the diagnostic value of data obtained by history-taking and physical examination in relation to PAOD. Such a project would fit in with the research programme "Efficacy of diagnostics in general practice' of the Department of General Practice. As a result of the experimental 'General Practitioner Research Training Programme' a proposal. for a study on the prevalence and clinical diagnosis of PAOD was formulated. ${ }^{2,3}$ It was awarded a grant from the "Netherlands Organization for Scientific Research". "This part of the Limburg PAOD Study is the subject of this book. Its official start was January 1988.

Recently, a third study - on the incidence and prognosis of PAOD - has started ("Netherlands Heart Foundation", 1994).

The experienced physician mentioned above was They Lemmens, general practitioner in Maastricht from 1959 to 1988 and senior member of the Department of General Practice. He died on 18 September 1990 at the age of 59. He was the spiritual father not only of the 'Limburg PAOD Study' but also of a study on the diagnosis of cardiac arrhythmias ("HRS Study") and a study on the prevention of thromboembolic complications of atrial fibrillation ('PATAF Study'). 
To me, They also was a mentor in matters concerning personal choices with regard to the triangle "practice - university - family". With pleasure I recall his straight forward opinions, our lively discussions, his practical wisdom and - above all - his stimulating enthusiasm. I hope he would have appreciated this first harvest of the scientific tree he helped to plant, the way he used to like the first apples from his orchard.

\section{Henri ('Jelle') Sroffers}

1 Lemmens ThGJ. De patiënt met een perifere arteriële circulatiestoornis. Nieuw kompas voor de huisarts 1986; IV: 6.1-12.

2 Geus CA de. De opleiding tot huisarts-onderzoeker in Maastricht. Medisch Contact 1986; 41: $1177-8$.

3 Root J Op "t, Geus CA de. Research training for general practitioners: an experiment in the Netherlands. Fam Practice 1992; 9: 82-4. 


\section{Contents}

Preface

Chapter 1 Introduction

\section{Literature reviews}

Chapter 2 Peripheral arterial occlusive disease in general practice.

A literature review.

Chapter 3 Noninvasive vascular tests in general practice.

A literature review.

Observational studies

Chapter 4 Aims of the observational studies

Chapter 5 General design, methods and variables

Chapter 6 Selection process and populations 50

Chapter 7 The reproducibility of the ankle-brachial systolic pressure ratio

Chapter 8 The diagnostic power of the measurement of the ankle-brachial systolic pressure ratio in general practice

Chapter 9 The prevalence of symptomatic and asymptomatic peripheral arterial occlusive disease. The Limburg PAOD Study.

Chapter 10 The predictive value of signs and symptoms for the diagnosis of peripheral arterial occlusive disease in general practice. $A$ multivariable approach.

Chapter 11 General discussion

Chapter 12 Summary

Chapter 13 Samenvatting

Dankwoord (Acknowledgements)

Curriculum Vitae

Appendices The measurement of the AB-ratio (Chapter 3)

Participating generall practice centres (Chapter 5)

The postal questionnaire (Chapter 5)

Registration forms (Chapter 5)

Commentary on registration forms \& variables (Chapter 5) 168

Additional tables (Chapter 6)

Comparison of ROC curves (Chapter 8)

Recalculation of prevalence figures (Chapter 9)

Calculation of the predicted probability of PAOD (Chapter 10) 176 
Streamline flow is silent

Remember that, my boys,

But when the flow is twrbulent

There's sure to be a noise.

So when your stethoscope picks up

A bruit, murmur, sigh,

Remember that it's turbulence

And you must figure wolby.

A.C. Burton 


\section{Chapter 1 Introduction}

Summary This book describes studies on the prevalence and diagnostic management of peripheral arterial occlusive disease (PAOD) in general practice. $P A O D$ refers to the manifestation of atherosclerosis in the lower limb distal to the arortic bifurcation.

There is a number of reasons for paying attention to the management of patients with $P A O D$ in general practice: diagnosis, conservative treatment and monitoring of patients with this chronic disorder are primarily tasks of the general practitioner; the disease may lead to serious complications that should be prevented wherever possible; PAOD is an expression of generalized atherosclerosis; therefore, regular monitoring of risk indicators for cardiovascular disease might be appropriate in PAOD patients.

In this book we try to answer the following principal research questions: "Wthat is the prevalence of PAOD in a general (practice) population?' and 'What is the diagnostic value of bistory-taking and physical examination with respect to PAOD?" In addition, we deal with the reproducibility and validity of the ankle-bracbial systolic pressure ratio (AB-ratio) in general practice.

Reviews of the literature are presented in the chapters 2 and 3. In chapter 4 the aims of our study are presented. The general methodology of the study is described in the chapters 5 and 6. In the chapters 7.10 the results of our studies are presented freproducibility and validity of the ABratio, prevalence of PAOD, diagnostic value of signs and symptoms. In the general discussion our findings are summarized and implications for general practice and future research are discussed (chapter 11).

Basic to general practice is adequate management of somatic problems: superfluous as well as insufficient diagnostic and therapeutic actions should be avoided. The guideline is to start out from a broad set of diagnostic hypotheses which is narrowed down along the way, taking into account not only general practice epidemiology but also the possibility of serious pathology. On the basis of this problem solving process the general practitioner is able to inform the patient about diagnosis and prognosis, to propose therapeutic strategies and to offer advice with regard to supplementary tests or referrall to a specialist. ${ }^{1}$

\section{Clinical research in general practice}

In order to be able to practice this skill, the general practitioner requires descriptive and clinical epidemiological data., Amongst other things, adequate diagnostic management presupposes that the general practitioner knows the prior probability of a disorder - incidence, prevalence - in his patient population or in relevant parts thereof, and knows the diagnostic significance - sensitivity, specificity, predictive values - of diagnostic procedures - history-taking, physical examination, 
supplementary tests - applied by him. ${ }^{3}$

General practice research on the diagnostic value of history and physical examination in specific disorders may contribute to the acquisition of this type of clinical epidemiological knowledge. This is also the case for research on the prevalence of particular disorders - or of the various stages of these disorders - in the general practice population. Research on these clinical aspects of the general practice field is still in its initial phase. Much of the knowledge of the relationships berween symptoms and diagnoses derives from medical specialist setings and ought to be reformulated for the general practice "clinic',

In contrast to the situation in the (university) hospital, scientific research and health care are physically separated activities in general practice. Health care is provided in the practice, while research is mainly conducted in university departments of general practice. A minority of general practitioners is at home in both worlds. Now and then these worlds meet: when the results of research are presented by researchers to their practising colleagues.

A crucial question is how it may be achieved that ideas for research arising in daily practice are given the opportunity to be transformed into a research proposal. If scientific research in general practice is to remain relevant for general practice care, it is imperative that such opportunities exist. In this respect it is essential that general practitioners have access to a critical but constructive forum and to the scientific literature."

\section{Peripheral arterial occlusive disease: the Limburg PAOD Study}

The Limburg PAOD Study is an example of a successful fecundation of 'practice' and 'research'. PAOD - peripheral arterial occlusive disease - is the manifestation of atherosclerosis of the arteries of the lower limb and is the most common peripheral vascular disorder in the elderly. In general practice publications the disease attracts less interest than coronary and cerebral artery disorders. Conceivably, this is because PAOD is generally assumed to run a mild course. Nonetheless, there is a number of reasons for paying attention to the management of patients with PAOD in general practice:

- (early) diagnosis, conservative treatment and monitoring of patients with this chronic disonder are primarily tasks of the general practitioner;

the disease may lead to serious complications - impaired mobility, severe pain, gangrene, amputation - that should be prevented wherever possible;

- PAOD is an expression of generalized atherosclerosis; therefore, regular monitoring of risk indicators for cardiovascular disease seems appropriate in PAOD
pacients.

This book presents the report of the first part of the Limburg PAOD Study. We

try to answer the following principal research questions:

- What is the prevalence of PAOD in a general (practice) population? What is the diagnostic value of history-taking and physical examination with
respect to PAOD?

Also the results of research on the reproducibility and validity of the ankle-brachial systolic pressure ratio (AB-ratio) - a noninvasive supplementary test - in general
practice are reported. 
The general goal of our study is to contribute to a more rational diagnostic approach by the general practitioner of patients with leg complaints in general and PAOD in particular. We also expect to increase the knowledge of the early phase of this disease: after all, it concerns patients with PAOD - including the asymptomatic, atypical and previously unknown patients - as they present themselves to the general practitioner. The results of the studies on the reproducibility and the validity of the "pocket Doppler method" will add to the discussion on the significance of this device in general practice and in epidemiologic research.

\section{Structure of this book.}

In chapter 2 a survey is presented of the literature on PAOD that was considered relevant for general practice. Considering the main topics of our study attention is focused primarily on data on the prevalence and the diagnostic management of PAOD. Chapter 3 offers a review of the literature on the measurement of the $A B-$ ratio, which is used as standard diagnostic test in this study.

The literature reviews reveal that a number of gaps exist in the knowledge on PAOD. These gaps are discussed in chapter 4, where the main and additional topics of the study are presented. The next chapters describe the methodology of the first part of the Limburg PAOD Study. In chapter 5 the general design and methods of the study are explained. Chapter 6 provides a quantitative overview of the selection process and the different populations that can be distinguished in this study.

Then the results of our studies are presented. The chapters 7 and 8 present the results of our studies on the reproducibility and the validity of the AB-ratio. In chapter 9 the results of our prevalence study are presented and chapter 10 offers the results of our analyses of the diagnostic value of clinical signs and symptoms.

The final section of this book starts with a general discussion of the study including its implications for daily practice (chapter 11). It ends with a Summary in English and Dutch ('Samenvatting') (chapters 12 and 13).

\section{References}

1 Grol R, Mesker P (red). Huisarts en toetsing. Nijmegen: Nijmeegs Unversitai Huisartsen Instituut, 1984.

2 Sturmans F. Epidemiologie. Theorie, methoden en toepassing. Derde druk. Nijmegen: Dekker \& wan de Vegn, 1986.

3 Knotmerus JA. Interpretatie van diagnostische gegevens $[\mathrm{PhD}$ Thesis]. Maastricht: Rijksunversiteit Limburg, 1986.

4 Knottnerus JA, Knipschild PG, Sturmans F. Symptoms and selection bias: whe influence of selection towards specialist care on the relationship between symptoms and diagnoses. "Theoretical Medicine 1989; 10: 67-81.4

5 Stoffers $\mathrm{HEJH}$, Kasser $\mathrm{V}$. De uitvoering wan patientgebonden aandoeningsgericht wetenschappelijk onderzoek in de huisartsprakijk. In. Es JW van, Mandema $E$, Olthuis $G$, Verstraete $M$ (red). Hat Medisch Jaur 1990. Utrecht/Antwerpen: Bohn, Sutheltema \& Holkema, 1990. 


\section{Chapter 2 Peripheral arterial occlusive disease in general practice. A literature review}

Summary This chapter presents a literature rewiew on peripheral arterial ocdusive disease (PAOD). The emphasis lies with data regarding the prevalence and the diagnosis of the disease. Literature was gathered systematically from the MEDLINE database and by using the snowball method. This chapter represents the state of affairs known to ws in March 1990.

The reported prevalence of $P A O D$ ranges from 0.2 to $11.7 \%$. It is plausible that many patients will not be known to the general practitioner and that there will be a large category of asymptomatic patients.

The prognosis of intermittent claudication is reported to be relatively favourable: in only about quarter of patients symptoms progress. However, the prognosis quod vitam" of patients with intermittent claudication is rather poor, due to the greatly increased risk of the development of cardiosascular and cerebrovascular complications. Possibly this applies to asymptomatic patients as well.

Little research bas been done on the diagnostic significance of signs and symptoms associated with PAOD. From the available data it may be concluded that the current clinical diagnostic metbods permit the general practitioner to exclude $P A O D$, whereas establishing the diagnosis cannot be done with sufficient certainty. Only few data on the diagnostic value of combinations of signs and symptoms are available. In this respect the measurement of the ankle-brachial systolic pressure ratio by means of a pocket Doppler device could be an asset to general practice.

\section{Introduction}

In this chapter a review is presented of the literature on PAOD that was considered relewant for general practice. In view of the main topics of this book the discussion is focused in particular to data concerning the prevalence and the diagnosis of PAOD.

\footnotetext{
This chapter represents a compilation and revision of the following publications:

Stoffers HEJH, Kaser V, Lemmens ThGJ, Knottnerus JA. Perifeer arterieel obstructief vatijen in de huisartspraktik: een verborgen ziektebeld? [Perpheral arterial occlusive vasculopathy in general practice: a hidden disease?] (with English summary). Huisarts Wet
$1988 ; 33: 202-6$.

Sroffers HEJH, Kaiser V, Zwetering PJ. Perifeer arterieel vatijden in de huisartspraktijk.
Bublijven 199\%; 5: (9)19-26. Stoffers FEMH, Kaiser V. Wetenschappelijke verantwoording van de NHG-Standaard Perfoer Arterieel Vaatijden. Utrech: Nederlands Huisartsen Genootschap, 1990.
} 


\section{Method}

From August 1986 the "Limburg PAOD Study" had a subscription to a twomonthly MEDLINE search via the university library. In the spring of 1988 the automatic subscription was replaced by searches in the MEDLINE database on CDROM approximately once per three months. At the time the MEDLINE database comprised articles dating from 1 January 1983. The following keywords were used: atherosclerosis, atteriosclerosis, peripheral arterial occlusive disease, intermittent claudication. The bibliographical entries thus selected were stored in a literature data base on a personal computer. Additionally, the current volumes of general medical journals were kept up with and references were looked up (snowball method'). Double entries were deleted.

This chapter represents the state of affairs known to us in March 1990." In order to check on the completeness of the collection of articles requested by us up to that date, our literature database was screened using the following keywords: general practice, family medicine; prevalence, incidence, epidemiology; diagnosis, clinical, signs, symptoms, complaint, subjective, intermittent claudication, findings, peripheral pulse, femoral, dorsal, tibial, trophic, skin, ulcer, examination; doppler, ultrasound; risk factor, predisposition; course, outcome, prognosis.

Prevalence data with regard to PAOD are only relevant to general practice if they stem from studies in moderately selected study populations. Studies using unclear inclusion criteria, an unclear method of patient selection or a highly selected sample of patients - e.g. only men or a narrowly confined age group or a specific risk group - were not considered.

There are three types of studies that produce relevant data on the prevalence of PAOD: morbidity registration studies by general practitioners, population studies on intermittent claudication and population studies using noninvasive tests. However, the results of the various prevalence studies may not simply be compared. A meaningful comparison was made possible by converting age specific prevalence data from these studies to the prevalence of PAOD in a hypothetical general practice of 2350 persons with the age distribution of the Dutch population on 1 January 1989 (i.e. the Dutch standard general practice). Minimal and maximal prevalence figures for each age category were derived from the results of the separate studies in so far as these were available for each category. The figures for all age categories were then combined to yield an estimate of the total prevalence in a standard practice (table 2.1). Obviously the validity of these comparisons is limited, given that the data stem from different studies in different populations.

Information on how to take a medical history and perform a vascular physical examination was gathered from general and specific medical textbooks. With regard to the interpretation of the results of the medical bistory and vascular examination two kinds of studies can be distinguished: studies on the variability of the peripheral pulses and studies in which signs and symptoms are compared to the outcome of noninvasive testing. Again, studies in highly selected populations were excluded from this review.

In Chapter 11 our research findings will be discussed in the light of the most recent literature. 


\section{Results}

\section{General}

The occurence of atherosclerotic disease is positively influenced by the presence of factors like hypertension, hyperlipidaemia (cholesterol, triglycerides), smoking, diabetes mellitus, obesity, little exercise and stress: the risk factors for cardiovascular disease. For PAOD in particular, risk factors are smoking, the presence of diabetes mellitus or hypertension as well as advanced age and male gender. The literature is not unequivocal as to the significance of raised serum cholesterol and triglyceride levels. In any case cholesterol level appears to be not as important as in ischemic heart disease. 1.8 All studies indicate that 'smoking' is the most significant risk factor for the development of PAOD and that it is an important parameter for the prognosis of the disease.

Atherosclerosis of the arteries of the limb may lead to a range of ischemic phenomena in the legs: no symptoms (Fontaine stage I), intermittent claudication (Fontaine II), pain at rest (Fontaine III) and (pre-)gangrene (Fontaine IV). The stages III and IV are generally referred to as 'critical ischemia'. These stages are not necessarily successive. In a review by Dormandy - discussing mainly outpatient series - was estimated that in three out of four known patients with complainrs of claudication symptoms do not progress." Generally, in approximately $25 \%$ of patients presenting with claudication complaints eventually increase. Three to $22 \%$ of these patients will undergo vascular surgery - this would correspond to $1.10 \%$ of all (known and unknown) subjects with claudication - and 1.5-5\% will undergo an amputation." The probability of clinical deterioration of PAOD or the need for an operation is greater in the first year after the diagnosis than thereafter. Important unfavourable prognostic factors are 'smoking' and 'multiple stenoses'; the level of the vascular occlusion seems less significant. ${ }^{10-13}$

Life expectancy of patients with claudication is approximately ten years less than that of healthy subjects. ${ }^{6}$ Untavourable factors for the prognosis quod witam are 'smoking', 'multiple stenoses', 'diabetes mellitus' and a 'distal' level of the vascular occlusion. 'The most important explanation for this reduced life expectancy is the fact that manifest PAOD in its turn is an unfavourable prognostic factor for the development of cardiovascular and cerebrovascular disease. 7,2 There are indications that for subjects with asymptomatic PAOD the probability of coronary or cerebral arterial disease is increased as well. ${ }^{3}$ The literature further suggests that patients with PAOD are at increased risk for developing an abdominal aortic aneurysm. ${ }^{15.16}$

Mortality in patients with PAOD is approximately 2-3 times as high as in subjects of the same age and gender without PAOD. Approximately $75 \%$ of the total mortality in patients with PAOD is accounted for by atherosclerosis of the coronary anteries $(50 \%)$, the cerebral arteries $(15 \%)$ and the abdominal aorta $(10 \%)^{9}$ One-firth of known claudication patients will experience fatal cardiovascular and cerebrovascular complications within five years."

\section{Prevalence}

In morbidity registration studies by general practitioners, data on PAOD concern patients with symptomatic PAOD - intermittent claudication or advanced stages of PAOD - that are known to the general practitioner. ${ }^{130}$ In general it may be assumed that the diagnosis 'intermittent claudication' will not have been made 
Table 2.1 Estimated prevalence tigures for PAOD in general practice

Source of the data

Morbidity charactenstics

Prevalence*

Min Max

Morbidity registration by general practitioners ${ }^{18-20}$

hinown cases of symptomatic $P A O D$

$(\geq$ Fontaine stage 2$)$, no strict critera

6

Population studies on inter-

mittent claudication ${ }^{6,222.25}$

known and unknown cases of sympto-

matic PAOD - according to 'Rose.21

- less strict criteria

827

Population study using noninvasive techniques ${ }^{23}$

known and unknown cases of symptomatic and asymptomatic PAOD

45

approxinately

61. -66

$\mathrm{n}=2350$, standardized to the gender and age distribution of the Dutch population on 1 January 1989

strictly according to the criceria of the "WHO/Rose questionnaire". ${ }^{21}$ In this group of studies the number of patients known to be afflicted with PAOD ranges from 0.2 to $0.7 \%$ of the practice population.

Various surveys on intermittent claudication were performed using oral or written questionnaires, whether or not according to the strict criteria of the "WHO/Rose questionnaire'. These studies concern patients with intermittent claudication, either known to a medical practitioner or not. ${ }^{6,22.25}$ When strict ("Rose") criteria for the definition of intermittent claudication are maintained prevalence figures range from $1.7 \%$ to $4.8 \%$, with most studies reporting percentages just below $2 \%$. The variation in the findings is partly explained by the age distribution of the examined populations.

Population studies carried out by means of noninvasive techniques provide an indication of the prevalence of both symptomatic and asymptomatic PAOD. . $3,26,27^{2}$ In one study men and women of approximately 40 years and older, selected from the population at large, were examined. ${ }^{23}$ The prevalence of PAOD in this sample was $11.7 \%$.

Apparently there is quite a difference between data stemming from different sources. Table 2.1 presents the estimated number of patients with PAOD in a Dutch standard general practice, recalculated on the basis of the literature. Table 2.2 presents prevalence figures derived from studies performed in older populations. ${ }^{19,23,25}$ 'The figures in table 2.1 suggest that only 10-30\% of all PAOD patients would be registered as such in primary health care, that $12.25 \%$ of all PAOD patients would be "asymptomatic" (no intermittent claudication) and that 50-80\% of all claudicants would not meet the WHO/Rose-criteria ('atypical' claudication). In the age category $65-75$ years (table 2.2) general practitioners seem to underregistrate female patients with intermittent claudication: in population studies the malefemale ratio is approximately 1.3 , whereas the male:female ratio in the morbidity registration study by wan den Hoogen et al. is 3.6 .

Medical history and physical examination ${ }^{28-37}$

Medical bistory

The typical symptom of PAOD (stage II) is 'intermittent claudication': the patient 
Table 2.2 Prevalence figures for PAOD among elderly subjects by age and gender in three types of studies

\begin{tabular}{|c|c|c|c|c|c|}
\hline \multirow[t]{2}{*}{ Reference } & \multirow{2}{*}{ Type of study } & \multicolumn{4}{|c|}{ Prevalence (\%) } \\
\hline & & Gender & $65-69$ yrs & $70-74$ yrs & $\geq 75 \mathrm{yrs}$ \\
\hline Hoogen & $\begin{array}{l}\text { gental practice } \\
\text { morbidity } \\
\text { registration }\end{array}$ & $\begin{array}{l}\text { male } \\
\text { ferralk } \\
\text { total }\end{array}$ & & & $\begin{array}{l}9.6 \\
3.6 \\
5.9\end{array}$ \\
\hline Evans ${ }^{25}$ & $\begin{array}{l}\text { population study } \\
\text { using WHO/Rose- } \\
\text { criteria for } \mathrm{KC}^{\circ}\end{array}$ & $\begin{array}{l}\text { malle } \\
\text { fermale } \\
\text { cotal }\end{array}$ & $\begin{array}{l}4.9 \\
3.6 \\
4.2\end{array}$ & $\begin{array}{l}5.6 \\
4.7 \\
5.1\end{array}$ & $\begin{array}{l}9.6 \\
2.8 \\
5.5\end{array}$ \\
\hline Crigut $^{23}$ & $\begin{array}{l}\text { Population study } \\
\text { using noninyasive } \\
\text { methods }\end{array}$ & $\begin{array}{l}\text { malt } \\
\text { Cenale }\end{array}$ & $\begin{array}{l}12 \\
12\end{array}$ & $\begin{array}{l}19 \\
12.5\end{array}$ & $\begin{array}{l}23 \\
21.5\end{array}$ \\
\hline
\end{tabular}

"IC: intermittent clatidication

complains of pain developing in a leg - usually in the calf - after walking a certain distance. The pain is quickly relieved by rest and reappears when approximately the same distance is covered. The pain arises sooner when walking fast or uphill or when carrying a load. The patient has no complaincs while situing or standing ${ }^{28}$ PAOD may also manifest itself in a unilateral experience of coldness in the feet. Possibly, the most important criteria for leg complaints due to PAOD are the exercise-related occurrence and the reproducibility of the pattern of complaints: the same complain of the same severity in the same location after the same exercise.

In stage III the arterial blood flow is insufficient not only during exercise, but also at rest. The patient experiences severe pain, localized especially in the forefoot and in the roes. Initially the complaint occurs only at might when the perfusion pressure is lower due to the horizontal body position and the nocturnal lowering of the systemic pressure (approximately $20 \mathrm{~mm}$ lg). Conseguently, many patients discover that they may lessen the pain by suspending the leg over the edge of the bed, or by getring up briefly.

A number of differenvial-diagnostic considerations are represented in averview $2 . l$.

\section{Phosical examination}

The vascular physical examination consists of inspection of the skin fcolour, trophic disorders), palpation of the skin (temperature), palpation of the peripheral pulses and auscultation of the femoral artery. With a nomal stethoscope one cannot detect an momur over the popliteal and pedal arteries.

The classic signs one looks for in a patient suspect for PAOD are: a red blue skin, a lefr-right difference in nail growth or hair growth on the lowery legs or feet, a onesided cold skin of the lower legs or feet, weak or absent pulsations of the Cemoral, popliteal, posterior tibial or dorsalis pedis artery, as well as a murmur over the femoral artery. Few authors mention the "capillary refill' test. ${ }^{29,37}$ Besides these commonly used methods there are a number of procedures that are possibly less common in general practice. By performing the palpation of peripheral pulses and the anscultation of the femoral artery after exercise the sensitivity of these examinations may be increased. ${ }^{33}$, By means of the "dependency-test" according to Ratschox-Büger, the 'visual flush method' and the determination of the maximal pain- 
Overview 2.1. Differential-diagnostic considerations

\section{Osteoarthritis}

- pain at rest (sitring, standing)

- complaints usually worst in the morning stiffness with inacrivity pair already on beginning to walk

- after some walking: pain decreases

- afrer long walking: pain increases

- then standing still: pain decreases only slowly or not at all

- not reproducible: 'good' and 'bad' days

- location: knee, hip, lumbar region

Chronic venous insulficiency

- history of varicosis

- swollen ankles

- tired, heary, dull, painful sensation in the (lower) legs, also at rest nocturnal cramps in the calves

- irch (secondary to dermatitis)

- not reproducible: 'good" and 'bad' days

- more complaints at night than in the morning

- walking: complaints often decrease

- standing: complaints usually increase

- leg elevation: complaints often decrease

- standing occupation

Sciatic pain. lumbar disc prolapse

- backache

- radiation into the leg

- worsened by coughing, sneezing, exerving pressure (LDP)

Peripheral neuropathies

loss of power, loss of sensation, paraesthesia, hyperaesthesia

distal pain

- association with diaberes

Spinal stenosis (pseudoclaudication,

Verbiest's syndrome)

- severity of complaints on walking are variable, i.e. not reproducible: 'good' and 'bad' days

- paraesthesia rather than pain

- pain on walking, not on cycling

- standing: pan usually increases

- only when patient sits down the pain decreases

- learing against wall: pain decreases

- bending back: pain decreases

- carrying heary object pain increases

Nocturnal leg cramps

- usually no PAOD

- especially in the elderly

- also occurs in chronic venous insulfciency

Restless legs

- usually no PAOD

- neurovegetative lability?

- iron deficiency?

Especially in young people the following diseases occur

- 'Thromboangitis obliterans (Bürger's disease)

- Entrapment of the popliteal artery

- Anterior tibial artery syndrome

less walking distance the functioning of the peripheral circulation may also be tested. $^{31,40}$

\section{Interpretation of bistory and physical examination}

What is the diagnostic value of a 'typical' pattern of complaints and 'classic' findings on physical examination? Before noninvasive tests were available, already some research has been done on the significance of peripheral pulsations. ${ }^{1-43}$ These studies showed that an absent dorsalis pedis artery pulse - due to its anatomical variability - often does not indicate PAOD. By contrast, an absent posterior tibial artery pulse does frequently indicate PAOD, and this relationship increases with age. The inter-observer variability in the determination of absent peripheral pulsations is large. ${ }^{4244}$ In one study doctors achieved a fair to good agreement with respect to the palpation of a 'normal' versus an 'absent' pulsation. The agreement 
Table 2.3 Signs and symptoms associated wh PAOD versus noninvasive testing ${ }^{\text {to }}$

Signs and symptoms

typical claudication

skin; erythema, cyanosis, trophic changes, leftright

difference in temperature

weak or absent pulsations of the femoral artery

$$
\text { popliteal artery }
$$

posterior tibial artery

dorsalis pedis artery

Femoral arery bruit

claudication or some disorder of pulse

claudication and some disorder of pulse
Sens. Spec. PV+

(\%)

$(\%)$

(o)

PV-

9

99

54

89

no research data avalable

13

98

47

90

no research data avalable

$\begin{array}{llll}71 & 91 & 49 & 96\end{array}$

50

73

18

93

20

96

37

91

78

85

40

97

$5 \quad 99.6 \quad 60$

90

PV-t predictive value of a positive test result. PV: predictive value of a negative test result. 'Sone disorder of pulse': diminished or absent femoral, tibial posterior, dorsalis pedis pulse and or murmur femonal artery. Standard diagnostic method: plethysmography and various ultrasound techniques. Population data: $\pi=575$ men and women, aged $38-82$ years, prevalence of $\mathrm{PAOD}=11.7 \%$

on the femoral artery pulsations was slightly better than on the popliteal artery pulsations. Regarding the assessment of a 'normal' versus a 'reduced' pulsation, the concordance was not better than by chance, both for the femoral artery and the popliceal arery pulsarions. ${ }^{44}$

The introduction of noninvasive tests for assessing $\mathrm{PAOD}$ has made it possible to compare complaints and findings of the plnysical examination to the results of those tests in large study populations. ${ }^{26,27,45-47}$ the noninvasive tests then function as "gold standard'. Table 2.3 summarizes the results of the only study in a moderately" selected population. ${ }^{\text {fis }}$

No publication on the diagnostic value of the 'capillary refill' test with regard to PAOD was found. In normal subjects the skin should turn from white to red immediately after release of the pressing finger. ${ }^{39}$ In one study was reported that capillary refill varies with age and gender - upper limit of "normal among adult men 2 seconds, adult women 2.9 seconds, elderly 4.5 seconds - and temperature. Given the temperature dependency the authors question the relability of this sign in prehospital setrings. ${ }^{* 8}$

One publicarion on the significance of Ratschow-Bürger"s test was found, describing a highly selected group of symptomatic patients admitted for surgery. In 'Buerger positive" legs significanty more distal or multiple occlusions on arteriography were found as compared to the 'Buerger negative" group. Also the mean ABratio was significantly lower in the "Buerger positive" group (0.37 vs. 0.62).49 Surgeons consider this an important diagnostic test to assess the severity of the disease, i.e. ro distinguish between Fontaine stage II and III. An example would be the differentiation between an arterial and a venous origin of the complaint "pain at rest". Ratschow's rest is less relevant in 'obvious' claudication without signs of 


\section{Doppler ultrasound}

Noninvasive techniques have become increasingly important in the diagnosis of patients with PAOD. Since the 1970 s special 'vascular laboratories' were set up in many clinics. ${ }^{50.56}$ One of the techniques based on the application of ultrasound is the measurement of the ankle-brachial systolic pressure ratio (AB-ratio). The principle of this technique is simple: a vascular stenosis causes a fall in blood pressure distal to the stenosis. By means of a 'Doppler stethoscope' - a convenient instrument that transmits ultrasound and receives the sound waves reflected by moving erythrocytes - and a sphygmomanometer the systolic blood pressure can be assessed accurately: the blood pressure thus measured agrees closely with the pressure registered intra-arterially. ${ }^{27,57}$ By measuring the blood pressure both proximal and distal to the expected stenosis one may determine whether a fall in pressure, i.e a stenosis, is present in the course of an artery.

Accordingly, the systolic pressure at the arm (brachial artery) and the ankle (posterior tibial or dorsalis pedis artery) are measured to determine whether there is a stenosis in the arterial circulation of the lower limb. The relationship between the arm and ankle pressures is expressed as the "ankle-brachial systolic pressure ratio"." It is represented as a fraction or a percentage. In contrast to the angiogram, the $A B$ ratio is not an anatomical but a functional measure of the arterial circulation in the lower limbs. The method is unreliable in patients with incompressible blood vessels due to mediasclerosis, a condition that may be in found in diabetic patients. In these cases erroneously high systolic blood pressures are measured.

In healthy persons the average $\mathrm{AB}$-ratio lies between 1.00 and 1.20. Table 2.4 shows how the values of the AB-ratio may be interpreted according to the literature. ${ }^{50,53,61-65}$ From this table one may deduce that it is not possible to distinguish sharply between 'no', 'mild' and 'major' vasculopathy. In general an AB-ratio $>1.00$ indicates that there is no PAOD, while an $A B$-ratio $<0.90$ renders PAOD very probable.

The ankle pressure is related to the prognosis of an individual parient: an ankle pressure exceeding $70 \mathrm{mmHg}$ means that the probability of an operation or an amputation in the future is minimal. ${ }^{10,11}$ "The course of PAOD may be observed by means of $\mathrm{AB}$-ratios determined at intervals. The difference between two successive AB-ratio measurements should be at least $0.10-0.15$ in order to be able to speak of a dinically relevant improvement or deterioration. $11,66,67$

In cases with an uncertain diagnosis the $A B$-ratio may be measured after exercise: in a patient with $P A O D$ the initially normal $A B$-ratio decreases to an abnormal value. Thus, the number of false negatives will be reduced. In the vascular laboratory often a treadmill is used, whether or not tilted at a specific angle and running at a particular speed (e.g. $4 \mathrm{~km} / \mathrm{h}$ ). The patient walks for a fixed period (e.g. 5 minutes) or until the pain forces him to stop..$^{65}$

An alternative is the post-occlusion reactive hyperaemia test. ${ }^{68.74}$ The $A B-r a t i o$

PJEHM Kitslaar, JA Lawson, personal communications to the working party on "Peripheral Arterial Diseases of the Dutch College of General Practitioners, spring 1990.

" or: ankle-arm-index, ankle-arm-ratio, ankle-brachial index, ankle-brachial pressure index, $A B(P) l$, Winsor index etc. 
Table 2.4 Interpretation of the values of the AB-ratio $50.93,61+5$

Value ABratio Clinical picture. Angiographic conclusion

$>1.00 \quad$ Generally no complaints. No severe stenosis or occlusion.

$<0.90$

Usually there are complaines. A rather severe stenosis is almost always present.

0.500 .90

Intermittent daudication is usually present (Fontaine ID). A rather serious stenosis or a single occlusion is usually present.

$<0.50$

Generally there is pain at rest and/or pain at night and/or trophic disorders (Fontaine III). Multiple occlusions may be present.

is measured repeatedly during the hyperamic period that follows the quick release of the sphygmomanometer cuff, which has been placed above the ankle with suprasystolic pressure for $3-5$ minutes. This method, which in theory could also be carried out in general practice, is sufficiently reproducible. In addition, the reactive hyperaemia test may be carried out not only in the absence of ECG control but also for both legs separately, which is not the case for the treadmill test. However, this theoretically ideal method requires $30-45$ minutes per patient and can be painful. The reproducibility of the test is reported to be inferior to that of the resting $A B$-ratio measurement. These properties make the reactive hyperaemia test less feasible to the general practitioner.

An exercise test available to the general practitioner is having the supine patient perform plantar flexion/extension (calf exercise) or flexion/extension of the knee (exercise of the upper leg) during two minutes in which the general practitioner's hand serves as a springy resistance. ${ }^{50,72}$

\section{Therapy}

Despite the uncertainties that still exist with regard to the course and the prognosis of PAOD, it appears possible to halt the progression of the disease. For the general pracritioner, conservative therapy is of particular importance. ${ }^{73.74}$ "The rationale of advice to be given by the general practitioner is to influence risk factor status. Daily walking exercises and the cessation of smoking have proved to be effective. ${ }^{7599}$ Maintaining a low-fat diet has a positive influence on the course of the atherosclerotic process in general, but its effect on the amelioration of PAOD is small. ${ }^{94.97}$ Proper foot-care is also important, especially in PAOD patients with diabetes.

Drug therapy in PAOD is still controversial.73,88:01 There are no rational arguments that support the use of vasodilator drugs: post-stenotic vascular dilatation is already maximal in PAOD. Furthermore, vasodilators possibly induce a 'steal' effect in non-disensed vascular areas. ${ }^{102,103}$ Anticoagulant therapy has been used in the past to prevent complications of PAOD. However, the effectiveness has proved to be small and probably does not balance the potential side-effects. ${ }^{100,104}$ Research on the effect of treatment of symptomatic patients with platelet aggregation inhibitors such as salicylic acid derivatives is ongoing. ${ }^{105-110}$ "The "rheological drugs" pentoxifylline and buflomedil have been proven effective in improving the walking distance of patients with severe PAOD. ${ }^{111-15}$ They might be prescribed when other therapeutic interventions are inappropriace or have faled. 
Concerning the developments in vascular surgery we must be brief here. An important development of the last years is that the indication for arteriography and vascular surgery has become more strict, owing to the development of noninvasive diagnostic procedures. ${ }^{51,52,5,5,56,54,65,116,117}$ Besides this, the improvement in vascular reconstructive techniques and the increasing experience with percutaneous transluminal angioplasty need to be mentioned. ${ }^{118,119}$

\section{Discussion}

\section{General}

From the literature it appears that much is still unclear about the natural course and the prognosis of PAOD. It is certain that patients diagnosed as having 'PAOD' bear a high vascular risk. PAOD, ischemic heart disease and cerebrovascular disease must be seen - not only theoretically but also actually - as manifestations of a single disorder: atherosclerosis. A patient with PAOD therefore deserves a full vascular physical examination. As far as risk factors are concerned, the general practitioner at least could pay attention to the important role played by smoking in the develop. ment and progression of PAOD and the beneficial effect of cessation of smoking on the course of the disease.

\section{Prevalence}

The data presented in the tables 2.1 and 2.2 suggest that many PAOD patients are not known to the general practitioner. A British population study in which the patients of two general practices were asked to participate, disclosed that only half of all persons with complaints of claudication had consulted a doctor. Similarly, in his review Dormandy concluded that probably at least half of all patients with intermittent claudication are unknown."

It is not clear how many patients with claudication actually exhibit a 'typical' picture (Rose') and how many report a less distinct or different pattern of complaints. The data of tables 2.1 and 2.2 give reason to assume that there is a large group of 'asymptomatic' and 'atypical' PAOD patients. In studies where a history is taken by means of the WHO/Rose questionnaire these types of patients are missed by definition. Furthermore, it turns out - provided that figures from studies using noninvasive tests may indeed be extrapolated to general practice - that the number of patients with PAOD in a Dutch 'standard general practice' would amount to 61 66.

\section{Medical history and physical examination}

Regarding the interpretation of diagnostic data derived from the history and the physical examination (table 2.3) the general conclusion can be that the predictive values of negative (normal) findings were found to be high and the predictive values of positive (abnormal) findings were found to be low. The high predictive values of negative findings imply that it would be well feasible to exclude PAOD on the basis of standard clinical-diagnostic methods. The low predictive values of positive findings imply that PAOD can be ruled in with less certainty. A rule of thumb could be 'the more positive findings, the more probable the diagnosis PAOD'. There are no data to quantify this statement.

If a "typical" history ("WHO/Rose questionnaire') is taken, then the asymptomatic 
and atypical patients are missed by definition. Possibly, the sensitivity of the history will be improved by inquiring after less typical symptoms or sensations, whereas the specificity might be increased by asking additional differential diagnostic questions (for example, about the effect of walking, standing, sitting and cycling, about the occurrence of 'good' and 'bad' days, and about the presence of paraesthesias, loss of power or loss of sensation).

\section{Doppler ultrasound}

An important question is to what extent the general practitioner is able to diagnose PAOD - at an early stage - in his practice population if he thinks in terms of a 'typical' pattern of complaints (i.e. intermittent claudication) and of 'classic' findings on physical examination (i.e. decreased peripheral pulsations, a murmur in the groin and trophic disorders). The measurement of the AB-ratio by means of the Doppler ultrasound method appears to be a potentially useful supplement to the clinical diagnostics currently used by the general practitioner. In chapter 3 the literature on the Doppler method will be reviewed more closely.

\section{References}

1 Reid DD, Holland WW, Humerfelt S, Rose G. A cardiovascular survey of british postal workers. Lancer 1966; I: 615-8.

2 Gordon T, Kannel WB. Predisposition to atherosclerosis in the head, heart and legs. The Framingham study. JAMA 1972; 221: 661-6.

3 Widmer LK, Biland L, Delley A, Da Silwa A. Zum Stellenwert der peripherer-arteriellen Ver-schlusskrankheir in der Praxis. Schweiz Med Wschr 1983; 113: 1924-7.

4 Jacobsen UK, Dige-Petersen H, Gyntelberg F, Svendsen UG. "Risk factors" and manifestations of arteriosclerosis in patients with intermitent claudication compared to nomal persons. Dan Med Bull 1984; 31: 145-8.

5 Kannel WB, MoGee DL. Update on some epidemiological features of intermittent claudication: the Franingham study. I Am Geriatr Soc 1985; 33: 13-18.

6 Hughson WH, Mann J, Garrod A. Intermittent claudication: prevalence and risk factors. Br Med J 1987; i: 1379-81.

7 Müller-Bühl U, Diehm $C$, Sieben U, et al. Prävalenz und Risikofakroren vor periphererartenieller Verschlusskrankheit und koronarer Herzkrankheit. Vasa 1987; 16[Supp 1.21]: 1-46.

8 Aronow WS, Sales $\mathbb{F F}$, Etienne F, Lee NH. Prevalence of peripheral arterial disease and its correlation with risk factors for peripheral arterial disease in elderly patients in a long-term health care facility. Am J Cardiol 1988; 62:644-5. 9 Dormandy J, Mahir M, Ascady $G$ et al. Fate of the patient with chronic leg ischaemia. J
Cardiovase Surg 1989: 30: 50-7.

10 Jelnes $R$, Gardsting $O$. Hougard Jensen $K$, et al. Fate in intermittent claudication: outcome and risk factors. Br Med J 1986; 293: 1137-40. 11 Naschitz JE, Ambrosio DA, Chang JB. Intermitent claudication: predictors and outcome.
Angiology 1988; 39: 16-21.

12 Jonason T, Ringquist 1. Factors of prognostic importance for subsequent rest pain in patents with intermittent daudication. Acta Med Scand 1985; 218:27-33.

13 Jonson T, Ringqvist 1. Mortality and morbidity in patients with intermintent claudication in relation to the location of the occlusive atherosclerosis in the leg. Angiology 1985; 36:
$310-4$.

14 Lassila $R$, Lepäntalo M, Lindfors O. Peripheral arterial disease - natural outcome. Acta Med
Scand 1986; 220: 295-301.

15 Allardice JT, Allwright $G$, Wafula JMC, Wyatt AP. High prevalence of abdominal aortic ancurysn in men with peripheral vascular disease. Screening by ultrasonography. Br J Surg
$1988 ; 75: 1402$. 
16 Colln J, Walton J, Arajo L, Lindsell D. Oxford screening programme for abdominal aortic aneurysm in men aged $65-74$ years. Lancet 1988 ; it: $613 \times 5$.

17 Dormandy JA, Mahir MS. The natural history of peripheral atheromatous disease of legs [congress-paper]. London: Department of vascular surgery, St Jamesªnd St George"s Hospitals, 1986.

18 Lamberts $H$. Morbidity in general practice. Diagnosis related information from the Monitoring Project. Utrecht: Huisartsenpers, 1984.

19 Hoogen HJM van den, Huygen FJA, Schellekens JWG, Strat JM, Van der Velden IGM. Morbidity figures from general practice. Data from fout general practices $19 \% 8-1982$. Nijmegen: NUHI, 1985.

20 Lamberts H. Transition Project. Amsterdam: Deparment of General Practice, Universty of Amsterdam, May 1987.

21 Rose GA, Blackburn H, Gillum RF, Prineas RJ. Cardiovascular survey methods 2nd ed. Geneva: World Health Organization, 1982.

22 Reumanen $\mathrm{A}$, Takkunen $\mathrm{H}$, Aromał $\mathrm{A}$. Prevalence of intermituent chudication and its effect on mortality. Acta Med Scand 1982; 211:249-56.

23 Criqui $\mathrm{MH}$, Fronek $\mathrm{A}$, Barret-Connor $\mathrm{E}$ et al. The prevalence of peripheral arterial disease in a defined population. Circulation 1985; 71: 510-5.

24 Hale WE, Marks RG, May FE, Moore MT, Stewart RB. Epidemiology of intermituent claudication: evaluation of risk factors. Age and Ageing 1988; 17:57-60.

25 Evans JG. Intermittent claudication. Age and Ageing 1988; 17: 139.

26 Marinelli MR, Beach KW, Glass MJ, Primozich JF, Strandness DE. Noninvasive testing vs clinical evaluation of arterial disease. JAMA 1979; 241: 2031-4.

27 Schroll M, Munck O. Estimation of peripheral arteriosclerotic disease by anlile blood pressure measurements in a population of 60-year-old men and women. fournal of Chronic Diseases $1981 ; 34: 261.9$.

28 Verstraete $M$. Onderzoek van de perifere bloedwaten en de lymfevaten. 1. Arterien. In: Hawwaert LG van den, Geest $H$ de, Kesteloot H, Verstraete M. Fysisch Onderzoek bij hart-en vaatlijen. Leiden: Staflew, 1975.

29 Terpstra JL, Beerstecker HJP, Heyde MN van der, Stubbé LThFL. Arteriäle en veneuze pathologie. Leiden: Stafleu, 1977.

30 Verhaeghe R, Suy R. Perifere vaatziekten. Leiden: Stafleu, 1986.

31 Lawson JA. Het onderzok van de patient met perifeer arterieel vaatijden. Amsterdan, Meducation Service Hoechst 1988.

32 Peart WS, Rob Ch. Arterial auscultation. Lancet 1960; ii: 219-20.

33 Barner HB, Kaiser GC, Willman VL, Rollins Hanlon $\mathrm{C}$. Intermittent claudication with pedal pulses. JAMA 1968; 204: 958-63.

34 Kappert A. Diagnose arterieller, venöser und lymphatischer Erkrankungen. Separateruck aus 'Lehrouch und Atlas der Angiologie'. Bern: Hans Huber, 1981.

35 Spittel JA. A clinical introduction to vascular disease. In: Bernstein EF (ed.). Noninvasive diagnostic techniques in wascular disease. 2nd ed. St.Louis, etca: Mosby, 1982.

36 Carter SA. Detection of peripheral arterial disease: is the clinical diagnosis adequate? In: Bernstein EF, ed. Noninvasive diagnostic techniques in vascular disease znd ed. St.Louis, erc.: Mosby, 1982.

37 Kuijer I J . Chirurgisch onderzoek. 2e druk. Leiden: Spruyt, 1974.

38 de Weese JA. Pedal pulses disappearing with exercise. A test for intermitcent daudication. NEngl J Med 1260; 262: 1214-7.

39 Garrison GE, Floyd W, Orgain ES. Exercise in the physical examination of peripheral arterial disease. Ann Intern Med 1967; 66:587.93.

40 Soepenberg O, Kitslaar PJEHM. Bloeddrukmeting aan de enkel met de "flush'-nethode. Ned Tijdschr Geneeskd 1988; 132: 208-11.

41. Ludbrook J, Clarke AM, McKenzie JK. Significance of absent ankle pulse. Br Med J 1962 ; II: 17247.

42 Barnhorst DA, Barner HB. Prevalence of congenitally absent pedal pulses. N Engl J Med $1968 ; 278: 264-5$.

43 Meade TW, Gardner MI, Cannon P, Richardson PC. Observer variability in recording the peripheral pulses. Br Heart J 1968; 30: 661-5. 
44 Myers KA, Scot DF, Devine Ty, Johnston AH, Denton MJ, Gilfllan IS. Eur J Wasc Surg $1987 ; 1: 245-9$.

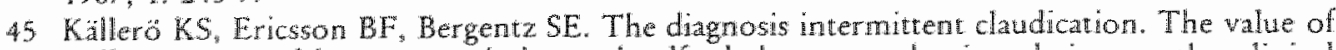
walking test, ankle pressure index and calf plettysmography in relation to the clinical findings. Acra Chir Scand 1983; 149:377-82.

46 Criqui MH, Fronek A, Klauber MR et al. The sensivivity, specificity and predictive value of traditional clinical evaluation of peripheral arterial disease: results from non-invaswe testing in a defined population. Circulation 1985; 71: $516-22$.

47 Christensen $\mathbb{N}$, Freundlich $M$. Jacobsen $B A$. Falstie Jensen $\mathbb{N}$. Clinical relevance of pedal pulse palpation in patients suspected of peripheral anterial insufficiency. I Internal Medicine 1989; 226: 95-9.

48 Schriger DL, Baraff $L$. Defining normal capllary refill, variation with age, sex, and temperature. Ann Emerg Med 1988; 17: 932-5

49 Insall RL, Davies Rl, Prout WG. Significance of Buerger's test in the assessment of lower limb ischaemial J R Soc Med 1989; 82:729-31.

50 Hylkema BS. Tussen polspalpatie en aortografie [Dissertatie]. Groningen: Rijksuriversiteit Groningen, 1975.

51 Bruminckx CMA. Pre- en post-operatieve evaluatie van claudicatio intermittens met behulp van een Dopplex-flowmeter [Dissertatie]. Nijmegen: Katholieke Universiteit Nijmegen, 1976.

52 Bernink PJLM. Parameters wan de circulatie in de onderste extremiteiten met betrekking vor atherosclerosis obliterans [Dissertatie]. Groningen: Rijksuniversizeit Groningen, 1978.

53. Buth I. Het vasculaire laboratorium [Dissertatic]. Ansterdarn: Universiteit van Arnsterdam, 1978.

54 Kitshar PJEHM. Doppler-ultrasoundtests in the diagnosis of chronic aorta-iliac obstructions [PhD Thesis]. Maastricht: Rijksunivarsiteit Limburg, 1982.

55 Bernstein EF (ed.). Noninvasive diagnostic techniques in peripheral vascular disease. 2nd edicion. St.Louis, etc: Mosby, 1982.

56 Breshu PJ. Jörning PJG, Greep JM. De Klinische betekenis van hemodynamisch, niet-invasief onderzoek bij patienten met arteriële vaatziekten van de benen. Ned Tijdschr Geneeskd 1984; $128: 996-8$.

57 Stegall MF, Kardon MB, Kemmerer WT. Indirect measurement of arterial blood pressure by Doppler ultrasonic sphygmanometry. J Appl Physiol 1968; 25:793 8.

58 Kazamias TM, Gander MP, Franklin DL, Ross Jr.J. Blood pressure measurement with doppler ultransonic flowmeter. I Appl Phys 1971; 30: 585-8.

59 Grintzig A, Schlumpf M. The valdity and reliability of post-stenotic blood pressure measurement by Doppler ultrasonic sphygmomanometry. VASA 1974; 3: 65-71.

60 Bollinger A, Barras JP, Mahler F. Measurement of foot artery blood pressure by micromanometry in nomal subjects and in parients with arterial occlusive disease. Circulation 1976: 53: $605-12$.

61 Carter SA. Indirect systolic pressures and pulse waves in arterial occlusive disease of the lower extremities. Circulation 1968; 37: 62437.

62 Ya ST, Hobbs JT, Irvine WT. Ankle systolic pressure measurements in arterial disease affecting the lower extremines. Br J Surg 1969; 56:676-9.

63 Thulesius $O$, Giones JA. Use of doppler shift detection for determining peripheral arterial blood pressure. Angiology $1971 ; 22: 594603$.

64 Buth I. Dopplorbloeddrukmeting an de enkel bij perifeer artericel valijden: een anwinst in de vatchirurgie. Ned Tujdschr Geneeskd 1975; 119:388-97.

65 Carter SA. Hamel ER. Role of pressure measurements in vascular disease. In: Bernstein EF (ed). Noninvasive diagnostic techniques in vascular disease. 2 d edicion, St.Louis, etc:
Mosby, 1982 .

66 Osmundson PhJ. OFallon WM, Clements IP, Kazmier FJ, Zimmerman BR, Palumbo PJ. Reproducibility of non-invasive tests of peripheral occlusive vascular disease. I Vasc Surg
$1985 ; 2.678 .83$.

67 Johnston KW, Hosang MY, Andrews DF. Reproducibility of noninvasive vascular laboratory measurements of the peripheral circulation. I Vasc Surg 1987; 6: 147-51. 
68 Ouriel KO McDonnel AE, Metz CE, Zarins CK. A critical evaluation of stress testing in the diagnosis of peripheral wascular disease. Surgery 1982; $91: 68693$.

69 Bernstein EF, Fronek A. Current starus of noninwasive tests in the diagnosis of peripheral arterial disease. Surg Clin North America 1982; 62: 473-87.

70 Fowkes FGR. The measurement of acherosclerotic peripheral arterial disease in epidemiological surveys. Int J Epidemiol 1988; 17: 248-54.

71 Fawkes FGR, Housley E, Macintyre CCA, Prescon RJ, Ruckley CV. Reproducibility of reactive hyperaemia test in the measurement of peripheral arterial disease $\mathrm{Br}$ J Surg 1988 ; 75: $743-6$.

72 Carter SA. Response of ankle systolic pressure to leg exercise in mild or questionable arterial disease. N Engl J Med 1972; 287: 578-82.

73 Blomberry PA. Intermittent claudication. An update on management. Drugs 1987: 34:40410.

74 Vroonhoven TJ van. Juist ook voor patiënten met claudicatio intermittens geldt do een is de ander niet. Ned Tijdschr Geneeskd 1986; 130: 1345-8.

75 Andriessen M. Het effect wan looptraining bij patienten met daudicatio intermittens [Dissertatie]. Groningen: Rijksuniverstiteit Groningen, 1986.

76 Ernst E. Physical exercise for periphenal vascular disease, a review. VASA 1987; 16;227-31.

77 Dahllof $\mathrm{AG}$, Holm J, Schersten 'T. Exercise training of patients with intermitent daudication. Scand J Rehabil Med 1983; 9[Suppl]: 20-6.

78 Skinner $J S$, Strandness DE. Exercise and intermitent daudication. I. Elfect of repetition and intensity of exercise. Cinculation 1967; 34: 15-29.

79 Zetterquist $S$. The effect of active traning on the nutritive blood flow in exercising ischemic legs. Scand J Lab Invest 1970; 25: 101-11.

80 Hoynck van Papendrecht AGM, Bemmelen SP van. De behandeling van patienten met daudicatio intermittens door Joopoefening. Ned Tijdschr Geneestid 1986; 130: 1360-4.

81 Hall JA, Barnard RJ. The effects of an intensive 26 dayprogram of diet and exercise on patients with peripheral arterial disease. I Cardiac Rehab 1982; 2: 569-74.

82. Schoop W won. Übungsbehandelung der arteriellen Verschlusskrankheit. Deutsches Med Journal $1972 ; 23: 348-50$.

83 Jonason $\mathrm{T}$, Jonzon B, Ringquist I, Oman-Rydberg A. Effect of physical training on different categories of patients with intermittenc claudication. Acta Med Scand 1979; 206: $253-8$.

84. Jonason 'T, Ringqvist $\mathbb{I}$. Prediction of the effect of training on the walking tolerance in patients with intermitrent claudication. Scand J Rehab Med 1987; 19: 47-50.

85. Ernst EEW, Matrai A. Intermittent daudication, exercise and blood rheology. Circulation 1987:76: 1110-4.

86. Sorlie $\mathrm{D}$, Mytre K. Effects of physical traning in intermitent claudication. Scand \& Reliab Med 1978; 38: 217-22.

87 Ekroth R, Dahllof AG, Gundevall B, Holm J, Schersten T., Physical training of patients with intermituent claudication; indications, methods and results Surgery 1978; 38: 217-22.

88 Birkenstock WE, Louw JH, Terblanche J, Immelman EJ, Dent DM, Baker PM. Snoking and other factors affecting the conservative management of peripheral vascular disease. $5 \mathrm{~A}$ Mediese "Tydskrif 1975;:1129-32.

89 Quick CRG, Cotton LT. "The measured effect of stopping smoking on intermituent claudication. Br J Surg 1982; 69[Suppl]: S24-6.

90 Jonason $T$, Bergstrom $R$. Cessation of smoking in patients with intermittent clatication. Effects on the risk of peripheral vascular complications, myocardial infarcion and mortali ty. Acta Med Scand 1987; 221: 253-60.

91 Juergens JL, Barker NW, Hines EA. Arteriosclerosis obliterans. Review of 520 cases with special reference to pathogenic and prognostic factors. Cinculation 1960; $21: 188$.

92 Kannel WB, Shurteff D. Cigarettes and the development of intermitient claudication. The Framingham study. Geriatrics 1973 ; 61-8.

93 Kotke TE, Battista RN, DeFriese GII, Brekke ML. Atributes of succesful smoking cessation interventions in medical practice. A metaunalysis of 39 controlled trials. IAMA $1988 ; 259: 2883-9$. 
94 Arntzenius AC. Hex reversibel zin van atherosclerotische afwikngen. Ned Tijdschr Generskd 1986; 130: 999-1002.

95 Duffield RGM, Miller NE, Brunt JNH et al. Treatment of hyperlipidaemia retards progression of symptomatic femoral atherosclerosis. a tandomised controlled trial. Laxcet $1983 ;$ II: $639-42$.

96 Glueck C. Role of risk factor management in progression and regression of coronary and fenoral artery atherosclerosis. Arn J Card 1986;57:35G-41G.

97 Coffman JD, Rasmussen HM. The peripheral circulation and treatment of hyperlipoproteinemias. Atherosclerosis $1983 ; 43: 147-59$.

98 Coffmann JD. Principles of conservative treatment of occlusive disease. Cardiovasc Clin $1983 ; 13: 240-3$.

99 Ritter JM, Dollery CT. Therapeutic opportunities in vasoöcclusive disease. Circulation $1986 ; 73: 24043$.

100 Boobis LH, Bell PRF. Can drugs help patients with lower limb ischeamia? Br J Surg 1982; 69[suppl]: $517-23$.

101 Cameron HA, Waller PC, Ramsay LE. Drug treatment of intermittent claudication: a critical analysis of the methods and findings of published clinical trials, 1965-1985. $\mathrm{Br} J$ Clin Pharmac 1988; 26: 569-76.

102 Zwieten PA van, Dunning AJ. Hoe nuttig zijn vatverwijdende farmaca bij de behandeling van claudicatio intermittens? Hart Bulletin 1980; 11: 81-4.

103 Offerhaus L. Indicaties en witwerking van vatverwijdende middelen, in het bijzonder bij cerebrale en perifere vaatsclerose. Ned Tijdschr Geneeskd 1981; 125: 228-34.

104 Poljwoda H, Avenarius HJ. Antiplatelet drugs or dicoumarol: what is the most effective prophylaxis in occlusiwe disease? Inter Angio 1986; 5: 169-80.

105 Kaiser V, Stoffers HEJH. Peripheral arterial obstructive disease in general, practice: diagnosis, natural history and interwention. Altgemein Medizin 1988; 17: $\$ 3$.

106 Verstraete M. Rationale for the use of drugs inhibiting platelet function in claudicating patients with atherosclerotic leg arteries. Agents Actions 1984; 15[suppl]: 173-87.

107 Orme M. Aspirin all round? Br Med J 1988; 296: 307-8.

108 Hess H, Mietaschk A, Deichsel G. Drug-induced inhibition of platelet function delays progression of periphera] occlusive arterial disease. Lancet 1985; i: $415-9$.

109 Davi G, Pinto A, Palumbo MG, Gallo V, Mazza A, Strano A. Dipyridamole and aspirin in arteriosclerosis obliterans of the lower limbs. Adv Prostaglandin Thromboxane Leukom triene Res. 1985; 13: 271-5.

110 Antipllatelet trialists collaboration. Secondary prevention of vascular disease by prolonged antiplatelet treatment. Br Med J 1988; 296: 320-31.

11. Pentoxifylline bij claudicatio intermittens. Geneesmiddelenbulletin 1988; 22: 45-8.

112 Reich T, Gillings D. Effects of pentoxifylline on severe intermittent claudication. Angiology 1987; 38: 651-6.

113 Johnson. G. Pentoxy filline and claudication [editorial]. J Vasc Surg 1988; 8: 649.

114 Lindgarde $F$, Jelnes $R$, Bjorkman $H$, Adielsson $G$ et al Conservative drug treatment in patients with moderately severe chronic occlusive peripheral arterial disease. Cinculation
$1989 ; 80: 1549-56$.

115 Clissold SP, Lynch S, Sorkin EM. Buflomedil. A review of its pharmacodynamic and pharmacokinetic properties, and therapeutic efficacy in peripheral and cerebral wascular
diseases. Drugs $1987 ; 33: 430-60$.

116 Fronek A, Johansen KH, Dilley RB, Bernstein EF. Non-invasive physiologric tests in the diagnosis and characterization of peripheral arterial occlusive disease. Am J Surg 1973;
126: $205 \times 14$. 117 Buth J. Niet-invasieve diagnostiek wan perifere arceriele andoeningen: het vataboratori-
um. Ned Tijdsch. Genceskd $1985 ; 2343-9$.

118 Breslau PJ, Jöning. PJG. De klinische en hemodynamische resultaten van artomiliacale rconstructie. Ned Tijdsch Geneeskd 1986; 130; 1358-60.

119 Andel GJ van. Percutane transhminale angioplastiek volgens Dotter in Nederland.
Medisch Contact 1987; 42: 967.9. 


\section{Chapter 3 Noninvasive vascular tests in general practice. A literature review."}

Summary The measurement of the resting ankle-bracbial systolic pressure ratio (ABratio) by means of a pocket Doppler device is a noninvasive technique used for diagnosing peripheral arterial occlusive disease (PAOD). In the present chapter the literature on the reproducibility and the validity of this method is examined. In addition the merits of the pocket Doppler device are compared to the possibilities of a vascular laboratory. Literature was gathered systematically from the MEDLINE database and by using the 'snowball methad'. This chapter represents the state of affairs known to us in March 1990.

The reproducibility of the AB-ratio measurement is reported to be acceptable: the $95 \%$ prediction interval around a measured value is \pm 0.14 to \pm 0.20 .

Using the resting $A B$-ratio it appears well feasible to differentiate between angiographically 'non-diseased' and 'occluded' arteries. The distinction between 'non-diseased' and 'stenosed' wessels seems less clear.

The selection of a cutoff value for the AB-ratio in the 0.90 to 1.00 range is open to dis. cussion. In the most valid studies sensitivity varies between 75 and $97 \%$ and specificity between 92 and $100 \%$ at a cutoff point of 0.90 . Pooling the results of four comparable studies yields $82 \%$ for mean sensitivity and $98 \%$ for mean specificity.

The vascular laboratory is able to offer diagnostic information that is barder and more comprebensive than the pocket. Doppler measurements. However, applying the pocket Doppler device in general practice may lead to a more selective management with regard to treatment and referral.

\section{Introduction}

In chapter 2 we suggested that the measurement of the resting AB-ratio by means of a Doppler device could play a useful role in general practice. The general practitioner might use the measurement of the $A B-r a t i o$ as an aid in diagnosing PAOD and in estimating the prognosis, as a method for following up the course of the disease or the effect of treatment, and for improved documentation of a referral to the vascular specialist. The principle of the measurement of the AB-ratio was also discussed in the former chapter.

In this chapter the following questions are dealt with:

"An abridged version of this literature study was published as part of: Stoffers HEJH, Kaiser V. Wetenschappelijke verantwoording van de NHG-Standaard Perifeer Arterieel Vaatlijden. Utrecht: Nederlands Huisartsen Genootschap, 1990. 
1 Is the measurement of the resting $\mathrm{AB}$-ratio sufficiently reproducible?

2 Is the measurement of the resting $A B$-ratio a valid method for making the diagnostic decision "PAOD: present/absent"?

3 What position does the simple hand held Doppler device take in comparison to the vascular laboratory:

a are there relevant differences in the measurement of the resting $A B$-ratio in the vascular laboratory as compared to general practice?

b what are the supplementary possibilities offered by the vascular laboratory?

The answers are important with respect to the evaluation of the relevance of the resting $A B$-ratio measurement for general practice and for epidemiological research on PAOD.

\section{Methods}

In connection with the first two questions literature on PAOD and noninvasive vascular tests was gathered according to the procedure described in chapter 2 (MEDLINE, snowball method, literature database on personal computer). Relevant titles were searched for in March 1990 by means of the following keywords: epidemiology, diagnosis, Doppler, ultrasound, validity, accuracy, precision, reproducibility. Each of the articles thereby collected was assessed on its quality and relevance.

The interpretation of the literature on the reproducibility of the measurement of the resting AB-ratio is hampered by several factors: the method used to determine the 'reproducibility' was usually described insufficiently; the parameters used to represent the 'reproducibility' were not uniform and could not simply be compared; generally, the observers were experienced staff members of surgical departments or vascular laboratories rather than general practitioners or practice assistants. One way to compare the results of different studies, is to calculate the " $95 \%$ prediction interval' around the measured value of the AB-ratio, on the basis of the standard deviations of the various components of variability given in (or deduced from) the articles concerned."

The assessment of the validity of the measurement of the AB-ratio for general practice with respect to the distinction 'PAOD: present/absent" on the basis of literature, is also encumbered by several factors. All studies were carried out in surgical or medical (outpatient) departments rather than in a primary health care setting. In the specialist's office there will be few or no patients in an early phase of PAOD. In general, tests were performed on persons with complaints. For "controls" either healchy volunteers - i.e. subjects without complaints - or the 'healthy legs' of patients with PAOD were used. When the control group consisted of volunteers angiography was usually not performed on these subjects, whereas in patients it was. By contrast, when the control group comprised "healthy legs" of patients with PAOD, an angiogram was made. Only rarely was discussed whether Doppler testing and clinical examination or angiogram were performed independently. Usually the noninvasive tests were performed before angiography. It was not always clear whether the data were analysed prospectively or retrospectively. Those studies in which the conclusion 'nomal' was based on an angiogram may be considered

\footnotetext{
Formula: $95 \%$ prediction interval $=1.96 * V\left(\sum \mathrm{SD}^{2}\right)$
} 
the most valuable.

With respect to question 3 , in addition to the literature study a vascular laboratory was visited. It was observed how several measurements were performed."

\section{Results}

\section{Reproducibility}

Eleven studies contained data on the variability of the measurement of the $A B$ ratio. ${ }^{111}$ The results from the four best studies (criteria: adequate description of patients, observers, method and design of analysis) were used to estimate the $95 \%$ prediction interval of the $\mathrm{AB}$-ratio. This interval comprises the range of $\mathrm{AB}$-ratio's between the measured value $\pm(0.14$ to 0.20$){ }^{5.4 .9}$. It concerns the total variability (i.e. the sum of measurement and biological variability). In general, the stage of the disease - i.e. the mean value of the AB-ratio - does not seem to influence the reproducibility. The difference between two measurements of the AB-ratio on different occasions in order to assess the course of PAOD, is only staristically significant and clinically relevant when it is greater than $0.15^{7.8 .11}$

\section{Validity}

Fifteen studies containing data on the diagnostic validicy of the AB-ratio were found. . $1,6,12 \cdot 22$ Table 3.1 provides an overview of the sensitivity and specificity reported in six studies in which the conclusion 'normal' was based on angiography and thus may be considered the most useful., ${ }^{3,13-17}$ Pooling the results of four studies using comparable criteria for "diseased/healthy" yields a weighted mean sensitivity of $82 \%(230 / 282)$ and a weighted mean specificity of $98 \%(88 / 90)$ if 0.90 is used as cutoff point for the AB-ratio. ${ }^{13-15,17}$ Using a cutoff value for the $A B$-ratio of 1.0 these figures would be $88 \%(115 / 130)$ and $81 \%(30 / 37)$ respectively. ${ }^{13.15}$

In some studies a different method was used to assess to what extent one may differentiate between 'healthy' and 'diseased' legs by means of the AB-ratio. ${ }^{13,18,19}$ In these studies the distribution of the AB-ratio in a population of angiographically normal vessels is compared to the distribution of the $A B$-ratio in a population of vessels with angiographic abnormalities. It then turns out that 'healthy arteries' and 'occluded arteries' can be readily distinguished. The distinction between 'liealuhy vessels' and 'stenosed vessels" can possibly not be made as clearly.

Conuparing the Doppler result to the clinical picture indicates that the group of patients without complaints overlaps the group of patients with intermittent claudication. The overlap in the AB-ratio especially concerns patients with 'moderate' complaints of claudication. ${ }^{20-22}$

\section{Comparison with the vascular laboratory}

The literature usually deals with the measurement of the AB-ratio as it takes place in vascular laboratories. Compared to the pocket Doppler measurement there are both similarities and differences (table 3.2). The most important skill - fixing the transducer at a correct angle and under adequate pressure - is similar in both situ-

details mentioned are as in use in the Vascular Function Department of the University Hospital Maastricht 
Table 3.1 Sensivity and specificity of the measurement of the resting $A B$-ratio

\begin{tabular}{|c|c|c|c|c|}
\hline \multirow{2}{*}{$\frac{\text { Ruference }}{\text { Burbh }^{3}}$} & \multirow{2}{*}{$\frac{\text { Curoff value }}{0.85}$} & \multicolumn{2}{|c|}{ Sensitivity } & Specificity \\
\hline & & $247 / 249$ & $=99 \%$ & $50 / 50=100 \%$ \\
\hline Thullesius $^{13 \mathrm{~d}}$ & 0.88 & $64 / 66$ & $=97 \%$ & $40 / 40=100 \%$ \\
\hline \multirow[t]{2}{*}{ Chamberllain } & 1.00 & $49 / 55$ & $=89 \%$ & $=80 \%$ \\
\hline & 0.90 & $43 / 55$ & $=78 \%$ & $=80 \%$ \\
\hline \multirow[t]{2}{*}{ Hylkemats } & 1.00 & $66 / 75$ & $=88 \%$ & $26 / 32=81 \%$ \\
\hline & 0.90 & $56 / 75$ & $=75 \%$ & $32 / 32=100 \%$ \\
\hline \multirow[t]{2}{*}{ Wylkemato } & 1.00 & $132 / 132$ & $=100 \%$ & $32 / 53=60 \%$ \\
\hline & 0.90 & $132 / 132$ & $=100 \%$ & $49 / 53=92 \%$ \\
\hline Smints" & 0.90 & $67 / 86$ & $=78 \%$ & $12 / 13=92 \%$ \\
\hline
\end{tabular}

the figures presented below derive from $2 \times 2$ tables that were deduced by the authors of this chapter from the results reported in the reference concerned

b criterium for normal and abnormal (stenoses and occlusions) based on angiography

c in contrast to the other studies, the figures here reter to the worst legs of the subjects only, and the study was carried out retrospectively.

4 in subjects less than 40 years old, no angiography was performed in subjects without any clinical signs of PAOD

not included in the analysis were subjects with angiographic abnormalities but without complaints and subjects with complaints but without angiographic abnomalities

ations. It is to be expected that the greater and continuous experience of the vascular laboratory technicians contributes to a better reproducibility of the vascular laboratory measurement. "The differences in measuring instruments may lead to a somewhat better fixation of the Doppler device in the vascular laboratory - particularly in the measurement of the ankle pressure - and to obtaining slightly higher pressures in the vascular laboratory. All these differences may, in theory, lead to somewhat higher AB-ratios in the vascular laboratory as compared to general practice.

The vascular laboratory offers a number of diagnostic possibilities that are too laborious or 100 expensive for routine use in general practice: ${ }^{315,15,24-32}$

- the determination of the post-exercise AB-ratio can reveal cases of PAOD who have a normal resting AB-ratio; it provides information on the cardiopulmonary and locomotive functioning of the patient;

- the postocclusion reactive hyperaemia serves the same goal, but can be used with patients for whom cardiopulmonary exercise is not appropriate;

- the systolic toe pressure can be measured in cases where the ABratio is not accurate, a.g. in patients with mediasclerosis;

- by using the Doppler device at different levels of the leg, segmental blood pressure measurements can be taken, enabling diagnosis of the location of a stenosis;

- by analysing the pulse waves (visual spectrum analyzed Doppler signal) at distinct levels, the stenosis can beter be located and the degree of dysfunctioning of the vessel assessed;

- these tests may, if necessary, be supplemented with the so-called 'duplex scan', 
Table 3.2 Comparison of the measurement of the ABratio in general practice and in at vascular laboratory"

$$
\text { General Practice } \quad \text { Vascular Laboratory }
$$

Observers: general practitioners, practice assistants

- experience variable; not daily

Procedure:

- transducer $8 \mathrm{MHz}$, pen-shaped

$R$ hand fixes (angle, pressure)

- inflation manual inflation by bulb

of cuff ( $L$ hand)

- deflation manual deflation using valve

of culf (L hand)

- sound adjustable small speaker, sensitive to background noise

- taking of Hg-column with mm scale or

reading

- stress test
VL technicians

every day again

$8 \mathrm{MHz}$, pen-shaped

$R$ hand fixes (angle, pressure)

automatically by pressing 1 butron

(L hand)

automatically by pressing 1 button

(L hand); rate set in advance

adjustable large speaker,

hardly sensitive to background noise

large dial with hand and mm scale

walking test (treadmill running at a speed of $4 \mathrm{~km} / \mathrm{h}$; the patient walks for 5 minutes or until the pain lores him to stop)

based on observations of the procedure in the Vascular Function Deparment of the University Hospial Maastricht

which is a combination of B-mode ultrasound ("picture) and Doppler pulse wave analysis ("flow"), permitting examination of individual blood vessels.

The goal of the latter three techniques is to locate stenoses and to assess their hemodynamic consequences.

\section{Discussion}

\section{Reproducibility}

The reproducibility of the AB-ratio measurement may be considered acceptable: the $95 \%$ prediction interval around the measured value varies between $\pm(0.14-0.20)$. This relates to the sum of measurement variability and biological variability. It is important that the inexperienced assessor schedules sufficient time to allow for re measurements, in order to artain an outcome of which he feels certain. "The longterm biological variability constitutes a reason for repeating the measurement within a few weeks.

\section{Validity}

In investigating the validity of the determination of the AB-ratio, the methodolog: cal remarks that can be made (study population, spectrum of the disease, gold standard, independence) imply that data concerning the high sensitivity of the measurement of the AB-ratio are better supported than statements about the high 
specificity. Nonetheless, the literature permits the conclusion that the measurement of the resting AB-ratio is a valid method for distinguishing between 'healthy' and 'occluded' vessels. It appears that the distinction between "healthy' and 'stenosed' vessels can be made less clearly. Thus, the measurement of the resting $A B$-ratio seems less valuable for the detection of minor (angiographic) vascular abnormallities. As a consequence of this fact the choice of the cutoff point for the AB-ratio is operi to discussion. There is a grey zone between 0.90 (higher specificity) and 1.00 (higher sensitivity). For general practice it would seem that 0.90 is to be preferred, the specificity becoming too low otherwise: with a relatively low prevalence (see chapter 2) a high specificity is essential in order to obtain an acceptable predictive value of a positive test result. On the other hand, sensitivity should not be too low: from a preventive perspective it is important to find cases with relatively mild PAOD. The higher number of false positive test results in case of a higher cutoff value, could be diminished by repeating the measurement a few times on consecutive occasions. For other medical disciplines or for epidemiological research other considerations may hold.

\section{Comparison with the vascular laboratory}

The most important manual skill required for assessing the resting AB-ratio in general practice is more or less identical to that in the vascular laboratory. However, the theoretical comparison of the measuring procedures leads one to expect that the reproducibility in general practice is lower.

It also may be presumed that the values for the $A B$-ratio obtained in general practice are systematically somewhat lower than the values measured in the vascular laboratory. This means that some of the subjects whose ABratio is close to the cutoff point would be labelled as 'PAOD' in general practice but not in the vascular laboratory. Thus, in addition to the reproducibility argument mentioned above, there is a second reason to repeat the measurement of the AB-ratio within a few weeks: reduction of the number of false positive cases.

The vascular laboratory offers supplementary possibilities. If clinical picture and resting $A B$-ratio do not produce enough evidence to establish the diagnosis, a treadmill test, reactive hyperaemia test or the measurement of the systolic toe pressure can yield additional information. Pulse wave analysis, measurement of segmental pressures and performing a duplex scan can provide information on the anatomical location and hemodynamic consequences of arterial stenoses.

\section{Conclusions}

The $A B$-ratio at rest differentiates between obvious and no $P A O D$. When an $A B$ ratio $<0.90$ is (repeatedly) found, this could be an argument for giving the patient specific advice with regard to smoking and exercise. The $A B$-ratio offers an impression of the severily of the disorder. Moreover, the ankle pressure provides an indication for the prognosis. The AB-ratio also permits monitoring the course of the disease and a better documentation of any referrals to the vascular specialist. A decrease in the AB-ratio exceeding $0.15-0.20$ could be a reason for referral with at
cherapeutic goal.

The pocket Doppler device may be useful in general practice. It may reduce the number of referrals, namely those cases that would primarily be referred for dia- 
Table 3.3 Proposal for the interpretation of the resting ABratio in general practice, taking criteria for reproduciblity and accuracy into account, as discussed in this review

$\begin{array}{ll}\begin{array}{l}\text { AB-ratio } \\ \text { (pocket-Doppler) }\end{array} & \text { Interpretation (in general practice) } \\ >1.05 & \text { PAOD may be ruled out confidently } \\ 0.90-1.05 & \text { PAOD cannor be ruled out, but a repeatedly measured value of more } \\ & \text { than 0.90 renders the presence of the disease unlikely" } \\ 0.750 .90 & \text { A healthy vascular system cannot be ruled out with certainty, but a } \\ & \text { repeatedly measured value of less than ogo renders the presence of } \\ <0.75 & \text { PAOD (stenosis, single ocdusion) very probable } \\ <0.50 & \text { MuD (stenosis, occlusion) is definitely present }\end{array}$

a normal resting pressure followed by an abnormal post-exercise AB-ratio indicates PAOD

gnostic purposes and not for surgical intervention. On the basis of the literature discussed, guidelines for the indications, the execution, and the interpretation (table 3.3) of noninvasive tests in general practice may be drawn up in a pragmatic fashion. ${ }^{33}$

\section{References}

1. Carter SA. Indirect systolic pressures and pulse waves in anterial occlusive disease of the lower extremities. Circulation 1968; 37: 624-37.

2 Carter SA. Clinical measurement of systolic pressures in limbs with arterial occlusive disease. JAMA 1969; 207: 1869-74.

3 Buth J. Het vasculaire laboratorium [Dissertatie]. Amsterdam: Universiteit van Am* sterdam, 1978.

4 Baker JD, DeEtte Dix PAC. Variability of Doppler ankle pressures with arterial occlusive disease: An evaluation of ankle index and brachial-anklle pressure gradient. Surgery 1981; 89: 1347 .

5 Schroll M, Munck $O$. Estimation of peripheral atteriosclerotic disense by ankle blood pressure measurements in a population of 60 year-old men and women. Journal of Chronic Diseases $1981 ; 34: 261-9$.

6 Ouriel KO, MeDonnel AE, Metz CE, Zarins CK. A critical evaluation of stress testing in the diagnosis of peripheral vascular disease. Surgery 1982; 91: 686-93.

7 Osmundson PhJ, O'Fallon WM, Clements IP, Kazmier FJ, Zimmerman BR, Palumbo PJ. Reproducibility of non-invasive tests of peripheral occlusive vascular disease. J Vasc Surg $1985 ; 2: 678-83$.

8 Johnston KW, Hosang MY, Andrews DF. Reproducibility of noninvasive viscular laboratory measurements of the peripheral circulation. I Vasc Surg 1987; 6: 147-51.

9 Fowkes FGR, Housley E, Macintyre CCA, Prescott RJ, Ruckley CV. Variability of ankle and brachial systolic pressures in the measurement of atheroscletric peripheral atrerial disease. J Epidem Community Health 1988; 42: 128-33.

10 Jeines $R$, Gaardsting $O$, Hougaard Jensen $K$, et al. Fate in intermittent daudication: outcome and risk factors. $\mathrm{Br}$ Med J 1986;293: 1137.40.

11 Naschitz JE, Ambrosio DA, Chang JB. Intermittent claudication: predictors and outcome. Angiology 1988; 39: 16-21. 
12 Yo $\$ \mathrm{~T}$, Hobbs JT, Irvine WT. Ankle systolic pressure measurements in arterial disease affecting the lower extremites. Br J Surg 1969; 56; 676-9.

13 Thulesius $\mathrm{O}$, Gjores $J A$. Use of doppler shift detection for determining peripheral arterial blood pressure. Anglology 1971; 22: 594603.

14 Chamberlain J, Housley $\mathbb{E}_{*}$ MacPherson AIS. The relationship berween ultrasound assessment and angography in occlusive arterial disease of the lower limb. Br I Surg 1975; 62: $64-7$.

15 Hylkema BS. Tussen polspalpatie en aortografie [Dissertatie]. Groningen: Rijksuniversiteit Groningen, 1975.

16 Hylkema BS. Diagnostiek van arteriéle circulatiestoomissen in de benen door bloeddrukmeningen met behulp van ultrageluid. Ned Tijaschr Geneeskd 1976; 120:733-41.

17 Smith RC, Ferrington $C$, Ruckley $C V$. Calf muscle wechnetium clearance and Doppler ankle pressure in patients with intermittent claudication. VASA 1977; 6: 236-43.

1.8 Bernink PJLM. Parameters van de circulatie in de onderste extremiteiten met betrekking tot atherosclerosis obliterans [Dissertatie]. Groningen: Rijksuniversiteit Groningen, 1978.

19 Bernink PJLM, Wouda AA. Meting van de bloedsomloop in de benen van patienten met atherosclerosis obliterans, wóó en na de operatie. Ned Tüdschr Geneeskd 1981; 125: 178692.

20 Yao ST. Haemodynamic studies in peripheral arterial disease. Br J Surg 1970; 57: 761-6.

21. Lepäntelo M, Lindfors $O$, Pekkola P. The ankle/arm systolic blood pressure ratio as a screening test for arterial insufficiency in the lower limb. Ann Chir Gyn 1983; 72: 57-61.

22 Piecuch $T$, Jaworkli $R$. Resting anklearm pressure index in vascular diseases of the lower extremities. Angiology 1989; 40: 181-5.

23 Fronek A, Johansen KH, Dilley RB, Bernstein EF. Non-invasive physiologic tests in the diagnosis and characterization of peripheral arterial occlusive disease. Am J Surg 197\%; 126: $205-14$.

24 Bruininck CMA. Pre- en post-operatieve exaluatie van claudicatio intermittens met behulp van een Doppler-flowmeter [Dissertatie]. Nijmegen: Karholieke Universiteit Nijmegen, 1976.

25 Kitslar PJEHM. Doppler-ultrasoundtests in the diagnosis of chronic aorta-iliac obstructons [ThD Thesis]. Maastricht: Rijksuniversiteit Limburg, 1982.

26 Bernstein EF, Fronek A. Current status of noninvasive tests in the diagnosis of peripheral arterial disease. Surg Clin North America 1982; 62: 473-87.

27 Breslau PJ, Jöning PJG, Greep JM. De klinische betekenis van hemodynamisch, niet-invasief onderzoek bij patiënten met arteriële watziekten vatu de benen. Ned Tijdschr Ge* neested 1984; 128: 996-8.

28 Buth J. Niet-invasieve diagnostiek van perifere arteriele andoeningen: het vaataboratorium. Ned Tijdschr Genceskd 1985; $2343-9$.

29 Fowkes FGR. The measuremen of atherosclerotic peripheral arterial disease in epidemiological surveys. Int J Epidemiol 1988; 17: 248-54.

30 Fowkes FGR, Housley E, Macintyre CCA, Prescotr RJ, Ruckley CV. Reproducibility of reactive hyperaemia test in the measurement of peripheral arterial disease. Br J Surg 1988; 75: $743-6$.

3 Strandness Jr DE. Duplex scanning for diagnosis of peripheral arterial disease. Herz 1988; 13: 372,7 .

32 Cossman DV, Ellison JE, Wagner WH, Carroll RM, Treiman RL, Foran RF et al. Comparison of contrast atteriography to arterial mapping with color-fow duplex imaging in the lower extremities. J Vasc Surg 1988; 10: 522-9.

33 Bonsema K. Boutens EJ, Kaiser V, Stoffers HEJH. Perifeer arterieel vaatlijden. Standaard M13 Nederlands Huisartsen Genootschap. Huisarts Wet 1990; 33: 440-6. 


\section{Chapter 4 Aims of the empirical studies}

Summary The main objectives of this study are to answer the following questions:

1 What is the prevalence of peripheral arterial occlusize disease (PAOD) in the general practice population?

2 What is the diagnostic significance of signs and symptoms in PAOD?

In addition we want to study the following issues:

- The reproducibility of the measurement of the ankle-brachial systolic pressure ratio.

- The diagnostic power of the measurement of the ankie-brachial systolic pressure ratio.

In the literature review of chapter 2 it is rendered plausible that PAOD occurs more frequently than is generally thought: there are many patients with PAOD of whom the general practitioner is not aware, both with and without complaints. In addition there seems to be an underregistration of female patients with intermittent claudication.

Much is still unclear about the natural course and the prognosis of PAOD but it is certain that patients diagnosed 'PAOD' are at high cardiovascular risk. Early diagnosis leading to timely conservative intervention might possibly procure a decrease in the progression of the atherosclerotic process and a reduction of the cardiovascular and cerebrovascular morbidity and mortality. In this respect the clinical relevance of 'asymptomatic' PAOD is still unclear.

There is a paucity of scientific information concerning the predictive values of data obtained from the medical history and the physical examination with respect to PAOD in general practice. Possibly, the classic textbook pattern should be modified for the general practice setting. The diagnostic value of combinations of signs and symptoms is unknown.

A number of questions therefore remain. For instance: can the value of the history (read: Rose questionnaire) be improved by elaborating it with questions relating to 'less typical' complaints, differential diagnostic questions and questions about risk factors? What is the value of signs and symptoms other than those discussed in the literature? Would it be possible to identify combinations of procedures that provide optimal information about the probability of the diagnosis 'PAOD'? Do arypical complaints occur more often in women than in men? Would it be possible to discern a characteristic pattern of signs and symptoms for the early phase of the disease in patients with manifest PAOD as well as in subjects initially considered asymptomatic?

In chapter 3 we concluded that the measurement of the AB-ratio using a hand held Doppler device could be a useful supplementary test in general praccice. However, there is reason for some reserve regarding the introduction of this diagnostic method in general practice. Validity and reproducibility have not been examined in 
populations relevant to general practice, using methods that are feasible in this setting. Factors such as the spectrum of the disease, the nature of decision-making in general practice and the use of the Doppler device by general practitioners or practice assistants - in stead of vascular laboratory technicians - may influence the validity and the reproducibility of the measurement of the AB-ratio considerably.

Accordingly, empirical research on the validity and the reproducibility of Doppler testing in general practice remains necessary. Research on the reproducibility of the AB-ratio in general practice should be carried out with patients from general practice and with general practitioners or their assistants as observers. Research on the validity of the method should take the spectrum of signs and symptoms occurring in general practice into account. In addition it should be relevant to the diagnostic situation of the general practitioner. Then, predictive values of posivive and negative Doppler test results could be assessed.

The outcomes of this type of research are important for deriving a judgment on the value of the pocket Doppler for general practice and for epidemiological research on PAOD in relatively unselected populations.

Thus, in view of the gaps in knowledge identified by analysis of the literature and of our possibilities for research in general practice, the following principal research topics were formulated:

1 What is the prevalence of PAOD in the general practice population, and how large are the categories 'asymptomatic', 'atypical' and 'manifest' PAOD, known and unknown to the general practitioner?

2 What is the value of clinical data (history, physical examination, patient record) for the diagnosis of PAOD? Or: What are the sensitivity, the specificity and the predictive values of clinical data - both separately and combined - in relation to PAOD?

Since we intended to use the ankle-brachial systolic pressure ratio (AB-ratio) by means of a hand held Doppler device as 'standard' diagnostic test, the following additional research topics were formulated:

- Regarding the reproducibility of the measurement of the AB-ratio:

- What is the magnitude of measurement variation due to the multi-observer design of the Limburg PAOD Study?

- What is the magnitude of other sources of measurement variation, relevant to clinical situations?

- Regarding the diagnostic power of the measurement of the AB-ratio in general practice:

- What is its accuracy and diagnostic value?

- What is its optimum cutoff value?

- Can we provide threshold cutoff values beyond which PAOD can be ruled in (high predictive value of a positive test result) or out (high predictive value of a negative test result)? 


\section{Chapter 5 Design, methods and variables}

Summary This chapter discusses the general design, methods and variables of the main study on the prevalence and clinical diagnosis of peripheral arterial occlusive disaese (PAOD). The definitive study population was recruted from a population of male and female patients - born between 1 November 1911 and 31 December 1946, on the list of 18 general practice centres - by means of a postal questionnatre an complaints and risk factors fyielding a 'prior risk score' ranging from zero to fivel followed by a sampling and selection procedure.

Data collection in the general practice centres occurred according to a cross-sectional design and consisted of two parts which bad to be executed independently:

1 data from the medical bistory were provided by the patient in a questionnaire and data on findings of the physical examination, presious medical bistory, medication, camorbidity and diagnosis were collected by the general practitioner.

2 the measurement of the ankle-brachial systolic pressure ratio (AB-ratio) by means of a pocket Doppler device was carried out by a practice assistant. This Doppler meatsurement' was used as standard diagnostic test. Patients with an AB-ratio lower than 0.95 on two consecutive occasions (interval: one week) were considered to bave PAOD.

All the anonymous and coded variables described in this chapter were read into the university's mainframe computer. Personal details of the patients were stored separately in a database on a personal computer.

Methodalogy and results of the additional studies on the reproducibility and the diagnostic validity of the measurement of the AB-ratio will be discussed in chapters 7 and 8 .

\section{Introduction}

Mid 1986 the Department of General Practice started a research project on the natural course of peripheral arterial occlusive disease (PAOD) and the effect of calcium-carbasalate on that course (the Limburg PAOD Study). The longitudinal data collection of this project (a combination of a cohort study and a randomized controlled trial) would be preceded by a phase during which patients with PAOD would have to be identified.

While preparing this study, the idea arose to expand the case-finding phase to a

Henri EJH Stoffers, Victor Kaser, J Andre Knotnerus. Also the following persons participated in the discussions and decisionmaking in the first phase of the 'Limburg PAOD Study": They GJ Lemmens", general practitioner; Prof. Cees $\mathrm{A}$ de Geus PhD, general practitioner; Paul JG Jörning PhD, surgeon; Arnold DM Kester PhD, statistician; Hubert JA Schouten PhD, statistician; Karin PM Aretz, research assistant. 
cross-sectional study on the prevalence and diagnosis of PAOD in general practice. It would cost relatively little extra effort to gather data on these topics. The measurement of the ankle-brachial systolic pressure ratio (AB-ratio) using a pocket Doppler device, which was used as a screening instrument in the longitudinal study, could be employed as standard diagnostic test.

In this chapter an overview is presented of the design of the cross-sectional study, the "prevalence \& diagnosis' study (Limburg PAOD Study, part 1) as it was embedded in the 'course \& intervention' study (Limburg PAOD Study, part 2).

\section{Populations and selection procedure.}

\section{Original design of the selection procedure}

In the first instance, the size of the study was determined by the requirements of the 'course \& intervention' study. Both studies were to be carried out in 20 general practices, with a total population of approximately 60 thousand subjects. It was expected that in the age category ' 40 to 75 years' (the 'source population': approximately 30 thousand subjects) a postal questionnaire would identify 5-6000 patients at risk for PAOD. These subjects, plus a sample of 1000 persons not at risk according to the answers provided in the postal questionnaire, would be asked to take part in the study. The group of patients which would subsequently be examined in the general practice centres (the "study population') was to yield the subjects with PAOD suitable for participation in the longitudinal study (the 'follow-up population'). The original design of the 'prevalence \& diagnosis' study is presented in figure 5.1.

The lower age limit was chosen arbitrarity because PAOD is a realistic passibility mainly in people of 40 years and older. The upper age limit was chosen arbitrarily on account of requirements posed by the 'course \& intervention' study: a greater drop-out percentage was expected with increasing age (co-morbidity, mortality, protracted hospital admissions), as well as decreased mobility, low compliance (cessation of smoking, daily exercise, daily drug intake), and a diminished relevance of the (longterm) intervention.

\section{General practice centres and patients}

The cooperation of the participating general practitioners (and their practice assistants) was obtained by means of a short course on PAOD, an informative session concerning the study, and personal contacts. Altogether, 32 general practitioners of 20 general practices with 23 practice assistants agreed to take part. The collaboration was laid down in a contract. The services offered would be remunerated. Moreover, all practices were supplied with a pocket Doppler device.

For this clinical and epidemiologic study, compliance with the research protocol and good motivation of the general practitioners were regarded more important than the regional or national 'representativeness' of the general practitioners. The recruitment methods were not expected to lead to relevant selection bias in relation to PAOD in the general population.

The personal details of all patients born between 1 January 1911 and 31 December 1946 were obtained from the administration of the participating general practitioners (mostly through manual work by the practice assistants, partly supplied on diskettes) and from the regional sick fund (diskette). All personal details were stored 
Figure 5.1 Original design of the Limburg PAOD Study

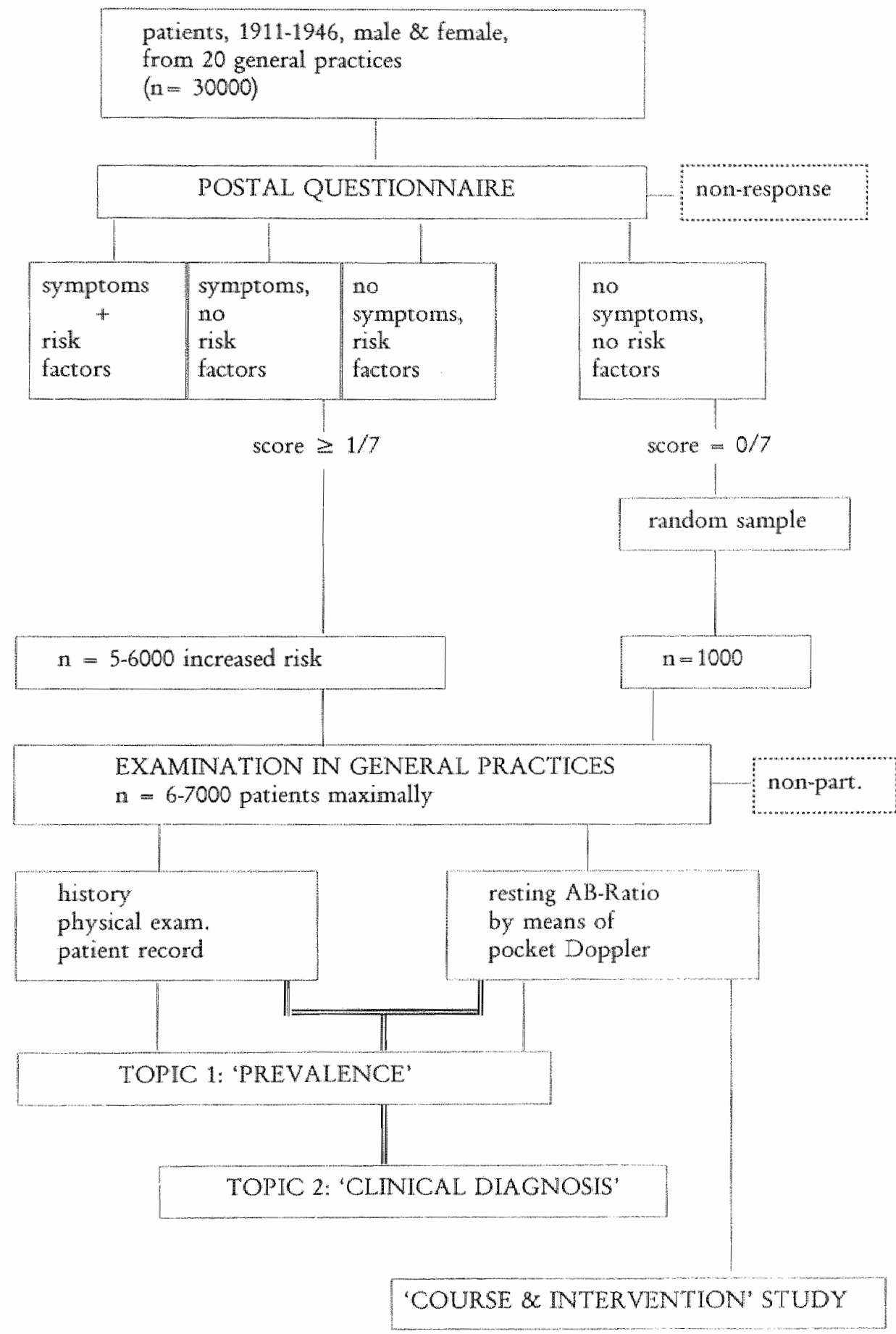


in a database in the personal computer of the project. Altogether, personal details of 30051 persons were obtained.

\section{The postal questionnaire}

In order to increase the efficiency of the identification of PAOD cases in the population to be selected for further study, all patients of whom personal details had been acquired were sent a questionnaire consisting of seven yes/no questions on complaints (pain while walking, cold feet) and risk factors for PAOD (smoking more than 15 cigarettes a day, hypertension, diabetes mellitus, a medical history of cardiovascular disease or a family history of cardiovascular disease) (appendix 5.2).The patients were asked to complete and return the questionnaire. The nonresponse was kept to a minimum by enclosing information on the study, by using note-paper of the patient's general practice, by requesting that the general practitioner would co-sign the covering letter, and by providing a post-paid envelope. Non-responders were sent up to two letters of reminder.

The aim was that all patients who had answered at least one question affirmatively (prior risk score ranging from $1 / 7$ to $7 / 7$ ) would be invited for an examination by their general practitioner. In addition, a sample would be taken from the category of subjects without increased risk (prior risk score $=0 / 7$ ). This sample would yield information on the prevalence of PAOD in the most healthy subpopulation. This was also necessary in order to be able to compute the total prevalence in the source population by calculating back from the prevalence measured in the sampled fraction.

\section{Adjustment of the selection procedure}

When the first results of the postal questionnaire came in, it turned out that the number of people with a prior risk score $\geq 1 / 7$ was much larger than expected. This was partly attributable to the question concerning a family history of cardiovascular disease. Had the initial criterion for participation in the study (prior risk score $\geq 1 / 7$ ) been maintained, then $15-16000$ people would have had to be examined by their general practitioner. This being infeasible, the selection procedure was adapted.

The population to be examined by the general practitioner had to meet all of the following conditions:

- the prevalence estimation had to be possible;

- it had to be possible to compare the AB-ratio with a wide range of signs and symptoms;

the percentage of PAOD patients had to be large enough to allow selection of a sufficient number of subjects for the 'course \& intervention' study;

- in order to be able to correct for selection mechanisms in studying diagnostic relationships, the selection process had to be fully documented.

With thase conditions as a starting point, the selection procedure was modified as follows. First of all, the criterion for 'increased risk' was narrowed down: the items 'family history of cardiovascular disease' and 'cold feet' - the least discriminatory, as expected - were excluded from consideration. Five items then remained: pain while walking, smoking of 15 or more cigarettes a day, hypertension, diabetes mellitus, and cardiac complaints or stroke in the past. Consequently, the answers could vary from one to five rimes "yes", corresponding with a prior risk score 
(termed 'score' below) of 0 to 5 .

Secondly, the sample from the group without increased risk (score $=0 / 5$ ) was reduced to 500 . This did not conflict with statistical considerations with regard to the prevalence estimation (research topic 1).

Thirdly, from the group with increased risk (score $\geq 1 / 5$ ) an initial random sample of $\mathrm{n}=1000$ was taken for the study on signs and symptoms. From a statistical viewpoint this sample size seemed large enough for research topic 2.

Finally, from the remaining group with increased risk, the 4500 patients at greatest risk were selected. Generally, these patients had a score of $\geq 3 / 5$; in some practices, addicional patients were recruited out of the $2 / 5$ score group. In this way an efficient tracing procedure for the 'course 8 intervention' study was guaranteed.

Each patient was given a code indicating to which selected subgroup he belonged: 'no risk' (1), 'increased risk" (2), or 'highest risk' (3). This revised selection procedure made it possible to estimate the prevalence both in the total population and in the various selected subpopulations. Moreover, the value of (combined) diagnostic data could be studied in the three subgroups which represent both an increasing level of prior probability and clinical relevance.

For two of the practices the adjusted procedure proved yet too laborious. Therefore, in these two practices only patients from the 'highest risk' group were selected for participation in the PAOD Study. Given the differently selected study population, the patients identified in these practices could be admitted to the 'course $\&$ intervention' study, but the data could not be used for the analysis of the 'prevalence $\&$ diagnosis' study. 'Thus, 18 general practices finally took part in the present study (appendix 5.1). The modified study design is presented in figure 5.2.

In summary, the following populations can be discerned:

1 a The source population: all subjects who were mailed a postal questionnaire (S)

b The respondenrs: those patients out of $S$ who returned a completed questionnaire (R).

c. The non-responders: those subjects out of $\mathrm{S}$ who did not return the postal questionnaire (NR).

2 a The invited population: all patients who - on the basis of the sampling and selection procedure - were invited to be examined by their general practitioner (I).

b The study population: the patients out of I who actually took part in the study (P).

c The non-participants: those patients out of I who did not partake in the study (NP).

\section{Data collection}

\section{The invited population}

The respondents who were invited to be examined by their general practitioner were divided into three groups. Group 1 (no risk) consisted of a random sample (500) of all patients belonging to the subpopulation of respondents with a prior risk score of $0 / 5$. Group 2 (increased risk) comprised patients belonging to the sample (1000) of the subpopulation with a score of $1 / 5$ to $5 / 5$. Group 3 (highest risk) consisted of those patients (4500) out of the subpopulation with a score of $1 / 5$ to 
Figure 5.2 Modified design of the Limburg PAOD Study

$1986 / 87$

1987

patients, 1911-1946, male \& fernale, from 18 general pracrices

$(n=$ approx. 26000)

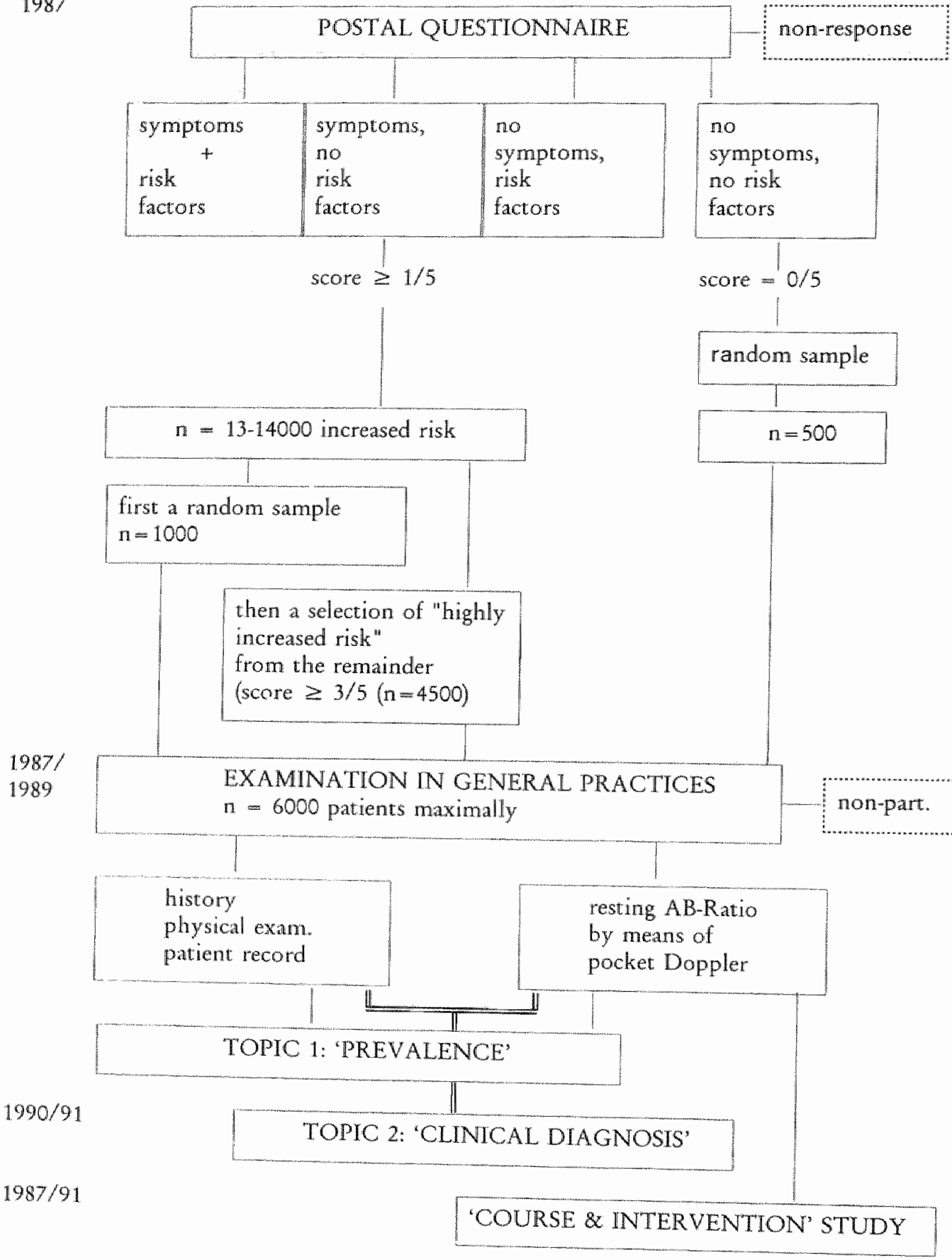


$5 / 5$ who remained after group 2 was formed and who moreover had the highest risk (score $5 / 5,4 / 5,3 / 5$, and, in some practices, $2 / 5$ ). The three groups comprised $8.3 \%$, $16.7 \%$, and $75 \%$, respectively, of the total population invited for an examination.

In order to increase the response, the practice assistants were asked to invite the subjects by telephone if possible. In addition, the practices were provided with letters of invitation and letters of reminder with the letterhead of the practice. The assistants were to note the reasons for drop-out on a special form.

\section{Procedure}

Data collection in the general practices followed a cross-sectional design, in which at one moment diagnostic data were gathered by means of two methods:

- the 'clinical method' - history, physical examination and data from the patient record - leading to a clinical diagnosis of the general pracritioner including at differential diagnosis, and

- the 'Doppler method': the measurement of the resting AB-ratio by means of a pocket Doppler device and a mercury sphygmomanometer.

The history was taken by means of a questionnaire, completed by the patient at home and taken along to the appointment. The practice assistant checked the questionnaire for completeness, after which the general practitioner read it. The patient was examined by the general practitioner. A Doppler measurement was performed by the practice assistant.

Clinical and Doppler data had to be collected independently in order to prevent bias by foreknowledge. It would have been ideal if in all cases the Doppler testing had been performed by the practice assistant or a fellow general practitioner, and the clinical part of the study by the patient's own general practitioner. However, it was foreseeable that this would not be possible in all practices and in all cases. Hence, record was kept as to who performed each of the two parts of the study, to allow control for bias.

In cases where the two data collections could actually be carried out independently, the sequence chosen was left to the practices. In those cases where the general practitioner collected both clinical and Doppler data, the Doppler testing was done last. Is was presumed that the Doppler measurement would be less sensitive to subjective influences as compared to the physical examniation.

In case of at least one AB-ratio $<0.95$ an appointment was made with the patient for a second Doppler measurement one week later. Preferably, this second measurement was taken by the same investigator who had done the first.

\section{The studied variables.}

The data collected by the general practitioners and their assistants were recorded on registration forms (appendix 5.3). These forms came together with a clarilication for the general practitioner and with instructions for the general practitioner and the practice assistant. Before the data collection started, the researchers personally went through the protocol with the general practitioners and the assistants.

After a few weeks of experimentation, the majority of practices had found a way of organizing the study that fitted in with their style of practice management: planning appointments with one or more patients in the course of the surgery hour 
on suitable days or alternatively, planning several patients on a fixed day in the week.

In the subsequent paragraphs the contents of the various forms will be discussed. Table S. 1 indicates the various steps that were involved in the process of developing the registration forms.

\section{The patient questionnaire (appendix 5.3)}

The aim of the questionnaire was to obtain data from the medical history of the patient on:

- complaints, whether typical for PAOD or not

- a number of risk factors for PAOD

- self-medication, especially of salicylic acid derivatives

- physical exercise

The diagnosis PAOD had to be made or rejected by the general practitioner on thebasis of these data plus the data derived from the physical examination and the patient record.

The items of the questionnaire were selected following a study of the literature on the history and pattern of complaints in PAOD (chapter 2), and after discussion within the project group. A commentary on the various groups of questions in the patient questionnaire is given in appendix 5.4.

The questionnaire was a deliberate compromise between those questions that general practitioners usually ask the patient and the data required for the research project. After all, the study aimed to establish whether complaints mentioned in the literature or considered potentially important by the research team, would be relevant for the general practitioner in assessing a case.

No existing questionnaire was found that would have suited our research topic without substantial adaptation. The 'Rose questionnaire' - a standardized questionnaire for intermittent claudication ${ }^{1}$ - though too restricted for the purpose of the study, was incorporated. At the time, no publications had appeared yet on the Edinburgh questionnaire.?

\section{The general practitioners' form (appendix 5.3)}

'The aim of the general practitioners' form was to obtain data on:

- lindings of the physical examination in subjects with and without PAOD; risk factors related to PAOD as recorded in the general practitioner's patient records;

- inclusion and exclusion criteria for the 'course \& intervention' study;

- the extent to which patients with PAOD were known to their general practitioner.

The items in the general practitioners' form were included after a study of literature (chapter 2) and discussion within the project group. The general practitioners were given the opportunity to comment on earlier versions. This questionnaire also became a deliberate compromise between what was current in general practice, what might be interesting to investigate on the basis of literature, and what was considered feasible in a patient and practice bound study. A commentary on the various groups of items of the general practitioners" form is presented in appendix
5.4 . 
Table 5.1 The development of the registration forms

\begin{tabular}{|c|c|c|}
\hline Date & & Activity \\
\hline 1986 & October & $\begin{array}{l}\text { Literature study and discussion about contents and utilisation of } \\
\text { registration forms. }\end{array}$ \\
\hline \multirow[t]{8}{*}{1987} & February & Tentative concept ready. \\
\hline & March & $\begin{array}{l}\text { Test of draft questionnaire among } 9 \text { patients. Written commentr of } \\
\text { general practitioners on all forms (response: } 2 / 36) \text {. }\end{array}$ \\
\hline & June & Professional layout. \\
\hline & July & Printing of tentative version. \\
\hline & August & Start of scudy in two pilot practices. \\
\hline & October & Analysis of 40 sets of forms. Adjustment of tentative version. \\
\hline & Nowember & $\begin{array}{l}\text { Oral comments by general practitioners and practice assistants } \\
\text { during an informative session for all participants. } \\
\text { Definitive layout and typesetting. }\end{array}$ \\
\hline & December & Printing of definitive registration forms. \\
\hline 1988 & January & Start of the study in the remaining $\mathbb{1 6}$ practices. \\
\hline
\end{tabular}

The measurement of the resting $A B$-ratio and the choice of a diagnostic cutoff walue (appendix chapter 3)

The function of the Doppler measurement was:

- to determine the prevalence of PAOD in the study population by means of an objective criterion,

- to obtain a standard to which signs and symptoms could be compared

- to select patients for the follow-up study

In review articles that appeared before the study had started $(1970$ to 1987) it was pointed out that exercise testing was the best way to diagnose PAOD. ${ }^{3-11}$ "Three methods qualified:

- the measurement of the course of the AB-ratio after a standardized treadmill test

- idem, after 1-2 minutes of ankle flexion/extension

- idem, during the reactive hyperaemia period following the abrupt release of the sphygnomanometer cuff pressure, applied at a suprasystolic level for 3.5 minutes, proximal to the ankle.

The literature indicates that - in contrast with the flexion/extension method - the reactive hyperaemia test was sufficiently reproducible. In addition, the latter test might be carried out not only in the absence of ECG control but also for both legs separately, which is not the case for the treadmill test. Fowkes, moreover, cautiously advocated the reactive hyperaemia test, although the present study had at the time already commenced ${ }^{12,13}$ However, this theoretically "ideal" method requires 30 . 45 minutes per patient and can be painful. The reproducibility of the test is reported to be inferior to that of the resting $A B$-ratio measurement. ${ }^{3,14}$

After discussion within the project group - which included a vascular surgeon the resting $A B$-ratio measurement was opted for. This method appeared sufficiently valid for use as 'standard diagnostic test' (chapter 3). According to the literature, the resting $\mathrm{AB}$-ratio permits a clear distinction between angiographically normal vessels and "significant disease", i.e. occluded vessels. 
However, there is an overlap between normal and stenosed vessels. Thus, the choice of the cutoff point in the range between 0.90 (higher specificity) and 1.00 (higher sensitivity) as subject to discussion. Considering the anticipated negative effect of too low a specificity on the predictive value of a positive Doppler test outcome, it was decided to select 0.95 as the cutoff point, this being a balanced compromise between the 'sensitive' 1.00 value and the 'specific' 0.90 value. The following considerations were taken into account:

With a cutoff point of 0.95 , the number of false positive Doppler test results should approximately balance the number of false negative outcomes, which is desirable in terms of the prevalence estimation;

With a cutoff point of 0.95 , fewer subjects would be labelled as patients incorrectly than with a cutoff point of 1.00. Consequently, the study population for the "course \& intervention" study would be less diluted with these false positives, and any effect of calcium carbasalate would be less rnasked.

In this study the Doppler measurement was carried out according to protocol, preferably by the practice assistant (appendix chapter 3). The results of the measurement were recorded on the 'Doppler form" (appendix 5.3). The Doppler test was repeated after a week if the $\mathrm{AB}$-ratio was lower than 0.95 for at least one leg. The subject was considered a 'PAOD patient' only, if at this second measurement an $A B$-ratio of less than 0.95 was again obtained for the leg concerned. The subject was considered not to have PAOD if the AB-ratio was normal for both legs at the initial measurement.

Before the data collection started, informative sessions were held for the general practitioners and their assistants, and a reproducibility measurement was organized in order to determine the inter-observer variability of the resting AB-ratio measurement. The patients for this reproducibility measurement were recruired from the outparient population of a vascular surgeon of the University Hospital Maastricht. All practice mercury sphygmomanometers were calibrated during these sessions as well.

\section{Data processing and analysis}

The researchers visited each practice at four- to six- week intervals in order to check on the course of the project, to discuss problems and to collect questionnaires. The general practitioners were kept informed about the progress via regular newsletters.

The registration forms were checked for completeness by the practice assistants and the researchers. Forms that were incomplete or erroneously filled in were returned to the practice with a request for completion and/or correction.

All data were coded by the research assistants. They were typed onto punch cards by two data typists working independent of each other. The punch cards were read into the university's mainframe computer, which compared the corresponding codes. Dissimilar sets of codes were thus identified and corrected.

The data were analyzed with the software programme BMDP (BMDP Statistical Software Inc, 1988/1990). The ultimate analyses were preceded by analyses on the incomplete data base to detect inconsistencies and gaps in the various data filles and the BMDP operator programme, to practise with various BMDP analysis programmes, to see whether the collected data would indeed yield plausible and useful 
results and to prepare presentations of preliminary results. ${ }^{1521}$ Additions, transformations and corrections of the data base that later proved necessary were read into the data base on screen by the research assistants. The analysis was further designed as follows:

- Account of the selection process as it occurred in actual fact. The various populations were described with regard to relevant variables (age, gender, score, group). Nonresponse and non-participation were also described in qualitative and quantitative terms. The methods and outcomes of these analyses are presented in chapter 6 .

- Determination of the prevalence of the various manifestations of PAOD by gender and by age category. The prevalence in the source population was determined by calculating back from the figures obtained for the selected study population. The methods and results of these analyses are discussed in chapter 9.

- Analysis of diagnostir relationships. T'he sensitivity, specificity predictive values were assessed separately for each diagnostic variable. Subsequently, the diagnostic value attained by combined diagnostic data was assessed. Multivariable logistic regression analyses was used. The methods and results of these analyses may be found in chapter 10.

\section{Additional studies: the measurement and interpretation of the AB- ratio}

A study on the reproducibility of the AB-ratio was organized in the spring of 1987. The magnitude of different sources of measurement variation, relevant to clinical practice as well as multi-observer studies, was estimated from a random effects analysis of variance model. Thirty-five GPs and 24 practice assistants - joining in the Limburg PAOD Study - performed 503 AB-ratio measurements on nine patients over a period of nine weeks, using pocket Doppler devices. Methodology and results of this study will be discussed in chapter 7.

In the spring of 1991 a validity study was undertaken in which the diagnostic outcome of the measurement of the AB-ratio in three general practice centres participating in the Limburg PAOD Study - was compared to the diagnostic conclusions of the Vascular Laboratory of the University Hospital in Maastricht. This Was done both for the outcome of single AB-ratio measurements (231 legs of 117 patients) and the outcome of measurements on three consecutive occasions (subgroup of 92 legs of 51 patients). Methodology and results of this study will be described in chapter 8.

\section{Ethical aspects}

The participation of the patients in the postal inquiry and the examination in the general practices was voluntary. The patient was aware of the noninvasive nature of the Doppler testing. He was guaranteed explicitly that non-participation would not influence the normal relationship with his general practitioner.

The registration forms were provided with cover pages on which the personal details of the patient and an identification number were recorded. These cover pages were removed from the forms after they had been checked for completeness. The personal details - including the identification number - were then entered into a 
database in the project's personal computer, and used for administrative purposes (letters to patients, overviews for the general practitioners, address stickers, etc.).

The completed and coded registration forms were kept in lockable filing cabinets in the project's office, which is closed after working hours. The anonymous and coded research data were processed by means of the universiry mainframe computer. The identification number was used to keep together the data of each patient, and, if necessary, to examine the personal details data file in the personal computer.

The 'Limburg PAOD Study' was approved by the Medical Ethics Committee of the University of Limburg and the University Hospital Maastricht, on 22 May 1987.

\section{References}

1 Rose GA, Blackburn H, Gillum $\mathrm{RF}^{*}$ Prineas RJ. Cardiovascular survey methods. Genewa: world Health Organization, 1982.

2 Leng GC. Questionnaires. In: Fowkes FGR (ed). Epidemiology of peripheral vascular disease. London, Berlin, Heidelberg etc.: Springer, 1991.

3 Spitcel JA, DeWolfe V, Hume M, Winsor T, Wylie EI. Prevention and early detection of peripheral vascular disease. Circulation 1970; 42: $A 43-A 45$.

4 Fronek A, Johansen KH, Dilley RB, Bernstein EF. Noninvasive physiologic tests in the diagnosis and chancterization of peripheral arterial occlusive disease. Am J Surg 1973; 126: 205-14.

5 Barnes RW. Noninvasive diagnostic techniques in peripheral vascular disease. Am. Heart J 1979; $97: 241-58$.

6 Prineas RJ, Harland WR, Janzon L, Kannel W. Recommendations for tase of non-invasive: methods to detect atherosclerotic peripheral arterial disease in population studies. Circulation 1982; 65: 1561A-1566A.

7 Bernstein EF, Fronek A. Current status of noninvasive tests in the diagnosis of peripheral arterial disease. Surg Clin North America 1982; 62 : $473-87$.

8 Carter SA, Hamel ER. Role of pressure measurements in vascular disease. In: Bernstein EF (ed.). Non-imvasive diagnosric rechniques in vascular disease (2nd Ed.). St. Louis etc.: Mosby, 1982.

9 Buth I. Niet-invasieve diagnoskiek van perifere arteriele aandoeningen; het vaatlaboratorium. Ned Tijdschr Geneeskd 1985, 129: 2543-9.

10 Pignoli P. Longo T. Ultrasound evaluation of arherosclerosis. Methodological problems and technological dewelopments. Eut Surg Res 1986:18: 238-53.

11 Rutherford RB, Flanigan DP, Gupta SK ex al. Suggested standards for reports dealing with lower extremity ischemia. I Vasc Surg 1986; 4: 80-94.

12 Fowkes FGR. The measurement of atherosclerotic peripheral arterial disease in epidemiological surveys. Int J Epidemiol 1988; 17: 248-54.

13 Fowks FGR. Housley $\mathrm{E}$, Macintyre CCA, Prescott RJ, Ruckley CV. Reproducibility of reactive hyperaemia test in the measurement of peripheral arterial disease. Br I Surg 1988 ;
$75: 743-6$.

14 Ouriel $\mathrm{K}$, McDonnell AE, Metz CE, Zarins CK. A critical evaluation of stress testing in the diagnosis of peripheral vascular disease. Surgery 1982; $91: 686-93$.

15 Stoffers HEJH. Perifeer artericel vatijden in de huisartspraknijk: prevalentio en diagnostiek [voordractit]. Bijeenkomst 'N.W.O. Stimuleringsprogramma Huisartsgeneeskunde", U. recht 22 september 1989 . Mastricht: Rijksuniversiteit Limburg, vakgroep Huisartsgenees-
kunde, september 1989 .

16 Stoffers HEJH, Kaiser V, Knottnerus JA. Peripheral arterial occlusive disease in general practice: prevalence and diagnostic management [abstract]. In: Anonymous. Book of abstracts of the Ist WONCA European regional conference on family medicine/general 
practice. Barcelona: 1990.

17 Stoffers HEJH, Kaiser V, Knotmerus JA. Peripheral arterial occlusive disease: prevalence and diagnosis in general practice. Ist WONCA European regional conference Barcelona 1990 [presentation]. Maastricht: Rijksuniversiceit Limburg, vakgroep Huisartsgeneeskunde, Decamber 1990.

18 Stoffers HEJH, Kaiser V, Knotneras JA. Prewalence in general practice. In: Fowkes FGR (ed.). Epidemiology of peripheral vascular disease. London, Berlin, Heidelberg etc: Springer, 1991.

19 Stoffers HEJH. Perifeer arterieel watlijen in de huisartspraktijk: prevalentie en diagnostiek [woordrache]. Bijeenkomst 'N.W.O. Stimuleringsprogramma Huisartsgeneeskunde', Unecht 11 oktober 1991. Maastricht: Rijksuniversiteit Limburg, wakgroep Huisartsgeneeskunde, oktober 1991.

20 Stoffers HEJH, Kaiser V, Knotmerus 『A. The prevalence of peripheral aterial occlusive disease in general practice [presentation]. Pfizer International Research Symposium 'Epidemiology of peripheral vascular disease', Edinburgh, 31 Ocrober/ 1 November 1991. Maastricht: Rijksuniwersiteit Limburg, vakgroep Huisartsgeneeskunde, October 1991.

21 Kaiser V, Stoffers HE IH. Perifeer arterieel vatlijden, arherosclerose en risico. In: Risico en risicoschatting. Randwigck-cursus n. 4, 28 november 1991. Maastricht: Rijksuniversiteit Limburg, vakgroep Huisartsgeneeskunde/Cö̈rdinatiebureau Eerste Lijn, november 1991. 


\section{Chapter 6 Selection process and populations*}

Summary This chapter presents a quantiative overviete of the processes of selection and drop-out that led to the definitive study population. The extent of selective drop-out is assessed. Finally, the study population is described for a number of key parameters.

The source population consisted of 26620 patients with a mean age of 56.5 years (range: $40.3-76.9$ years) of whom $52.5 \%$ were female. The overall response on the postal questionnaire was $86.4 \%$. The average response rate per practice was $85.7 \%$ (SD: $3.4 \%$ ). The non-response did not cause a significant selective drop-out by age or gender.

There were 9095 responders with a prior risk score of zero and 13909 responders with a score from one to five. From the population of responders two random samples were taken: from the category with a score of zero (group 1, 'no risk', $n=451$ ) and from the category with a score of one to five (group 2, 'increased risk", $n=897$ ). Both samples proved to be representative for their respective source populations with regard to age and gender. Of the remaining patients with a score between one and five, those at bighest risk were selected (group 3, 'bigh risk', $n=3953$ ).

Thus, 5301 subjects were invited for an examination in one of the 18 general practice centres. The invitation was accepted by $68.9 \%$. The average participation rate per practice was $70.2 \%$ (SD: $11.9 \%$ ). Non-participation was due to various reasons: patients stayed in bospital for a protracted period or had moved or had died (17.5\%); many patients were 'not interested' (48\%); sometimes general practitioners decided that a patient would not participate for medical or practical reasons (11\%). The remaining causes for non-participarion were unknown (23.5\%). The non-participation was selective to at certain degree for 'age' (older age groups), 'gender' (males), and 'score" (inconsistent patrerni).

The definitive study population comprised 3654 patients (group 1: 292; group 2: 626; group 3: 2736) aged 40.7.78.3 years (mean age: 59.1 years) of whom $53.0 \%$ were fenale.

\section{Introduction.}

In chapter 5 the design, populations, methods and variables of the study were described. The present chapter discusses the selection process as it actually occurred. Subsequently, the extent of selective drop-out is examined. Finally, the definitive study population is described with reference to a number of key characteristics. These analyses are essential in order to identify any bias in the results. In addition, they may help the general practitioner to decide on the significance of the results for his particular practice. 


\section{Methods}

To determine whether selective drop-out occurred, populations were compared on two levels:

- level 1: source population (S) versus responders (R) and non-responders (NR) (see chapter 5);

- level 2: invited population (I) versus study population (P) and non-participants (NP) (see chapter 5).

In addition it was checked whether the sampling procedure had been successful.

\section{Level 1: source population, responders, non-responders}

It was examined to what extent selective drop-out occurred with respect to the variables 'age' and 'gender'. This is relevant for the prevalence computations, and thereby indirectly for the analysis of the diagnostic value of data from the history and physical examination. A chi-square test was used to investigate the hypothesis that the distribution over age and gender categories of the NR and R populations is similar.

\section{Sampling procedure}

To assess in how far the random samples from the population of responders with a score of $O$ (random sample $=$ group 1$)$ and 1.5 (random sample $=$ group 2) were representative for their respective source populations, the distributions of 'age' and 'gender' were compared. The subpopulation of $R$ with score $=0$ was compared to its sample, group 1 , and the subpopulation of $\mathrm{R}$ with score $=1-5$ was compared to its sample, group 2. The chi-square test was used for assessing statistical significance.

\section{Level 2: invited population, study population, non-participants}

It was examined to what extent selective drop-out had occurred with respect to the variables "age', 'gender', 'group", and 'score". A chi-square test was used to invesrigate the hypothesis that the distribution over the various categories of these variables in the NP and $S$ populations is similar. The reasons for non-participation were classified into ten categories. The study population was described for a number of key characteristics: age, gender, score, group, and co-morbidity.

\section{Statistical Software}

The programme BMDP (BMDP Statistical Software Inc., 1988/1990) was used to describe the age distribution in various populations. Confidence intervals (95\%) of proportions were calculated with the programme CIA (CIA, version 1.0, British Medical Journal \& MJ Gardner, 1989). In most cases, the BMDP programme was used to calculate the Pearson chi-square tests and the corresponding p-values. The spreadsheet programme Lotus (Lotus 1-2-3, release 2.2, Lotus Development Corporation, 1989) was used for determining the Pearson chi-square test in respect of the representativeness of the sampling procedure; the corresponding $p$-values were computed with the Epistat programme (True Epistat, Epistat Services, 1987). 
Figure 6.1 Selection procedures and populations

Population level 1

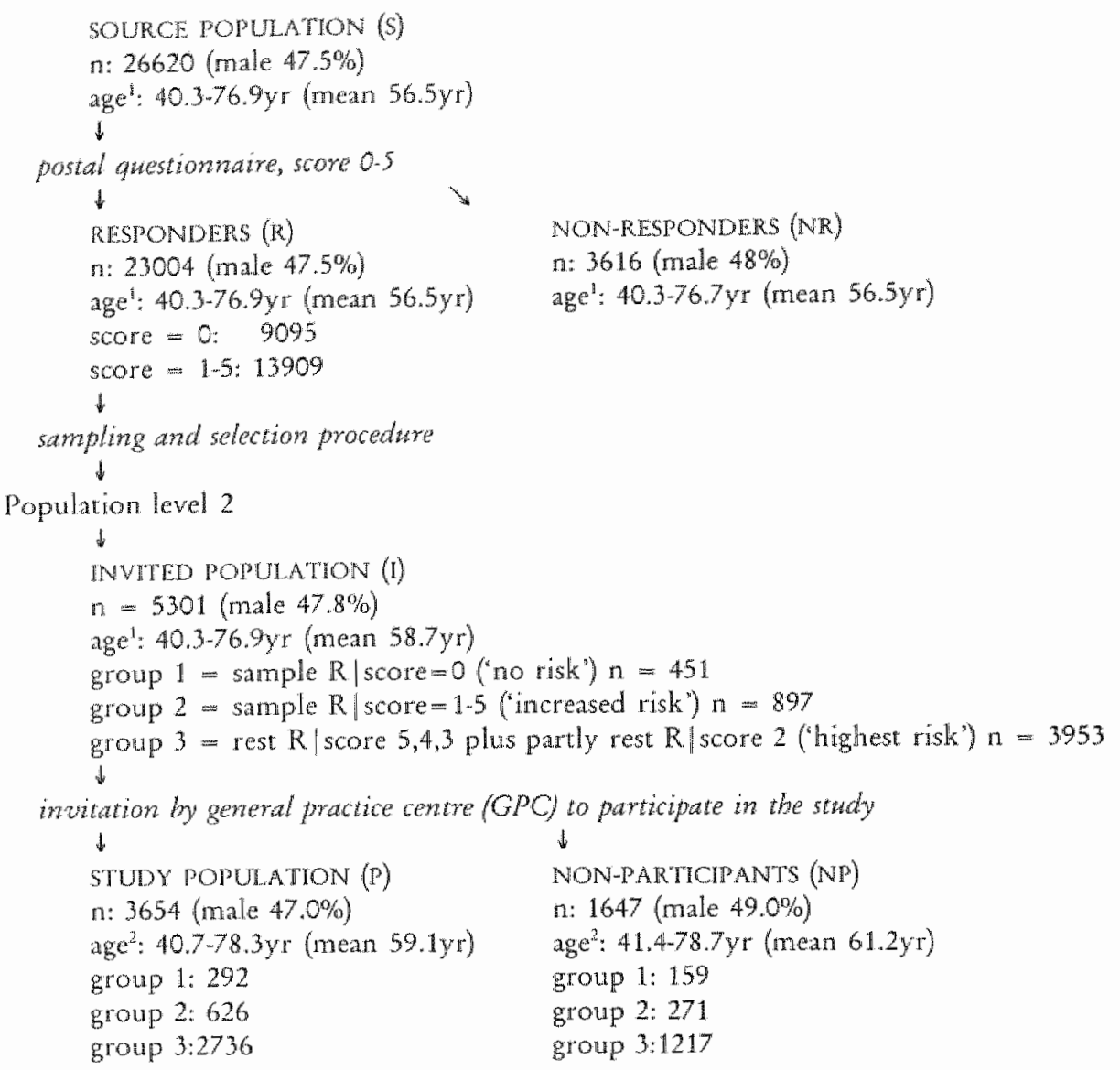

ange: age at the of postal inguiry

age age at time of examination in GPCs

Results

\section{The selection process}

In figure 6.1 the successive phases of the selection process are quantified for the most important parameters. "Ihe response to the postal questionnaire was $86.4 \%$. The average response percentage per practice was $85.7 \%$ ( $\mathrm{SD}=3.4 \%$, range $=76.0$ $90.4 \%)$

From the category of responders with score $=0$, a random sample was taken (group 1). From the category of responders with a score of one to five also a random sample was taken (group 2). Of the remaining patients in this category ( $\mathrm{n}$ $=13012$ ) $30.4 \%$ were in the 'highest risk' group (group 3). Altogether, $23 \%$ of the responders were invited for an examination by their general practitioners ( $\mathrm{n}=$ 
5301). The percentage of parients that subsequently participated amounted to $68.9 \%$ of the invited population. The average participation percentage per practice was $70.2 \%(S D=11.9 \%)$ of the invited practice population. Two practices had a relatively low participation level $(38.1 \%$ and $47.7 \%$, respectively) whereas two other practices had a relatively high participation level $(83.8$ and $89.8 \%$, respectively).

\section{Non-response on population level 1 (S-R-NR)}

The age distributions of $N R, R$, and $S$ correspond very closely (appendix 6.I). In the highest age category a significantly greater percentage non-responders is found (appendix 6.2). Comparison of the gender distribution of the three populations (appendices 6.3a, 6.3b) indicates that the gender distribution of NR does not differ significantly from the gender distribution in $R$ and $S$. "The percentage of nonresponders among men does not differ significantly from that among women (appendix 6.4).

\section{Representativeness of the sampling procedure}

The two random samples from $\mathbb{R}$ (see figure 6.1) are representative in terms of age and gender for the respective populations from which they were drawn (appendix 6.5). According to the chi-square tests, the minimal deviations of the sample fractions per age category as well as the slight overrepresentation of women in both samples are not significant.

\section{Non-participation on population level 2 (I-P-NP)}

In order to identify any age-specific drop-out, it was examined in how far patients from NP and P differed both in comparison to each other and in relation to $I$ regarding the distribution of the variable 'age at time of postal inquiry' (appendix 6.6). On the average non-participants were almost 2 years older than participants. The non-participation percentage per age category was also assessed (appendix 6.7). The participation rate of subjects aged 45 to 65 was higher than average, whereas in subjects older than 65 it was lower. Although women participated more than men, the gender distribution of NP and P did not differ significantly from that in I (appendices 6.8 and 6.9).

The participation by score and group is represented in appendices 6.10 and 6.11 , respectively. "The distribution of "score" in the three populations reveals a varying pattern: in the categories with score $=0,3$, and 4 the drop-out was more than average, whereas in the category with score $=2$ the drop-out was less. Although the drop-out in the group without increased risk (group 1) was more than average, the distributions of "group" in $I, P$, and NP are comparable.

Table 6.1 indicates for what reasons patients did not participate. In $17.5 \%$ of cases this was because the period between postal questionnaire and the examination by the general practitioner had lapsed: some subjects had moved, others had died, or were absent due to protracted hospital admission (reasons 1-3). In almost half of all cases the parient was 'not interested' in the study (reason 4). In $11 \%$ the general practitioner decided that the patient would not participate (reasons 5-8). For the remaining quarter of the non-participation the reason remained unknown or was due to administrative errors (reasons 9 and 10).

On the average, the lapse of time between the completion of the postal questionnaire and the GP's examination was one year $(S D=0.42$ year, median 0.9 year $\approx$ 
Table 6.1 Reasons for not participating. Percentages of rotal number of non-participants $(n=1647)$

\begin{tabular}{|c|c|c|}
\hline & Reason for not participating & $\%$ of non-participants \\
\hline 1 & Paticnt had moved & 9.0 \\
\hline 2 & Patient had died & 7.3 \\
\hline 3 & $\begin{array}{l}\text { Patient had been transfered to hospital or nursing home or } \\
\text { psychiatric cente }\end{array}$ & 1.2 \\
\hline 4 & $\begin{array}{l}\text { Patient was not interested in study, had no time or did not } \\
\text { keep appointment }\end{array}$ & 48.0 \\
\hline 5 & $\begin{array}{l}\text { GP excluded patient because of medical, psychological or } \\
\text { social "contra-indications" (research would harm patient") }\end{array}$ & 1.3 \\
\hline 6 & $\begin{array}{l}\text { GP excluded the patien because in his opirion the patient } \\
\text { was not suited to participate in research, e.g. mon-compliance } \\
\text { (patient would harm research") }\end{array}$ & 0.5 \\
\hline 7 & $\begin{array}{l}\text { GP excluded the patient because the patient could not come } \\
\text { to the GPC (not mobile, living in home for the elderly etc) }\end{array}$ & 5.5 \\
\hline 8 & GP failed in reaching the patient (e.g secret phone number) & 3.4 \\
\hline 9 & Unknown reasons & 23.0 \\
\hline \multirow[t]{2}{*}{10} & Error by GPC or research team & 0.9 \\
\hline & Total & 100.0 \\
\hline
\end{tabular}

11 months); this 'investigation delay' ranged from 0.29 year ( 3.5 months) to 2.16 years (26 months).

\section{The study population}

The composition of the study population $(n=3654)$ in terms of gender $(53 \%$ female), group (group 1, 'no risk': 292, group 2, 'increased risk': 626, group 3, 'highest risk': 2736), and score may be found in column ' $\mathrm{P}$ ' of appendices 6.8, 6.10, and 6.11 respectively. The age distribution of the study population is depicted in table 6.2. "The mean age ("age at examination") in the study population is 59.1 years and the median 59.3 years. The age ranges from 40.7 to 78.3 years. Among subjects between 40 and 65 years of age men are somewhat overrepresented, among subjects over 65 women are. Finally, the tables 6.3 and 6.4 provide an overview of relevant comorbidity in the study population.

\section{Discussion and conclusion}

A high percentage of patients returned the postal questionnaire $(86.4 \%)$. In accordance with this high response, the population of responders is comparable to the source population in terms of age and gender distribution. This means that age- and gender-dependent associations that are found in the population of responders (R) may be extrapolated to the source population (S).

'The samples 'group 1 (no risk)' and 'group 2 (increased risk)' are representative with respect to age and gender for the populations from which they were taken: the responders with score $=0$ and score $=1-5$, respectively. 
Table 6.2 Age \& gender distribution in the study population

\begin{tabular}{lccc} 
Age category & Male $(\%)$ & Fermale $(\%)$ & Total $(\%)$ \\
\hline $40 \leq 45$ & $157(9.2)$ & $162(8.4)$ & $319(8.8)$ \\
$45 \leq 55$ & $481(28.0)$ & $499(25.9)$ & $980(26.9)$ \\
$55 \leq 65$ & $602(35.1)$ & $645(33.4)$ & $1247(34.2)$ \\
$65 \leq 75$ & $410(23.9)$ & $526(27.3)$ & $936(25.7)$ \\
$>75$ & $65(3.8)$ & $98(5.1)$ & $163(4.5)$ \\
\hline $\mathrm{N}$ & $1715(100.0)$ & $1930(100.0)$ & $3645(100.0)$ \\
Missing & 4 & 5 & 9 \\
Total & $1719(47 \%)$ & $1935(53 \%)$ & $3654(100 \%)$
\end{tabular}

The participation percentage, $68.9 \%$ of the invited population, is considerable. In contrast with the response to the postal questionnaire, there was a large variation between practices with respect to degree of participation. According to the reports of the practices, only a small percentage of the drop-out $(11 \%)$ was partly influenced by the factor "general practitioner". However, in three-quarters of all cases, the reason for drop-out was in fact unknown ('not interested', 'unknown', 'mistake). The variation in these categories possibly indicates that differences related to practice management and attitude to scientific research played a role. The study data do not seem to suggest that this variation led to bias in the study population as a whole.

Older patients are overrepresented among the non-participants. Consequently, the average age of the participants decreased relative to the invited population as a whole.

Owing to the time period taken by the study, an 'investigation delay' of one year on average arose, and ultimately the mean age of the study population was higher than of the invited population. Hence, age-dependent associations will have to be evaluated per age category. For the calculation of prevalence figures this is desirable for other reasons as well: the youngest and oldest age categories ( $40 \leq 45$ years and $75 \geq 80$ years) will be excluded from the analysis due to their relative underrepresentation in the study population as compared to the population of responders. The participation of men was lower (32.3\% drop-outs) than that of women $30.0 \%$ drop-outs). However, there are no significant differences in the gender distribution of the non-participants, participants and invited population. Nonetheless it is desirable to evaluate gender-dependent associations for men and women separately in order to increase or reduce the plausibility of any existing differences between men and women.

The pattern of drop-out per "score" category was somewhat variable: in the score $=0,3$, and 4 categories the degree of participation was lower, whereas in the score $=2$ category it was higher than average. This means that the prevalence figures are best computed by means of the frequency per score category; this method is also the most precise and efficient (see chapter 9).

Looking at the drop-out per "group", one notices a smaller degree of participation in the group "no risk" (group 1) than in the other two groups. "The distribution of 'group' of non-participants, participants and invited population is similar, however. 
Table 6.3 Candiovascular morbidity in the sudy populazion $(n=3654, f=53 \%$, age $40.7-78.3$ years)

$\begin{array}{lc}\text { Diagnosis: } & \text { Prevalence in \% } \\ \text { Angina pectoris, coronary ischacmia } & 19.0 \\ \text { Myocardial infarction } & 12.8 \\ \text { Transient ischemic attack, carotid stenosis } & 3.6 \\ \text { Srroke } & 2.7\end{array}$

Tabla 6.4 Leg diagnoses in the study population $(\mathrm{n}=3654, f=53 \%$, age 40.778 .3 years)

Diagnosis

Prevalence ${ }^{a}$

$G P^{*}$ 's diagnosis "PAOD

highly probable/possible"

$[n=653]^{3}$ :

concomitant leg disorders

$(\%)$

Raynaud, Bürger, chilblained feet

Varicose veins, venous insufficiency, venous ulcer

Osteoarthritis of hip, knee, ankle and leg n.o.s."

Peripheral neuropathy, neuralgia, sciatic pain, tumbar disc lesion,

Restless legs, parwesthesia

Pain, cramps and other complaints of legs n.o.d.

No (other) leg problems
$2(0.03)$

$89 \quad(13.6)$

$67(10.3)$

44. (6.7)

$13(2.0)$

$13(2.0)$

$420 \quad(64.3)$
GP's diagnosis "PAOD nor probable'

$[\mathrm{n}=2980]^{\mathrm{t}}$ :

differential diagnosis

$(\%)$

$\begin{array}{rr}16 & (0.5) \\ 417 & (14.0) \\ 319 & (10.7) \\ 207 & (6.9) \\ 93 & (3.1) \\ 246 & (8.3) \\ 1682 & (56.4)\end{array}$

the sum of percentages exceeds $100 \%$ since patients may have more than one diagnosis missing values in 21 patients

not otherwise specified

not otherwise defined

For the calculation of prevalence figures, the noted difference is of no consequence, since the variable "score" will be used for calculating backwards. With respect to the analysis and interpretation of diagnostic relationships it may be important that the study population as a whole is at a slightly higher risk. Considering that the variable "group" can be viewed as an operationalization of "level of selection", it would be interesting to determine diagnostic associations per "group" as well.

"The "investigation delay" may have led to an increase of the risk score due to (co)morbidity: 'complaints while walking", "diabetes mellitus", "hypertension", and "a history of cardiovascular disease" may have become relevant in the meantime. "The mean score per group may thus be somewhat higher than measured.

In summary, it may be observed that there are no indicarions that significant selective drop-out occurred: the differences that arose are minimal. Nevertheless, these differences will be taken into account as much as possible in the analyses. 


\section{Chapter 7 The reproducibility of the ankle-brachial systolic pressure ratio"}

Summary One of the noninuasive techniques used in the diagnosis of patients with peripheral arterial occlusive disease is the measurement of the ankle-brachial systolic pressure ratio ( $A B$-ratio").

The magnitude of different sources of measurement variation, relevant to clinical practice as well as multi-observer studies, was estimated from a random effects analysis of variance model. Thirty-five general practitioners and 24 practice assistants performed 503 AB-ratio measurements on nine patients over a period of nine reeks, using pocket Doppler devices.

When the AB-ratio is used for diagnostic purpases, a $95 \%$ prediction interval consisting of the measured value $\pm 0.15-0.20$ has to be taken into account.

Furbermore, when the AB-ratio is used in the follow-up of a patient with vascular disease, the difference between two stabsequent measurements bas to be at least 0.16 . 0.19 to bave an $80 \%$ certainty that this difference is not due to (intra-observer) measure. ment error.

Key words peripheral arterial occiusive disease, general practice, epidemiology, diag. nosis, ultrasound.

\section{Introduction}

Peripheral arterial occlusive disease of the lower limbs ('PAOD') is the manifestation of atherosclerosis in the arteries below the wortic bifurcation. In a general practice population, the prevalence of intermittent claudication (i.e. cases of whom the general practitioner is aware) has been reported to be three to seven per thousand.' It can be estimated from population screening studies that this figure rises to 25 per thousand if asymptomatic and unknown cases of PAOD are allowed for as well. ${ }^{1,2}$

Over the last two decades noninvasive techniques have become a major tool in the diagnosis of PAOD. Vascular laboratories offer sophisticated diagnostic possibilities to the vascular surgeon. ${ }^{3,4,5}$ One of these techniques, which is based on the use of ultrasound, is the measurement of the ankle-brachial systolic pressure ratio (ABratio), reflecting the functional state of the circulation in the lower limbs. Most suited for use in general practice and in epidemiological research on PAOD is the pocket-sized Doppler device which is used like a stethoscope together with a

- Published as: Stoffers HEJH, Kaiser V, Kester ADM, Schouten HJA, Knotinerus JA. Peripheral Arterial Occlusive Disease in General Practice: the Reproducibility of the AnkleArm Systolic Pressure Ratio. Scand J Prim Health Care 1991; 9: 109-14. 
mercury sphygmomanometer ('Doppler method'). Since the predictive value of 'classic' signs and symptoms that are indicative of PAOD is not very high," the Doppler method may be useful in establishing the diagnosis 'PAOD'. An $A B$-ratio larger than 1.0 indicates that there is no PAOD, while an AB-ratio smaller than 0.90 strongly suggests. PAOD., ${ }^{4.10}$

Although the diagnostic validity of the method in cross-sectional research is reported to be good if a cut-off value of 0.90 is used, ${ }^{8,9,11,12}$ the interpretation of data on the reproducibility of the AB-ratio is difficult and results cannot easily be generalized to general practice (i.e. general practitioners and their practice assistants). ${ }^{3,8,13}$. 18 The Department of General Practice of the University of Limburg is currently investigating some aspects of $\mathrm{PAOD}$ relevant to general practice such as prevalence, diagnosis, natural course, and therapeutic interventions (the "Limburg PAOD Study').! The resting AB-ratio, measured with a pocket Doppler device, is used as the standard diagnostic procedure and as one of the outcome measures.

Because of the forementioned uncertainty regarding the reproducibility of the ABratio, a study was conducted with the primary intention of estimating the magnitude of measurement variation due to the multi-observer design of the 'Limburg PAOD Study". A secondary intention was to obtain information on other sources of measurement variation, relevant to clinical situations.

\section{Material and methods}

\section{Patients}

Four male and five female patients, aged 47-74, participated in the study. Table 7.1 shows the selection pattern and the clinical characteristics of the patients.

\section{Observers}

Fifty-nine observers ( 35 general practitioners, 24 practice assistants), participants in the forementioned 'Limburg PAOD Study', cooperated in the study. 'They participated in a Doppler training course. At the start of the reproducibility study, the observers had all been using Doppler devices in their own practices for some nine months.

\section{Measurements}

For practical reasons we had to divide patients into two groups, the "Wednesday' (patients A-E, measured on four Wednesdays) and the 'Thursday' group (patients F. I, measured on five 'Thursdays) (see table 7.1). For each 'measurement day' there were four to nine observers, who each measured four or five patients. The interval between the first and last measurement day was eight or nine weeks. The interval between two consecutive measurement days was one or two weeks. The time between the first and last measurements on one day varied between two and three hours.

8 MHz pocket-sized Doppler devices (Hundleigh D500) and calibrated mercury sphygmomanometers, cuff size $12 \mathrm{~cm}$, were used for both ankle and arm measurements. The patients were lying supine, each in a separate, heated room. The observers were unaware of any detail of the medical history of the patients. Each individual observer measured systolic pressures of the left arm (brachial artery) and the left and right ankles (posterior tibial artery or dorsalis pedis artery). The obser- 
Table 7.1 patients

\begin{tabular}{|c|c|c|c|c|}
\hline Patient & Gender & Age & $\begin{array}{l}\text { Diagnosis [and location of } \\
\text { vascular diagnosis] }\end{array}$ & $\begin{array}{l}\text { Vascular } \\
\text { surgery }\end{array}$ \\
\hline$A$ & $F$ & 66 & $\begin{array}{l}\text { intermittent cladication } \mathrm{R}>\mathrm{L} \\
\text { [vascular laboratory] }\end{array}$ & - \\
\hline B & $F$ & 58 & $\begin{array}{l}\text { arthrosis knee and hip } \\
{[G P: A B \text {-atio } L+R>1.0]}\end{array}$ & - \\
\hline$C$ & $F$ & 56 & $\begin{array}{l}\text { intermittent claudication } \mathbb{R} \\
{[G P: \text { A B-ratio } R \text { absent, } L .0 .50]}\end{array}$ & - \\
\hline$D$ & F & 47 & $\begin{array}{l}\text { intermittent claudication } L>\mathbb{R} \\
\text { [vasc. laboratory/arteriogr.] }\end{array}$ & + \\
\hline$E$ & M & 50 & $\begin{array}{l}\text { no leg complaints } \\
\text { [vasc. laboratory /arteriogr.] }\end{array}$ & + \\
\hline $\mathrm{F}$ & M & 74 & $\begin{array}{l}\text { myalgia, sciatica } \\
\text { [GP; AB-ratio not available] }\end{array}$ & - \\
\hline G & $\mathrm{F}$ & 73 & $\begin{array}{l}\text { intermittent claudication } \mathrm{R}>\mathrm{L} \\
\text { [vascular laboratory] }\end{array}$ & - \\
\hline $\mathrm{H}$ & M & 68 & $\begin{array}{l}\text { intermittent claudication } \mathrm{L}+\mathrm{R} \\
\text { [vascular laboratory] }\end{array}$ & + \\
\hline I & $\mathrm{M}$ & 69 & $\begin{array}{l}\text { intermittent claudication } \mathbb{R} \\
\text { [vascular laboratory] }\end{array}$ & - \\
\hline
\end{tabular}

$M=$ male, $F=$ female, $L=$ left $R=$ right, $G P=$ general practitioner

vers changed rooms after twenty minutes and they were not allowed to exchange results. Two authors (HSt, VK) supervised the whole procedure.

\section{Statistical analysis}

Apart from the inter-patient variation, the variation in measured AB-ratios can be attributed to different sources:

1 The AB-ratio of one patient varies from day to day. This long-term biological variation was subdivided into the variation which is common to both legs (the analysis of variance term for this component is "patient by day") and in the remaining biological variation: the difference in variation between both legs (called "leg by patient by day").

2 Observers exhibit different systematic measurement variation, observer bias (observer").

3 The remaining measurement error comprises two components. First, error common to the measurements of both legs ("patient by observer") and second, the residual error ("residual), including any short-term biological variation as well as a possible interaction ('leg by patient by observer') that occurs when the error of an observer is systematically different for different legs.

The long-term biological variation, observer bias, and both components of the remaining measurement error were estimated from a random effects analysis of variance model. ${ }^{1 \%, 20}$ Results are presented as estimated variances. From chese variances, measurement variation SDs and $95 \%$ prediccion intervals were computed 
Table 7.2 Measurements, mean AB-ratios and standard deviations

\begin{tabular}{|c|c|c|c|c|c|}
\hline Patient & $\begin{array}{l}L \mathrm{Leg} \\
\mathrm{L} / \mathrm{R}\end{array}$ & $\begin{array}{l}\text { Number of } \\
\text { measure- } \\
\text { ments }\end{array}$ & $\begin{array}{l}\text { Number of } \\
\text { measure } \\
\text { ment days }\end{array}$ & $\begin{array}{l}\text { Mean } \\
\text { AD-ratio }\end{array}$ & $\begin{array}{l}\text { Standard } \\
\text { Deviation } \\
\text { (pooled) }\end{array}$ \\
\hline \multirow[t]{2}{*}{$A$} & $L$ & \multirow[t]{2}{*}{21} & \multirow[t]{2}{*}{4} & 0.82 & 0.081 \\
\hline & $\mathrm{R}$ & & & 0.70 & 0.081 \\
\hline \multirow[t]{2}{*}{$\mathbb{B}$} & $\mathbb{L}$ & \multirow{2}{*}{22} & \multirow[t]{2}{*}{4} & 1.05 & 0.111 \\
\hline & $\mathrm{R}$ & & & 1.19 & 0.125 \\
\hline \multirow[t]{2}{*}{$\mathrm{C}$} & L. & \multirow[t]{2}{*}{22} & \multirow[t]{2}{*}{4} & 0.82 & 0.190 \\
\hline & $\mathrm{R}$ & & & 0.74 & 0.133 \\
\hline \multirow[t]{2}{*}{$D$} & $L$ & \multirow[t]{2}{*}{22} & \multirow[t]{2}{*}{4} & 0.66 & 0.072 \\
\hline & $R$ & & & 0.67 & 0.124 \\
\hline \multirow[t]{2}{*}{$E$} & $\mathbb{L}$ & \multirow[t]{2}{*}{20} & \multirow[t]{2}{*}{4} & 1.07 & 0.128 \\
\hline & $\mathrm{R}$ & & & 1.10 & 0.211 \\
\hline \multirow[t]{2}{*}{$\mathrm{Fi}$} & $\mathbb{L}$ & \multirow[t]{2}{*}{37} & \multirow[t]{2}{*}{5} & 0.66 & 0.112 \\
\hline & $\mathrm{R}$ & & & 0.56 & 0.093 \\
\hline \multirow[t]{2}{*}{$G$} & $\mathbb{L}$ & \multirow[t]{2}{*}{35} & \multirow[t]{2}{*}{5} & 0.69 & 0.082 \\
\hline & $\mathrm{R}$ & & & 0.65 & 0.100 \\
\hline \multirow[t]{2}{*}{$\mathrm{H}^{\mathrm{b}}$} & $\mathrm{L}$ & \multirow[t]{2}{*}{20} & \multirow[t]{2}{*}{3} & 0.85 & 0.109 \\
\hline & $\mathrm{R}$ & & & 0.79 & 0.109 \\
\hline \multirow[t]{2}{*}{1} & $\mathbf{L}$ & \multirow[t]{2}{*}{36} & \multirow[t]{2}{*}{5} & 0.83 & 0.096 \\
\hline & $\mathrm{R}$ & & & 0.79 & 0.101 \\
\hline \multirow[t]{2}{*}{$\mathrm{H}^{n^{2}}$} & $\mathbb{L}$ & 7 & \multirow[t]{2}{*}{1} & $0.36^{\circ}$ & $0.077^{a}$ \\
\hline & $\mathrm{R}$ & 8 & & $0.67^{3}$ & $0.068^{\mathrm{a}}$ \\
\hline \multirow[t]{2}{*}{$E^{3, b}$} & $L$ & \multirow[t]{2}{*}{9} & \multirow[t]{2}{*}{$\mathbb{1}$} & $0.74^{x}$ & $0.101^{3}$ \\
\hline & $\mathrm{R}$ & & & $0.73^{a}$ & $0.113^{\prime \prime}$ \\
\hline
\end{tabular}

"Day-mean and day-SD.

On his fourth measurement day, patient $\mathbb{H}$ appeared to be suffering from sevare pain in his lef leg, which corresponded well with a dramatic fall in his $A B$-ratio ( $\mathrm{H}^{\prime}$ in the cable). Therefore, on the fift: measurement day patient $H$ was replaced by patient $\mathbb{E}(=\mathrm{E})$.

for various situations.

Results

Table 7.2 summarizes the results of the pressure measurements. The total number of AB-ratio measurements was 503. The standard deviations of individual legs varied between 0.068 and 0.21 with a mean of 0.11 . Table 7.3 presents the results of the 

variance (s.e.)

Long term biological variation ${ }^{2}$

- patient by day

- leg by patient by day

$\begin{array}{ll}0.812(0.297) & 0.090 \\ 0.109(0.065) & 0.033\end{array}$

Variation due to the measurement process

- observer

- patient by observer

s.e. standard error

"patients $H, H^{\prime}$ and $E^{\prime}$ excluded (see Table 7.2 )

" including short term biological wariation and 'leg by patient by observer')

Table 7.4 Total measurement waration SDs and $95 \%$ prediction limits for mean AB-ratio under various conditions

\begin{tabular}{lll} 
Condition & $\begin{array}{l}\text { Total } \\
\text { measurement } \\
\text { variation SD }\end{array}$ & $\begin{array}{l}95 \% \text { Prediction } \\
\text { limits of AB-ratio } \\
(\mathrm{AB}-\mathrm{ratio} \pm \ldots)\end{array}$ \\
\hline 1 observer, 1 measurement & 0.114 & 0.223 \\
1 observer, 2 measurements & 0.097 & 0.190 \\
1 observer, 3 measurements & 0.091 & 0.178 \\
2 observers, 1 measurement each & 0.080 & 0.157 \\
2 observers, 2 measurement each & 0.069 & 0.135 \\
\hline
\end{tabular}

"The calculations assume that repeated measurements by the same observer have the same "patient by observer" error and also that the "residual' errors are independent. This may be accomplished by the use of a random-zero sphygmomanometer.

analysis of variance. The observer bias was low in comparison with the other two components of variation due to the measurement process. Table 7.4 presents measurement variation SDs and $95 \%$ prediction intervals for different situations. For the first condition ("one observer, one measurement') the variance is equal to the sum of the variances of the three components of variation due to the measurement process (see table 7.3). Therefore, the SD of the variation in a single measurement of the AB-ratio by one of the 59 observers, which is the inter-observer error SD, equals 0.114 . This means that the true $A B$-ratio is within 0.223 units from the observed value (95\% pre-diction limits). Further entries in table 7.4 show how the interval improves when multiple measurements are taken.

The intra-observer error $\mathrm{SD}$ was estimated from the applied random effects analysis of variance model. The intra-observer error $\mathrm{SD}$ of the $\mathrm{AB}$-ratio was not larger than 0.105 , yielding a $95 \%$ prediction interval of the measured value \pm 0.206 . 


\section{Discussion}

We studied the reproducibility of AB-ratio measurements by general practitioners and their practice assistants using pocket Doppler devices, in order to determine its usefulness in a multiobserver epidemiological study. Therefore, determination of the inter-observer error was our primary goal. Our estimate of the inter-obserwer error $\mathrm{SD}(0.114,95 \%$ prediction interval \pm 0.223$)$ agrees with other research workers, even though they used different study designs and statistical techniques. ${ }^{15,16}$

The observer bias appeared to be relarively low. This implies that a multi-observer epidemiological study will be only slightly less efficient than a hypothetical singleobserver study with the same number of patients. Fonkes et al. drew a similar conclusion. ${ }^{1 \%}$

In a single-observer situation, e.g. a general practitioner's practice, the so-called intra-observer error is of interest. This is the measurement variation pertinent when observations are only to be compared with (previous) observations by the same observer. Buth reported an intra-observer error SD (including short-term biological variation) of $6.5 \%$ of the mean of two measurements on one day. From Forvees" detailed analysis of variance components, intra-observer error SDs can be calculated as 0.072 (diseased) and $0.104 \mathrm{AB}$-ratio (normals). ${ }^{18}$

To obtain a direct estimate of the intra-observer error, ideally one needs independent repeated measurements of the same patient by the same observer. This can be achieved using random-zero sphygmomanometers. ${ }^{18}$ As the determination of the intra-observer variation was not our primary intention and the random-zero sphygmomanometers were not readily available at the time, we did not use them in this reproducibility-study. Nevertheless, the intra-observer error (including short-term biological variation and leg by patient by observer' interaction) could be estimated indirectly from the forementioned random effects analysis of variance model. Conceptually in such a model the intra-observer error is obtained by comparison of the measurement error in different patients measured by one observer. Since the observer bias will be the same with every patient measured by this observer, the observer bias cancels out in the comparison.

The intra-observer error $\mathrm{SD}$ of the AB-ratio being 0.105 implies that wen the Doppler method is used in the follow up of vascular patients, the difference between two subsequent measurements (of the same patient by the same observer) has to be at least 0.29 , before one can be sure with $95 \%$ certainty that the observed difference is not due to (intra-observer) measurement error. When two measurements are taken on each occasion, this difference would have to be at least 0.24 . If one accepts a lower degree of certainty, e.g. $80 \%$, the minimum significant differences between consecutive occasions can be calculated as 0.19 (one measurement) and 0.156 (two repeated measurements) respectively.

It can be concluded that the Doppler method is suitable for diagnostic purposes in a clinical setting (e.g. general practice) as well as for epidemiological research. The measurement of the AB-ratio is a reproducible and valid technique to make the diagnostic decision whether PAOD is present or not, under the condition that a $95 \%$ prediction interval of $0.15-0.20$ around the measured value of the AB-ratio is taken into account. Repeated measurements should be taken to minimize the measurement variation and to enhance the diagnostic conclusion. 
Using the intra-observer error SDs from this study and others, ${ }^{3,18}$ it can be concluded that the difference between measurements (of the same patient by the same observer) on two subsequent occasions has to be at least $0.12-0.20$ to have an $80 \%$ certainty that this difference is not due to (intra-observer) measurement error. This conclusion is important if the Doppler method is used in the follow-up of patients treated for PAOD. This conclusion is more relevant to epidemiological research, in which the AB-ratio is an outcome measure, than to clinical practice where the complaints of the patient are the main factor in medical decision making.

\section{Acknowledgements}

The 'Limburg PAOD Study' was supported by the 'Praeventiefonds' (28-1323) and the 'Netherlands Organization for Scientific Research' (900-715.154). Doppler devices were financed by ASTA Medica B.V.

\section{References}

1 Stofers HEJH, Kaiser V, Lemmens ThGJ, Knotmerus JA. Perifeer arteried vathden in de huisartspraktij]: een verborgen ziektebeeld? [Peripheral arterial occlusive vasculopathy in general practice: a hidden disease ?](English summary). Huisarts Wet 1988; 31: 202-6.

2 Dormandy J, Mahir M, Ascady $G$ et al. Fate of the patient with chronic leg ischaemia. I Cardiovase Surg 1989; 30:507.

3. Buth J. Het vasculaire laboratorim [The vascular laboratory] (English summary) [PlsD Thesis]. Amsterdam: Universiteit van Amsterdam, 1978.

4 Kitslaar PEHM. Doppler-ultrasoundtests in the diagnosis of chronic aorta-iliac obstructions [PhD Thesis]. Maastricht: Rijksuniversiteit Limburg, 1982.

5 Bernstein EF, ed. Noninvasive diagnostic techniques in peripheral vascular disease. 2nd edition. St.Louis, etc. Mosby, 1982.

6 Yao ST, "Takaki HS. Noninvasive techniques of measuring lower limb arterial pressures. In: Bernstein EF, ed. Noninvasive diagnostic techniques in peripheral vascular disease. 2nd edition. St.Louis, etc.: Mosby, 1982.

7 Criqui $\mathrm{MH}$, Fronek $\mathrm{A}$, Klauber $\mathrm{MR}$ et al, "The sensitivity, specificity and predictive value of traditional dinical evaluation of peripheral arterial disease: results from non-invasive testing in a defined population. Circulation $1985,71: 516-22$.

8 Carter SA. Indirect systolic pressures and pulse waves in arterial occlusive disense of the lower extremities. Circulation 1968; 37: 624-37.

9 Thulesius $\mathrm{O}$, Giöres JA. Use of Doppler shife detection for determining peripherall arterial blood pressure. Angiology 1971; 22: 594-603.

10 Fronek A, Johansen KH, Dilley RB, Bernstein EF. Non-invasive plyysiologic tests in the diagnosis and characterization of peripheral arterial occlusive disease. Am J Surg 1973; 126: 205-14.

11 Yao ST, Hobbs JT, Irvine WT. Ankle systolic pressure measurements in arterial disease affecting the lower extremices. Br J Surg 1969; 56: 676-9.

12 Hylkema BS. Diagnostiek wan arteriële circulatiestoomissen in de benen door bloeddruk metingen met behulp van ultrageluid [The diagnosis of obliterative arteriosclerotic disease of the legs by ultrasonic decemination of blood pressures] (English summary). Ned T Geneeskd 1976; 120:73342.

13 Schroll $\mathrm{M}$, Munck $\mathrm{O}$. Estimation of peripheral arteriosclerotic disease by ankle blood pressure measurements in a population of 60 -year-old men and women. I Chronic Dis $1981 ; 34: 261-9$. 
14. Osmundson Ph], OFallon WM, Clements P, Kazmier Fl, Zimmerman BR, Palumbo PJ. Reproducibility of nom-invasive tests of peripheral occlusive vascular disease. I Vasc Surg 1985; 2: 678-83.

15 Johnston KW, Hosang MY, Andrews DF. Reproducibility of noninvasive vascular laboratory measurements of the peripheral cinculation. J Vasc Surg 1987; 6: 147-51.

16 Baker JD, DeEtte Dix PAC. Variability of Doppler ankle pressures with arterial occlusive disease: An evaluation of ankle index and brachial-ankle pressure gradient. Surgery 1981; 89: $134-7$.

17 Ouriel KO, McDonnel AE, Metz CE, Zarins CK. A critical evaluation of stress testing in the diagnosis of peripheral vascular disease. Surgery 1982; $91: 686-93$.

18 Fowkes FGR, Housley E, Macintyre CCA, Prescott RJ, Ruckley CV. Variability of ankle and brachial systolic pressures in the measurement of atherosclerotic peripheral arterial disease. I Epidem Community Health 1988; 42: 128-33.

19 Fiseiss JL. "The design and analysis of clinical experiments. New York: Wiley, 1986.

20 Dunn OJ, Clark VA. Applied statistics: analysis of variance and regression. 2 nd ed. New York: Wiley, 1987. 


\section{Chapter 8 The diagnostic power of the measurement of the ankle-brachial systolic pressure ratio in general practice*}

Summary The general practitioner has to rely on history taking and physical examin. ation when be wants to diagnose peripheral arterial occlustwe disease (PAOD). However, the positive predictive values of these diagnostic procedures do not seem to be very bigh. In this respect the band-held Doppler device could be an asset to general practice.

We assessed the accuracy and diagnostic value of the ankle-bracbial systolic pressure ratio (AB-ratio), estimated the optimum cutoff value for the AB-ratio and estimated threshold cutoff walues beyond which $P A O D$ can be ruled in or out. The diagnostic outcome of the measurement of the ABratio in three general practice centres was compared to the diagnostic conclusions of a Vascular Laboratory. This was done for the outcome of single AB-ratio measurements (231 legs of 117 patients) and the outcome of measurements on three consecutive occasions (ssubgroup of 92 legs of 51 patients).

Receiver Operating Characteristic analysis showed that the diagnostic value of the mean of three $A B$-ratios is better than that of a single $A B$-ratio. The best theoretical optimum cutoff walue was a mean AB-ratio of 0.92 (sensitivity $87 \%$, specificity $91 \%, L R+$ 10, LR- 0.14). Accuracy, corrected for prevalence, was $90 \%$. We estimated that the positive predictive value $\geq 95 \%$ if the mean of three consecutive AB-ratios is below 0.88 ; the negative predictive value $\geq 99 \%$ if the mean $A B$-ratio is above 0.98 (prevdlence range $5.33 \%$.

Key words peripheral arterial occlusive disease, diagnosis, ultrasound, general practice, clinical epidemiology

\section{Introduction}

Regarding the diagnosis of peripheral arterial occlusive disease (PAOD) vascular laboratories offer various sophisticated noninvasive ultrasound techniques to the vascular specialist. ${ }^{1,2-6}$ On the other hand, the general practitioner still has to relly on history taking and physical examination as major tools for establishing the diagnosis of PAOD. According to the literature, however, the positive predictive values of intermittent claudication, diminished peripheral pulses or a femoral bruit do not seem to be very high. ${ }^{7,8}$ In this respect the hand-held Doppler device could be an asset to general practice. "This simple instrument already exists for many years, but

Henri EJH Stoffersa, Arnold DM Kester , Victor Kaisera, Paula ELM Rinkens", Peter JEHM Kitslaar", J André Knottnerus". University of Limburg, Mastricht, The Netherlands: Department of Generall Practice, Department of Methodology and Statistics' and Department of Surgerye. Submitted for publication. 
has only recently been introduced in general practice." In combination with a sphygmomanometer it can be used to measure systolic blood pressures. ${ }^{1012}$ "The ankle-brachial systolic pressure ratio (AB-ratio) provides a measure of the functional state of the circulation in the lower limbs and normally is above 1.0 in healthy persons. ${ }^{13}$ 'The measurement of the resting AB-ratio by means of a Doppler device will be called 'Doppler method' hereafter.

Measuring the AB-ratio is appropriate in case of a mobile patient with leg complaints of whom medical history and physical examination do not yield unequivocal results. It is also relevant in case of a patient whose mobility is impaired due to other causes (e.g. cardiac, respiratory, arthritis) and who has leg complaints when resting. 9.14

The measurement of the AB-ratio is considered to be a well-researched technique. However, a systematic review of literature 9.14 revealed that most studies on the validity of the method had been conducted in rather selected study populations. 2.15-26 In a specialist setting many PAOD cases will be in a more developed stage than in general practice and the validity of the Doppler method in general practice may be different from the validity in referred populations. ${ }^{27,28}$ Moreover, in only six studies a 'gold standard" had been applied to PAOD-cases and non-cases. ${ }^{2,15,202.23}$ Also, it was often not clear whether test and standard procedure had been performed independently from each other.

Which cutoff value for the AB-ratio is considered best depends on whether a high sensitivity or a high specificity is preferred. From the above-mentioned literature an AB-ratio of 0.90 emerges as the "specific' cutoff point whereas 1.00 is the 'sensitive' cutoff value. ${ }^{9,14}$ Correspondingly, in recent epidemiological studies on the prevalence of $P A O D$, cutoff values for the $A B$-ratio mostly were chosen in the range between 0.90 and $0.97 .{ }^{29.33}$ To medical practice the positive and negative predictive value $(\mathrm{PV}+$ and $\mathrm{PV}-$ ) ) of the measured AB-ratio are more relevant than a fixed cutoff walue. The literature provides no data on this subject.

The aims of the present study were to assess the accuracy and diagnostic value of the pocket Doppler AB-ratio, to estimate the optimum cutoff value for the ABratio, and to provide threshold cutoff values beyond which PAOD can be ruled in (high PV+) or out (high PV-).

\section{Method}

\section{Design}

In the present study the diagnostic outcome of the measurement of the AB-ratio in three general practice centres (GPCs) using a hand-held Doppler device ("rest') was compared to the diagnostic conclusions of the Vascular Laboratory (VL) of the University Hospital in Maastricht ('standard'). This comparison was made for the outcome of single AB-ratio measurements and for the outcome of measurements on three consecutive occasions.

\section{Patient selection}

'The 'Limburg PAOD Study' is a research project on peripheral arterial occlusive disease conducted by the University of Limburg in Maastricht and 22 general practice centres in the region. In the first part of this project data on signs and symptoms of PAOD were collected among 3654 patients. ${ }^{34}$ The second part of the 
Limburg PAOD Study is a randomised clinical trial among identified PAOD-cases on the effect of aspirin in PAOD.

Using the database of the first part of the Limburg PAOD Study, patients of three participating GPCs in Maastricht were selected. The objective was to create a casemix with a spectrum relevant to the diagnostic situation of the general practitioner. The following criteria were used: at that time an AB-ratio lower than 0.95 (78 patients); at that time an $\mathrm{AB}$ ratio of 0.95 or thigher with either complaints of typical intermittent claudication $(\mathrm{IC})^{35}$ or with leg complaints less typical for IC but with one or more absent foot pulses ( 84 patients).

\section{Measurements in the GPCs}

Hundred seventeen patients ( 51 malle, 66 female; age 44-80, mean 62.5 years) agreed to participate. They filled in a modified version of the WHO-questionnaire ${ }^{35}$ assessing current complaints of IC. "The patients' records were examined for $1 \mathrm{C}$, vascular surgery and relevant co-morbidity. In the GPCs the (six) practice assistants assessed systolic blood pressures on both arms and ankles with the patient lying in supine position, using a hand-held Doppler device (Huntleigh Mini Dopplex D500, 8 $\mathrm{MHz}$ ). On the average each practice assistant had performed Doppler measurements in more than 200 patients (range 118-339) during the last three years.

In a subgroup of 54 patients (30 male, 24 female; age 44-79, mean 65.6 years) admitted to the second part of the Limburg PAOD Study, results of previous Doppler measurements were available (once in four months). Of these patients the last three $A B$-ratios before the visit to the $V L$ were averaged for each leg. This mean of three consecutive AB-ratios was also compared to the VL outcome. Legs with consecutive $\mathrm{AB}$-ratios showing a continuous decrease or increase exceeding 0.20 , were excluded. Such a trend indicates a clinically relevant change in the course of the disease for this leg. ${ }^{36-39}$

In the GPCs participating in the Limburg PAOD Study an AB-ratio lower than 0.95 was considered a positive outcome. This cutoff value was chosen as a balance between the 'specific' cutoff value of 0.90 and the 'sensitive' cutoff value of 1.0 , as reported in the literature. 9,14

\section{Measurements in the Vascular Laboratory}

The patient's visit to the VL took place within two weeks after his (last) visit to the $G^{3} \mathrm{C}$. The tests in the VL were performed by (two) experienced vascular laboratory technicians using sophisticated ultrasound instruments (Medasonics Vasculab D10 8 $\mathrm{MHz}$ ) and Medasonics Vasculab Spectrum Analyzer SP25). The VL technician had no prior knowledge of either the results of the GPC measurement or the clinical condition of the patient. Measurements were performed on the right arm and on both ankles at rest and after a standardized walking test on a treadmill. The VL technician also interpreted the acoustic and audiospectrum analyzed pulsewave-sig. nals from the posterior tibial and dorsalis pedis arteries as being either 'normal' or 'pathologic'. A.ter the last patient had visited the VL, both VL technicians independently reviewed all VL registration forms to categorize legs as to whether PAOD was present or not. Subsequently, they sought consensus on those cases they disagreed upon. Criteria for a positive VL diagnosis were: a resting AB-ratio lower than 0.90 , a significant drop in the AB-ratio after exercise (below 0.90) and pathologic waveforms over both pedal arteries. 


\section{Analysis}

Since single Doppler measurements could not be obtained in three legs, data on 116 left legs and 115 right legs of 117 patients were suitable for analysis. In the subgroup of patients of whom also repeated measurements were available, data on 47 left legs and 45 right legs of 51 patients were included in the analysis.

From a $2 \times 2$ table, comparing the diagnostic outcome of the GPCs with the diagnostic conclusion of the VL, accuracy (percentage correct classifications), sensitivity, specificity, likelihood ratios ( $L R+, L R-)$ and the diagnostic odds ratio (OR) were calculated ${ }^{40}$ Data from left and right legs were combined. Confidence intervals $(95 \%)$ were calculated for left and right legs separately and then averaged. ${ }^{41.12}$

A Receiver Operating Characteristic (ROC) analysis was done to describe the association between sensitivity and specificity at different cutoff values and to estimate the theoretical optimum cutoff walue. This is the AB-ratio with the highest sum of sensitivity and specificity. ${ }^{4344}$ Using logistic regression, smoothed ROC curves were designed as well ('model"). ROC analyses were also performed for males and females separately and the smoothed $R O C$ curves were used to compare the sexes with respect to maximum validity and optimum cutoff value (appendix chapter 8). A method was used that allowed for the dependence of left and right legs of each patient. ${ }^{45.47}$

On the basis of the figures for sensitivity and specificity threshold cutoff values of the AB-ratio were calculated for a PV $+\geq 95 \%$ and a PV $-\geq 99 \%$ at three different levels of prior probability of PAOD $(33 \%, 10 \%, 5 \%)$, following Bayes' theorem. This range of prevalence figures was reasonable for the 'indicated population' in general practice. $29,30,33,44,48,49$

\section{Results}

\section{Population}

Table 8.1 displays the prevalence of leg problems in the study population according to the GPC patient records. According to the questionnaire, eight percent of all patients currently had complaints of IC. According to the VL criteria PAOD was present in $33 \%$ of all legs ( $42 \%$ of all patients). Only seven (VL) to eight percent (GPCs) of all legs had a resting AB-ratio lower than 0.70 , which is considered to indicate "major disease". "Table 8.2 presents the distribution of the resting AB-ratios measured in the GPCs. The range of overlap of AB-ratios of diseased and non-diseased legs was smaller if the mean of three consecutive AB-ratios was taken for test outcome.

\section{Diagnostic value and accuracy at the preset cutoff value of 0.95}

The comparison between GPC outcome and VL outcome, using the preset cutoff value of 0.95 resulted in the following diagnostic parameters (between brackets the $95 \%$ ci). When the AB-ratio was measured once, sensitivity was $71 \%(54-85 \%)$, specificity $83 \%(73-91 \%), L R+4.2(2.5-7.6), L R-0.35(0.21-0.58)$ and the diagnostic odds ratio (OR) was 12 (5-31). If the mean of three consecutive AB-ratios was taken for test-outcome, sensitivity was $91 \%(72-99 \%)$, specificity $83 \%(6.1-95 \%), \mathrm{LR}+5.3$ (2-15), LR - $0.11(0.03-0.4)$ and the OR was 50 (8-318). In spite of the large confidence interval, the diagnostic odds ratio was much higher in the subgroup with 
Table 8.1 Leg problems in the study population according to the GPC patient racords

Diagnosis

Number of parients

No leg problens

54

Thtermittent clandication and/or vascular surgery or PTA" 22

without other leg problems

- with other leg problems

- osteoarthritis

- varicose veins

- peripheral neuropathy

other complaints

Other leg problems, no PAOD

- osteoarthritis

- varicose veins

- peripheral neuroparhy

- other complaints

\section{4}

2

2

1

$4]^{3}$

21

10

9

8

Total

percutaneous transluminal angioplasty

bsome patients with more than one leg problem

Table 8.2 Distribution of the general practice centre AB-ratio acconding to vascular laboratory disease status

VL outcome General practice centre AB-ratio

One measurement

Mean of three measurements

(231 legs; PAOD +: 76 legs)

(92 legs; PAOD + : 46 legs)

$\begin{array}{llll}\text { PAOD + } & \text { range } & 0.441 .10 & 0.52-1.01 \\ & \text { mean } & 0.82 & 0.78 \\ \text { PAOD }- & & & \\ & \text { range } & 0.75-1.36 & 0.88-1.23 \\ & \text { mean } & 1.06 & 1.05\end{array}$

VL: vascular laboratory

repeated measurements than in the single measurement group: 50 versus 12 respectively.

In case of a single $A B$-ratio measurement the accuracy of the GPC outcome was $79 \%$. False negative classifications (FN) occurred in 22 legs of 18 patients $(9.5 \%$ of all legs). There were false positive classifications (FP) in 26 legs of 21 patients $11.3 \%$ of all legs). Taking the mean of three consecutive AB-ratios for test outcome and correcting for the higher prevalence in this subgroup, accuracy was $85 \%$, the percen- 
tage of FN decreased to $3.0 \%$ and the percentage of FP increased slightly to $11.7 \%$ of all legs.

\section{ROC analyses}

ROC analyses for males and females separately revealed no significant differences between the sexes with respect to maximum validity and optimum cutoff value. Table 8.3 and figure 8.1 show the results of the ROC analyses for the population as a whole. The ROC curve representing the repeated measurements is positioned more towards the upper left corner of the figure than the curve representing the single measurements. This implies that one should always perform repeated measurements before reaching a definite diagnostic conclusion.

In case of a single $\mathrm{AB}$-ratio measurement the $\mathrm{ROC}$ analysis yielded $0.97(95 \% \mathrm{ci}$ : 0.86-1.04; model: 0.89-1.05) as theoretical optimum cutoff value. The associated diagnostic parameters were (95\% ci between brackets): sensitivity 79\% (63-90\%), specificity $82 \%(72-90 \%), L R+4.4(2.7-7.6), L R-0.26(0.14-0.48)$, OR 17 (7-55). Accuracy was $81 \%$.

If the mean of three consecutive AB-ratio measurements was taken for test outcome, the ROC analysis yielded 0.92 (95\% ci: 0.82-1.02; model: 0.90-0.95) as theoretical optimum cutoff value. Now the associated diagnostic parameters were: sensiLivity $87 \%(67-97 \%)$, specificity $91 \%(72-99 \%), L R+10(2.6-73), L R-0.14$ (0.05$0.41)$, OR 70 (11-688). Accuracy, corrected for prevalence, was $90 \%$.

\section{Threshold cutoff values}

Table 8.4 shows the threshold cutoff values of the AB-ratio calculated for a desired value for $\mathrm{PV}+$ of $95 \%$, a desired value for $\mathrm{PV}$ - of $99 \%$ and prevalence figures in the range $5-33 \%$.

\section{Discussion}

In this study the performance of the AB-ratio as a tool for diagnosing PAOD in general practice was assessed. In theory the ideal study population would have been the 'indicated population', i.e. patients who visit their general practitioner and of whom the elinical picture (medical history, physical examination) motivates the general practitioner to perform a Doppler measurement. ${ }^{9.14}$ This would have required a long period of data collection or a large number of participating general practitioners and more than one cooperating vascular laboratory. For reasons of efficiency we selected the study population from a cohort of the Limburg PAOD Study. The spectrum of PAOD and co-morbidity in this population appeared appropriate for assessing the validity of the AB-ratio in a non-specialist setting: relatively mild disease predominated and sufficient non-arterial leg complaints were present as well.

For practical reasons we could not perform repeated measurements in all patients. ${ }^{30.50}$ Instead we used available data of a subgroup of patients who had visited their GPC three times during the last eight months as part of the Limburg PAOD Study. This was allowed because we only included legs with a stable pattern of consecutive AB-ratios. When extrapolating the results of this subgroup to the total. study population (accuracy, FN, FP) we corrected for the higher prevalence of PAOD in this subgroup, according to Bayes' theorem. 
Figure 8.1 ROC curves of the general practice centre AB-ratio

_. empirical data _. model single measurement b mean of 3 measurements

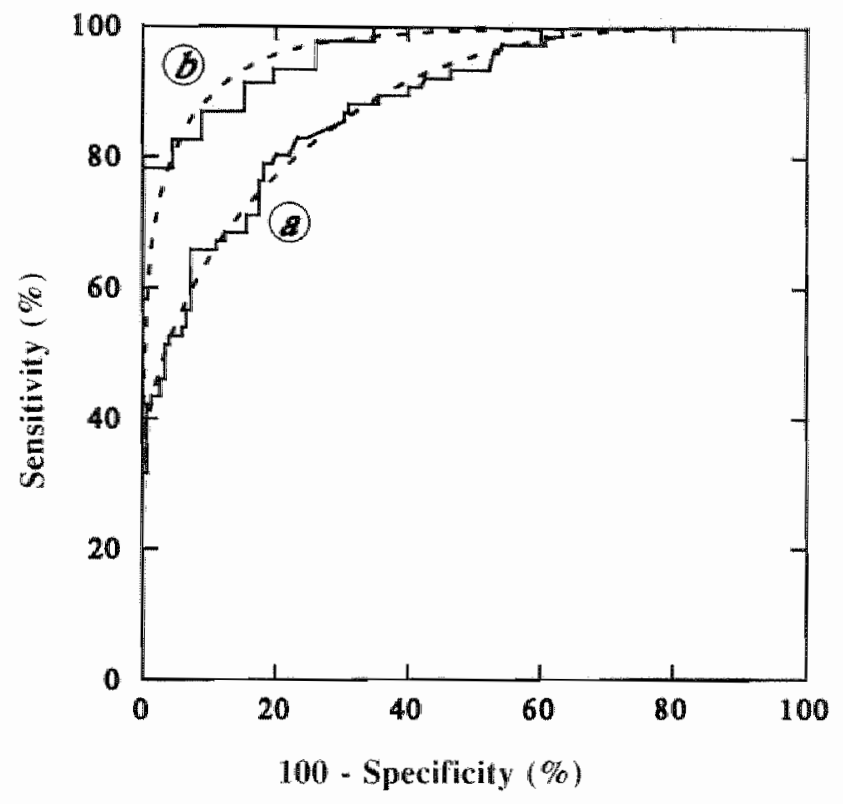

Table 8.3 ROC analyses. Sensitivity and specificity of the GPC resting AB-ratio at different curoff values for single and repeated measurements (between brackets the values for the 'smoothed' models)

\begin{tabular}{|c|c|c|c|c|}
\hline \multirow[b]{2}{*}{$\begin{array}{l}\text { Cutol } \\
\text { value }\end{array}$} & \multicolumn{2}{|c|}{$\begin{array}{l}\text { Single GPC measurement } \\
(\mathrm{n}=231 \mathrm{legs})\end{array}$} & \multicolumn{2}{|c|}{$\begin{array}{l}\text { Mean of } 3 \text { GPC measurements } \\
(\mathrm{n}=92 \text { legs })\end{array}$} \\
\hline & Sensitiony" & Specificity" & $\overline{\text { Sensinuity }}$ & Specincity" \\
\hline 1.15 & $100 \quad(100)$ & $19(19)$ & $100(100)$ & $22(22)$ \\
\hline 1.10 & $100 \quad(99)$ & $37 \quad(36)$ & $100(100)$ & $30 \quad(30)$ \\
\hline 1.05 & $92 \quad(93)$ & $56(56)$ & $100 \quad(100)$ & $50 \quad(50)$ \\
\hline 1.00 & $83 \quad(86)$ & $76 \quad(70)$ & $98(98)$ & $72 \quad(72)$ \\
\hline 0.95 & $71 \quad(73)$ & $83 \quad(84)$ & $93(95)$ & $80 \quad(82)$ \\
\hline 0.90 & $67 \quad(67)$ & $89 \quad(88)$ & $83 \quad(85)$ & $91 \quad(93)$ \\
\hline 0.85 & $53(55)$ & $94 \quad(95)$ & $70 \quad(68)$ & $100(99)$ \\
\hline 0.80 & $43 \quad(44)$ & $98(98)$ & $50 \quad(50)$ & $100 \quad(100)$ \\
\hline 0.75 & $33 \quad(35)$ & $99(100)$ & $39(39)$ & $100(100)$ \\
\hline 0.70 & $24 \quad(26)$ & $100(100)$ & $26(26)$ & $100 \quad(100)$ \\
\hline
\end{tabular}

rounded figures 
Table 8.4 "Threshold" curof walues of the AB-ratio for PV+ $\geq 95 \%$ and PV- $\geq 99 \%$ at different levels of prior probability

\begin{tabular}{|c|c|c|c|c|}
\hline \multirow[t]{2}{*}{ Prior probability } & \multicolumn{2}{|c|}{$\begin{array}{l}\text { Cutoff value below which } \\
\text { PV }+\geq 95 \%\end{array}$} & \multicolumn{2}{|c|}{$\begin{array}{l}\text { Cutoff walue above which } \\
\text { PV }-\geq 99 \%\end{array}$} \\
\hline & $\begin{array}{l}\text { Single } \\
\text { madasurement }\end{array}$ & $\begin{array}{l}\text { Meav of } 3 \\
\text { meatsurements }\end{array}$ & $\begin{array}{l}\text { Single } \\
\text { measurement }\end{array}$ & $\begin{array}{l}\text { Mean of } 3 \\
\text { measurements }\end{array}$ \\
\hline $33 \%$ (this study) & $<0.79$ & $<0.88$ & $>1.09$ & $>0.98$ \\
\hline $10 \%$ & $<0.75$ & $<0.88$ & $>1.07$ & $>0.94$ \\
\hline $5 \%$ & $<0.75$ & $<0.88$ & $>1.02$ & $>0.88$ \\
\hline
\end{tabular}

The 'gold standard' in this study was the consensus diagnosis made by two experienced VL technicians on the basis of the results of a combination of noninvasive tests. Duplex scanning was not used and segmental pressure measurements or wave form analysis of proximall leg arteries were nor performed. With those techniques the exact site of an arterial obstruction or stenosis can be established, which was not our aim. Furthermore, duplex scanning is not the primary diagnostic procedure to establish or exclude the diagnosis 'PAOD", but is used before percutaneous transluminal angioplasty or vascular surgery.

"The ROC analyses (table 8.3, figure 8.1) demonstrated that performing repeated measurements is always better than performing a single measurement. Using a cutoff value for the pocket Doppler AB-ratio of 0.95 , yielded acceptable results for accuracy and diagnostic parameters especially in the repeated measurement situation. The better performance of the Doppler method in case of repeated measurements was mainly achieved through a reduction in false negative test results.

The ROC analyses yielded theoretical optimum cutoff values (single measurement: 0.97; mean of three measurements: 0.92) that did not differ much from the preset cutoff value (0.95) used in the GPCs. Hiatt et al., using a different approach, reported to consider an $A B$-ratio at rest $<0.94$ to be abnormal. ${ }^{8}$ In our study the Doppler method performs best when a cutoff value of 0.92 for the mean of three consecutive AB-ratio measurements is used (sensitivity $87 \%$, specificity $91 \%, \mathrm{LR}+$ 10, $L R-0.14)$.

At the theoretical optimum cutoff value sensitivity and specificity are given about equal weight. If a higher sensitivity (less FN) or a higher specificity (less FP) is preferred, a different cutoft value should be chosen. Our results (table 8.3, figure 8. ) may help an investigator to decide whether to accept the qualities of the resting $A B$ ratio at each cutoff value, or to use an alternative procedure. ${ }^{51.54}$

In everyday practice the positive and negative predictive value of the measured $A B$ ratio are more relevant than a fixed cutoff value. Often it is relevant to rule out disease. A false negative Doppler result implies that therapy which is in fact appropriate will not be started or that referral to a specialist will be postponed. To rulle out disease (high $P V-$ ) in a population with a relatively low prevalence, a cutoff value with a high sensitivity - i.e. higher than the theoretical optimum cutoff value has to be chosen. ${ }^{*}$

On the other hand, establishing a diagnosis is important as well. A fallse positive 
Table 8.5 Decision tules for the measurement and interpretation of the pocket Doppler AB. ratio (in the range of prior probabilities of $5-33 \%$; based on table 8.4 )

\begin{tabular}{|c|c|c|}
\hline AB-ratio & Action & Interpretation \\
\hline$A B-$ ratio $>1.09$ & even if single measurement: & no PAOD (99\% certain) \\
\hline AB-ratio $0.75-1.09$ & $\begin{array}{l}\text { repeat measurement (e.g. } 2 \\
\text { - if mear } \mathrm{AB} \text {-ratio }>0.98 \text { : } \\
\text { - if mean } \mathrm{AB} \text {-ratio < } 0.88 \text { : } \\
\text { - if mean } \mathrm{AB} \text {-ratio } 0.88-0.98 \text { : }\end{array}$ & $\begin{array}{l}\text { nes): } \\
\text { no PAOD ( } 99 \% \text { certain) } \\
\text { PAOD ( } 95 \% \text { cetain) } \\
\text { the higher the prior probability } \\
\text { that PAOD is present the higher } \\
\text { the ABratio has to be to rule out } \\
\text { disease. }\end{array}$ \\
\hline
\end{tabular}

AB-ratio $<0.75$ even if single measurement: PAOD (95\% certain)

a e.g. if prevalence is $5 \%$ then the AB-ratio has to be $>0.88$ and if prevalence is $10 \%$, then the ABrratio has to be $>0.94$ to rule out PAOD

conclusion implies that a patient is labelled 'PAOD' incorrectly and thus will receive the advice to 'stop smoking and keep walking' on an erroneous basis. ${ }^{55}$ Although this advice would be beneficial to many patients, being labelled "PAOD' could lead to fear of disablement or limb loss. Furthermore, referral to a specialist or vascular laboratory should be as efficient as possible. To establish a diagnosis (high $P V+$ ) in a population with a relatively low prevalence a cutolf value for the AB-ratio associated with a high specificity should be selected. Then, a cutoff value lower than the theoretical optimum has to be chosen.

On the basis of our threshold cutoff values of the AB-ratio for high predictive values (able 8.4) practical decision rules for the use and interpretation of the Doppler method can be derived for the range of prior probabilities of $5.33 \%$ (table 8.5). By repeating the Doppler measurement, the range of less conclusive AB-ratios is reduced from $0.75-1.09$ to $0.88-0.98$. Within this range it applies that the higher the prior probability of $\mathrm{PAOD}$, the higher the $\mathrm{AB}$-ratio should be to rule out disease. The prior probability of PAOD in this diagnostic situation depends not only on age and gender of the patient but also on the results of history and plysical examination performed by the doctor.

We conclude that the measurement of the AB-ratio with a hand-held Doppler device is a valid diagnostic method for general practice. To maximize diagnostic performance one ought to measure the $A B$-ratio on more than one occasion before reaching a definite diagnostic conclusion. In that case the Doppler method can be a useful tool to support diagnostic decision making in daily practice.

\section{Acknowledgements}

The authors thank the practice assistants of the general practice centres and the personnel of the Vascular Laboratory for their enthusiastic and efficient cooperation. The Limburg PAOD Study was financed by the Netherlands Organization for Scientific Research' (900-715.154) and the 'Praeventiefonds' (28-1323). Doppler 


\section{References}

1 Wilt TJ. Current strategies in the diagnosis and management of lower extremity peripheral vascular disease. J Gen Intern Med 1992; 7: 87-101.

2 Buth J. Her vasculaire laboratorium [The vascular laboratory] (English summary) [PhD Thesis]. Amsterdam: Universiteit van Amsterdam, 1978.

3 Kitslaar PJEHM. Doppler-ultrasoundtests in the diagnosis of cluronic aorta-iliac obstruetions [PhD Thesis]. Maastricht: Rijksuniversiteit Limburg, 1982.

4 Bernstein EF, ed. Noninvasive diagnostic techniques in peripheral wascular disease. 2nd edirion. St.Louis etc.: Mosby, 1982.

5 Strandness Jr DE. Duplex scanning for diagnosis of peripheral vascular disease. Herz 1988; 13: 372.7 .

6 Cossman DV, Ellison JE, Wagner WH, Carroll RM, Treiman RL, Foran RF et al. Comparison of contrast angiography to arterial mapping with color-flow duplex imaging in the lower extremities. J Vasc Surg 1988; 10: 522-9.

7 Criqui $M H$, Fronek A, Klauber MR, Barret Connor E, Gabriel S. The sensitivity, specificity and predictive value of traditional clincal evaluation of peripheral arterial disease: results from non-invasive testing in a defined population. Circulation 1985; 71: 516-22.

8 Miatt WR, Marshall JA, Baxter J, et al. Diagnostic mehods for peripheral arterial disease in the San Luis Valley diabetes study. J Clin Epidemiol 1990; 43: 597-606.

9 Bonsema K, Boutens EI, Kaiser V, Stoffers HEJH. Perifeer arterieel vatlijden. Standaard M13 Nederlands Huisartsen Genootschap. Huisarts Wet 1990; 33; 4406.

10 Stegall HF, Kardon MB, Kemmerer WT". Indirect measurement of arterial blood pressure by Doppler ultrasonic sphygmanometry. J Appl Physiol 1968; 25: 793-8.

11 Kazamias TM, Gander MP, Franklin DL, Ross Jr. J. Blood pressure measurement with doppler ultrasonic flowmeter. J Appl Phys 1971; 30: 585-8.

12 Grüntzig $A$, Schlumpt $M$. The validity and reliability of post-stenotic blood pressure measurement by Doppler ultrasonic sphygmomanometry. VASA 1974; 3: 65-71,

13 Ya ST, Takaki HS. Non-invasive techniques of measuring lower limb arterial pressures. In: Bernstein EF, ed. Noninvasive diagnostic techniques in peripheral vascular disease. 2nd edirion. St.Louis, etc.: Mosby, 1982.

14 Bonsema K, Boutens EJ, Kaiser V, Stoffers HEJH. NHG-Standaard Perifeer arterieel vartijden. In: Rutten GEHM, Thomas $S$ (red). NHGStandarden voor de huisarts. U. recht: Nederlands Huisartsen Genootschap/Bunge, 1993 (233-244).

15 Hylkema BS. Tussen polspalpatie en aortografie [Between pulse-palpation and aortography] (English summary) [PhD Thesis]. Groningen: Rijksuniversiteit Groningen, 1975.

16 Bernink PJLM, Wouda A. Meting van de bloedsomloop in de benen van patienten met aherosclerosis obliterans, wor en na de operatie [The reference values and the usefulness of methods of pre- and postoperative determination of the blood circulation in patients with atherosclerosis obliterans] (English summary). Ned Tijdschr Geneesk 1981; 125 : 1786.92

17 Carter $S A$. Indirect systolic pressures and pulse waves in arterial occlusive disease of the lower extremities. Circulation 1968; 37: 624-37.

18 Carter SA. Clinical measurement of systolic pressures in limbs with arterial occlusive disense. JAMA 1969; 207: 1869.74.

19 Yao ST, Hobbs JT, Irvine WT. Ankle systolic pressure measurements in arterial disease affecting the lower extremities. Br J Surg 1969; 56: 676-9.

20 Thulesius $O$, Gjöres $J A$. Use of doppler shift detection for determining peripheral arterial blood pressure. Angiology 1971; 22: 594-603. 
21. Chamberlain J, Housley E, MacPherson AIS. The relationship between ultrasound assessment and angiography in occlusive arterial disease of the lowar limb. Br I Surg 1975; 62: 64.7 .

22 Hyllkema BS. Diagnostiek van arteriele circulatiestoomissen in de benen door bloeddrukmetingen met behulp van ultrageluid The diagnosis of obliterative arteriosclerotic disease of the legs by ultrasonic determination of blood pressures] (English summary). Ned Tijdschr Geneeskd 1976; 120: 733-41.

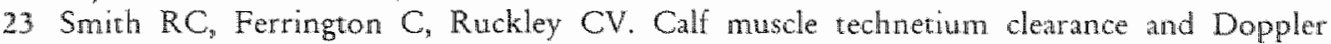
ankle pressure in patients with intermittent daudication. VASA 1977; 6:236-43.

24 Onrel KO, McDonnel AE, Metz CE, Zarins CK. A critical evaluation of stress testing in the diagnosis of peripheral vascular disease. Surgery $1982 ; 91: 686-93$.

25 Lepäntelo $M$, Lindfors 0 , Pekkola $P$. The ankle/arm systolic blood pressure ratio as a screening test for arterial insufticiency in the lower limb. Ann Chir Gyn 1983; 72: 57-61.

26. Piecuch T. Jaworski $R$. Resting anklearm pressure index in vascular diseases of the lower extremities. Angiology 1989; 40: $181-5$.

27 Knotmerus $\mathrm{jA}$. The effects of disease verification and referral on the relationship between symptoms and diseases. Med Decis Making 1987; 7: 139-48.

28 Knotmerus JA. Medical decision making by general practitioners and specialists. Family Practice 1991; 8: 305-7.

29 Fowkes FGR, Housley E, Cawood EHH, Macintyre CCA, Ruckley CV, Prescott RJ. Edinburgh Artery Study: prevalence of asymptomatic and symptomatic peripheral arterial disease in the general population. Int I Epidemiol 1991; 20: 384-92.

30 Newman AB, Sutton-Tyrrel K, Rutan GH, Locher J, Kuller LH. Lower extremity arterial disease in elderly subjects with systolic hypertension. J Clin Epidemiol 1991; 44: 15-20.

31 Novo S, Avellone $G$, Garbo $V$ di, Abrignani MG, Liquori M, Panno AV, Strano A. Prevalence of risk factors in parients with peripheral arterial disease. A clinical and epidemiological evaluation. Int Angiol 1992; 11: 218-29.

32 Postiglione A, Cicerano U, Gallotta G, Gnasso A, Lamenza F, Rubba P, Mancini M. Prevalence of peripheral arterial disease and related risk factors in elderly institutionalized subjects. Gerontology 1992; 38: 330-7.

33 Vogt MT, Cauley JA, Kuller LH, Hulley SB. Prevalence and correlates of lower extremity arterial disease in elderly women. Am J Epidemiol 1993; 137: 559-68.

34 Stoffers HEJH, Kaiser V, Knottnerus JA. Prevalence in general practice. In: Fowkes FGR, ed. Epidemiology of peripheral vascular disease. London etc: Springer, 1991 (109-115).

35 Rose GA, Blackburn H, Gillum RF, Prineas RJ. Cardiovascular survey methods. 2nd ed. Geneva: World Health Organization, 1982 (162-165).

36 Osmundson PhJ, O'Fallon WM, Clements IP, Kazmier FJ, Zimmerman BR, Palumbo PJ. Reproducibility of non-invasive tests of peripheral occhasive vascular discase. I Vasc Surg 1985; $2: 678.83$.

37 Johnston KW, Hosang MY, Andrews DF. Reproducibility of noninvasive wascular laboratory measurements of the peripheral circulation. J Vasc Surg 1987; 6: 147.51.

38 Naschitz $J E_{*}$ Ambrosio DA, Chang JB. Intermittent claudication: predictors and outcome. Angiology 1988; 39: 16-21.

39 Stoffers HEJH, Kaiser V, Kester ADM, Schouten HJA, Knotnerus JA. Peripheral arterial occlusive disease in general practice: the reproducibility of the ankle-arm systolic pressure ratio. Scand J Prim Health Care 1991; 9: 109.14.

40 Sacket DL, Haynes RB, Tugwell P. Clinical epidemiology. A basic science for clinical medicine. Boston, Toronto: Little, Brown, 1985.

41 Dixon WJ (ed), Brown MB, Engelman L, Hill MA, Jennich RI. BMDP Stanistical Sofware Manual. Berkeley etc: University of Califomia Press, 1990.

42 Gardner M], Gardner SB, Winter PD. Confidence Interval Analysis (CIA). Microcomputer Program Manual. London: British Medical Journal, 1989.

43 Weinstein MC, Fineberg HV. Clinical decision analysis. Philadelphia: Saunders, 1980. 
44 Connell FA, Koepsell TD. Measures of gain in certainty from a diagnostic test. Am. I Epidemiol $1985 ; 121: 744-53$.

45 Zeger SL, Liang KY. Longitudinal data analysis for discrete and continuous outcomes. Biometrics 1986; $42: 121-30$.

46 Karim MR, Zeger SL. GEE: a SA macro for longitudinal data analysis. Baltimore: John Hopkins University, 1988.

47 Gebski V, Leung O, McNeil D, Lunn D. SPIDA version 6. Eastwood: Statistical Laboratory Maquarie Uniwersity, 1992.

48 Coni W, Tennison $\mathrm{B}$, Troup M. Prevalence of lower extremity arterial disease among. elderly people in the community. Br J Gen Pract 1992; 42: 149.52.

49 Criqui MEI, Fronek A, Barret-Connor E et al. The prevalence of peripheral arterial disease in a defined population. Circulation 1985; $71: 510-5$.

50 Fowkes FGR, Housley E, Macintyre CCA, Prescott RJ, Ruckley CV. Variability of ankle and brachial systolic pressures in the measurement of atherosclerotic peripheral arterial disease. J Epidem Community Health 1988; 42: 128-33.

51 Carter SA. Response of ankle systolic pressure to leg exercise in mild or questionable arterial disease. New Engl J Med 1972; 287: 578.582.

52 Bernstein EF, Fronek A. Current status of noninvasive tests in the diagnosis of peripheral arterial disease. Surg Clin North Am 1982; 62: 473-87.

53 Verhagen PF. Post-ischemic reactive hyperemia in the diagnosis of peripheral arterial obstructive disease [PhD Thesis]. Nijmegen: Katholieke Universiteit Nijmegen, 1985.

54 Fowkes FGR. The measurement of atherosclerotic peripheral arterial disease in epidemi. ological surveys. Int J Epidemiology 1988; 17: 248-54.

55 Housley E. Treating claudication in five words. Br Med J 1988; 296: 1483. 


\section{Chapter 9 The prevalence of symptomatic and asymp- tomatic peripheral arterial occlusive disease. The Limburg PAOD Study."}

Summary The prevalence of peripheral arterial occlusive disease (PAOD), including asymptomatic cases and cases unknown to the general practitioner, was estimated in 18884 patients, aged $45-75$ years, on the list of 18 general practice centres (GPCS).

The study population $(n=3171)$ consisted of a sample of the total population. In the GPCs data were collected on intermittent daudication (IC), peripheral pulses, vascular risk factors, cardio-and cerebrovascular disease and the ankle brachial systolic pressure ratio (AB-ratio). PAOD was defined as an ABratio < 0.95 on two consecutive occasions. Results were recalculated for the total poptalation.

The prevalence of PAOD was $6.9 \%$ (95\%ci $5.7-8.2 \%)$. One third (2.2\%) of all cases had an $A B$ ratio < 0.75 . The prevalence of $I C$ was $6.6 \%$ (95\%ci 5.2-7.9\%), of which a quanter (1.6\%) met the classic WHO-criteria. The prevalence of abnomal pedal pulses weas $8 \%$ (95\%ci 6.5-9.5\%). PAOD did not occur significantly more often among men than among women but men suffered more often from an advanced stage of PAOD. Of all cases of PAOD $22 \%$ was symptomatic. This proportion correlated positively with bigher age, male gender and lower ABratio. Among asymptomatic PAOD cases the prevalence of concomitant cardion and cerebrovascular disease toas three to four times as high as in the group without PAOD. Sixty-eight \% of all PAOD cases was unknown to the general practitioner. This 'unknown" group mainly represented less advanced cases of atherosclerosis. However, in the group of PAOD cases with an $A B$-ratio $<0.75,42 \%$ wat wnknown to the general practitioner.

We conclude that general practitioners succeed in selecting the worst cases of manifest atherosclerosis but can enbance their efforts towards secondary prevention.

Key words peripheral arterial occlusive disease, epidemiology, population study, general practice, prevalence, internittent daudication, noninvasive testing

\section{Introduction}

Peripheral arterial occlusive disease (PAOD) is one of the many terms to describe the manifestation of atherosclerosis below the bifurcation of the abdominal aorta. Due to ageing of the population in western societies, the prevalence of atherosclerotic disease will rise and the diagnostic and therapeutic management (adequate

Henri EJH Stoffers", Paula ELM Rinkens", Arnold DM Kester", Victor Kaiser" "I André Knotrnerus:. University of Limburg, Maastricht, the Netherlands: Department of General Practice ${ }^{a}$, Department of Methodology and Statustics ${ }^{b}$. Submitted for publication. 
diagnosis, regular follow up, conservarive therapy, preventive measures and selection for refertal) of this chronic disease will become more important to general practitioners. ${ }^{4}$

Figures on the prevalence of PAOD diverge, depending on study population and diagnostic criteria. In general practice morbidity registrations, patients with intermittent claudication who visited their general practitioner are included. ${ }^{57}$ Such figures depict the work load a chronic disease entails to primary health care. They also indicate the "prior probability' of PAOD, which is important in the diagnostic process of the general practitioner. Data from population studies demonstrate the total extent of the burden this disease could impose on the health care system. In many studies the WHO-questionnaire on intermittent claudication was used (symptomatic cases of PAOD). ${ }^{8} 15$ In a number of population studies also noninvasive diagnostic techniques were applied. ${ }^{16-22}$ In the latter studies both symptomatic and asymptomatic cases were observed.

A review of these studies suggests that only a minority of all PAOD patients is known as such in primary health care ("tip of the iceberg"). ${ }^{2,23}$ It is unclear whether the unknown cases of PAOD represent a subcategory of patients with atherosclerosis to whom the general practitioner should pay more attention, either for therapeutic or preventive reasons.

Moreover, there appears to be a large group of 'asymptomatic' or 'atypical' patients with PAOD. ${ }^{2,23}$ The importance of asymptomatic PAOD was recently demonstrated by the results of a longitudinal study showing that not only symptomatic patients, but also asymptomatic patients had a higher cardiovascular mortality as compared to subjects without PAOD. ${ }^{24}$

Review of the literature also brought up the question whether the general idea of PAOD as a predominantly male disease is correct.

The aim of the present study was to estimate the prevalence of PAOD in a population of middle-aged and elderly men and women. We were especially interested in the proportion of asymptomatic clisease and in the number of PAOD cases 'unknown' to the general practitioner. We also investigated the association of PAOD with cardio- and cerebrovascular disease.

\section{Method}

\section{Background}

The "Limburg PAOD Study" is a research project conducted by the University of Limburg in Maastricht (the Netherlands) and a number of general practice centres in the region. This project consists of three interrelated elements: a prevalence study, a diagnostic study and an intervention study (on aspirin). ${ }^{3,25}$ The results of the prevalence study are presented here.

\section{General design}

In the Netherlands every subject is registered in a general practice. Therefore, the registered population of a general practice is a segment of the general population. From the list of eighteen general practice centres all patients were identified who were between 40 and 75 years of age (source population). For reasons of efficiency data were collected in a part of this population, selected through a stratified sampling procedure (study population). Strata were formed by gender, age category 
and the score on a postal questionnaire that had been sent to all patients of the source population. Prevalence figures for the general population were recalculated from the stratum specific data yielded by the study population to the population of patients who had responded to the postal questionnaire (base population).

\section{Sampling procedure}

All patients on the list of the 18 general practice centres, who were between 40 and 75 years of age, received a postal questionnaire with 5 yes/no questions: pain on walking, smoking $\geq 15$ cigarettes, known high blood pressure, diabetes, heart disease or TIA/stroke. 'Thus, each responder was characterized by a 'prior risk score' between 0 and 5 . The population invited to participate in the study was composed of three categories. A random sample was drawn from the category with risk score 0. Another random sample was drawn from the population with risk score 1-5. Subsequently, from the remaining patients in the latter category, those with the highest risk score were selected (score 5, 4, 3 and in some practices score 2). This complex sampling procedure was necessary to meet the demands of the three studies mentioned above in an efficient way.

\section{Data collection}

Each participant filled in a questionnaire which incorporated the WHO-questionmaire on intermittent claudication. ${ }^{8}$ The questionnaire also contained questions on smoking habits. The general practitioner subsequently performed a physical exanination (palpation of the pedal and femoral pulses, auscultation of the femoral artery). He also copied relevant data from the patient record to the registration form (presence of peripheral, cardio- or cerebrovascular disease, hypertension, hypercholesterolaemia, diabetes mellitus).

Without knowing the results of the general practitioner's examination, the practice assistant (or a colleague general practitioner) assessed the ankle brachial systolic pressure ratio (AB-ratio) of both legs using a hand-held Doppler device (Huntleigh Mini Dopplex D500, $8 \mathrm{MHz}$ ) and a mercury sphygmomanometer. ${ }^{1.26}$ Systolic pressures were recorded on both arms and legs with the patient lying in supine position. The AB-ratio was defined as the systolic pressure at the ankle divided by the highest systolic arm pressure. If the AB-ratio of at least one leg was less than 0.95 , the parient was requested to return for a second assessment one week later. All sphyrg momanometers were calibrated before the start of the study. The general practitioners and practice assistants had been trained in performing AB-ratio measurements. In a previous study the reproducibility of these measurements proved to be satisfactory. ${ }^{27}$

\section{Definitions}

The general practitioner indicated whether a patient was already known to him as suffering from PAOD ("PAOD according to patient record") and whether such a patient had experienced percutaneous transluminal angioplasty (P'TA), vascular surgery or an amputation (specialist care). If the patient record mentioned the diagnoses angina pectoris, coronary ischemia or myocardial. infarction the patient was considered to suffer from ischemic beart disease (IHD). If the patient record mentioned carotid stenosis, TIA, RIND or stroke, the patient was considered to suffer from cerebral arterial disease (CeAD). 
The variable "internittent clandication" (IC) was divided in two main categories: definite IC and non-calf IC. The category 'definite $I C$ ' was defined according to the criteria developed by Leng and co-workers: pain or discomfort in the calf when walking (at an ordinary pace on the level or uphill or when in a hurry), never beginning when standing still or sitting. ${ }^{28,29}$ This category comprised 2 subcategories. Firstly, the subcategory 'Rose' was defined as: definite IC, restricted to 'pain' (excluding other complaints), also meeting two extra criteria: "not disappearing while walking' and 'stopping or slow down when you get it'. Secondly, the subcategory 'pain or discomfort, not meeting all Rosecriteria' was defined as: definite IC (pain or ocher complaints), not meeting the two extra criteria. The category 'only non-calf $I C$ was defined as absence of definite $I C$, but presence of nonradiating pain or discomfort in buttock, thigh or foot, and otherwise meeting the overall criteria for definite IC.

The pedal pulses (dorsalis pedis artery and tibial posterior artery) were called 'abnormal' if the following combinations of pulses occurred: both pulses absent, or both pulses weak, or one pulse absent and the other one weak. Other positive test results were absence of the femoral artery pulse and presence of a femoral bruit.

After the physical examination the general practitioner had to state whether he thought PAOD (i.e. intermittent claudication) was currently present (' $G P$ 's diagnosis").

$P A O D$ was considered to be present in a leg, if the $\mathrm{AB}$-ratio was lower than 0.95 on two consecutive occasions. This cutoff value was a balanced choice between the 'specific' cutoff value of 0.90 (sensitivity $75-100 \%$, specificity $80-100 \%$ ) and the 'sensitive' cutoff value of 1.0 (sensitivity $88-100 \%$, specificity $60-81 \%$ ) as reported in studies on the validity of the Doppler-method. ${ }^{30.35}$ 'This relatively high cutoff value was chosen because in primary care a sensitive cutoff value is more important than in the specialist's setting, where a high specificity (i.e. a lower cutoff value) is desired.

Some analyses also were carried out at lower cutolf values of the AB-ratio: 0.75 and 0.50 . Below 0.75 a stenosis or occlusion is definitely present and referral to a vascular specialist might be useful, e.g. to answer the question whether PTA is appropriate. Values for the AB-ratio smaller than 0.50 indicate that multiple occlusions are probable and surgical intervention might be considered. '

PAOD was called 'symptomatic' if the AB-ratio was lower than 0.95 and there were leg complaints meeting the criteria for intermittent claudication (definite and non-calf. "Asymptomatic' PAOD was defined as the combination of an ABratio lower than 0.95 with no symptoms of intermittent claudication. A case of PAOD was called "enoron" if the ABratio was lower than 0.95 and there was PAOD according to the patient record.

\section{Analysis}

Due to the time period that passed between postal questionnaire and general practitioner's examination, the youngest ( $40-45$ years) and oldest age category ( $>75$ years) were incomplete. These age caregories were excluded from the analysis.

The study population and base population were divided in strata defined by the variables 'age' (45-55, 55-65, 65-75), 'gender' (male, female) and 'prior risk score' (05). Prevalence figures for the base population were recalculated as appropriately weighted means of stratum-specific prevalences. Confidence intervals (95\%) were 
Table 9.1 Prevalence of atherosclerotic disease as registered by general practitioners $(\mathrm{n}=18884$, $47.2 \%$ men; age 45.75 years, mean age 58.6 years)

\begin{tabular}{|c|c|c|c|c|}
\hline Atherosclerotic disease & $\begin{array}{c}\text { Prevalenes } \\
(95 \% \text { cil }) \\
\%\end{array}$ & & $\begin{array}{l}\text { Prevalence by gender } \\
(95 \% \mathrm{c}) \\
\%\end{array}$ & $\begin{array}{l}\mathrm{M} / \mathrm{F} \\
\text { ratio }\end{array}$ \\
\hline $\begin{array}{l}\text { PAOD according to patient re- } \\
\operatorname{cord}^{\circ}\end{array}$ & $3.8 \quad(2.9-4.6)$ & $\begin{array}{l}\mathrm{M} \\
\mathrm{F}\end{array}$ & $\begin{array}{l}5.9(4.2-7.6) \\
2.1(1.3-2.9)\end{array}$ & 2.8 \\
\hline $\begin{array}{l}\text { - of whom had experienced } \\
\text { specialist care }\end{array}$ & $1.6(1.0 .2 .2)$ & $M$ & $\begin{array}{ll}3.0 & (1.6-4.5) \\
0.5 & (0.1-0.9)\end{array}$ & 5.8 \\
\hline $\begin{array}{l}\text { Ischemic heart disease } \\
\text { (IHD) }\end{array}$ & $10.8(9.5-12.1)$ & $\begin{array}{l}M \\
F\end{array}$ & $\begin{array}{cc}15.6 & (13.0-18.1) \\
6.9 & (5.6-8.2)\end{array}$ & 2.3 \\
\hline $\begin{array}{l}\text { Cerebral arterial disease } \\
(C \mathrm{CD})^{4}\end{array}$ & $3.4(2.4-4.4)$ & $\begin{array}{l}\mathrm{M} \\
\mathrm{F}\end{array}$ & $\begin{array}{l}5.2(3.2-7.3) \\
2.0(1.0-2.9)\end{array}$ & 2.6 \\
\hline
\end{tabular}

definitions: see text

based on normal approximation and p-values for differences in prevalence figures were calculated using an unpaired two-sample t-test.

Results

\section{Populations}

The source population consisted of 26620 patients (male: $47.5 \%$ ) with a mean age of 56.5 years (SD: 9.8 years). The number of patients that returned the postal questionnare was $23004(86.4 \%)$. The distribution of age and gender in the population of responders was the same as in the source population.

As result of the sampling procedure 5301 patients were invited to partake in the study. The participation rate was $68.9 \%$. Non-participation was due to various reasons: patients had died, had moved, or were absent due to protracted admission to a hospital or nursing home (17.5\% of the non-participants); patients showed "no interest' (48\%); there were medical or practical reasons according to the general practitioner (11\%). For a quarter of the non-participation the reason nemained waknown.

The strdy population consisted of 3654 patients aged $40.7-78.3$ years (mean: 59.1 years). Data analysis was restricted to 3171 patients (male: $47.2 \%$ ) who were between 45 and 75 years of age (mean: 59.8 years, SD 8.0 years). Frequencies found in this population were used to calculate the prevalence figures for the base population, which consisted of 18884 patients (male: $47.3 \%$ ) between 45 and 75 years (mean. 58.6 years, SD 8.1 years).

\section{Registered atherosclerotic morbidity}

Table 9.1 presents the recalculated prevalence in the base population of various manifestations of atherosclerotic disease as registered in the patient records of the general practitioners. Among men the prevalence of registered atherosclerotic morbidity is significantly higher than among women. "The proportion of cases of PAOD according to the patient record, who had experienced PTA, vascular surgery or an amputation is $52 \%$ among men and $25 \%$ among women. 
Table 9.2 Prevalence of clinical signis and symptoms associated with PAOD $(n=18884$, $47.2 \%$ men: age $45-75$ years, mean age 58.6 years)

\begin{tabular}{|c|c|c|}
\hline $\begin{array}{l}\text { Signs and symptoms } \\
\text { (definitions: see text) }\end{array}$ & $\begin{array}{l}\text { Prevalence (\%), total } \\
(95 \% \text { ci) }\end{array}$ & $\begin{array}{l}\text { Malef } \\
\text { Femals } \\
\text { ratio }\end{array}$ \\
\hline IC, questionnaire, all & $6.6(5.2-7.9)$ & 1.2 \\
\hline - definite (calf) & $5.3(4.2-6.5)$ & 1.3 \\
\hline meeting Rosecriteria & $1.6(0.92 .2)$ & 0.6 \\
\hline pain or discanfort, not meting Rose-criteriat & $3.7(2.7 \cdot 4.7)$ & 1.8 \\
\hline - only non-calf & $1.2(0.6-1.9)$ & 0.7 \\
\hline Abnormal pedal pulses & $8.0(6.5-9.5)$ & 0.8 \\
\hline Absent femoral pulse & $1.0(0.5 \times 1.5)$ & 0.5 \\
\hline Fetnoral bruit & $4.5(3.6 \cdot 5.9)$ & 1.4 \\
\hline GP's diagrosis & $2.7(2.0-3.3)$ & 3.0 \\
\hline
\end{tabular}

\section{Current signs and symptoms of PAOD}

Table 9.2 shows the prevalence figures of clinical signs and symptoms associated with $\mathrm{PAOD}$, as recalculated based on the population survey. The prevalences of $\mathrm{IC}_{\text {, }}$ abnormal pedal pulses and a femoral bruit increase wirh rising age. Women more often meet the Rose-criteria for IC than men. The figures on clinical signs and symptoms do not demonstrate an unequivocal male predominance. Nonetheless, general practitioners diagnose 'PAOD' more often among men than among women. This difference is significant in the two oldest age categories.

\section{Noninvasive testing}

The mean AB-ratio in the base population is 1.08 (men:1.10, women 1.07). Seven percent of the base population has an $\mathrm{AB}$-ratio of 0.95 or less. In only $0.4 \%(95 \% \mathrm{ci}$ $0.1-0.6$ ) an AB-ratio of 0.50 or less is present. Figure 9.1 presents the cumulative frequency distribution of the AB-ratio for the range of 'positive' Doppler outcomes (i.e AB-ratios lower than 0.95). The frequency of a positive Doppler outcome is higher for men as compared to women at each cutoff value of the AB-ratio. This difference is significant for the range of $\mathrm{AB}$-ratios between 0.65 and 0.85 . The total prevalence of PAOD (twice an AB-ratio < 0.95$)$ among women $(6.5 \% ; 95 \%$ ci: 4.8 $8.2)$ is not significantly lower than the prevalence in men $(7.2 \% ; 95 \%$ ci: $5.5-9.0)$.

Table 9.3 provides the prevalence figures of PAOD for the various age and gender 


\begin{tabular}{|c|c|c|c|}
\hline & $\begin{array}{l}\text { Prevalence in } \%(95 \% \text { c) } \\
45-55 \text { years } \\
(m=3474, f=3500)\end{array}$ & $\begin{array}{l}55-65 \text { years } \\
(m=389, f=3735)\end{array}$ & $\begin{array}{l}65.75 \text { yats } \\
(m=20 \% t, f=263.3)\end{array}$ \\
\hline$M$ & $3.7(1.0-6.4)$ & $9.2(5.5-12.8)^{2}$ & $10.1(5.7-14.6)$ \\
\hline $\mathrm{F}$ & $5.7(2.49 .1)$ & $4.9(2.6-7.3)$ & $8.2(4.3-12.1)$ \\
\hline$M$ & $2.8(0.4-5.3)$ & $8.4(4.7 \cdot 12.0)^{4}$ & $8.8(4.4-13.2)$ \\
\hline $\mathbb{F}$ & $2.8(0.7-4.9)$ & $4.6(2.3-6.9)$ & $7.5(3.6-11.4)$ \\
\hline$M$ & $0.5(0.20 .9)$ & $0.9(0.5 \cdot 1.3)$ & $2.4(1.5-3.3)$ \\
\hline$F$ & $0.3(0.1-0.5)$ & $2.2(0.4 .4 .1)$ & $3.7(0.3 \cdot 7.0)$ \\
\hline$M$ & $2.3(0.4 .7)$ & $7.5(3.9-11.0)^{\circ}$ & $6.4(2.1 \cdot 10.8)$ \\
\hline$F$ & $2.5(0.44 .6)$ & $2.3(0.9 .3 .7)$ & $3.8(1.6-5.9)$ \\
\hline$M$ & $0.9(0-2.0)$ & $0.8(0.4-1.2)$ & $1.3(0.6-2.0)$ \\
\hline F & $2.9(0.3-5.6)$ & $0.4(0.1-0.7)$ & $0.7(0.2-1.2)$ \\
\hline M. & $2.7(0.2-5.1)$ & $6.6(3.8-9.4)$ & $17.6(11.3-23.8)$ \\
\hline$F^{*}$ & $5.6(2.6-8.6)$ & $8.3(4.9-11.6)$ & $13.8(8.4-19.2)$ \\
\hline $\mathrm{M}$ & $0.2(0-0.5)$ & $0.3(0.1-0.6)$ & $2.1(0-4.7)$ \\
\hline F & $1.8(0-3.5)$ & $1.3(0.2-2.3)$ & $0.8(0.3-1.3)$ \\
\hline $\mathrm{M}$ & $2.0(0.8-3.3)$ & $6.2(3.2 \cdot 9.2)$ & $9.5(5.3-13.7)$ \\
\hline$F$ & $2.2(0.4-4.0)$ & $4.3(1.9-6.8)$ & $6.8(2.6-11.1)$ \\
\hline$M$ & $1.4(0.2-2.6)$ & $3.7(1.8-5.6)^{4}$ & $10.6(5.6-15.5)^{2}$ \\
\hline$E$ & $0.8(0-1.9)$ & $1.0(0.6-1.4)$ & $2.9(2.0-3.7)$ \\
\hline
\end{tabular}

$p<0.05$ for differences between men and women in the same age category (unpaired two sample t-test)

categories. The prevalence of PAOD increases with rising age. In the youngest age group the prevalence among women is higher, in the oldest age category the prevalence among men is higher. These differences are not statistically significant. However, the figures on symptomatic cases, cases with concomitant $\mathrm{HD}$ or $\mathrm{CeAD}$ and known cases, indicate that the proportion of cases with manifest atherosclerosis is evidently higher among men.

Table 9.4 shows that the proportions of symptomatic cases, cases with concomitant IHD or CeAD and known cases, are larger at the cutoff value of 0.75 . The prewalence of PAOD is higher in patients with a diagnosis of hypertension, hyperchollesterolaemia or diabetes mellitus in their patient record. Smoking, currently or in the past, also increases the probability of PAOD being present (table 9.5).

\section{Symptomatic and asymptomatic PAOD}

Twenty-two percent of all PAOD cases is symptomatic. Of these symptomatic cases $75 \%$ is male, $49 \%$ belongs to the oldest age group, $69 \%$ has an AB-ratio lower than $0.75,12 \%$ has an $\mathrm{AB}$-ratio lower than 0.50 . The proportion having concomitant IHD is $33 \%$, CeAD $6 \%$.

On the other hand, of the asympromatic cases only $43 \%$ is male, $22 \%$ has an $A B$. ratio lower than 0.75 and $2 \%$ has an $A B$-ratio lower than 0.50 . "The age distribution is shifted only slightly to the younger age groups (oldest age group $47 \%$ ) as com- 
Table 9.3 Prevalence of PAOD according to noninvasive testing $(\mathrm{n}=18884,47.2 \%$ men; age $45-75$ years, natan age 58.6 years)

\begin{tabular}{lll}
$\begin{array}{l}\text { Category } \\
\text { PAOD, total (2x AB-ratio < 0.95) }\end{array}$ & $\begin{array}{l}\text { Prevalence in } \% \\
(95 \% \mathrm{ci})\end{array}$ & $\begin{array}{l}\text { Male } \\
\text { Female } \\
\text { ratio }\end{array}$ \\
\hline symptomatic cases (IC present) & $6.9(5.7-8.2)$ & 1.1 \\
concomitant IHD or CeAD & $1.5(1.1-1.9)$ & 3.3 \\
known cascs & $2.4(1.9-3.0)$ & 2.6 \\
\hline
\end{tabular}

Figure 9.1 Number of patients with an AB-racio lower than a specific cutoff value. Cumulative frequency ( $y$-axis) for the range of cutoff values of the AB-ratio in the range between 0.50 and 0.95 ( $x$-axis) $(n=18884,47.2 \%$ men; age $45-75$ years, mean age 58.6 years $)$

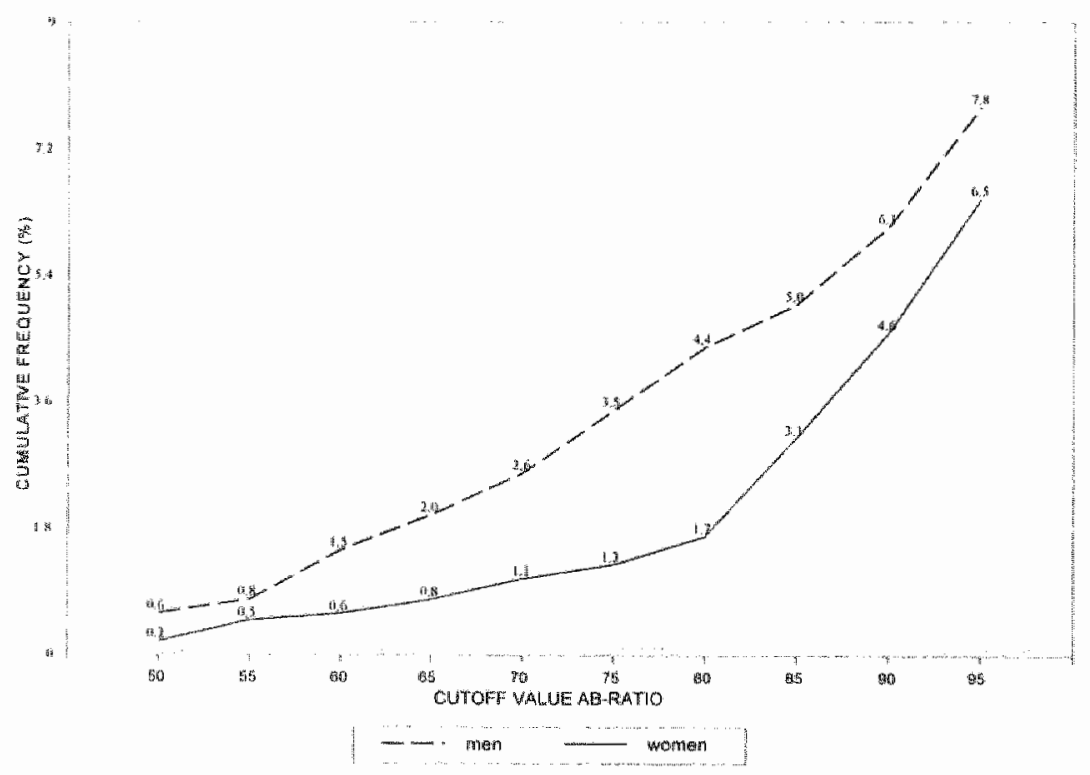

pared to the symptomatic cases. The proportion having concomitant atherosclerosis also does not differ much from the symptomatic cases (IHD 29\%, CeAD 12\%). 


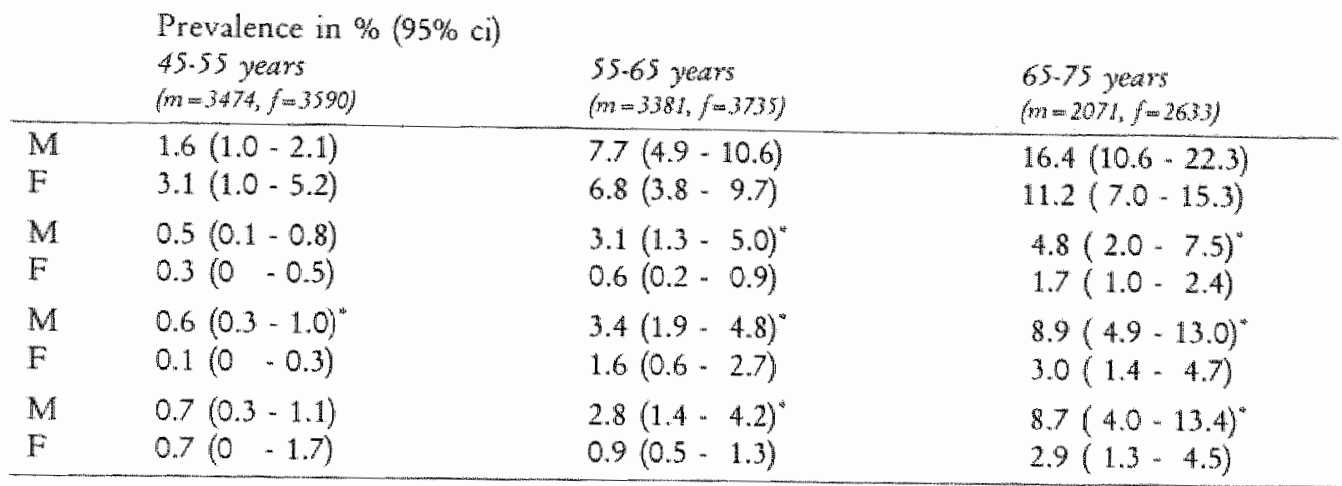

$p<0.05$ for differences berween men and women in the same age category (unpaired two sample t-test:

Table 9.4 Characteristics of PAOD at 2 cutoff values for the AB-ratio $(n=18884,47.2 \%$ men; age $45-75$ years, mean age 58.6 years)

\begin{tabular}{|c|c|c|c|c|c|}
\hline Gender & $\begin{array}{l}\text { Cut off } \\
\text { value } \mathrm{AB} \text { - } \\
\text { ratio }\end{array}$ & $\begin{array}{l}\text { Prevalence in } \% \\
(95 \% \text { ci })\end{array}$ & $\begin{array}{l}\text { Proportion } \\
\text { symptomatic }\end{array}$ & $\begin{array}{l}\text { concomitant } \\
\text { HHD/CeAD }\end{array}$ & "known" \\
\hline \multirow[t]{2}{*}{ Men } & 0.75 & $3.4(2.2-4.6)$ & $53 \%$ & $57 \%$ & $58 \%$ \\
\hline & 0.95 & $7.2(5.5-9.0)$ & $34 \%$ & $50 \%$ & $46 \%$ \\
\hline \multirow[t]{2}{*}{ Women } & 0.75 & $1.3(0.8-1.8)$ & $32 \%$ & $46 \%$ & $57 \%$ \\
\hline & 0.95 & $6.5(4.8 .8 .2)$ & $11 \%$ & $22 \%$ & $20 \%$ \\
\hline \multirow[t]{2}{*}{ All } & 0.75 & $2.2(1.7-2.8)$ & $47 \%$ & $54 \%$ & $58 \%$ \\
\hline & 0.95 & $6.9(5.7-8.2)$ & $22 \%$ & $35 \%$ & $32 \%$ \\
\hline
\end{tabular}

due to sparse data in the study population for the age categories $45-55$ years and $55-65$ years, the results for an $A B$ ratio $<0.50$ are not presented

\section{PAOD and concomitant arterial disease}

The total prevalence of ischemic heart disease in the base population is $10.8 \%$ (table 9.1). If $P A O D$ is present (AB-ratio < 0.95 ) the probability of IHD increases to $29.6 \%$. In the subcategory of $\mathrm{PAOD}$ patients with an $\mathrm{AB}-\mathrm{ratio}$ lower than 0.75 , the prevalence of IHD is $49.6 \%$. If PAOD is absent (AB-ratio $\geq 0.95$ ) the probability of IHD is $9.3 \%$. The total prevalence of cerebral arterial disease is $3.4 \%($ able 9.1$)$. If $\mathrm{PAOD}$ is present the probability of $\mathrm{CeAD}$ increases to $11.0 \%$. In the subcategory of PAOD patients with an AB-ratio lower than 0.75 , the prevalence of CeAD is $13.1 \%$. If $\mathrm{PAOD}$ is absent the probability of $\mathrm{CeAD}$ is $2.8 \%$.

Reversely, the prevalence of (symptomatic and asymptomatic) PAOD is $19.1 \%$ among patients with IHD and $22.5 \%$ among patients with CeAD. If IHD or CeAD are absent these figures are $5.4 \%$ and $6.3 \%$ respectively. 
Table 9.5 Prevalence of PAOD in various vascular risk groups $(\mathrm{n}=18884,47.2 \%$ men; age 45 75 years, mean age 58.6 years; prevalence of PAOD $6.9 \%$ )

\begin{tabular}{|c|c|c|c|c|}
\hline Vascular risk indicator & $\begin{array}{l}\text { Status } \\
\text { Grevalle }\end{array}$ & $\% \% ; 95 \%$ & $\begin{array}{l}\text { Probability } \\
\text { of PAOD in } \\
\%\end{array}$ & $\begin{array}{l}\text { Relative } \\
\text { Risk }\end{array}$ \\
\hline Hypertension & $\begin{array}{l}\text { present } \\
\text { absent }\end{array}$ & $(24.2 ; 22.0-26.4)$ & $\begin{array}{r}13.3 \\
4.8\end{array}$ & $\begin{array}{l}2.8 \\
1\end{array}$ \\
\hline Hypercholesterolaemia & $\begin{array}{l}\text { Present } \\
\text { absent }\end{array}$ & $(8.7 ; 7.1-10.3)$ & $\begin{array}{r}12.4 \\
6.2\end{array}$ & $\begin{array}{l}2.0 \\
1\end{array}$ \\
\hline Diabetes mellitus & $\begin{array}{l}\text { present } \\
\text { absent }\end{array}$ & $(5.6 ; 4.6-6.7)$ & $\begin{array}{r}20.5 \\
6.2\end{array}$ & $\begin{array}{l}3.3 \\
1\end{array}$ \\
\hline Smoking & $\begin{array}{l}\text { ever sm } \\
- \text { smok } \\
\text { - stopp } \\
\text { never } s 1\end{array}$ & $\begin{array}{l}(65.4 ; 62.3-68.4) \\
(36.7 ; 33.8-39.5) \\
(28.7 ; 25.8-31.6) \\
d\end{array}$ & $\begin{array}{l}8.0 \\
8.7 \\
7.2 \\
4.8\end{array}$ & $\begin{array}{l}1.7 \\
1.8 \\
1.5 \\
1\end{array}$ \\
\hline
\end{tabular}

"bivariate RR

\section{Known and unknown cases of PAOD}

Thirty-two per cent of all cases of PAOD (AB-ratio < 0.95 ) is known as such to their general practitioner; in general this proportion is larger when the AB-ratio is lower (tables 9.3 and 9.4). Of these known cases $69 \%$ is malle, $60 \%$ is older than 65 years and $60 \%$ has concomitant cardio- or cerebrovascular disease. Thirty-seven per cent of the known cases has complaints of intermittent claudication (symptomatic PAOD). The proportion of known cases with an AB-ratio of 0.75 or less is $59 \%$, while an $A B$ rratio of 0.50 or less occurs in $5 \%$ of known cases.

Of the unknown PAOD cases $60 \%$ is female, $58 \%$ is younger than 65 years, only $24 \%$ has concomitant cardio- or cerebrovascular disease and only $15 \%$ is symptomatic. The proportion of unknown cases with an A.B-ratio of 0.75 or less is $20 \%$ and an AB-ratio of 0.50 or less occurs in $4 \%$ of the unknown PAOD cases.

The probability that a patient with PAOD is known as such to his general practitioner is higher when he has complaints of IC $53 \%$ of the symptomatic cases is known against $26 \%$ of the asymptomatic cases), also suffers from other atherosclerotic disease (53\% of the cases with concomitant IHD or CeAD is known against $20 \%$ of cases without concomitant manifestations of atherosclerosis) and is older than $65(40 \%$ of the cases who are $65-75$ years of age are known against $28 \%$ in the age group $45-55$ and $24 \%$ in the age group 55-65). The proportion of known cases of PAOD among men is higher than among women (table 9.4).

\section{Discussion}

In this population study the prevalence of $\mathrm{PAOD}$ (twice an $\mathrm{AB}$-ratio lower than 0.95 ) in the age group of $45-75$ years, was $6.9 \%$ of which one third (2.2\%) had an AB-ratio lower than 0.75 . The prevalence of current complaints of intermittent claudication was $6.6 \%$, of which a quarter $(1.6 \%)$ met the WHO/Rose-criteria. ${ }^{8}$ The prevalence of PAOD according to the patient record of the general practitioners was lower $(3.8 \%)$. 


\section{Signs and symptoms}

There is no consensus on the "correct' definition of IC. Our definition permits comparison with studies in which the classic WHO/Rose-questionnaire is used as well as studies that use a modern version of this questionnaire. ${ }^{8,28,29}$

Studies on the prevalence of intermittent claudication in the general poptlation have produced divergent results. The prevalence of IC varies between 0.6 and 6.1 (men: 1.1-7.0, women 0.7-7.4). 10,13-77,19-21,36,37 Our results for Rose-JC are at the lower end of this range (table 9.2). Hale et al. found relatively high prevalence figures in an elderly population, using a definition of IC not strictly meeting the Rose-criteria. ${ }^{1,12}$ Our results for total IC for the age group 65-75 years (men: 10\%; women: $8 \%$ ) correspond quite well with their figures for this age group (7-12\%).

Few studies have reported on the prevalence of absent or diminished peripheral pulses. Our results for the prevalence of abnormal pedal pulses $(8 \%)$ are within the range reported by others $(3.2-18 \%) .{ }^{16-18}$

\section{Noninvasive testing}

There is no unanimous answer to the question which noninvasive test should be applied in epidemiological studies on PAOD. Population based prevalence studies on PAOD using noninvasive tests can be divided in two groups: those in which a certain cutoff value of the AB-ratio is used as criterion for PAOD and those in which more extensive tests are performed.

In our study the AB-ratio measured with a hand-held Doppler-device was chosen, as explained in the "Method" section. The reactive hyperaemia test was not used, since its application on a large scale is less feasible in general practice: one session takes about 30-45 minutes and is often painful for the patient. Furthermore, the reproducibility of the reactive hyperaemia test is less than the reproducibility of the assessment of the resting AB-ratio. ${ }^{418.3842}$ Our results (figure 9.1, tables 9.3 and 9.4) are within the range of results found by other authors who used the AB-ratio (cutoff values between 0.75 and 0.95 ) as criterion for PAOD (3.4 to 14.3\%). ${ }^{16,18,20.21 \text {. }}$ 4,44

In the second group of studies prevalence figures are reported to be $11.7 \%, 13.7 \%$ and $8 \%$ ('grossly abnormal') to $25 \%$ ("moderately and grossly abnormal'). ${ }^{17,18,19}$ Aside should be noticed that in the study of that et al. $87 \%$ of all PAOD cases were discovered using only the $\mathrm{AB}$-ratio at rest (cutoff value 0.94$).^{18}$ In the age group 65 75 years Criqui et al, using extensive noninvasive testing, found a prevalence among men of $12-19 \%$, among women of $12 \% .{ }^{17} \mathrm{Vogt}$ et al. $(\mathrm{AB}-\mathrm{ratio}<0.90)$ found a prevalence of $4 \%$ among women of this age group. ${ }^{37}$ In our study these figures were $16.4 \%$ for men and $11.2 \%$ for women in this age category. Ogren et al. found a prevalence of $14 \%$ among men, 68 years of age (AB-ratio <0.90). In the study by Coni et al., the prevalence of an AB-ratio lower than 0.75 was $9.1 \%$ among 264 patients between 66 and 96 years of age. Using this cutoff value in our - younger - population a prevalence of $5.5 \%$ was found.

\section{Gender}

We know of only one study in which an apparent male predominance of PAOD was reported (gender ratio 1.4-2.0). ${ }^{43}$ In our study the prevalence of PAOD in men was somewhat higher than in women (gender ratio 1.1). However, manifest atherosclerosis (symptomatic PAOD, IHD, CeAD) occurred significantly more 
often in men than in women. Furthermore, among men more often an advanced stage of PAOD was present (more lower AB-ratios, more often surgical interventions).

The results of noninvasive testing in two other studies were similar to ours: PAOD occurred about 1.3 times more often among men. ${ }^{17,19}$ Fotwes et al. found a higher mean $\mathrm{AB}$-ratio for men but a larger proportion with an AB-ratio lower than 0.80 , which is comparable to our findings (higher mean, larger proportion lower than 0.75 ). ${ }^{19}$ In two other studies no (significant) gender differences were found regarding the height of the AB-ratio. ${ }^{16,20}$ However, Schroll and Munck did find a higher prevalence of 'symptomatic' cases (IC, pulselessness, AB-ratio lower than 0.90) among men (3.3\% versus $1.0 \%)^{16}$

\section{Asymptomatic cases}

In their study among women between 65 and 93 years of age, Vogt et al. found that $18 \%$ of all PAOD cases (AB-ratio <0.90) suffered from (Rose)IC." Ögren et al. found that $15 \%$ of all cases of PAOD in his male population of 68-year-olds (ABratio $<0.90$ ) suffered from (Rose)IC. ${ }^{36}$ In our study the overall proportion of symptomatic cases (positive $\mathrm{rC}$ and noninvasive testing) was 22\% and correlated with age, gender (women: 11\%) and AB-ratio (tables 9.3 and 9.4). Asymptomatic cases of PAOD differed from symptomatic PAOD cases with regard to gender (more women) and AB-ratio (more higher values), but age distribution and prevalence of concomitant arterial disease did not differ much.

Compared to the population without PAOD, the prevalence of concomitant arterial disease was three to four times as high among asymptomatic PAOD cases. A high prevalence of concomitant atherosclerosis among asymptomatic cases of PAOD was also found in the Edinburgh artery study, where ischaemic heart disease occurred 1.6 times as often among asymptomaric PAOD cases as compared to subjects without PAOD. ${ }^{19}$

The results of our study gave rise to a new longitudinal study on the prognosis of $P A O D$, in which we will further investigate the clinical relevance of asymptomatic cases.

\section{Unknown cases}

A British population study in which the patients of two general practices were asked to participate, disclosed that only half of all persons with complaints of claudication had consulted a doctor. Similarly, Domandy concluded in his review that probably at least half of all patients with intermittent claudication are unknown. ${ }^{45}$

The results of our study show that about two third of all PAOD cases is not known in primary care. As compared to the subpopulation "known" cases of PAOD, the group 'unknown' PAOD cases could be characterized as: more female, younger, with less complaints, higher $\mathrm{AB}$-ratios and less concomitant arterial disease. It follows that this 'unknown' group mainly represents less advanced cases of PAOD. Still, in the group of PAOD cases with clinically important disease (i.e an AB-ratio lower than 0.75) $42 \%$ of all cases appeared to be unknown to the general practitioner.

Applying these figures to an average Dutch general practice (2350 patients) standardized to the age distribution of the Dutch population (691 patients between 
45 and 75 years of agej, yields 46 patients with $P A O D$ in this age group, of whom 15 have an $A B$-ratio lower than 0.75. A total of 32 patients with PAOD will not be registered as such, of whom 6 will have an $A B$-ratio lower than 0.75 .

Although the general practitioner is successful in selecting the worst cases of atherasclerosis for treatment, our results demonstrate that efforts can still be made to improve secondary prevention. Firstly, general practitioners should try to achieve a complete picture of the vascular risk profile of their middle-aged patients. Secondly, in female patients with leg complaints the possibility of PAOD could more often be considered. Finally, a Doppler examination might be useful when taking a careful history and performing a vascular examination in a patient with leg complaints do not yield unambiguous results.

\section{Conclusions}

Figures for the prevalence of symptomatic and asymptomatic PAOD differ among studies. This is partly explained by the use of different criteria for intermittent claudication and PAOD.

Although the prevalence of PAOD in men and women is quite equal, men more often suffer from manifest atherosclerotic disease and more often have an advanced stage of PAOD.

Compared to symptomatic PAOD, asymptomatic PAOD is characterized by a higher proportion of women and higher values for the AB-ratio. Compared to subjects without PAOD, symptomatic as well as asymptomatic PAOD correlate with a higher probability of concomitant IHD and CeAD. We confirmed the hypothesis that many cases of PAOD are unknown to the general practitioner. 'This group of unknown cases mainly represents less advanced cases. Since conservative treatment of PAOD has been proven successful, general practitioners could enhance their efforts towards secondary prevention.

\section{Acknowledgments}

The authors thank the participating general practitioners and their practice assistants for collecting the data for this study. The Limburg PAOD Study was financed by the 'Netherlands Organization for Scientific Research' (900-715.154) and the 'Praeventiefonds' (28-1323). Doppler devices were donated by ASTA Medica BV.

\section{References}

1. Bonsema K, Boutens EJ, Kaiser V, Stoffers HEJH. Perifeer arterieel yaathijen. Standaard M13 Nederlands Huisartsen Genootschap. Huisarts Wet 1990; 33; 440-6.

2 Bonsema K, Boutens EJ, Kaiser V, Stoffers HEJH. NHG-Standard Perifeer arterieel waatlijden. In: Rutten GEHM, Thomas S (red). NHG.Standaarden woor de huisarts. Uurech: Nederlands Huisartsen Genootschap/Bunge, 1993.

3. Stoffers HE]H, Kaiser V, Knottnerus JA. Prevalence in general practice. In: Fowkes EGR (ed.). Epidemiology of peripheral wascular disease. London etc.: Springer, 1991: 109-15.

4 Wilt TJ. Current strategies in the diagnosis and management of lower extremity peripheral vascular disease. J Gen Intern Med 1992; 7: 87-101.

5 Royal College of General Practitioners, Office of Population Censuses and Surveys, Department of Health and Social Security. Morbidity from General Practice 1981-1982. "Third national study London, Her Majesty"s Stationary Office, 1986. 
6 Lambers H, Brouwer HJ, Groen ASM, al. Het Transitiemodel in de husartspraktik. Huisarts Wet 1987; 30: 105-13. Supplement Juni $1990 \mathrm{~m}$.b.t. ICPC rubriek K92.

7 Hoogen HJM van den, Huygen FJA, Schellekers. JWG er al. Morbidity figures from general practice. Data from four general practices 1985-1988. Nigmegen, NUHI, 1990.

8 Rose GA, Blackburn H, Gillum RF, Prineas RJ. Cardiovascalar survey methods. 2nd ed. Geneva: World Health Organization 1982: 162-5.

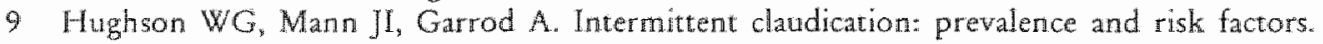
$\mathrm{Br}$ Med J 1978; i: 1379-81.

10 Reunanen A, Takkunen $H$, Aromaa A. Prevalence of intermittent claudication and its effect on mortality. Acta Med Scand 1982; $211: 249-56$.

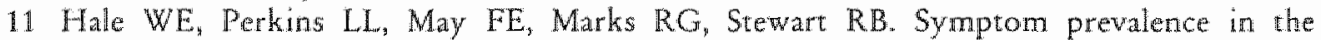
elderly. An cvaluation of age, sex, disease and medication use. I Am Geriatr Soc 1986; 34: $333-40$.

12 Hale WE, Marks RG, May FE, Mocre MT, Stewart RB. Epidemiology of intermittent claudication: evaluation of risk factors. Age Ageing 1988; 17: 57-60.

13 Evans JG. Intermittent dádication. Age Ageing $1988 ; 17$ : 139.

14 Dewhurst $G$, Wood DA, Walker $F$, et al. A population survey of cardiovascular disease in elderly people: design, methods and prevalence results. Age Ageing 1991; 20: 353-60.

15 Smith WCS, Woodward M, Tunstall-Pedoe H. Intermittent claudication in Scotland. In: Fowkes FGR (ed.). Epidemiology of peripheral vascular disease. London etc.: Springer, 1991: 117-23.

16 Schroll M, Munck O. Estimation of peripheral arteriosclerotic disease by ankle blood pressure measurements in a population of 60 -year-old men and women. Journal of Chronic Diseases 1981:34: 261-9.

17 Criqui MH, Fronek A, Barret-Connor E, Klauber MR, Gabriel S, Goodman D. The prevalence of peripheral arterial disease in a defined population. Circulation 1985; 71 : 510 5.

18 Hiat WR, Marshall JA, Baxter J, et al. Diagnostic methods for peripheral arterial disease in the San Luis Valley diabetes study. J Clin Epidemiol 1990; 43: 597-606.

19 Fowkes FGR, Housley E, Cawood EIH, Macintyre CCA, Ruckley CV, Prescott RJ. Edinburgh artery study: prevalence of asymptomatic and symptomatic peripheral arterial disease in the general population. Int J Epidemiol 1991; 20: 384-92.

20 Coni N. 'Tennison B, Troup M. Prevalence of lower extremity arterial disease among elderly people in the community. BrJ Gen Pract 1992; 42: 149-52.

21 Newman AB, Siscovick DS, Manolio TA et al. Ankle-Arm Index as a rnarker of atherosclerosis in the Cardiovascular Health Study. Circulation 1993; 88: 837-45.

22 Strat T, Jönsson B. Prevalence of symptomatic leg ischaemia in a Swedish community. An epidemiologic study. Eur J Vase Surg 1993; 7: 432-7.

23 Stoffers HEJH, Kaiser V, Lemmens ThGJ, Knottnerus JA. Perifeer arterieel vatijden in de huisartspraktijlk: een verborgen ziektebeeld? [Peripheral arterial occlusive vasculopathy in general practice; a hidden disease?] (English summary) Huisarts Wet 1988; 31: 202-6.

24 Criqu MH, Langer RD, Fronek $A$, et al. Mortality over a period of 10 years in patients with peripheral arterial disease. N Engl J Med 1992; 326: 381-6.

25 Kaiser V, Stoffers HEJH, Knottnerus JA. Peripheral arterial occlusive disease in general practice: natural course and intervention (the Limburg PAOD Study, part II). CVD Newsletrer $1991 / 1992 ; 47: 489$.

26 Yao ST, Takaki HS. Non-invasive techniques of measuring lower limb arterial pressures. Int Bernstein EF (ed). Noninvasive diagnostic techniques in peripheral vascular disease. 2 rad edition. St Loulis, erc.: Mosby, 1982.

27 Stoffers HEJH, Kaiser V. Kester ADM, Schouten HJA, Knottnerus JA. Peripheral arterial occlusive disease in general practice: the reproducibility of the ankle-arm systolic pressure ratio. Scand J Prim Health Care 1991; 9: 109-14. 
28 Leng GC. Questionnaires. In: Fowkes FGR (ed). Epidemiology of peripheral vascular disease. London exc: Springer, 1991: 2940.

29 Leng GC, Fowkes FGR. The Edinburgh Claudication Questionnaire: an improved version of the WHO/Rose Questionnaire for use in epidemiological surveys. I Clin Epidemiol 1992; 45: 1101-9.

30 Thulesius $O$, Gjöres JA. Use of doppler shift detection for determining peripheral arteriat blood pressure. Angiology $1971 ; 22,594603$.

31 Chamberlain J, Housley E, MacPherson AIS. The relation-ship between ulrasound assessment and angiography in occlusive arterial disease of the lower limb. Bu I Surg 1975; 62: 647.7.

32 Hylkema BS. Tussen polspalpatie en aortografie. [Berween pulse-palpation and aortography] (English summary) [PhD Thesis]. Groningen: Riksuniwersiteit Groningen, 1975.

33 Hylkema BS. Diagnostiek wan arteriele circulatiestoornissen in de benen door bloeddrukmetingen met behulp van ultrageluid. [The diagnosis of obliterative arteriosclerotic disease of the legs by ultrasonic determination of blood pressures] (Englisli summary). Ned Tijdschr Geneeskd 1976; 120: 733-41.

34 Smith RC, Ferrington C, Ruckley CV. Calf muscle technetim clearance and Doppler ankle pressure in patients with intermittent claudication. VASA 1977; 6: 23643.

35 Stoffers HEJH, Kaiser V. Het gebruik van het pocket-Doppler-apparat bij perifere arterièle vaataandoeningen. Een literaturanderzoek. [The use of the pocker Doppler device in peripheral arterial occlusive disease. A licerature review] (English summary). Huisarts Wer 1994; $37: 333-8$.

36 Ögren M. Hedblad B, Jungquist $G$, Isacsson SO, Lindell SE, Janzon L. Low ankle-brachial. pressure index in 68-year-old men: prevalence, risk factors and prognosis. Eur J Vasc Surg $1993 ; 7: 500-6$.

37 Vogt MT, Cauley JA, Kuller LH, Hulley SB. Prevalence and correlates of lower extremity arterial disease in elderly women. Am J Epidemiol 1993; 137: 559-68.

38. Ouriël KO, McDonnel AE, Metz CE, Zarins CK. A critical evaluation of stress testing in the diagnosis of peripheral vascular disease. Surgery 1982; $91: 686-93$.

39 Bernstein EF, Fronek A. Current status of noninvasive tests in the diagnosis of peripheral arterial disease. Surg Clin North America 1982; 62: 473-487.

40 Fowkes FGR. The measurement of atherosclerotic peripheral arterial disease in epidemiological surveys. Int J Epidemiol 1988; 17: 248-54.

41 Fowkes FGR, Housley E, Macintyre CCA, Prescott RJ, Ruckley CV. Reproducibility of reactive hyperaemia test in the measurement of peripheral arterial disease. Br J Surg 1988; 75: $743-6$.

42 Leng GC, Fowkes FGR, Donnan PT, Housley E. Reactive hyperemia test in a random sample of the general population. J Vasc Surg 1993; 17: 479-86.

43 Novo 5 , Avellone $G$, Garbo V di, Abrignani MG, Liquori M, Panno AV. Strano A. Prevalence of risk factors in patients with peripheral arterial discase. A clinical and epidemiological. evaluation. Int Angiol 1992; 11: 218-29.

44 Puilia $A$, Gnasso $A$, Mancuso $G$ et al. Arteriopatia asintomatica degli arti inferiori. Prevalenza e fattori di rischio in una populazione de] Sud Italia. [Asymptomatic peripheral vascular disease. Prevalence and risk Gactors in a free-living population of southern laly] (English summary). Minerna Cardioangiol 1993; 41: $133-8$.

45 Dormandy J, Mahir M, Ascady $G$ et al. Fate of the patient with chronic leg ischaemia. I Cardiovasc Surg 1989; 30: 50-7. 


\section{Chapter 10 Predictive value of signs and symptoms for the diagnosis of peripheral arterial occlusive disease in general practice. A multivariable approach.}

Summary To the general practitioner medical bistory and physical examination are the major tools for suspecting and establishing the diagnosis peripheral arterial occlusive disease ( $P A O D)$. We compared clinical data on PAOD - collected in 18 general prac. tice centres (1340 women, 1115 men, age $40.7-78.4$ years) - to the outcome of the measurement of the ankle-brachial systolic pressure ratio (AB-ratio). $P A O D$ was con. sidered to be present if the $A B$-ratio was below 0.95 on two consecutive occasions $111.5 \%$ of all legs). Data were analyzed using multiple logistic regression analysis.

Three classic features of PAOD appeared to be the most informative diagnostic tests: questioning the patient for intermittent claudication (bivariate diagnostic odds ratio (OR) 5.5, sensitivicy $28 \%$, specificity 93\%), palpation of both foot pulses (OR 22.7, sensitivity $66 \%$, specificity $80.92 \%$, best single diagnostic procedure) and auscultation of the femoral artery (OR 7.7 , sensitivity $27 \%$, specificity 95\%). The multivariable ORs were $3.3,12.8$ and 4.1 respectively.

Data like gender $(O R$ 1.3), age above $60(O R$ 2.2), unilateral lower skin temperature (OR 2.1), bigh blood presstire (OR 1.5), a bistory of smoking (OR 2.2) or the presence of coronary artery disease (OR 1.8) can also significantly contribute to the probability of $P A O D$. This is particularly relevant in cases that do not represent the classic clinical picture.

Key words peripheral arterial occlusive disease, diagnosis, noninvasive, general practice, clinical epidemiology

\section{Introduction}

Peripheral arterial occlusive disease (PAOD) is the manifestation of atherosclerosis distal to the artic bifurcation. PAOD usually has a relatively benign course ${ }^{\prime}$ and conservative therapy of intermittent claudication has proven to be effective. ${ }^{2.3}$ In addition, recognising and treating intermittent claudication will reduce cardiovascular risk in general and contribute to the prevention of coronary artery and cerebral artery disease (COAD and CeAD). Referral to a vascular specialist can be restricted to progressive cases. ${ }^{4.5}$ However, a progressive course cannot be predicted in individual patients at the time of diagnosis. Therefore regular follow up is neces-

Henri EJH Stoffers, Victor Kaisera" Paula ELM Rinkens", Arnold DM Kester ${ }^{\text {b }}$, A André Knotuerus. Universiry of Limburg, Mastricht, The Netherlands: Department of Generall Pracrice", Department of Methodology and Statistics "Submitted for publication. 
sary, especially in the first year after diagnosis. ${ }^{6,7}$

As a consequence, PAOD is relevant to the general practitioner. The role of the general practitioner can be summarized as follows: dragnose adequately, inform the patient properly, start conservative treatment, monitor cardiovascular risk in general, follow up the course of disease, and select efficiently for referral. ${ }^{4,5}$

Adequate diagnostic management of PAOD presupposes that the doctor knows the significance of available diagnostic procedures. To the general practitioner medical history and physical examination are the major tools for suspecting and establishing the diagnosis of PAOD. The question is: how good are these tools? Some research has been done on the diagnostic vallue of signs and symptoms in PAOD. ${ }^{8: 13}$ It appears that the negative predictive value $(\mathrm{PV}-)$ of a history of intermittent claudication, absent peripheral pulses or a femoral bruit is high. ${ }^{{ }} 11,13$ However, the positive predictive value $(\mathrm{PV}+)$ of each of these diagnostic procedures is rather low. ${ }^{11,13}$ There are few data available on the value of combinations of signs and symptoms. ${ }^{9,11,13}$

The first objective of the present study was to assess the diagnostic value (sensitivity, specificity, diagnostic odds ratio, predictive values) of single as well as combined data from history, physical examination and patient record (signs, symptoms and vascular risk factors) with regard to PAOD. A second objective was to construct an effective and efficient diagnostic model for the general practitioner.

\section{Methods}

\section{General design}

The 'Limburg PAOD Study' is a research project conducted by the University of Limburg in Maastricht (the Netherlands) and 22 general practice centres (GPCs) in the region. This project consists of three interrelated studies: a prevalence study, a diagnostic study and an intervention study (on aspirin). ${ }^{14,15}$ The results of the diagnostic study are presented here. Its design is cross-sectional: signs, symptoms and data from the patient record are compared to the outcome of the measurement of the resting ankle-brachial systolic pressure ratio (AB-ratio).

\section{Selection of the study population}

Cooperation of GPCs was obtained by means of a lecture and through personal contacts. Eighteen GPCs (31 general practitioners (GPs), 27 practice assistants) decided to take part in the present study.

It is important to realize that in the Netherlands everyone is registered in a general practice. Therefore, the registered population of a general practice is a segment of the general population. "The population to be examined by the GP had to approach the 'indicated population', which comprises those patients for whom the GP would feel the need to take a history and perform a physical examination, to rule in or out the diagnosis PAOD. In table 10.1 is described how the patients for this study were selected. From the registered population patients were selected who were over 40 years of age, who had stated they had "pain on walking" in a postal questionnaire and who belonged to the "increased risk" or "high risk" group (table 10. .). Thus, the study population represented a wide spectrum of signs, symptoms and vascular risk. ${ }^{16}$ 
Table 10.1 The selection process

Population

Number

Sounce population

all patients on the list of 18 GPCs, aged $40-75$

$n=26620$

years received a postal questionnaire with 5 Yes/No questions (pain on walking, smoking $\geq 15$ cigarettes, high blood pressure, diabetes, heart disease or TIA/ stroke) resulting in a score from $0-5$

Responders response rate $86.4 \%$ $n=23004$

Exclusion subjects with no "pain on walling' $(n=15342)$

Invited population selected by a sampling and selection procedure among $n=3525$ patients with "pain on walking' $(n=7662)$ "

Study population participation rate $69.6 \%$

$n=2455$

a random sample was taken from all patients with a score from 1-5 (increased risk); subseguently in each practice remaining patients with the highest scores were selected: all patients with score 5,4 or 3 and part of the patients with score 2 ("high rish" ${ }^{3}$ ). This selection procedure was part of the selection process for the Limburg PAOD Study as a whole. Methodological criteria set by the prevalence study and the intervention study had to be taken into account as well.

\section{Data collection}

Before visiting their GP's office, each participant filled in an extensive questionnalre addressing symptoms of PAOD, smoking habits and physical exercise. 'The questionnaire incorporated the WHO/Rosequestionnaire on intermittent claudication," and was differentiated towards specific sensations and sites of leg complaints.

When the patient visited the GP's office, a practice assistant recorded height, weight and blood pressure. The GP read the questionnaire and performed a physical examination: inspection of both legs, palpation of the skin and posterior tibial and dorsalis pedis arteries (ATP, ADP), palpation and auscultation of the femoral arteries. He copied various data from the patient record to the registration form: the presence of CoAD, CeAD, hypertension, hypercholesterolamia, diabetes mellitus and overweight.

Without knowing the results of the examination by the $G \mathbb{P}$, the practice assistant (or colleague GP) assessed the ABuratio of both legs using a pocket Doppler device (Hunteigh Mini Dopplex D500, $8 \mathrm{MHz}$ ) and a mercury sphygmomanometer. ${ }^{4,8}$ Systolic pressures were recorded on both arms and legs with the patient lying in supine position in a properly heated examination room. In three solo practices independent assessment of clinical and Doppler data was not feasible and the GP himselt performed the pocket Doppler measurement after the physical examination. The $A B$-1tio was defined as the ankle pressure divided by the highest arm pressure. If the $A B$-ratio of at least one leg was less than 0.95 , the patient was requested to return for a second measurement one week later. All sphygmomanometers were calibrated before the start of the study. The GPS and practice assistants had been trained in performing AB-ratio measurements and reproducibility proved to be satisfactory. 


\section{Definitions.}

IC was defined as pain or cramps in the calf on walking, disappearing when standing still and not present at rest (typical $\llbracket \mathrm{C}$ ). ${ }^{17}$ Also other complaints of the calf showing this ischemic pattern as well as complaints of foot, thigh or buttock showing this ischemic pattern were included in the definition of IC (atypical IC). 'The categories of other signs and symptoms are listed in the tables 10.2 and 10.3 .

PAOD was considered to be present in a leg, if the AB-ratio was below 0.95 on two consecutive occasions. This cutoff value chosen as a balance between the 'specific' cutoff value of 0.90 (sensitivity $75-100 \%$, specificity $80-100 \%$ ) and the 'sensitive' cutoff value of 1.0 (sensitivity $88-100 \%$, specificity $60-81 \%$ ) as reported in studies on the validity of the Doppler-method.2.24

\section{Binariate analysis}

All analyses were done using BMDP statistical software..$^{25}$ Bivariate analyses were done to assess the association (diagnostic odds ratio, OR) of each sign or symptom (predictor variable) with the dichotomized outcome of the measurement of the ABratio (outcome variable). Significance testing was done using the chi-square test for association.

Variables with a p-value lower than 0.15 (statistical criterion) ${ }^{26}$ and an $\mathrm{OR} \geq 1.5$ or $<0.6\rangle$ (clinical criterion) for left and right legs simultaneously, were entered in the next stage of the analysis. For these selected variables sensitivity, specificity, predictive values and odds ratios were calculated. ${ }^{16}$ Since observations of both legs of the same patient cannot be considered to be independent, confidence intervals $(95 \%)$ of the diagnostic parameters were calculated for left and right legs separately and then averaged.

\section{Multiple logistic regression: selection within clinical clusters}

To create a reduced set of candidate variables for the final multiple logistic regression analysis, all selected variables were grouped into six clusters of clinically associated variables: 'age \& gender', 'potential symptoms of PAOD', 'inspection and palpation of the skin", 'peripheral pulses', 'risk factors in parient record', 'risk factors in history and physical examination'. Within each of these clusters a logistic regression analysis (stepwise backward) was done. Variables with a p-value lower than 0.05 and an $O R \geq 1.5$ or $<0.67$ for left and right legs simultaneously, were considered candidate variables for the final logistic regression models.

\section{Multiple logistic regression: final analysis}

In order to approach the clinical diagnostic process, the selected variables were regrouped into four subgroups: (1) 'age \& gender', (2) 'symptoms of PAOD', (3) "physical examination', (4) "risk factors". Successively four stepwise backward logistic regression analyses were done, starting with subgroup (1), followed by subgroups (1) and (2), then subgroups (1) to (3) and finally subgroups (1) to (4) together. Thus, four successive reduced models were constructed for both legs apart. After the models of the main effects had been constructed, several potentially relevant first order interaction-terms (e.g. with age and gender) were included in the four models. ${ }^{26}$ For males the effect of the variable 'erection problems' was tested as 
Table 10.2 Diagnostic value of single signs \&e symptoms. Results of the bivariate analysis $(n=2 \times 2455=4910$ legs; prevalence AB-ratio < $0.95: 11.5 \%$ of all legs - cont on next page -

Variable

Categories

$N_{\text {and all }} \quad N_{\text {cat mpos }}$

Neg,Pos

Gender

Female, Male

4871

2202

Age group

40-60,60-80

4868

2336

COAD (patient record)

No,Yes

4855

1137

GeAD (patient record)

$\mathrm{No}_{0}$ Yes

4855

238

Hypercholesterolemia (patient record)

No, Yes

4817

577

Diabetes mellitus (patient record)

No, Yes

4859

495

Intermittent Claudication

Snoking (history)

Physical exercise work (history)

No, Yes ${ }^{3}$

4826

453

No/stop > 5yrs, Yes/stop < 5yrs $4811 \quad 2851$

Physical exercise leisure time (history)

Not little, Little

4655

2829

Not little, Little

4794

No, Yes

4855

1866

Wounds or sores toes/foot

Colour foot $/ \mathrm{leg}$

Unilateral lower skin temperature

Normal,Abnormale

4843

No, Yes

4670

Strong, Absent

Strong, Weak

4188

Normal,Abnormal ${ }^{d}$

4778

Normal,Doubt ${ }^{\text {\# }}$

3840

658

ATP \& ADP pulse 1

No, Yes

4356

491

Femoral artery bruit

Queteler Index (phys. exam.)

$\leq 30,>30$

4853

1007

Normal,Highe

4843

: 'Yes'= typical +atypical IC

" $42 \%$ if a patient meets the criteria for "typical" IC

c Abnormall: pale, red or blue;

well. None of these terms contributed statistically or clinically to the models.

In three solo practices independent assessment of clinical and Doppler data was not feasible ( $14 \%$ of all data records). It was tested whether the variable independent assessment of clinical and Doppler data' had a significant and relevant effect on the models. This proved not to be the case. Since precision would increase using a larger number of observations, we did not restrict the analysis to the 'independent' data records only.

$U_{p}$ till then all analyses were done for left and right legs separately but decisions to include or exclude a variable were taken simultaneously for corresponding left and right variables. Inclusion in the four final models for both legs combined, was based on statistical significance $(\mathrm{p}<0.05)$ and clinical relevance $(\mathrm{OR} \geq 1.5$ or $<$ 0.67 ) for left and right legs simultaneously. Confidence intervals $(95 \%)$ of odds ratios were calculated for left and right legs separately and then averaged.

The four final models were compared using the likelihood ratio test. ${ }^{26}$ To visualize the diagnostic performance of each model, receiver operating characteristics (ROC) curves were constructed and the area under the curve (AUC) was estimated. ${ }^{27.28}$ For the most comprehensive model predicted probabilities were calculated (appendix chapter 10) and compared to the observed probability of PAOD. The overall fit of this model to the data was assessed by the Hosmer-Lemeshow 
shown are the wariables that met all analytic criteria)

\begin{tabular}{|c|c|c|c|c|c|c|}
\hline Diagn & $\begin{array}{l}\text { ostic O } \\
195 \% \text { o }\end{array}$ & $\begin{array}{l}\text { Ddds Ratio } \\
\text { c) }\end{array}$ & $\begin{array}{l}\text { Sents. } \\
\%\end{array}$ & $\begin{array}{l}\text { Spec. } \\
\%\end{array}$ & $\begin{array}{l}\mathrm{PV}+ \\
\%\end{array}$ & $\begin{array}{l}\mathrm{PV}- \\
\%\end{array}$ \\
\hline 1.7 & $(1.3$ & -2.2 ) & 57 & 56 & 14 & 91 \\
\hline 3.6 & $(2.7$ & $-4.7)$ & 74 & 55 & 18 & 94 \\
\hline 3.2 & $(2.4$ & $-4.1)$ & 45 & 79 & 22 & 92 \\
\hline 3.4 & 2.2 & $-5.2)$ & 12 & 96 & 29 & 90 \\
\hline 1.7 & $(1.2$ & -2.4 & 18 & 89 & 17 & 90 \\
\hline 2.4 & $(1.7$ & $-3.3)$ & 19 & 91 & 21 & 90 \\
\hline 5.0 & $(3.7-$ & $-6.8)$ & 28 & 93 & $34^{b}$ & 91 \\
\hline 1.8 & $(1.4$ & $-2.4 j$ & 71 & 42 & 14 & 92 \\
\hline 2.0 & $(1.5$ & $-27\}$ & 74 & 41 & 14 & 93. \\
\hline 1.6 & $(1.2)$ & $-2.0\}$ & 49 & 62 & 14 & 90 \\
\hline 6.7 & $(2.2$ & $-21.7)$ & 2 & 99.7 & 46 & 89 \\
\hline 3.3 & 2.5 & $-4.4 j$ & 32 & 88 & 25 & 91 \\
\hline 5.3 & $(3.2)$ & $-9.7 j$ & 8 & 98 & 38 & 90 \\
\hline 6.2 & $(3.1$ ) & $-12.8)$ & 7 & 99 & 37 & 91 \\
\hline 3.8 & $(2.9 \mathrm{w}$ & (ones) & 33 & 89 & 27 & 91 \\
\hline 22.6 & $(15.8$ & $-32.7)$ & 66 & 92 & 45 & 97 \\
\hline 7.9 & $(5.6)$ & $-11.1)$ & 66 & 80 & 22 & 97 \\
\hline 7.7 & $(5.5)$ & $-10.8 j$ & 27 & 95 & 43 & 91 \\
\hline 0.6 & $(0.42-$ & $-0.86)$ & 14 & 79 & 8 & 88 \\
\hline 1.8 & $(1.4$ & $-2.3)$ & 51 & 63 & 15 & 91 \\
\hline
\end{tabular}

Normal combinations: strong/strong or strong/weak; Abnormal combinations: ab sent/absent or absent/weak; Doubtful combinations: weak/weak or strong/absent High: systolic pressure $>160 \mathrm{mmHg}$ or diastolic pressure $\geq 95 \mathrm{mmHg}$.

goodness-of-fit test. ${ }^{25,26}$

Results

The study population consisted of 1340 women and 1115 men with a mean age of 59.3 years (range: 40.7-78.4). The mean (lowest) ABuratio was 1.09 ( $\mathrm{SD} 0.17$, range 0.20-2.31). Relatively mild disease predominated: only $0.6 \%$ of all legs had an $A B-$ ratio $<0.50,11.5 \%$ had an $\mathrm{AB}$-ratio $<0.95$.

Table 10.2 shows the results of the bivariate analysis for those predictor variables that fulfilled our criteria for clinical relevance and statistical significance. Overall, the diagnostic procedures with the highest individual diagnostic value (OR) are: palpation of both foot arteries, auscultation of the femoral artery, inspection for wounds or sores on toes and foot, palpation of the femoral artery, comparing the temperature of the skin of both feet, and asking whether or not IC is present. These variables also have a high specificity. Other variables with a high specificity are: a history of CeAD, diabetes or hypercholesterolaemia. An abnormal colour of the skin of the foot is a rather specific sign as well. In general, sensitivity is low but findings with a relatively high sensitivity for PAOD are: a history of little physical 
Table 10.3 Variables excluded during the andysis process

\begin{tabular}{|c|c|}
\hline Variable & $\begin{array}{l}\text { Category: } \\
\text { Neg,Pos }\end{array}$ \\
\hline \multicolumn{2}{|l|}{ Excladed dering the bivariate andysis: } \\
\hline $\begin{array}{l}\text { Various symptoms white walking, differentiated } \\
\text { towards "site" and sensation" }\end{array}$ & No,Yes \\
\hline Various symptoms while resting & No,Yes \\
\hline Complaints of cold feet, unilateral & No, Yes \\
\hline Complaints of cold feet, recent onset & No, Yes \\
\hline Complaints of cold feet, on exercise & No, Yes \\
\hline COAD or CeAD in the family (history) & No, Yes \\
\hline Amount of walking during work (history) & Not little Little \\
\hline Unilateral loss of hair foot/leg & No, Yes \\
\hline Ulcer ankle & Medial/No,Lateral \\
\hline Hypertension (patient record) & No, Yes \\
\hline Overweight (patient record) & No, Yes \\
\hline
\end{tabular}

Excluded during LR wibin clinical clusters:

Physical exercise during leisure time (history)

Not litrle, Little 1

Wounds or sores toes/foot:

Femonal artery pulse 1

No, Yes 2

2

Strong, Absent 3

Strong, Weak 3

Hypercholesterolaemia (patient record)

No, Yes

Excluded during the final LR:

Physical exercise during work (history)

Not little, Little 1

Colour of foot/leg

Quetelet Index (physical examination)

Normal, Abnormal 1

CeAD (patient recond)

Diabetes mellitus (patient record)

$\leq 30,>30$

No, Yes 1

No, Yes 1

Not included after main effects bad been established:

Euction problems (males) (history)

No, Yes 1

Interactions with 'Age group' various 1

Interactions with "Gender" various 1

1: not meeting analytical criteria 2: large confidence interyal for each leg apart 3: variables in the cluster 'peripheral pulses' were highly correlated with one another (collinearity)

4: variables that survived the bivariate analysis were replaced by the compound variable "incemittent claudication", which had the advantage of being easier to interpret clinically

exercise during working activities, being older than 60 years, a history of (recent) smoking, or diminished loot pulses on palpation. $\mathrm{PV}+$ of most variables is also 
fairly low, the best predictors of PAOD being the presence of distal wounds or sores, abnormal foot pulses, the presence of a femoral brut, or suffering from typical IC. The best single predictor of absence of PAOD (high $\mathbb{P V}-$ ) is a strong pulse of both foot arteries.

Table 10.3 lists the variables that were excluded during the analytical process and provides the reasons for exclusion. Table 10.4 presents the four final reduced logistic regression models and figure 10.1 shows the corresponding ROC curyes. Each model performs significantly better than the previous one according to the likelihood ratio test. The corresponding AUC show the same pattern.

Using the multivariable models, the predicted probability of $\mathrm{PAOD}$ for an individual patient can be estimated (appendix chapter 10).26 E.g. using the most comprehensive model, a 62 year old woman with IC, abnormal pedal pulses, and all other 'tests' negative has a probability of $37 \%$ to have PAOD in this leg; a 75 year old man with IC, abnormal pedal pulses and a femoral bruit, who smokes, but with a negative outcome of the other 'tests', has a probability of $87 \%$ to have PAOD in this leg. Similar calculations can be made using the less differentiated models (appendix chapter 10).

The differential diagnostic abilities of the various models can be shown by calculating the minimum and maximum predicted probabilities of each model. In the study population the prior probability of having PAOD is $11 \%$. If age and gender are known (model 1) the predicted - posterior - probability ranges from 3 to $22 \%$. If the general practitioner also knows whether or not $\mathrm{IC}$ is present (model 2), this range increases to $3-48 \%$. After the physical examination (model 3) the range of predicted posterior probabilities is enlarged to $1-96 \%$. Model 4 , though statistically significantly better than model 3 , yields a range of predicted probabilities that is only slightly larger $(0.6-97 \%)$.

In order to see whether the predicted probability of PAOD of the most comprehensive model agreed with the observed probability, the predicted probability was divided in categories of $10 \%$ and the observed probability (prevalence) of PAOD was assessed for each category of predicted probability. Table 10.5 shows that the observed probability of PAOD agreed well with the predicted probability in all but two categories. Likewise, the Hosmer-Lemeshow goodnessof-fit test indicated a reasonable overall fit of this model $(p=0.26)$.

\section{Discussion}

The results of our bivariate analysis of signs and symptoms traditionally associated with PAOD, show that some of these variables are of no diagnostic relevance, that other variables can have a limited diagnostic function and that some signs, symptoms and vascular risk factors indeed can be used as a diagnostic test. Using a multivariable model that combines the outcome of various relevant diagnostic variables, the general practitioner can estimate the predicted probability of PAOD for an individual patient. The result of this differential diagnostic procedure enables him to evaluate the need for further diagnostic or therapeutic accion.

The GPCs where the data for this study were collected were not a random sample of the GPCs in the region around Mastricht. 'The participants' main motives for cooperation will have been interest in the subject of the study, in (the prevention of) cardiovascular disease and in doing research in general. 'This will have contribu- 
Table 10.4 Diagnostic walue of signs and symptoms in the four final reduced logistic models $\left(N_{L}=4310\right.$ legs, prevalence of AB-ratio $<0.95=10.7 \%$ of all legs)

Model $\rightarrow$

Log likelihood

Constant

\begin{tabular}{|c|c|c|c|}
\hline $\begin{array}{c}\text { Variables } \\
\downarrow\end{array}$ & $\begin{array}{l}\text { Categories } \\
\text { (Neg }{ }_{3} \text { Pos) }\end{array}$ & $N_{\text {call } m \text { poss }}$ & OR $(95 \% \mathrm{ci})$ \\
\hline Gender & Female, Male & 1947 & $1.9(1.4-2.5)$ \\
\hline Age group & $40-60,60-80$ & 2018 & $3.7(2.7 .5 .1)$ \\
\hline Intermittent claudication & No, Yes ${ }^{3}$ & 397 & \\
\hline Lower skin temperature Left/Right & No,Yes & 107 & \\
\hline \multirow[t]{2}{*}{ ATP \& ADP pulse } & Normal,Abnorm," & 424 & \\
\hline & Normal,Doubt ${ }^{b}$ & 879 & \\
\hline Femoral artery bruit & No,Yes & 296 & \\
\hline CoAD (patient record) & No,Yes & 957 & \\
\hline Smoking (history) & $\mathrm{No}, \mathrm{Yes}^{c}$ & 2557 & \\
\hline Blood pressure (physical examination) & Normal, $\mathrm{High}^{\mathrm{d}}$ & 1635 & \\
\hline
\end{tabular}

1: Age E Gender

$-1369.6$

$-3.23$

" 'Yes' = typical +atypical IC

1. Mormal combinations: strong/strong or strong/weak; Abnormal combinations: absent/absent or absent/weak; Doubtful combinations; weak/weak or strong/absent

ted positively to the quality of the data collection, which was performed according to a detailed protocol. A relationship between the selection of the GPs and the clinical characteristics of their registered population cannot be assumed. Therefore, it seems unlikelly that a 'GP-selection bias' has occurred.

We aimed at creating a study population that would represent a wide spectrum of signs, symptoms and wascular risk. ${ }^{86}$ If selecting the patients for this study would have been the GP's responsibility, this might have resulted in an over-representation of symptomatic and typical PAOD patients. Furthermore, data collection or even parient selecrion during consulting hours would not have been appreciated by the GPs and would have led to a slower process of data collection and a smaller number of patients.

In this study the diagnostic criterion for the presence of PAOD was a value for the pocket-Doppler $A B$-ratio lower than 0.95 , measured on two consecutive occasions. In other studies where traditional clinical evaluation of PAOD had been compared to the results of noninvasive testing, cutoff values for the resting $A B$-ratio were chosen between 0.80 and $0.95 .^{8 \cdot 12}$ In a recent population study an $A B$-ratio lower than 0.94 was defined as abnormal. ${ }^{13}$ In recent surveys on the prevalence of PAOD cutoff values for the AB-ratio were chosen in the range between 0.75 and $0.97 .{ }^{29.34}$ Using a cutoff value for the AB-ratio lower than 0.95 , would imply that 


\begin{tabular}{|c|c|c|c|c|}
\hline $2:(1)+$ History & 3: (2)+Pbysical Exam & \multicolumn{3}{|c|}{$4:(3)+$ Risk Factors } \\
\hline $\begin{array}{l}-1310.6 \\
-3.46\end{array}$ & $\begin{array}{l}-1030.5 \\
-4.42\end{array}$ & \multicolumn{3}{|l|}{-1002.4} \\
\hline OR $(95 \% \mathrm{ci})$ & $\operatorname{OR}(95 \% \mathrm{cl})$ & OR $(95 \% \mathrm{ci})$ & \multicolumn{2}{|c|}{$\begin{array}{l}\text { logistic } \\
\text { coefficient }\end{array}$} \\
\hline $1.7(1.3-2.3)$ & $1.7(1.3-2.4)$ & $1.3(0.9-1.8)$ & 7 & 0.25 \\
\hline $3.5(2.64 .8)$ & $2.2(1.6-3.1)$ & $2.2(1.5-3.2)$ & $y$ & 0.78 \\
\hline \multirow[t]{8}{*}{$4.3(3.1-6.2)$} & $3.5(2.3-5.4)$ & $3.3 \quad(2.2-5.1)$ & $\not$ & 1.18 \\
\hline & $2.1(1.1-4.2)$ & $2.1 \quad(1.0-4.1)$ & $t$ & 0.72 \\
\hline & $14.0(9.1-21.7)$ & $12.8 \quad(8.4-20.2)$ & $y$ & 2.55 \\
\hline & $7.0 \quad(4.8-10.2)$ & $6.6(4.5-9.8)$ & $y$ & 1.89 \\
\hline & $4.6 \quad(2.9-7.2)$ & $4.1 \quad(2.6-6.4)$ & 1 & 1.40 \\
\hline & & $1.8(1.2-2.5)$ & $f$ & 0.56 \\
\hline & & $2.2(1.5-3.3)$ & $t$ & 0.80 \\
\hline & & $1.5(1.1-2.2)$ & $f$ & 0.42 \\
\hline
\end{tabular}

No: never smoked or stopped for longer than 5 yis; Yes: currently smoking or stopped for shorter than 5 yrs

High: systolic pressure $>160 \mathrm{mmHg}$ or diastolic pressure $\geq 95 \mathrm{mmHg}$

the multivariable models would predict a more advanced stage of PAOD. In primary care it is important to diagnose also less advanced stages of PAOD. Therefore the cutoff value of the AB-ratio should not be chosen too low.

The reactive hyperaemia test was not applied, since its disadvantages make this test less feasible for use in general practice: one session takes about 30-45 minutes and is often painful for the patient. Furthermore, the reproducibility of the reactive hyperaemia test is less than the reproducibility of the measurement of the resting AB-ratio. ${ }^{13,33-40}$

Although our multiple logistic regression models can easily be written into a spreadsheet programme on a personal computer, the resulting estimates of predicted probabilities in individual patients should not be used in an absolute way. The population of an individual general practitioner may be similar to, but will not be the same as our study population. Methodological choices we made with regard to the cutoff value for the AB-ratio and the selection of variables for the multiple logistic regression analyses, influence the absolute and relative magnitude of the coefficients in the models. Furthermore, although table 10.5 shows there is good agreement between observed and predicted probabilities of PAOD, our model is not yet 'validated' in a new population and thus may tend to perform in an optimistic way. The variables that finally were included in the logistic regression models 
Figure 10.1 ROC Curves of the four final reduced logistic models $\left(N_{L R}=4310\right.$ legs)

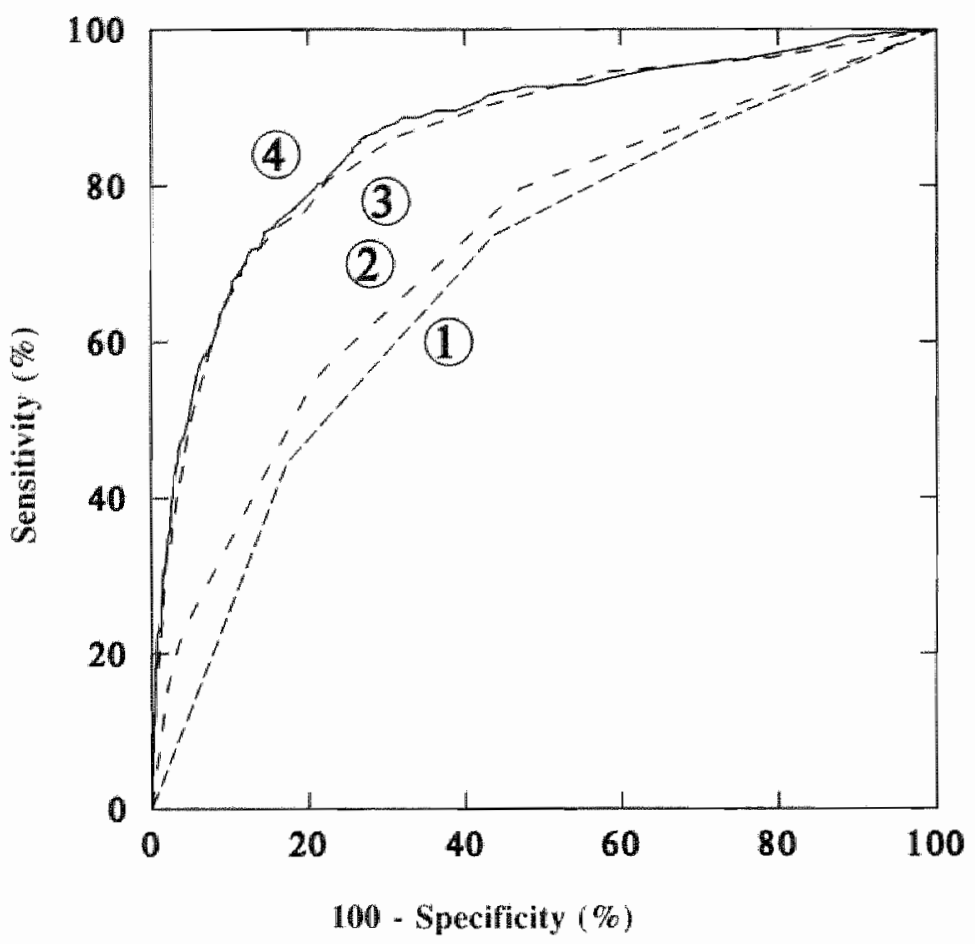

Model 1.: Age \& gender

$A U C=0.686$

Mode 2. (1) + History

$A U C=0.723$

Model 3: (2) + Physical examination

$A \cup C=0.861$

Model 4: (3) + Risk factors

$A \cup C=0.868$

Table 10.5 Observed probability in categories of predicted probability of the most comprehensive logistic model (model 4)

\begin{tabular}{cc} 
Categories of Predicted Probability of PAOD & Observed Probability (\%) \\
\hline $0 \leq 10 \%$ & 3.0 \\
$10 \leq 20 \%$ & 12.6 \\
$20 \leq 30 \%$ & 24.6 \\
$30 \leq 40 \%$ & 34.1 \\
$40 \leq 50 \%$ & 52.0 \\
$50 \leq 60 \%$ & 57.1 \\
$60 \leq 70 \%$ & 60.3 \\
$70 \leq 80 \%$ & 73.5 \\
$80 \leq 90 \%$ & 81.6 \\
$90 \leq 100 \%$ & 88.2
\end{tabular}


were selected both on clinical relevance and statistical significance and the presence or absence of these variables will contribute to differential diagnosis in an individual patient.

"The results of our bivariate analyses show that some signs and symptoms traditionally associated with PAOD do not have a statistically significant diagnostic relevance, e.g. complaints of cold feet, unilateral loss of hair on foot or leg, a lateral ankle ulcer (table 10.3). Some procedures are relevant when used as a single test but their diagnostic value is reduced when used in combination with other, more powerful diagnostic procedures. E.g. inspection for sores or wounds, and palpation of the femoral artery. This is partly due to the low prevalence of an abnormal (positive) test result of these features. Other diagnostic procedures are characterized by either a relatively high sensitivity (age, history of smoking, history of physical exercise during working activities) or a relatively high specificity (inspection of the feet for wounds or sores, palpation of the femoral artery pulse, palpation of the temperature of the skin; table 10.2).

Few studies have been done where traditional clinical evaluation of PAOD was compared to the results of noninvasive testing. ${ }^{8.13}$ Only the results of studies in which the study population was not highly selected can be indicative for general practice. ${ }^{9,11,13}$ In these studies the sensitivity of typical $\mathrm{IC}^{17}$ varies between 9 and $19 \%$ and specificity is reported to be $99 \%{ }^{9,11}$ If 'possible' or 'probable' IC is accounted for as well - comparable to our definition of IC - sensitivity varies from 8 to $20 \%$ and specificity is $96 \% .^{11,13}$ Our results were higher for sensitivity $(28 \%)$ and lower for specificity $(93 \%)$.

In stead of the compound variable IC, we initially analyzed the diagnostic value of various leg complaints appearing on walking, differentiated towards specific site and sensation. Thus we hoped to identify a cluster of leg complaints with a higher sensitivity than positive 'Rose-claudication'." However, in accordance with the results of the Edinburgh Artery Study, a differentiated description of the pain or discomfort in the leg did not have diagnostic relevance. ${ }^{41}$

The results of Criqui et al. for the presence of a femoral bruit (sensitivity 20\%, specificity $96 \%$ ) were similar to our findings ( $27 \%$ and $95 \%$ respectively).

Our results for sensitivity and specificity of absent or diminished foot pulses (sensitivity $66 \%$, specificity $80-92 \%$ ) were in the range of values found by orher authors (sensitivity 5-71\%, specificity 73-97\%). ${ }^{9 ! 11,13}$ In each of the studies mentioned here, the sum of sensitivity and specificity of the palpation of the foot pulses was higher than that of the other clinical diagnostic procedures, making it the best single clinical diagnostic procedure.2 We can confirm that palpation of both pedal pulses is the best single diagnostic procedure: specificity and PV- are high and sensitivity and $\mathrm{PV}+$ are relatively high.

The results of the bivariate and multivariable analyses in this study (tables 2 and 4) show that in particular palpation of the foot anteries, auscultation of the femoral artery and questioning the patien for IC are the signs and symptoms that can be used as diagnostic tests. Our most comprehensive regression model reveais that apart from these classic clinical diagnostic procedures, data on gender, age (above 60), unilateral lower skin temperature, high blood pressure, a history of (recent) smoking and the presence of COAD can increase or decrease the probability of PAOD being present (abble 10.4). This information will be particularly relevant in cases that do not represent the classic clinical picture of IC with absent foot pulses 
and a femoral bruit. E.g. in our population (prior probability of PAOD: 11\%) it 56 year old man with intermittent claudication but doubtful pedal pulses has a predicted probability of PAOD of only $15 \%$ if all other 'tests' of model 4 are negative, but the probability increases to $28 \%$ if he also smokes, to $37 \%$ if he smokes and his blood pressure is too high, and to $51 \%$ if he smokes, has a high blood pressure and suffers from coronary artery disease. For a woman of the same age these figures would be $12 \%, 23 \%, 32 \%$ and $45 \%$ respectively. These examples demonstrate that it is important for the general practitioner to know the cardiovascular risk profile of his patients.

The multivariable models support the intuitive estimate of the probability of $P A O D$ the general practitioner will have after each stage of his clinical evaluation of the patient. In many patients he will be able to rule out disease with a high degree of certainty (e.g. 60\% of all legs in our study population had a predicted probability of $\mathrm{PAOD}<0.05$ ). In a small group of patients he can reach a high degree of certainty that PAOD is present and he will feel confident to discuss conservative measures with the patient (e.g. 1.3\% of all legs in our study population had a predicted probability of PAOD $>0.8$ ). If the probability of $\mathrm{PAOD}$ is not low enough to exclude disease but not high enough to establish the diagnosis PAOD (e.g. in our study population $38 \%$ of all legs had a predicted probability of PAOD between 0.05 and 0.80 ), the general practitioner might consider noninvasive testing to resolve his diagnostic uncertainty. 4,5

In conclusion, it would be useful to realize an external validation of our models by testing their performance in a similar study population. Our current analysis indicates that traditional clinical evaluation enables the general practitioner to decide upon the need for further diagnostic or therapeutic action. The classic features of PAOD appear to be the most informative diagnostic tests: questioning the patient for IC, palpation of both foot pulses and auscultation of the femoral artery. But also various other data from history, physical examination and patient record can significantly influence the probability of PAOD being present. This information will be particularly relevant in cases that do not represent the classic clinical picture.

\section{Acknowledgements}

The Limburg PAOD Study was financed by the 'Netherlands Organization for Scientific Research' (900-715.154) and the 'Praeventiefonds' (28-1323). Pocket Doppler devices were donated by ASTA Medica B.V. We thank the participating general practitioners and their practice assistants for collecting the data for this study.

\section{References}

1. Dormandy J, Mahir $M$, Ascady $G$, et al. Fate of the patient with chronic leg ischaemia. I Cardiovase Surg 1989; 30: 50-7.

2 Blomberry PA. Intermittent claudication. An update on management. Drugs 1987; 34: 40410.

3 Radack $K$, Wyderski RJ. Conserwative management of intermittent claudication. Ann Int Med 1990; 113: 135-46. 
4 Bonsema $\mathrm{K}$, Boutens EJ, Kaiser V, Stoffers HEJH. Perifeer arterieel wathiden. Standaard M13 Nederlands Huisartsen Genootschap. Huisarts Wet 1990; 33: 440-6.

5 Bonsema $K$, Boutens EJ, Kaiser V, Stoffers HEJH. NHG-Standard Perifeer arterieel watlijden. In: Rutten GEHM, Thomas S (red). NHG-Standaarden voor de huisarts. Utrecht: Nederlands Huisartsen Genootschap/Bunge, 1993.

6 Jelnes $\mathbb{R}$, Gaardsting $O$, Hongaard Jensen $K$, et al. Fate in intermittent claudication: outcome and risk factors. Br Med J 1986; 293: 1137-40.

7 Naschitz JE, Ambrosio DA, Chang JB. Intermittent daudication: predictors and outcome. Angiology 1988; 39: 16-21.

8 Marinelli MR, Beach KW, Glass MJ, Primozich JF, Strandness DE. Noninvasive resting ws clinical evaluation of arterial disease. JAMA 1979; 241: 20.11-4.

9 Schroll M, Munck $O$. Estimation of peripheral arteriosclerotic disease by ankle blood pressure masurements in a population of 60 yearold men and women. Journal of Chronic Diseases $1981 ; 34: 261-9$.

10 Kälero KS, Ericsson BF, Bergentz SE. The diagnosis intermittent claudication. "The value of walking test, ankle pressure index and calf plethysmography in relation to the clinical findings. Acta Chir Scand 1983; 149: 377.82.

11 Criqui MH, Fronek $A, K$ lauber $M R$ et al. The sensitivity, specificity and predictive value of traditional clinical evaluation of peripheral arterial disease: results from non-invasive testing in a defined population. Circulation 1985; 71: 516-22.

12 Christensen JH, Freundlich M. Jacobsen BA, Falstie-Jensen $\mathbb{N}$. Clinical relevance of pedal pulse palpation in patients suspected of peripheral arterial insufficiency. I Internal Medicine 1989; 226: 95-9.

13 Hiat WR, Marshall JA, Baxter J, et al. Diagnostic mehods for peripheral arterial disease in the San Luis Valley diabetes study. J Clin Epidemiol 1990; 43: 597-606.

14 Stoffers HEJH, Kaiser V, Knotmerus JA. Prewalence in general practice. In: Fowkes FGR, ed. Epidemiology of peripheral vascular disease. London etc: Springer, 1991: 109-15.

15 Kaiser $\mathrm{V}$, Stoffers $\mathrm{HEJH}$, Knottnerus JA. Peripheral arterial occlusive disease in general pracrice: natural course and intervention (the Limburg PAOD Study, part II). CVD Newsletter 1991/1992; 47:48-9.

16 Sackett DL, Haynes RB, Tugwell P. Clinical epidemiology. A basic science for clinical medicine. Boston, Toronto: Little, Browm, 1985.

17 Rose GA, Blackburn H, Gillum RF, Prineas RJ. Cardiovascular survey methods. 2nd ed. Geneva: World Health Organization 1982: 162-5.

18 YaO JST. Noninwasive techniques of measuring lower limb arterial pressures. In: Bernstein EF, ed. Noninvasive diagnostic techniques in wascular disease. St. Louis etc: Mosby, 1985: $83-90$.

19 Stoffers HEJH, Kaiser V, Kester ADM, Schouten HJA, Knottnerus JA. Peripheral arterial ocdusive disease in general practice: the reproducibility of the anklearm systolic pressure ratio. Scand J Prim Healh Care 1991; 9: 109-14.

20 Thulesius $O$, Gjöres JA. Use of doppler shift detection for determining peripheral arterial blood pressure. Angiology 1971; 22: 594-603.

21 Chamberlain J, Housley E, MacPherson A.T. The relationship between ultrasound assesment and angiography in occlusive arterial disease of the lower limb. Br J Surg 1975; 62: 64-7.

22 Hylkema BS. Tussen polspalpatie en aortografie. [Between pulse-palpation and aortography] (English summary) [PhD Thesis]. Groningen: Rijksuniversiteit Groningen, 1975.

23 Hylkema BS. Diagnostiek wan arteriele circulatiestoonissen in de benen door bloeddrukmetingen met behulp van ultrageluid. [The diagnosis of obliterative arteriosclerotic disease of the legs by ultrasonic determination of blood pressures] (English summary). Ned Tijdschr Geneeskd 1976; 120: 733-41.

245 mith RC, Ferrington $\mathrm{C}$, Ruckley CV. Call muscle technetium clearance and Doppler ankle pressure in patients with intermitent claudication. VASA 1977; 6: 236-43. 
25 Dixon WI (ed), Brown MB, Engelman L, Hill MA, Jennrich RT. BMDP Statistical Software Manual Berkeley etc.: University of Califorma Press, 1990.

26 Hosmer DW, Lemeshow \$. Applied logistic regression. New York etc: Wiley, 1989.

27 Hanley JA, McNeil BJ. The meaning and use of the area under the Recener Operaning Characteristic (ROC) curve. Radiology 1982; 143:29-36.

28 Brummelkamp EP. Stratman H, Verbeek ALM. Roccurve. Nijmegen: Epidemiology unit, Dept. of Social Medicine, Catholic University Nijmegen, 1988.

29 Coni N, Tennison B, Troup M. Prevalence of lower extremity arterial disease among elderly people in the community. Br J Gen Pract 1992; 42: 1.49-52.

30 Newman $A B$, Sutron-Tyrel $K$, Rutan GH, Locher 】, Kuller LH. Lower extremity arteral disease in elderly subjects with systolic hypertension. J Olin Epidemiol 1991; 44: 15-20.

31 Bots ML, Swieten JC van, Breteler MMB et al. Cerebral white matter lesions and atherosclerosis in the Rotterdam Study. Lancet 1993; 341: 1232-7.

32 Vogt MT, Cauley JA, Kuller LH, Hulley SB. Prevalence and correlates of lower extremity arterial disease in elderly women. An J Epidemiol 1993; 137: 559-68.

33 Novo S, Avellone G, Garbo V di, Abrignani MG, Liquori M, Panno AV, Strano A. Prewalence of risk factors in patients with peripheral arterial disease. A clinical and epidemiological evaluation. Int Angiol 1992;11:218-29.

34 Postiglione $A$, Cicerano $U$, Gallotta $G$, Gnasso $A$, Lamenza $F$, Rubba $P$, Mancini $M$. Prevalence of peripheral arterial disease and related risk factors in elderly institutionalized subjects. Gerontology 1992; $38: 330-7$.

35 Ouriell KO, McDonnel AE, Metz CE, Zarins CK. A critical evaluation of stress testing in the diagnosis of peripheral vascular disease. Surgery 1982; 91: 68693.

36 Bernstein EF, Fronek $A$. Current status of noninvasive tests in the diagnosis of peripheral arterial disease. Surg Clin North America 1982; 62: 473-487.

37 Fowkes FGR. The measurement of atherosclerotic peripheral arterial disease in epidemiological surveys. Int J Epidemiol 1988; 17: 248-54.

38 Fow thes FGR, Housley E, Macintyre CCA, Prescott RJ, Ruckley CV. Reproducibility of reactive hyperaemia test in the measurement of peripheral arterial disease. $\mathrm{Br}$ I Surg 1988; $75: 743-6$.

39 Wilt TJ. Current strategies in the diagnosis and management of lower extremity peripheral wascular disease. J Gen Intern Med 1992; 7: 87-101.

40 Leng GC, Fowkes FGR, Donnan PT, Housley E. Reactive hyperemia test in a random sample of the general population. J Vasc Surg 1993; 17: 479-86.

41 Leng GC. Fowkes FGR. The Edinburgh claudication questionnaire: an improved version of the WHO/Rose questionnare for use in epidemiological surveys. J Clin Epidemiol 1992: 45: 11019 .

42 Connell FA, Kocpsell TD. Measures of gain in certainty from a diagnostic test. Am $₫$ Epidemiol 1985: 121:744-53. 


\section{Chapter 11 General discussion}

Summary In this chapter the main results of this study are discussed in relation to our objectives and the literature. Various methodological issues are summarized. The implications of our results for general practice are formulated and some ideas on future research in this field are presented.

The present study demonstrates that in many cases the general pratitioner can reject or confirm the bypothesis that PAOD is present, on the basis of medical bistory, physical examination and the vascular risk profile of a patient. If this is not possible, the general practitioner can use the band beld Doppler device for measuring the ABratio, a walid and reproducible supplementary test, to reduce bis diagnostic uncertainty. Practical decision rules for the meastrement and interpretation of the AB-ratio are provided.

The results of the present study can contribute to good agreements between general practitioners, vascular function deparments and vascular specialists on the ase of noninvasive diagnostic techniques for PAOD.

The notion that PAOD is a manifestation of systemic atherosclerosis should bave practical implications for the general practitioner. This study shows that there are possibilities for the general practitioner to optimize bis performance with regard to the secondary prevention of cardiovascular disease.

In the near future we hope to publish results on the conservative treatment of $P A O D$, prognostic indicators and the relevance of asymptomatic disease. An altemative approach to the anabsis of diagnostic data could be tested using our data set.

More studies on the quality of life in PAOD patients are required. It would also be worthrehile to study the effect of the use of the Doppler device in primary care on the quantity, quality and outcome of veferrals to the vascular specialist.

Above all, practice based research on PAOD requires consistent definitions and codes for PAOD. In general, practice based epidemialogic research of chronic diseases is possible only if everyday dinical data are collected according to research standards. This will be facilitated when computerized protocols that easily can be integrated in the daily routine of the general pracitioner will become available.

In this chapter the main results of our studies will be discussed in relation to the objectives formulated in chapter 4 and be compared to recent literature." Subsequently, various methodological issues will be summarized. Finally, we will outline the implications of our results for general practice and conclude this chapter with some ideas on future research in this field.

Recent literature was gathered according to the methods described in the chapters 2 and 3. In this chapter publications from 1990 up till august 1994 will be discussed. 


\section{Aims, results \& recent literature}

\section{PREVALENCE}

\section{Aims}

Reviewing the literature on the prevalence of peripheral arterial occlusive disease (PAOD), generated a number of topics for further investigation (chapter 2).

A population study using noninvasive testing reported a much higher prevalence (11.7\%) of PAOD as compared to the data derived from general practice morbidity registrations $(0.2-0.7 \%)$ and population studies using questionnaires on intermittent claudication $(1.7-4.8 \%)$.

In contrast with general medical belief the prevalence of objectively diagnosed PAOD in women was reported to be not much lower than the prevalence of PAOD among men. If this is true, the question arises whether PAOD possibly has a more benign course in women, i.e do women with PAOD generally present with a less advanced stage of the disease?

Moreover, the literature suggested that there were many asymptomatic patients and patients with atypical complaints. Compared to patients without PAOD, asymptomatic cases were reported to have a high prevalence of cardiovascular comorbidity. This would make screening or case finding in subjects without complaints more appropriate.

Many patients (50\% or more) with PAOD appeared not to be known as such to their general practitioner. The relevance of this 'tip of the iceberg' phenomenon was not clear: are unknown PAOD cases' important from a therapeutic or preventive perspective?

Our first research question was: "What is the prevalence of PAOD in the general practice population, and how large are the categories 'asymptomatic', 'atypical' and 'manifest' PAOD, known and unknown to the general practitioner?' (chapter 4).

\section{Results}

In chapter 9 we described our study on the prevalence of PAOD in a stratified sample of 3171 patients aged 45-75 years, who were on the list of 18 general practice centres. Results were recalculated for the base population of these general practice centres (18884 patients aged 45-75 years) and are summarized here. PAOD was considered to be present in a patient, if the ankle-brachial systolic pressure ratio (AB-ratio) of at least one leg was lower than 0.95 on two consecutive occasions (interval of one week). The AB-ratio was defined as the arm systolic pressure (brachial artery) divided by the ankle systolic pressure (posterior tibial or dorsalis pedis artery). Pressures were assessed with a hand held Doppler device and a sphygmonanometer.

The difference in prevalence figures provided by epidemiological studies can be explained partly by the use of different criteria for intermittent claudication and PAOD. In our study we can demonstrate this phenomenon. In our population the prevalence of "Rose-claudication" is $1.6 \%$, the prevalence of "definite (calf) intermittent claudication ${ }^{2.3}$ is $5.3 \%$ and the prevalence of all ischemic leg complaints on walking ("total intermittent claudication") is $6.6 \%$.

Our bivariate analyses of high risk groups identifiable to the general practitioner, confirmed once more that the prevalence of PAOD is higher among patients with 
hypertension (relative risk" 2.8), hypercholesterolemia (relative risk 2.0 ), diabetes mellitus (relative risk 3.3) or patients with a history of smoking (relative risk 1.7).

Although the prevalence of PAOD in men $(7.2 \%)$ and women $(6.5 \%)$ is quite equal (malefemale $=1.1$ ), men more often suffer from manifest atherosclerotic disease (male:female ratio for symptomatic PAOD: 3.3 ; for PAOD with concomitant ischemic heart disease or cerebrovascular disease: 2.6 ) and more often have an advanced stage of PAOD (male:female ratio for AB-ratio < $0.75: 2.6$ ).

Compared to symptomatic PAOD, asymptomatic PAOD is characterized by a higher proportion of women $(57 \%$ is female versus $25 \%$ among symptomatic PAOD) and by higher values for the AB-ratio (only 22\% with an AB-ratio $<0.75$, versus $69 \%$ among symptomatic cases). Compared to subjects without PAOD, subjects with symptomatic or asymptomatic PAOD have a higher probability to suffer from concomitant ischemic heart disease (relative risk $=3$ ) and cerebrovascular disease (relative risk $=4$ ).

We confirmed the hypothesis that many cases of PAOD are unknown to the general practitioner $(68 \%)$. Among these unknown cases female and young patients are relatively overrepresented $(60 \%$ female, $58 \%$ younger than 65 years) as are less advanced cases: only $20 \%$ with an AB-ratio < 0.75 , only $15 \%$ symptomatic cases and only $24 \%$ with concomitant ischemic heart disease or cerebrovascular disease.

\section{Recent literature}

Eleven recent population studies with data on the prevalence of PAOD in moderately selected populations were found. ${ }^{414}$ These publications were already discussed in relation with our findings in chapter 9.

A relevant issue, addressed in a number of publications, is the possible significance of asymptomatic PAOD. In an extensive review by Vogt et al it was concluded that detection of asymptomatic PAOD in the elderly is important because it can provide a rapid and easy indicator of the degree of systemic atherosclerotic cardiovascular disease, and thereby identify individuals at high risk for mortality and morbidity. ${ }^{15}$ Newman et al. demonstrated an inverse relation of the AB-ratio with cardiovascular risk factors and the presence of subcinical and clinical cardiovascular disease. Even asymptomatic patients with modest reductions in the AB-ratio (0.8-1.0) appear to be at increased risk of cardiovascular disease." In a prospective study Criqui et al. demonstrated that among asymptomatic PAOD patients the cardiovascular mortality was much higher as compared to subjects without PAOD. ${ }^{16}$

\section{CLINIGAL DIAGNOSIS}

\section{Airns}

Reviewing the literature on the diagnostic value of medical history and physical examination with regard to PAOD (chapter 2), revealed that the knowledge in this field is tragmentary. Although medical textbooks give long lists of clues to support the diagnosis PAOD (medical history, inspection, palpation, auscultation) quantitative data to support this knowledge are sparse.

relative risk: occurence of disease when determinant is present, divided by the occurence of disease when determinant is absent 
Furthermore, medical textbooks with regard to PAOD are usually written by medical specialists, i.e. vascular specialists, and are based on their experience with more advanced stages of PAOD. The question may be posed whether the classic textbook pattern of PAOD should be modified for the general practitioner.

Although the specificity of intermittent claudication (meeting the WHO-criteria) was reported to be high (99\%), the sensitivity appeared to be quite low $(9 \%)$. This raised the question whether the sensitivity of the medical history could be improved, e.g. by differentiating leg complaints towards site and sensation or by adding questions concerning risk factors. Data on the diagnostic significance of abnormal peripheral pulses or a femoral bruit were limited and showed a pattern similar to intermittent claudication: a fairly low sensitivity (13-71\%) and an acceptable specificity (73-98\%). On the diagnostic value of combined data from history and physical examination, almost no data were available.

Our second research question was: "What is the value of clinical data (history, physical examination, patient record) for the diagnosis of PAOD?" Or: "What are the sensitivity, the specificity and the predictive values of clinical data - separately and combined - in relation to PAOD?' (chapter 4).

\section{Results}

In chapter 10 our study on the diagnostic value of signs and symptoms associated with PAOD is described. Using both bivariate analyses and multiple logistic regression, clinical data of 3654 patients aged $40.7-78.4$ years (mean age 59.3 years) were compared to the outcome of Doppler ankle pressure measurements.

The results of the bivariate analyses show that some signs and symptoms traditionally associated with PAOD do not have a statistically significant diagnostic relevance. E.g.: complaints of cold feet, unilateral loss of hair on foot or leg, a lateral ankle ulcer (table 10.3).

Some clinical signs are relevant when used as a single test but their independent diagnostic value is reduced when they are used in combination with other signs or symptoms. E.g.: inspection for sores or wounds, colour of foot or leg, palpation of the femoral artery, history of cerebrovascular disease, history of diabetes, history of hypercholesterolaemia. This phenomenon is partly explained by the low prevalence of an abnormal ('positive') test result of these features. "The sensitivity of these features also is relatively low (table 10.2).

Other diagnostic procedures are characterized by either a relatively high sensitivity (age, history of smoking, history of (little) physical exercise during work) or a relatively high specificity (inspection of the feet for wounds or sores, palpation of the femoral artery pulse, palpation of the temperature of the skin; table 10.2).

Some signs, symptoms and vascular risk factors indeed can be used as a diagnostic test. The results of the bivariate and multivariable analyses in this study (tables 10.2. 10.4) show that in particular palpation of the foot arteries, auscultation of the femoral artery and questioning the patient for intermittent claudication - the three classic features of PAOD - are the signs and symptoms that can be used as diagnostic tests. We could confirm the results of other studies that showed that palpation of both pedal pulses is the best single diagnostic procedure: specificity and negative predictive value are high, and sensitivity and positive predictive value are relatively high.

In stead of the compound variable intermittent claudication, we initially analyzed 
the diagnostic value of various leg complaints appearing on walking, differentiated rowards specific site and sensation. Thus we hoped to identify a cluster of leg complaints with a higher sensitivity than positive "Rose-clatudication". However, a differentiated description of the pain or discomfort in the leg did not have diagnostic relevance. This result is in accordance with the experience described by Leng et al. who tried to improve the WHO/Rose-questionnaire for intermittent claudication ${ }^{2,3}$

Our most comprehensive logistic regression model revealed that besides the classic dinical diagnostic trio, data on gender (male), age (above 60), unilateral lower skin temperature, high blood pressure, a history of smoking and the presence of ischemic heart disease can increase the probability of PAOD being present (table 10.4).

\section{Recent literature}

Data on the diagnostic value of complaints of intermittent claudication were found in three recent articles. $6,10,11$ The study of Hiatt et al. was discussed in chapter 10. In the study of Skau and Jonsson (353 men and women aged 50-89 years) a modified definition of intermittent claudication was used. From their $2 \times 2$ table comparing the presence of intermittent claudication with the $\mathrm{AB}$-ratio (cutoff value 0.80 ), the diagnostic odds ratio of intermittent claudication could be recalculated as 4.7 (sensitivity $42 \%$, specificity $87 \%$ ). ${ }^{10}$ A similar calculation performed with the data of Ogren et al., who studied a population of 477 men aged 68 years, resulted in a diagnostic odds ratio of Rose-claudication of 8.8 (sensitivity $15 \%$, specificity $98 \%$ ) when compared to the AB-ratio (cutoff value 0.90$)_{*}{ }^{11}$

The value of the vascular physical examination was adressed in five papers. ${ }^{6,1720}$ The study of Hiatt et al. was discussed earlier. In two British studies the interobserver agreement and accuracy of the palpation of the foot pulses was assessed. In one study four observers (consultant, registrar, senior house officer, vascular clinic nurse) examined 33 patients with intermittent claudication. There was $67 \%$ agreement in palpation of the dorsalis pedis pulse, and $53 \%$ agreement in palpation of the posterior tibial pulse, suggesting that the dorsalis pedis pulse is easier to palpate than the posterior tibial pulse. ${ }^{17}$ In the second study fifty observers (surgeons, other doctors, medical students) examined the femoral and distal pulses of four patients with PAOD and one asymptomatic subject. Using the consensus diagnosis of two vascular surgeons as a reference, there were $10 \%$ false positive (not palpable when present) and $10 \%$ false negative (palpable when absent) outcomes. ${ }^{+18}$

In the study of Nicholson et al., 37 limbs of 50 symptomatic patients (43 presenting with intermittent claudication, seven with rest pain) referred to an outpatient surgery department were studied. The presence of an arterial bruit in the iliac, femoral or popliteal artery was compared to the outcome of arteriography. The odds ratio for 'any bruit' could be recalculated as 12 . The predictive value of a bruit for PAOD confirmed at arteriograplyy, was $87 \%$ in this small, selected population."

Endean et al. reported a considerable inaccuracy in both performance (total score: 63\% correct, predefined minimum score: $70 \%$ ) and interpretation of the vascular physical examination performed by interns and medical students. ${ }^{20}$

In conclusion, recent studies on the diagnostic value of a history of intermittent

positive test: puise not palpable; negative test: pulse palpabte 
claudication confirmed the results from formerly reviewed studies and our study: this symptom has a low sensitivity and a high specificity. Recent studies on the inter-observer agrement and accuracy of the physical vascular examination confirm the conclusions of our previous review that there is considerable disagreement among doctors whether a particular pulse is palpable or not. Yet, in our study as well as in other studies, the physical examination proved to have a high diagnostic value.

\section{ANKLE-BRACHIAL SYSTOLIC PRESSURE RATIO}

\section{Aims}

While preparing our main study, the literature on noninvasive tests for PAOD was reviewed. We were particularly interested in the measurement of the ankle-brachial systolic pressure ratio because of its assumed feasibility in general practice (chapter 3).

Many older studies on the reproducibility of the measurement of the anklebrachial systolic pressure ratio (AB-ratio), appeared to be of limited value: the method used to determine the reproducibility was usually described insufficiently; the parameters used to represent the reproducibility were not uniform and may not simply be compared; the observers were generally experienced staff members of surgical departments or vascular laboratory technicians rather than general practitioners or general practice assistants. From the literature we estimated that the preferable $95 \%$ prediction interval of the AB-ratio comprised the measured value \pm $0.14-0.2$. The difference between two measurements of the AB-ratio on different occasions had to be larger than 0.15 to be statistically significant and clinically relevant.

The assessment of the validity of ankle pressure measurements for general practice on the basis of the literature, was encumbered by several factors. All research was carried out in surgical or medical (outpatient) departments rather than in primary health care settings. In the specialist's office there will be few or no patients in an early phase of PAOD. In general, tests were performed on persons with complaints. For 'controls' either 'healthy" volunteers (i.e. without complaints) or the "healthy legs" of patients with PAOD were used. When the control group consisted of 'healthy' volunteers, angiography was usually not performed on these subjects, whereas in patients it was. By contrast, when the control group comprised healthy legs' of patients with PAOD, an angiogram was made. The issue of independency of Doppler testing and angiogram was only rarely discussed explicitly. Usually the noninvasive tests were performed before angiography. It was not always clear whether the data were examined prospectively or retrospectively.

Study of the literature demonstrated that the choice of a cutoff value for the ABratio was open to discussion: there appeared to be a grey zone between the 'specific" cutoff value of 0.90 and the 'sensitive' cutoff value of 1.0 . The figures for sensitivity and specificiry in most studies were high, but varied among studies.

We decided to investigate the reproducibility and the diagnostic validity of the measurement of the AB-ratio for the general practice setting. The following research questions concerning the measurement of the AB-ratio, were formulated (chapter 4): - what is the magnitude of the measurement variation due to the multi-observer design of the Limburg PAOD Study? 
- what is the magnitude of other sources of measurement variation, relevant to clinical situations?

- what is the accuracy and diagnostic value of the measurement of the AB-ratio?

what is its optimum cutoff value?

- can we provide threshold cutoff values beyond which PAOD can be ruled in (high positive predictive value) or out (high negative predictive value)?

\section{Results}

In chapter 7 we described our study on the reproducibility of the measurement of the AB-ratio in general practice. Fifty-nine observers performed 503 AB-ratio measurements on nine patients over a period of nine weeks. The magnitude of the inter-observer error (SD 0.114) was comparable to other studies. The contribution of the systematic measurement variation of each observer ("observer bias") was low (SD 0.044). This implies that multi-observer studies using AB-ratio measurements are only slightly less efficient than a hypothetical single observer study. Our results for the intra-observer error were slightly higher than the results of other studies (SD 0.105).

In chapter 8 we reported on our study on the diagnostic power of the measurement of the AB-ratio. Single and repeated AB-ratio measurements performed in three general practices were compared to the outcome of measurements by a specialized vascular laboratory (single measurements: 231 legs of 117 patients; repeated measurements in a subgroup of 92 legs of 51 patients). ROC analysis showed that the outcome of (three) repeated measurements leads to more valid results than single measurements of the $A B$-ratio. The optimum cut off value for the AB-ratio was calculated as 0.92 (sensitivity $87 \%$, specificity $91 \%$, accuracy $90 \%$ ) in the case of three repeated measurements. In case of a single measurement the $A B$ ratio performed less well, but still acceptable. 'The optimum cut off value was 0.97 (sensitivity $79 \%$, specificity $82 \%$, accuracy $81 \%$ ). We calculated threshold cutoff values for high predictive values for a positive and negative test outcome: the positive predictive value is higher than $95 \%$ if the $A B$-ratio (mean of three) is lower than 0.88; the negative predictive value is higher than $99 \%$ if the AB-ratio (mean of three) is higher than 0.98 .

\section{Recent literature}

Five recent publications on noninvasive testing contained data on the diagnostic value of the AB-ratio. We have referred earlier to two of these publications. ${ }^{4,21}$ Baxter and Polak found a high sensitivity and accuracy of the AB-ratio (standard: angiography) but their study population was small and highly selected.". Nilsson et al. compared a combination of noninvasive tests to computer-assisted arteriography and concluded that the AB-ratio was the single variable (out of 5 noninvasive tests) most closely correlated to the likelihood of arterial occlusions. ${ }^{23}$ Newman et al. analyzed the occurrence of cardiovascular risk factors, noninvasive signs of cerebral or cardiac disease and manifest cardiovascular disease for four levels of the AB-ratio $(\geq 1-<1.5, \geq 0.9-<1.0, \geq 0.8-<0.9,<0.8)$ in a population of 508.4 subjects aged 65 years or older. They found an inverse relation of the AB-ratio with cardiovascular risk factors, subclinical and clinical cardiovascular disease. Even asymptomatic patients with modest reductions in the AB-ratio (0.8-1.0) appeared to be at increased risk of cardiovascular disease. The occurence of reported hypertension, current 
smoking, carotid plaque, major ECG abnormality, angina pectoris and myocardial infarction was significantly higher among subjects with an $A B$-ratio between 0.9 and 1.0 as compared to subjects with an $\mathrm{AB}$-ratio above 1.0."

In conclusion, the results of these recent studies support our conclusion that measuring the AB-ratio is a valid diagnostic method and a marker of overall atherosclerosis.

\section{Methodological issues}

In this section the most important methodological issues of our studies will be discussed. Detailed discussions are presented in the chapters 7.10.

\section{PREVALENCE}

The general practice centres where the data for the prevalence and diagnostic studies were collected, were not a random sample of the general practices in the region around Mastricht. Yet, it seems unlikely that a 'GP-selection bias' has occurred (chapter 10).

The methodological crux of our study on the prevalence of PAOD was the complex stratified sampling procedure, necessary to meet the demands of all parts of the 'Limburg PAOD Study' in an efficient way (chapter 5). Complex sampling implied complex recalculations (chapter 9).

There is no unanimous answer to the question which noninvasive test should be applied in epidemiological studies on PAOD. In our studies the diagnostic criterion for the presence of $\mathrm{PAOD}$ was a value for the pocket-Doppler $\mathrm{AB}$-ratio lower than 0.95 , measured on two consecutive occasions. In the prevalence study this relatively high cutoff value was appropriate because in primary care a sensitive cutoff value is important in order to detect early stage cases to be evaluated further.

Prevalence figures and their confidence intervals for the general population had to be recalculated from the stratum specific data yielded by the study population to the population of patients who had responded to the postal questionnaire. Formulas for weighted means of stratum-specific prevalences and confidence intervals were entered into a spreadsheet programme (chapter 9). The formulas and an example for one variable are given in the appendix of chapter 9.

\section{CLINICAL DIAGNOSIS}

In the study on the diagnostic value of signs and symptoms associated with PAOD (chapter 10), we aimed at creating a study population that would represent a wide spectrum of signs, symptoms and vascular risk. ${ }^{24}$ Selecting the so-called indicated population ${ }^{25}$ (or "clinically relevant population', i.e. the sub-population of patients with leg complaints that visit their general practitioner, of whom the latter wants to take a specific history aimed at establishing or ruling out PAOD) was not feasible in daily practice, would have led to a slower process of data collection and a smaller number of patients, and might have resulted in an over-representation of symptomatic and typical PAOD patients.

The goal of the multiple logistic regression analysis was to reduce the total number of possible diagnostic variables ('tests') to an effective minimum number, i.e. to 
define the most efficient combination of signs and symptoms. The variables that finally were included in the logistic regression models were selected both on clinical relevance (odds ratio $\geq 1.5$ or $<0.67$ ) and statistical significance $(\mathrm{p}<0.05$ ). Consequently, the presence or absence of these variables indeed will contribute to differential diagnosis in an individual patient. Although we demonstrated good agreement between observed and predicted probabilities of PAOD, our models are not yet 'validated" in a new, similar population and thus may tend to perform in a too optimistic way.

\section{ANKLE-BRACHIAL SYSTOLIC PRESSURE RATIO}

In the Doppler reproducibility study (chapter 7), the intra-observer error could be estimated indirectly from a random effects analysis of variance model. ${ }^{26,27}$ To obtain a direct estimate of the intra-observer error, ideally one needs independent repeated measurements of the same patient by the same observer. This can be achieved using random-zero sphygmomanometers.

In the Doppler validity study (chapter 8) the study population was selected from a cohort of the Limburg PAOD Study. The spectrum of PAOD and co-morbidity in this population was appropriate: relatively mild disease predominated and sufficient non-arterial leg complaints were present as well. ${ }^{24}$ In theory the ideal study population would have been the "indicated population', i.e. the sub-population of patients who visit their general practitioner and of whom the clinical picture (medical history, physical examination) motivates the general practitioner to perform a Doppler measurement.

The 'gold standard' in this study was the consensus diagnosis made by two experienced vascular laboratory technicians on the basis of the results of a combination of noninvasive tests. Duplex scanning was not used in this gold standard because it was not our aim to establish the exact site of an arterial obstruction or stenosis.

\section{Implications for general practice}

\section{DIAGNOSTIC MANAGEMENT OF PAOD}

Previously, patients with PAOD often have been referred to vascular surgeons for diagnosis and long-term care despite the fact that the majority were managed conservatively. ${ }^{23}$ "The role of the primary care physician for these patients is evident: he is the principal health care provider responsible for the conservative management of these patients. ${ }^{29}$ Appropriate management of PAOD should start with a thorough clinical investigation including ankle pressure measurements. ${ }^{28}$

\section{Signs, symptoms and risk profile}

When a patient with leg complaints visits his general practitioner, the latter has to come up with a diagnosis. Our multivariable diagnostic models (chapter 10) may support this process by quantifying the feeling of certainty on the diagnosis PAOD the general practitioner will experience after he has taken a medical history and performed a physical examination. In the figures 11.1 and 11.2 some examples are given of the predicted probability of PAOD when data from history and physical examination are combined. These examples stress the diagnostic importance of 
Figure 11.1 Predicted probability of PAOD (\%) using information from medical history and physical examination (based on the multivariable diagnostic models $1-3$ described in chapter 10 )

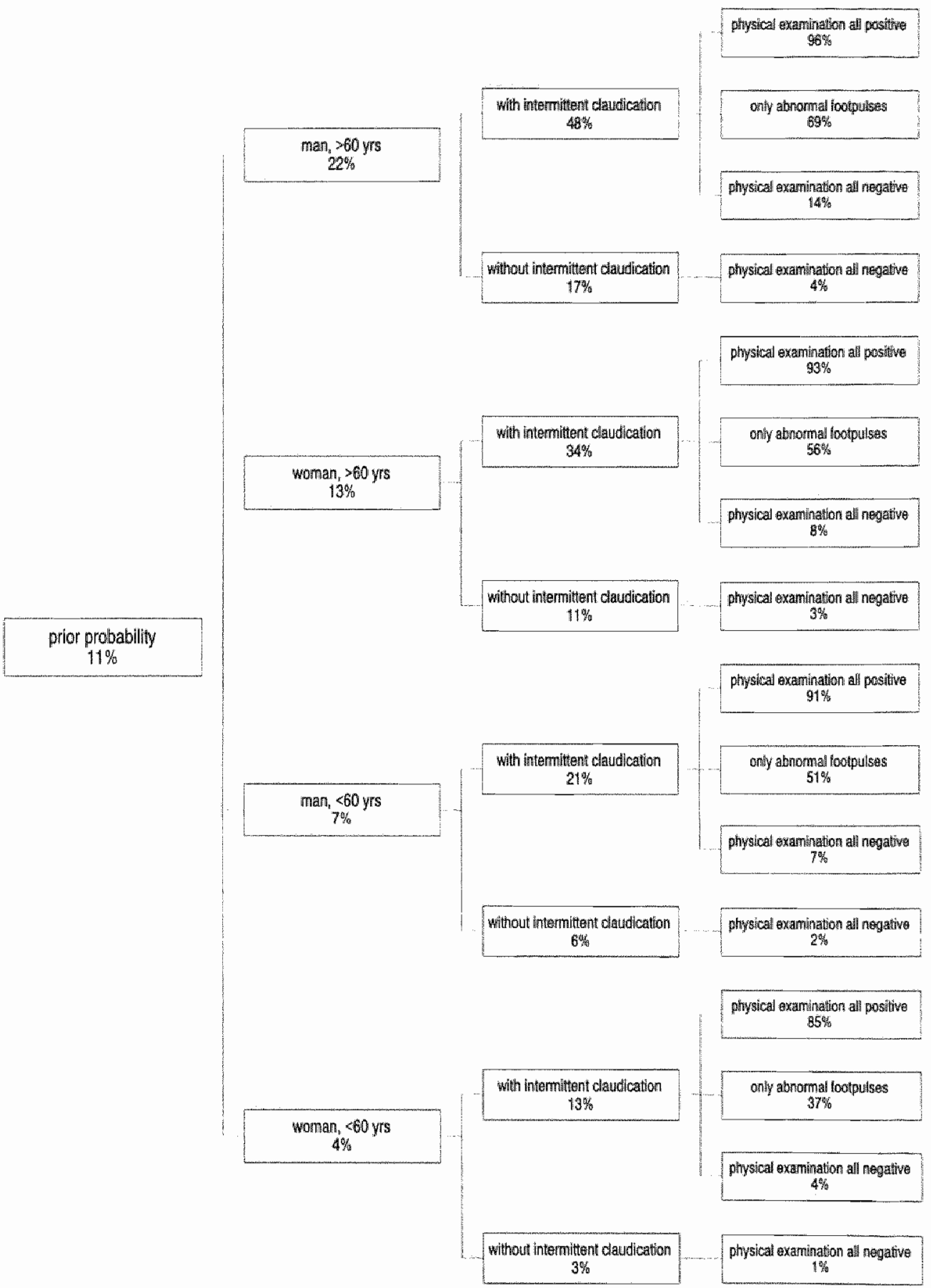


Figure 11.2 Some examples of the predicted probability of PAOD (\%) using information from medical history, physical examination and parient record (based on the multivariable diagnosnc models $1-4$ described in chapter 10)

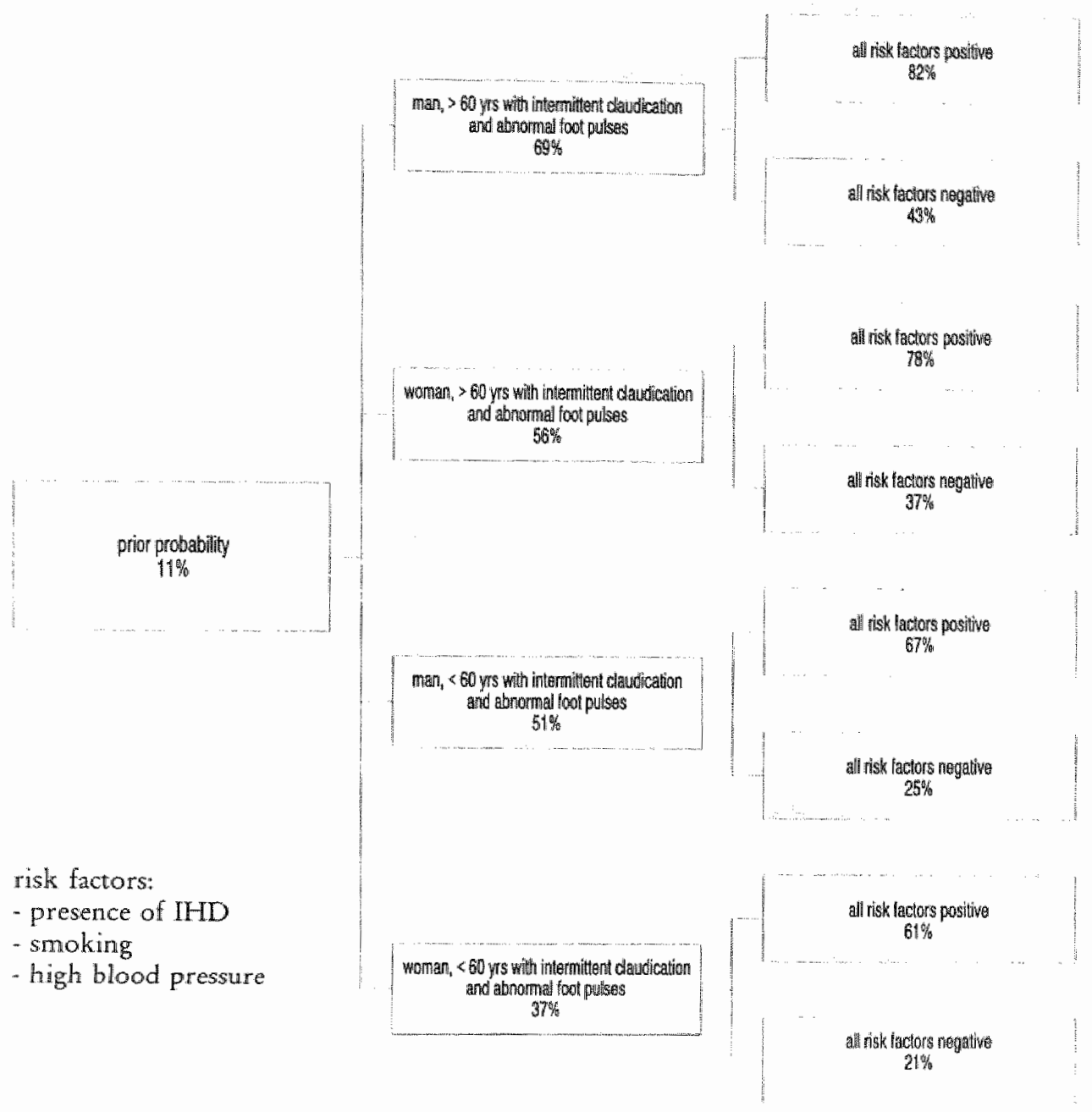

performing a physical examination. If only the fact that a patient suffers from intermittent claudication is taken into consideration, the predicted probability of PAOD will never exceed $50 \%$.

Our results demonstrate that on the basis of history and physical examination the general practitioner will often be able to rule out disease with a high degree of certainty (e.g. $60 \%$ of all legs in our study had a predicted probability of PAOD < $5 \%$ ). In a small group of patients he can reach a high degree of certainty that PAOD is present (e.g. 1.3\% of all legs in our study had a predicted probability of $\mathrm{PAOD}>80 \%$ ) and he will feel confident to discuss conservative measures with the patient. If the probability of PAOD is not low enough to exclude disease but not high enough to establish the diagnosis PAOD (e.g. in our study $38 \%$ of all legs had 
Table 11. Decision rules for the measurement and interpretacion of the pocket Doppler Abratio (in the range of prior probabilities of $5-33 \%$ )

\begin{tabular}{|c|c|c|}
\hline AB-talio & Action & Interpretation \\
\hline ABratio $>1.09$ & even if single measurement: & no PAOD (99\% certain) \\
\hline AB-ratio $0.75-1.09$ & $\begin{array}{l}\text { repeat measurement }(\mathrm{e} . \mathrm{g} .2 \mathrm{~m} \\
\text { - if mean } A B \text {-ratio > } 0.98 \text { : } \\
\text { - if mean } A B \text {-tatio < } 0.88 \text { : } \\
\text { - if mean } A B \text {-ratio } 0.88-0.98 \text { : }\end{array}$ & $\begin{array}{l}\text { nes): } \\
\text { no PAOD ( } 99 \% \text { certain) } \\
\text { PAOD ( } 95 \% \text { certain) } \\
\text { the higher the prior probability } \\
\text { that PAOD is present the higher } \\
\text { the } A B-\text { ratio has to be to rule out } \\
\text { disease }\end{array}$ \\
\hline
\end{tabular}

AB-ratio $<0.75$ even if single measturement: PAOD (95\% certain)

e.g. If the prevalence is $5 \%$ then the $A B$-ratio has to be $>0.88$ and if the prevalence is $10 \%$, then the AB-ratio has to be $>0.94$ to rula out PAOD

a predicted probability of $\mathrm{PAOD}$ between 5 and $80 \%$.), the general practitioner might consider noninvasive testing to resolve his diagnostic uncertainty.

\section{Doppler measurement}

On the basis of our study on the diagnostic performance of the AB-ratio measured with a hand held Doppler device, practical decision rules for the use and interpretation of the Doppler method in general practice could be derived for the range of prior probabilities of 5-33\% (table 11.1). To maximize diagnostic performance one ought to measure the AB-ratio on more than one occasion before reaching a definite diagnostic conclusion. Thus, the range of less conclusive $A B$-ratios is reduced to values between 0.88 and 0.98 . In the population in which we investigated the diagnostic value of signs and symptoms about $10 \%$ had an AB-ratio in this range. Within this range it applies that the higher the pre-Doppler probability of $P A O D$ - which depends on age and gender of the patient and on the results of history and physical examination performed by the doctor - the higher the AB-ratio should be to rule out disease.

Our study on the reproducibility of the AB-ratio leads to the conclusion that the Doppler method is a reproducible technique to make the diagnostic decision whether PAOD is present or not, under the condition that a $95 \%$ prediction interval of $0.15-0.20$ around the measured value is taken into account. Repeated measurements should be taken to minimize the measurement variation.

We also concluded that the difference between measurements (of the same patient by the same observer) on two subsequent occasions has to be at least $0.12-0.20$ to have an $80 \%$ certainty that this difference is not due to (intra-observer) measurement error. This conclusion is important if the Doppler method is used in the follow-up of patients treated for PAOD.

Measuring the AB-ratio is a skill that has to be acquired, trained and maintained. ${ }^{30}$ "To acquire this skill instructions by experts might be useful: experienced colleagues or practice-assistants, vascular specialists, vascular laboratory technicians. To gain 
experience one will have to examine healthy and diseased legs. Initially the indication for performing the measurement will have to be taken quite liberally and half an hour should be reserved for one measurement (two arms, two legs). With growing experience the time needed for one measurement decreases to 10-15 minutes. Optimum reproducibility and accuracy will be achieved if one person in a practice (e.g. the practice assistant) performs all $\mathrm{AB}$-ratio measurements.

\section{Vascular function laboratory}

In what situations is referral to a vascular function laboratory appropriate? Dutch vascular specialists recently described three situations that would be relevant. In a patient with a clinical picture suspect for PAOD but with a normal AB-ratio, a reactive hyperaemia test is suitable. If in a similar situation also information on musculoskeletal or cardiopulmonary functioning is needed, a (standardized) walking test is appropriate. Finally, if the measurement of the AB-ratio yields an inaccurate result, e.g. a very high $A B$-ratio in case of mediasclerosis, measurement of the toe syscolic pressure is required. ${ }^{3 .}$

Referral to a vascular surgeon is necessary in case of disabling or progressive complaints. On the basis of the results of duplex-scanning he often can make a decision on the most suitable option for treatment: conservative therapy, percutaneous transluminal angioplasty or vascular surgery. ${ }^{31}$

\section{MANAGEMENT OF ATHEROSCLEROSIS}

Our prevalence study confirmed the findings of others that the prevalence of PAOD is higher among patients with hypertension, hypercholesterolaemia, diabetes mellitus or a history of smoking, i.e. high risk groups identifiable to the general practitioner. In accordance with others we found that compared to subjects without PAOD, both symptomatic and asymptomatic PAOD correlate with a higher probability of concomitant ischemic heart disease and cerebrovascular disease. ${ }^{7,9.32}$

We confirmed the hypothesis that many cases of PAOD are unknown in primary care. Figure 11.3 presents our results recalculated for an average Dutch solo-practice with a gender and age distribution standardized according to the Dutch population. Our data showed that the general practitioner is fairly successful in selecting the worst cases of atherosclerosis for treatment. Our results also demonstrate that efforts still can be made to improve secondary prevention.

Firstly, PAOD should be regarded as a manifestation of a systemic disease, atherosclerosis, not only in theory but also in practice. General practitioners could try to achieve a complete picture of the vascular risk profile of their middle-aged patients. In our view increased cardiovascular risk is a legitimate reason to perform a physical examination, if necessary followed by (repeated) measurement of the AB-ratio. 'This is illustrated in figure 11.4 , presenting the possible outcomes of a physical examination performed in patients without complaints of intermittent claudication but with increased cardiovascular risk.

A positive outcome can be an additional motive to give lifestyle advice (smoking, exercise) to this category of patients. ${ }^{30,33}$ In addition, it can enhance the patient's motivation to comply with such advices. The question whether this approach indeed would be effective in reducing the number of cardiovascular events should be answered by prospective studies. 
Figure 11.3 Known and unknown cases of PAOD in a standard general practice (based on the results of the prevalence study described in chapter 9)

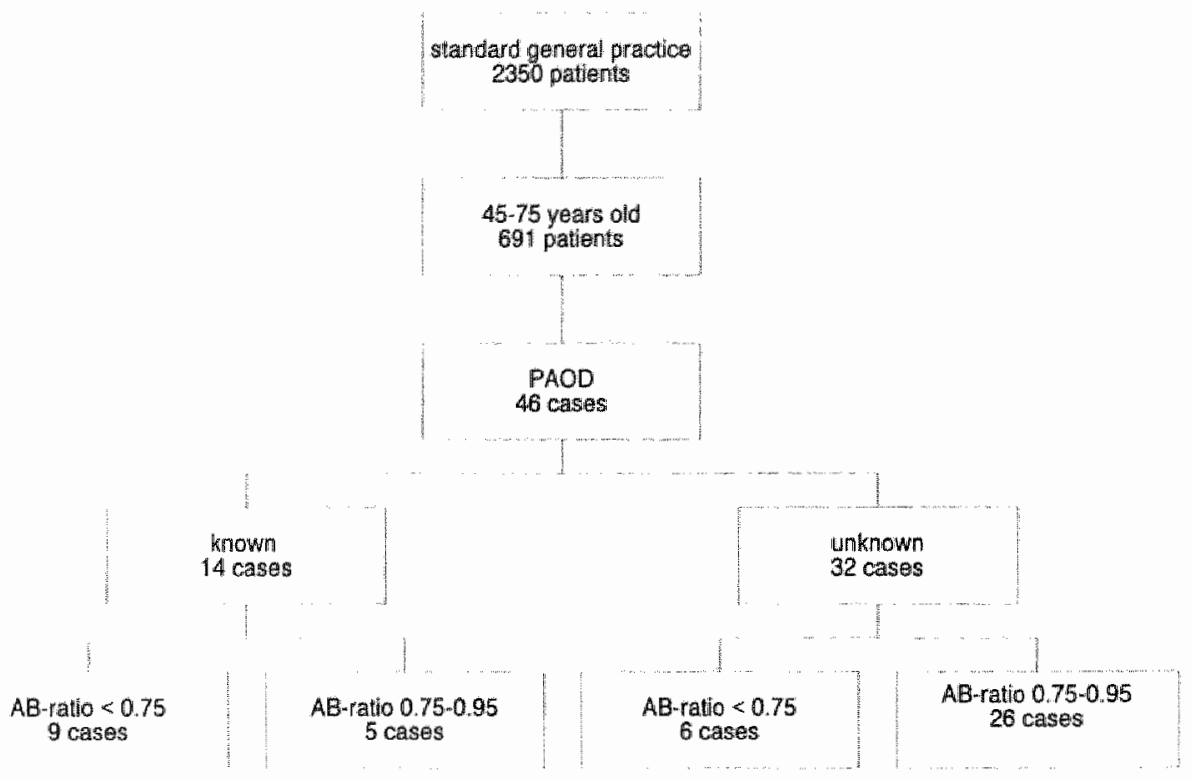

Furthermore, in order to reduce the number of 'unknown' cases of PAOD, thegeneral practitioner could more often consider the possibility of PAOD in female patients with leg complaints. Finally, a Doppler examination is appropriate when taking a careful history and performing a vascular physical examination in a patient with leg complaints yield ambiguous results.

\section{CONCLUSIONS}

In many cases the general practitioner can reject or confirm the hypothesis that PAOD is present, on the basis of medical history, physical examination and vascular risk profile. If this is not possible, he can measure the $\mathrm{AB}$-ratio to reduce his diagnostic uncertainty.

Along with the clinical guidelines on the management of PAOD, published by the Dutch College of General Practitioners ('NHG-standaard') and the 'Consensus' on noninvasive diagnostic methods mentioned above, the present thesis provides a basis for good agreements between general practitioners, vascular function departments and vascular specialist. ${ }^{29,31,3+1.36}$

The notion that PAOD is a manifestation of systemic atherosclerosis should have practical implications for the general practitioner. He still can optimize his performance with regard to the secondary prevention of cardiovascular disease. In our view casefinding among high-risk patients is a tenable option. 
Figure 11.4 Predicted probability of PAOD (\%) in patients without complaints of intermitreat claudication but with increased cardiovascular risk depending on the outcome of a vascular physical examination

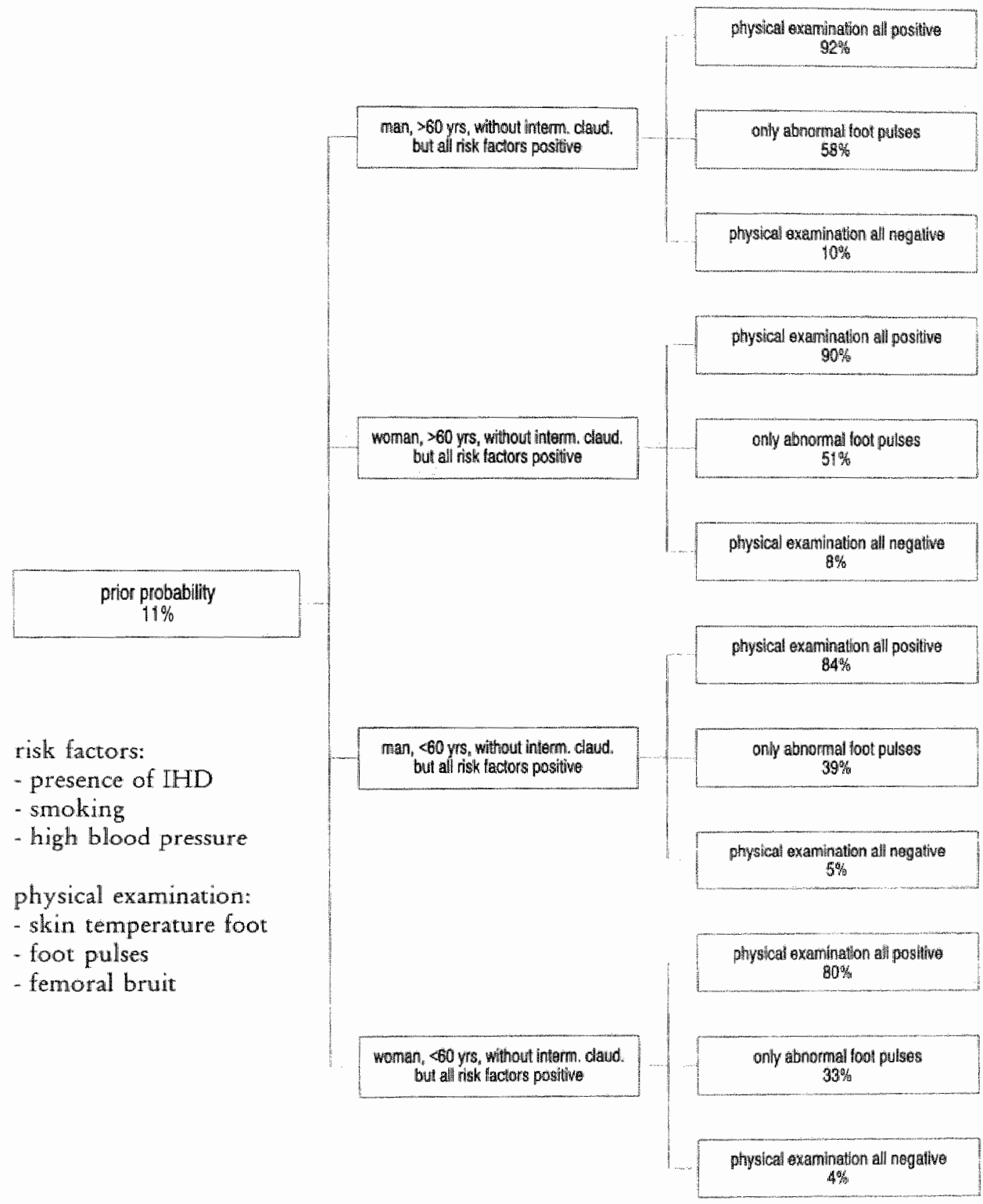




\section{The present dataset}

The dataset described in this book offers various opportunities for interesting analyses in the near future.

Essential to epidemiologic studies of PAOD is the use of clear criteria and definitions when describing patients with any form of PAOD (claudication, criteria for noninvasive testing) ${ }^{28}$ During their work on the Edinburgh Artery Study, Leng and Fowes and corworkers tried to improve (the sensitivity of) the WHO/Rose-questionnaire on claudication., An 'external' validation of their questionnaire is possible using their criteria for intermittent claudication on our dataset and comparing them to noninvasive testing.

In the prevalence study we observed that although the frequency of signs and symptoms associated with PAOD were similar for men and women, general practitioners more often diagnosed "PAOD" among men. It would be worthwhile to do a multiple logistic regression analysis of signs, symptoms and data from the patient record using the general practitioner's diagnosis as outcome variable. This would reveal those factors which general practitioners consider important in the diagnosis of PAOD. A separate analysis for men and women would reveal whether the general practitioner's clinical judgement is different in men and women.

\section{Future studies}

To pass a definitive judgement on the value of the measurement of the AB-ratio for the general practitioner, it would be worthwhile to study the effect of the use of the Doppler device in primary care on the quantity, quality and outcome of referrals to the vascular specialist (less referrals? less diagnostic referrals and more therapeutic referrals? more PTA and less vascular surgery?).

Little is known of the effects of PAOD on the quality of life of the elderly population. ${ }^{15}$ As it was not the main focus of attention in our study, we addressed this subject only superficially in our questionnaire and did not yet analyze these data. In future studies adequate clinimetric scales to assess the quality of life of claudicants are required. ${ }^{28}$ 'The 'PAD Walking Impairment Questionnaire' might serve this goal. ${ }^{37,38}$

\section{The Limburg PAOD study, part II}

In the second part of the Limburg PAOD Study the effect of a platelet-inhibitor on the course of PAOD was investigated, using the design of a randomized controlled trial. "Three hundred and eight patients were randomly assigned to one of the following groups: no intervention (natural course), calciumcarbasalate (plateletinhibitor), placebo. All patients were instructed to stop smoking and walk daily. They were re-examined every four months during 2,5 years by their own general practitioners. Also a second study on the reproducibility of the AB-ratio was performed, using random-zero sphygmomanometers. The results of these studies will be published in the near future. 


\section{The Limburg PAOD study, part III}

There still are gaps in our knowledge of the natural course of PAOD and the factors that determine its outcome. ${ }^{35}$ Early in 1994 we started to prepare a follow-up study of patients that were examined during the years 1987-1990. ${ }^{39}$ Goal of this third Limburg PAOD Study is to investigate the incidence of PAOD and to assess prognostic determinants for the disease. We hope to find those signs, symptoms and risk factors for PAOD that have prognostic value for the course of the disease, i.e. factors that can discriminate between those patients who are at high risk for progression to critical limb ischemia or for the occurrence of other atherosclerotic disease, and those patients who are not. From a preventive perspective we have a particular interest in the fate of formerly asympromatic PAOD cases.

\section{Criteria and codes for PAOD}

If general practice morbidity registration systems are to be used as epidemiological databases, a clear definition of codes is necessary. In this connection it should be noticed that the current codes for PAOD in the International Classification of Primary Care (ICPC) impede epidemiologic research in general practice. ${ }^{40}$ Intermittent claudication can be coded K03 (pain attributed to circulation) and K92 (other arterial obstructions, peripheral vascular disease). In fact code $\mathbb{K} 91$ (atherosclerosis excluding heart/brain) would be more appropriate. This is a confusing situation.

In our view 'intermittent claudication' should be regarded as a complaint that is associated with PAOD but is not identical to PAOD. Therefore, if no other data are available, code $\mathrm{KO} 3$ would be appropriate, with a sub-code to distinguish it from complaints normally associated with venous insufficiency. If more clinical data are available (physical examination, risk factors, AB-ratio, extensive noninvasive testing, a history of PTA, vascular surgery or amputation) code $\mathrm{K} 91$ would be suitable. Subcodes could be given to indicate the severity of the disease. Code K92 could be reserved for non-atherosclerotic peripheral vascular diseases (Bürger"s disease, Raynaud's disease).

\section{DAGNOSTLC RESEARCH}

Multivariable analysis of diagnostic associations is not a textbook procedure yet. ${ }^{41,42}$ Few examples to learn from were available. ${ }^{43-45}$ Using multiple logistic regression to analyze the diagnostic value of clinical data, some conceptual inconveniences were encountered.

In order to approach the normal clinical diagnostic work up, we had to ensure a hierarchical order of our successive models. Therefore the sequence of variable clusters was input of the analysis, not outcome of the model. Changing the combination of variables, e.g. by varying the sequence of entering clusters of terms, implies a change of the coefficient i.e. the odds ratio of a variable. In contrast to the 'adjusted odds ratio' in etiologic studies - being the true (s= unconfounded) measure of the independent contribution of a risk factor to the outcome of interest - the multivariable diagnostic odds ratio should be interpreted as a measure of the relative contribution of a specific diagnostic test given a certain combination of tests. Intuitively, one is inclined to regard upon the bivariate diagnostic odds ratio as the 'true' estimate of the diagnostic value of this particular test for the outcome 
of interest (i.e. a particular diagnosis).

The presence of collinearity in some clusters of variables forced us to skip variables from the models (e.g. 'femoral pulse') or to combine variables into a new compound variable (eg. "dorsalis pedis pulse: no-weak-yes" and 'posterior tibial pulse: no-weak-yes" were combined to 'pedal pulses: abnormal-doubt-normal'). From a clinical point of view this felt rather artificial.

An alternative approach to the analysis of diagnostic data was suggested by Knottnerus. ${ }^{46}$ After discussing the limitations of conventional multiple logistic regression for this purpose, he proposes a method based on a particular transformation of test variables, a simple branching structure and a sequence of entering terms in decreasing order of gain in certainty. This approach takes account of the fact that the next step in a diagnostic work up is dependent on the outcome of the previous step. Another benefit of this method would be that entering or skipping variables does not affect coefficients previously included in the model. A computer programme using this method is currently being developed. We intend to analyze our data using this alternative analysis method.

EPIDEMIOLOGIC RESEARCH AND MORBIDITY REGISTRATION IN (DUTCH) GENERAL PRACTICE

Having completed this part of the Limburg PAOD study, the question can be raised: are large scale population studies the most efficient way to study the descriptive and clinical epidemiology of chronic diseases the general practitioner has to deal with? Should clinical research in general practice not be done by its natural investigators, the general practitioner and his practice assistant, in its natural surroundings, the general practitioner's office?

Every day general practitioners collect data on the incidence and clinical diagnosis of diseases, the prevalence of manifest disease, the course of chronic diseases, treatment strategies and the relationship between disease and social context. The work of Lamberts et al. shows how - even in the pre-computer era - basic clinical data describing the 'transition' from reason for encounter via diagnosis to treatment, can be used to create a research based textbook of general practice. ${ }^{47}$

However, clinical data recorded in the average general practice do not meet criteria for validity and precision to be expected from research data, like the use of clear and consistent definitions, completeness of patient records, and the independent assessment of predictor and outcome variables. Therefore, - as was the case with our study - collecting research data in general practice often is done according to a special research protocol that interferes more or less with normal patient care activiries. ${ }^{48}$

The extent of computerization among (Dutch) general practitioners is increasing. Personal computers are used not only for the financial administration but also for keeping electronic medical records. Hoppener concluded that collecting research data 'at the source' i.e. in the general practitioner's office, still is the stepchild of practice computerization. He and his colleagues showed that it can be done. ${ }^{.9}$ The growth of practice computerization has facilitated the development of general practice morbidity registration networks. ${ }^{50}$ Metsemakers et al. have demonstrated how data of a computerized registration network can be used for research, medical education and quality assurance. ${ }^{50}$ 
Doctors involved in morbidity registration will get used to coding according to well defined criteria. Doctors involved in quality assurance and practice audit will get used to working with clinical guidelines and protocols. General practice guidelines based on general practice research, systematic literature reviews and consensusprocedures, are increasingly becoming available. A positive effect of these trends could be a growing interest and willingness among general practitioners to record clinical data in a complete ('according to protocol') and accurate ('according to criteria') fashion.

To facilitate these processes computerized clinical protocols (on diagnostic management, on monitoring the course of a disease, on functional status etcetera) will have to be developed. Only if these programmes can easily be integrated in the daily routine of the general practitioner, the electronic medical record can transform into a medical database to be used in medical education, research and practice audit. ${ }^{51}$

With regard to diagnostic research the advantage of computerized practice based data collection would be a controlled and realistic selection of patients for whom a (new) diagnostic test would be appropriate ('indicated' or 'clinically relevant' population). Also the issue of the 'gold standard' could be solved in some cases by watchful waiting for a disease to develop to a clear, predefined concition ('pseudo follow-up study'). E.g. the diagnostic programme for PAOD currently being developed on the basis of our multivariable diagnostic models (LIMB', 9 items, available from the author) could be used to facilitate a study to validate our models in an indicated population. In such a study the outcome of repeated AB-ratio measurements could serve as a gold standard.

\section{CONCLUSIONS}

Data on the conservative treatment of PAOD, prognostic indicators and the relevance of asymptomatic $\mathrm{PAOD}$ will become available in the next years. The alternative approach to the analysis of diagnostic data proposed by Knotmerus, can be tested using our data set.

It would be worthwhile to study the effect of the use of the Doppler device in primary care on the quantity, quality and outcome of refermals to the vascular specialist. Also, more studies on the quality of life in PAOD patients are required.

Practice based epidemiologic research of chronic diseases is possible only if everyday clinical data are collected according to research standards. Practice based research on PAOD requires above all consistent definitions (e.g. on intermittent claudication) and codes (ICPCI) for PAOD. Practice based data collection will be facilitated when computerized protocols that easily can be integrated in the daily routine of the general practitioner will become available.

\section{References}

1 Rose GA, Blackburn H, Gillum RF, Prineas RJ. Cardiovascular surway methods. 2nd ed. Geneva: World Health Organization 1982: 162-5.

2 Leng GC. Questionnaires. In: Fowkes FGR (edi.). Epidemiology of peripheral vascular disease. London etc: Springer, 1991: 2940.

3 Leng GC, Fowkes FGR. The Edinburgh Claudication Questionnatre: an improved version of the WHO/Rose Questionmaire for use in epidemiological surveys. I Clin Epidemiol 
$1992 ; 45: 1101-9$

4 Dewhurst $G$, Wood DA, Walker $F$, et al. A population survey of cardiovascular disease in elderly people: design, methods and prevalence results. Age Ageing 1991; 20: 353-60.

5 Smith WCS, Woodward $M$, Tunstall-Pedoe $H$. Intermittent claudication in Scotland. In Fontkes FGR (ed). Epidemiology of peripheral vascular disease. London etc.: Springer, 1991: 117-23.

6 Hiat WR, Marshal.] JA, Baxter J, et al. Diagnostic methods for peripheral arterial disease in the San Luis Valley diabetes study. J Clin Epidemiol 1990; 43: 597-606.

7 Fowkes FGR, Housley E, Cawood EHH, Macintyre CCA, Ruckley CV, Prescot RJ. Edinburgh artery study: prevalence of asymptomatic and symptomatic peripheral arterial disease in the general population. Int J Epidemiol 1991; 20:384-92.

8 Coni $N$, Tiennison $\mathbb{B}$, Troup $M$. Prevalence of lower extremity arterial disease among elderly people in the community. BrJ Gen Pract 1992; 42: 149-52.

9 Newman $A B$, Siscovick DS, Manolio TA et al. Ankle-Arm Index as a marker of atherosclerosis in the Cardiovascular Health Study. Circulation 1993; 88: 837-45.

10 Skau T, Jönsson B. Prevalence of symptomatic leg ischaemia in a Swedish community An epidemiologic study. Eur $\mathbb{}$ Vasc Surg 1993; 7: 432-7.

11 Ogren M, Hedblad B, Jungquist $G$, Isacsson SO, Lindell SE, Janzon L. Low ankle-brachial pressure index in 68year-old men: prevalence, risk factors and prognosis. Eur J Vasc Surg $1993 ; 7: 500-6$.

12 Vogt MT, Cauley JA, Kuller LH, Hulley SB. Prevalence and correlates of lower extremity arterial disease in elderly women. Am Epidemiol 1993; 137: 559-68.

13 Novo S, Avellone G, Garbo V di, Abrignani MG, Liquori M, Panno AV, Strano A. Prevalence of risk factors in patients with peripheral arterial disease. A clinical and epidemiological evaluation. Int Angiol 1992; 11: 218-29.

1.4 Pujia A, Gnasso A, Mancuso $G$ et al. Arteriopatia asintomatica degli arti inferiori. Prewalenza e fattori di rischio in una populazione del Sud Italia. [Asymptomatic peripheral vascular disease. Prevalence and risk factors in a frectiving population of southern Italy] (English summary). Minerva Cardioangiol 1993; 41: 133-8.

15 Vogt MT, Wolfson SK, Kuller LH. Lower extremity arterial disease and the aging process: a review. J Clin Epidemiol 1992; 45: 529-42.

16 Criqui $\mathrm{MH}$, Langer $\mathrm{RD}$. Fronek $\mathbb{A}$, et al. Mortality over a period of 10 years in patients with peripheral arterial disease. $N$ Engl J Med 1992; 326: 381-6.

17 Magee TR, Stanley PRW, A1 Mufti R, Simpson LS, Campbell WB. Should we palpate foot pulses? Ann Royal Coll Surg 1992; 74: 166-8.

18 Brearley S, Shearman CP. Simms MH. Peripheral pulse palpation: an unreliable physical sign. Ann Royal Coll Surg 1992; 74: 169-71.

19 Nicholson ML, Byrne RL, Steele GA, Callum KG. Predictive value of bruits and Doppler pressure masurements in detecing lower limb arterial stenosis. Eur J Vasc Surg 1993; 7 : 59.62.

20 Endean ED, Sloan DA, Veldenz HC, Donnelly MB, Schwarcz TH. Performance of the vascula: physical examination by residents and medical students. IVasc Surg 1994; 19: 149. 56.

21 Leng GC, Fowkes FGR, Donnan PT, Housley E. Reactive hyperemia test in a random sample of the general population. I Vase Surg 1993; 17: 479-86.

22 Baxter GM, Polak JF, Lower limb colour flow imaging: a comparison with ankle brachal measurements and angiography. Clin Radiol 1993; 47:91-5.

23. Nilsson $S$, Kaijser L, Erikson U, Johansson J, Walldius G. Correlation between computer-assisted femonl arteriography and physiological tests in hypercholes-terolaenic patients: a methodological study with special reference to dinical trials. Clin Physiol 1992; 12: $53-68$.

24 Sacket DL, Haynes RB, Tugwell P. Clinical epideniology. A basic science for dinical medicine. Boston, Toronto: Litule, Brown, 1985. 
25 Dinast GI. Knotmerus JA, Wersch JWJ van. Discriminating ability of the erychrocyte sedimentation rate: a prospective study in general practice. $\mathrm{Br} J$ Gen Pract 1991; 41: 365 70.

26 Fleiss JL. The design and analysis of dinical experiments. New York: Wiley, 1986.

27 Dunn OJ, Clark VA. Applied statistics: analysis of variance and regression. 2nd ed. New York: Wiley, 1987.

28 Bergquist D, Karacagil S. Femoral artery disease. Lancet 1994; 343: 773-8.

29 Wilt TJ. Current strategies in the diagnosis and management of lower extremity peripheral vascular disease. I General Intern Med 1992; 7: 87-101.

30 Stoffers, HEJH, Kaiser V. Her gebruik van het pocket-Doppler-apparat bij perifere arteriele vaataandoeningen. Een literatuuronderzoek. (English summary) Huisarts Wet $1994 ; 37: 333-8$.

31 Verenging voor Non-Invasieve Vaatiagnostiek, Nederlandse Vereniging voor Angiologie, Nederlandse Vereniging voor Vaatchirurgie. Consensus non-invasieve diagnostiek van perifeer arterieel vatlijden. Utrecht: Centraal Begeleidingsorgaan voor de Intercollegiale Toetsing, 1994.

32 Widmer LK, Biland L, Delley A, Da Silva A. Zum Stellenwert der peripherer-arteriellen Verschlusskrankheit in der Praxis. Schweiz Med Wschr 1983; 113: 19247.

33 Kaiser V, Bonsema K, Stoffers HEJH. Perifeer arterieel vaatijden: helpen medicinen? 'The Practitioner (NL) 1992; 9:263-6.

34 Bonsema K, Boutens EJ, Kaiser V, Stoffers HEJH. Perifeer arteried warlijden. Standaard M13 Nederlands Huisartsen Genootschap. Huisarts Wet 1990; 33: 4406.

35 Bonsema K, Boutens EJ, Kaiser V, Stoffers HEJH. NHG-Standard Perifeer arterieel vathijden. In: Rutten GEHM, Thomas 5 (red). NHG-Standarden woor de huisarts. U. trecht: Nederlands Huisartsen Genootschap/Bunge, 1993.

36 Stoffers HE]H, Knottnerus JA. Commentaar (op de consensus "Non-invasieve diagnostiek van perifeer arterieel vaatijden). Consensus in de Geneeskunde (sept. 1994); B42:18-21.

37 Regensteiner JG, Steiner JF, Panzer RJ et al. Evaluation of walking impaiment by questionnaire in patients with peripheral arterial disease. $J$ Vasc Med Biol 1990; 2: 142-52.

38 Regensteiner JG, Hargarten ME, Rutherford RB, Hiatc WR. Functional benefits of peripheral vascular bypass surgery for parients with intermittent cladication. Angiology $1993 ; 44: 1-10$.

39 Ree JW van, Kaiser V, Stoffers HEJH, Knotenerus JA. Peripheral arterial occlusive disease in general practice: incidence, course and prognostic determinants (The Limburg PAOD Study, part three). CVD Epidemiology Newsletter, number 49, Spring 1994: 667.

40 Lamberts H. Wood M (eds.). ICPC. International Classification of Primary Care. Oxford etc.: Oxford University Press, 1987.

41 Knotnerus JA. De evaluarie van dianostische techneken. In: Habbema JDF, Casparie AF, Mulder JH, Rutten FFH. Medische technology assessment en gezondheidsbeleid. Alphen aan den Rijn: Samson Stafleu, 1989.

42 Schouw YT van der. The assessment of new diagnoscic ests: guidelines and applications [PhD Thesis]. Nimegen: Katholieke Universiteit Nijmegen, 1993.

43 Numans ME. Gastroscopie op verzock van de huisarts, deteminanten van relevante uirstagen [Determinants of relevant diagnoses in Open Access Gastroscopy IIPhD "Them sis]. (English summary). Utrecht: Rijksuniversiteit Utrecht, 1992.

44 Boeke AJP, Dekker $\mathbb{H}$. Vaginale klachten in de huisartspraktijk $[\mathrm{PhD}$ Thesis]. (English summary). Ansterdam: VU Uitgeverij, 1992.

45 Fijten GH. Rectal bleeding, a danger signal? [PhD Thesis]. Amsterdam: Thesis Publishers, 1993.

46 Knotnerus JA. Application of logistic regression to the analysis of diagnostic data: exact modelling of a probability tree of muluiple binary wariables. Med Decis Making 1992; 12 : 93-108. 
47 Lamberts $H$. In het huis van de huisarts. Verslag van het Transitieproject. Lelystad: Medicekst, 1991.

48 Stoffers HEJH, Kaiser $V$. De uirvoering wan patiëntgebonden aandoeningsgericht wetenschappelijt onderzoek in de huisartspraktijk. In: Es JC van, Mandema E, Olthwis $G$, Verstratte M (red). Het Medisch Jaar 1990. Utrecht, Antwerpen: Bohn, 1990.

49 Höpener P. Automatisering en wetenschappelik onderzoek in de huisartspraktijk [PhD Thesis]. (English summary). Maastricht: Rijksuniversiteit Limburg, 1990.

50 Metsemakers JFM. Unlocking patients' records in general practice for research, medical education and quality assurance: the Registration Network Family Practices [PhD "Thesis]. Maastricht: Rijksuniversiteit Limburg, 1994.

51 Knottnerus JA. Registreren van morbiditeit in de huisartsgeneeskunde. Over diversiteit van doelstellingen en vereisten [Commentaar]. Huisarts Wet 1994; 37: 136-41. 


\section{Chapter 12 Summary}

This thesis describes studies on the prevalence and diagnostic management of peripheral arterial occlusive disease (PAOD) in general practice. PAOD refers to the manifestation of atherosclerosis in the lower limb distal to the aortic bifurcation.

There is a number of reasons for paying attention to the management of patients with PAOD in general practice: diagnosis, conservative treatment and monitoring of patients with this chronic disorder are primarily tasks of the general practitioner; the disease may lead to serious complications that should be prevented wherever possible; PAOD is an expression of generalized atherosclerosis; therefore, regular monitoring of risk indicators for cardiovascular disease might be appropriate in PAOD patients.

Chapter 2 presents a literature review on PAOD. The emphasis lies with data regarding the prevalence and the diagnosis of the disease. Literature was gathered systematically from the MEDLINE database and by using the 'snowball method'. This chapter represents the state of affairs known to us in March 1990.

The reported prevalence of $P A O D$ ranges from 0.2 to $11.7 \%$. It is plausible that many patients will not be known to the general practitioner and that there will be a large category of asymptomatic patients.

The prognosis of intermittent claudication is reported to be relatively favourable: in only about a quarter of patients symptoms progress. However, the prognosis quod vitam of patients with intermittent claudication is rather poor, due to the greatly increased risk of the development of cardiovascular and cerebrovascular complications. Possibly this applies ro asymptomatic patients as well.

Little research has been done on the diagnostic significance of signs and symptoms associated with PAOD. From the available data it may be concluded that the cur rent clinical diagnostic methods permit the general practitioner to exclude $P A O D$, whereas establishing the diagnosis cannot be done with sufficient certainty. Only few data on the diagnostic value of combinations of signs and symptoms are available.

In this respect the measurement of the resting ankle-brachial systolic pressure ratio (AB-ratio) by means of a pocket Doppler device - a noninvasive technique used for diagnosing PAOD - could be an asset to general practice. In chapter 3 the literature on the reproducibility and the validity of this method is examined. In addition the merits of the pocket Doppler device are compared to the possibilities of a vascular laboratory. Literature was gathered systematically from the MEDLINE database and by using the 'snowball method'. This chapter represents the state of alfairs known to us in March 1990.

The reproducibility of the $\mathrm{AB}$-ratio measurement is reported to be acceptable: the 
$95 \%$ prediction interval around a measured value is \pm 0.14 to \pm 0.20 .

Using the resting AB-ratio, it appears well feasible to differentiate between angiographically 'nondiseased' and 'accluded' arteries. The distinction between 'nondiseased' and 'stenosed" vessels seems less clear.

The selection of a cutoff value for the AB-ratio in the 0.90 to 1.00 range is open to discussion. In the most valid studies sensitivity varies between 75 and $97 \%$ and specificity between 92 and $100 \%$ at a cutoff point of 0.90 . Using a cutoff value of 1.00 , sensitivity varies between 88 and $100 \%$ and specificity varies between 60 and $80 \%$. Pooling the results of four comparable studies yields $82 \%$ for mean sensitivity and $98 \%$ for mean specificity at the cutoff value of 0.90 . Using a cutoff value of 1.00 these figures are $88 \%$ and $81 \%$ respectively.

The vascular laboratory is able to offer diagnostic information that is harder and more comprehensive than the pocket Doppler measurements. However, applying the pocket Doppler device in general practice may lead to a more selective management with regard to treatment and referral.

In chapter 4 the main objectives of the study are described. We wanted to answer the following questions:

1 What is the prevalence of PAOD in the general practice population?

2 What is the diagnostic significance of signs and symptoms in PAOD?

In addition we wanted to study the following issues:

- The reproducibility of the measurement of the ankle-brachial systolic pressure ratio.

- The diagnostic power of the measurement of the ankle-brachial systolic pressure ratio.

Chapter 5 discusses the general design, methods and variables of the main study on the prevalence and clinical diagnosis of PAOD. The definitive study population was recruited from a population consisting of the malle and female patients - born between 1 November 1911 and 31 December 1946, on the list of 18 general practice centres - by means of a postal questionnaire on complaints and risk factors (yielding a 'prior risk score' ranging from zero to five), followed by a sampling and selection procedure.

Data collection in the general practice centres occurred according to a crosssectional design and consisted of two parts which had to be executed independently: 1 data from the medical history were provided by the patient in a questionnaire, and data on findings of the physical examination, previous medical history, medication, co-morbidity and diagnosis were collected by the general practirioner.

2 the measurement of the AB-ratio by means of a pocket Doppler device was carried out by a practice assistant. This 'Doppler measurement' was used as standard diagnostic test. Patients with an $\mathrm{AB}$-ratio lower than 0.95 on two consecutive occasions (interval: one week) were considered to have PAOD.

All the anonymous and coded variables described in this chapter were read into the university's mainframe computer. Personal details of the patients were stored separately in a database on a personal computer.

Chapter 6 presents a quantitative overview of the processes of selection and drop-out that led to the definitive study population. The extent of selective drop-out is 
assessed. Finally, the study population is described for a number of key parameters. The source population consisted of 26620 patients with a mean age of 56.5 years (range: $40.3-76.9$ years) of whom $52.5 \%$ were female. The overall response on the postal questionnaire was $86.4 \%$. The average response rate per practice was $85.7 \%$ (SD: $3.4 \%$ ). The non-response did not cause a significant selective drop-out by age or gender.

There were 9095 responders with a prior risk score of zero and 13909 responders with a score from one to five. From the population of responders two random samples were taken: from the category with a score of zero (group 1, 'no risk', $\mathbf{n}=$ 451 ) and. from the category with a score of one to five (group 2, 'increased risk', $\mathbf{n}=$ 897). Both samples proved to be representative for their respective source populations with regard to age and gender. Of the remaining patients with a score between one and five, those at highest risk were selected (group 3, 'high risk', $1=$ 3953).

Thus, 5301 subjects were invited for an examination in one of the 18 general practice centres. The invitation was accepted by $68.9 \%$. The average participation rate per practice was $70.2 \%$ (SD: $11.9 \%$ ). Non-participation was due to various reasons: patients stayed in hospital for a protracted period or had moved or had died $(17.5 \%)$; many patients were 'not interested' (48\%); sometimes general practitioners decided that a patient would not participate for medical or practical reasons $(11 \%)$. The remaining causes for non-participation were unknown $(23.5 \%)$. The nonparticipation was selective to a certain degree for 'age' (older age groups), 'gender" (males), and 'score' (inconsistent pattern).

The definitive study population comprised 3654 patients (group 1: 292; group 2: 626; group 3: 2736) aged 40.7-78.3 years (mean age: 59.1 years), of whom 53.0\% were female.

Since we intended to use the measurement of AB-ratio by means of a hand held Doppler device as 'standard' diagnostic test, we performed additional studies on the reproducibility and validity of this method for general practice.

In chapter 7 the results of our study on the reproducibility of the measurement of the $A B$-ratio are described. The magnitude of different sources of measurement variation, relevant to clinical practice as well as multiobserver studies, was estimated from a random effects analysis of variance model. Thirty-five general practitioners and 24 practice assistants performed 503 AB-ratio measurements on nine patients over a period of nine weeks, using pocket Doppler devices.

When the AB-ratio is used for diagnostic purposes, a $95 \%$ prediction interval consisting of the measured value $\pm 0.15 \cdot 0.20$ has to be taken into account. Furthermore, when the AB-ratio is used in the follow-up of a patient with vascular disease, the difference between two subsequent measurements has to be at least 0.16-0.19 to have an $80 \%$ certainty that this difference is not due to (intra-observer) measurement error.

In conclusion, the measurement of the $\mathrm{AB}$-ratio is a reproducible technique under the condition that a $95 \%$ prediction interval of $0.15-0.20$ around the measured value is taken into account. Repeated measurements should be taken to minimize the measurement variation.

In Chapter 8 our study on the diagnostic power of the measurement of the AB-ratio 
is described. We assessed the accuracy and diagnostic value of the AB-ratio, estimated the optimum cutoff value for the AB-ratio and estimated threshold cutoff values beyond which PAOD can be ruled in or out. The diagnostic outcome of the measurement of the AB-ratio in three general practice centres was compared to the diagnostic conclusions of a Vascular Laboratory. This was done for the outcome of single AB-ratio measurements (231 legs of 117 patients) and the outcome of measurements on three consecutive occasions (subgroup of 92 legs of 51 patients).

Receiver Operating Characteristic (ROC) analysis showed that the diagnostic value of the mean of three AB-ratios is better than that of a single AB-ratio. The best theoretical optimum cutoff value was a mean AB-ratio of 0.92 (sensitivity $87 \%$, specificity $91 \%$, likelihood ratio of a positive test 10 , likelihood ratio of a negative test 0.14). Accuracy, corrected for prevalence, was $90 \%$.

We estimated that the positive predictive value $\geq 95 \%$ if the mean of three consecutive $A B$-ratios is below 0.88 ; the negative predictive value $\geq 99 \%$ if the mean AB-ratio is above 0.98 (prevalence range $5-33 \%$ ).

We concluded that the measurement of the AB-ratio with a hand-held Doppler device is a valid diagnostic method for general practice. "To maximize diagnostic performance one ought to measure the AB-ratio on more than one accasion before reaching a definite diagnostic conclusion.

Chapter 9 presents our study on the prevalence of peripheral arterial occlusive disease. The prevalence of PAOD, including asymptomatic cases and cases unknown to the general practitioner, was estimated in 18884 patients, aged $45-75$ years, on the list of 18 general practice centres.

The study population $(n=3171)$ consisted of a sample of the total population. In the general practice centres data were collected on intermittent claudication (IC), peripheral pulses, vascular risk factors, cardio- and cerebrovascular disease and the AB-ratio. PAOD was defined as an AB-ratio $<0.95$ on two consecutive occasions. Results were recalculated for the total population.

The prevalence of PAOD was $6.9 \%(95 \%$ ci $5.7-8.2 \%)$. One third of all cases (2.2\%) had an $\mathrm{AB}$-ratio < 0.75 . The prevalence of IC was $6.6 \%(95 \%$ ci $5.2-7.9 \%)$, of which a quarter $(1.6 \%)$ met the classic WHO-criteria. The prevalence of abnormal pedal pulses was $8 \%$ (95\%ci $6.5-9.5 \%$ ). PAOD did not occur significantly more often among men than among women but men more often suffered from an advanced stage of PAOD. Of all cases of PAOD $22 \%$ was symptomatic. This proportion correlated positively with higher age, male gender and lower AB-ratio. Among asymptomatic PAOD cases the prevalence of concomitant cardio- and cerebrovascular disease was three to four times as high as in the group without PAOD. Sixtyeight \% of all PAOD cases was unknown to the general practitioner. This 'unknown' group mainly represented less advanced cases of atherosclerosis. Still, of the group of $\mathrm{PAOD}$ cases with an $\mathrm{AB}$-ratio $<0.75,42 \%$ was unknown to the general practitioner.

We concluded that general practitioners succeed in selecting the worst cases of manifest atherosclerosis but can enhance their efforts towards secondary prevention.

In chapter 10 the our study on the diagnostic value of signs and symptoms associated with PAOD is presented. We compared clinical data on PAOD - collected in 18 general practice centres ( 1340 women, 1115 men, age $40.7-78.4$ years) - to the 
outcome of the measurement of the AB-ratio. PAOD was considered to be present if the AB-ratio was below 0.95 on two consecutive occasions (11.5\% of all legs). Data were analyzed using multiple logistic regression analysis.

Three classic features of PAOD appeared to be the most informative diagnostic tests: questioning the patient for intermittent claudication (bivariate diagnostic odds ratio 5.5 , sensitivity $28 \%$, specificity $93 \%$ ), palpation of both foot pulses (odds ratio 22.7 , sensitivity $66 \%$, specificity $80-92 \%$, best single diagnostic procedure) and auscultation of the femoral artery (odds ratio 7.7 , sensitivity $27 \%$, specificity $95 \%$ ). The multivariable odds ratios of these variables were $3.3,12.8$ and 4.1 respectively. Data like gender (odds ratio 1.3), age above 60 (odds ratio 2.2), unilateral lower skin temperature (odds ratio 2.1), high blood pressure (odds ratio 1.5), a history of smoking (odds ratio 2.2) or the presence of coronary artery disease (odds ratio 1.8) can also significantly contribute to the probability of PAOD. This is particularly relevant in cases that do not represent the classic clinical picture.

Our multivariable diagnostic models support the intuitive estimate of the probability of $\mathrm{PAOD}$ the general practitioner will have after each stage of his clinical evaluation of the patient. In many patients he will be able to rule out disease with a high degree of certainty $(60 \%$ of all legs in our study population had a predicted probability of $\mathrm{PAOD}<0.05$ ). In a small group of patients he can reach a high degree of certainty that PAOD is present (1.3\% of all legs in our study population had a predicted probability of $\mathrm{PAOD}>0.80$ ). If the probability of $\mathrm{PAOD}$ is not low enough to exclude disease but not high enough to establish the diagnosis PAOD (in our study population $38 \%$ of all legs had a predicted probability of PAOD between 0.05 and 0.80 ), the general practitioner might consider noninvasive testing to resolve his diagnostic uncertainty.

In conclusion, it would be useful to realize an external validation of our models by testing their performance in a similar study population. Our current analysis indicated that traditional clinical evaluation enables the general practitioner to decide upon the need for further diagnostic or therapeutic action in patients suspected of having PAOD.

In chapter 11 the main results of this study are discussed in relation to our objectives and the literature. Also various methodological issues are summarized, the implications of our results for general practice are formulated and some ideas on future research in this field are presented.

The present study demonstrates that in many cases the general practitioner can reject or confirm the bypothesis that PAOD is present, on the basis of medical history, physical examination and the vascular risk profile of a patient.

If this is not possible, the general practitioner can use the hand held Doppler device for measuring the AB-ratio, a valid and reproducible supplementary test, to reduce his diagnostic uncertainty. Practical decision rules for the measurement and interpretation of the $\mathrm{AB}$-ratio are provided. The results of the present study can contribute to good agreements between general practitioners, vascular function departments and vascular specialists, on the use of noninvasive diagnostic techniques for PAOD.

The notion that PAOD is a manifestation of systemic atherosclerosis should have practical implications for the general practitioner. This study shows that there are possibilities for the general practitioner to optimize his performance with regard to 
the secondary prewention of cardiovascular disease.

In the near future we hope to publish results on the conservative treatment of $\mathrm{PAOD}$, prognostic indicators and the relevance of asymptomatic disease. An alternative approach to the analysis of diagnostic data could be tested using our data set.

More studies on the quality of life in PAOD patients are required. It would also be worthwhile to study the effect of the use of the Doppler device in primary care on the quantity, quality and outcome of referrals to the vascular specialist.

Above all, practice based research on PAOD requires consistent definitions and codes for PAOD. In general, practice based epidemiologic research of chronic diseases is possible only if everyday clinical data are collected according to research standards. This will be facilitated when computerized protocols that easily can be integrated in the daily routine of the general practitioner will become available. 


\section{Chapter 13 Samenvatting}

In dit boek wordt een onderzoek naar de prevalentie en de diagnostiek van perifeer arterieel obstructief vaatlijden (PAV, perifeer arterieel vaatlijden) in de huisartspraktijk beschreven. Met 'perifeer arterieel obstructief valatijden' bedoelen we arterieel vaatlijden distaal van de bifurcatie van de aorta veroorzaakt door atherosclerose.

Hoofdstuk 1 bevat de inleiding. Om een aantal redenen verdient perifeer arterieel vaatlijden de aandacht van de huisarts: diagnostiek, conservatieve behandeling en het blijven volgen van patiënten met deze chronische aandoening zijn primair taken van de huisarts; de ziekte kan leiden tot ernstige complicaties die zo goed mogelijk voorkómen dienen te worden; perifeer arterieel vaatlijden is een manifestatie van gegeneraliseerd arterieel vaatlijden, hetgeen regelmatige controle van risicofactoren voor hart-en vaatziekten wenselijk maakt.

In boofdstuk 2 geven we een overzicht van de literatuur over perifeer arterieel vaatlijden voor zover relevant voor de huisartsgeneeskunde. De nadruk ligt bij gegevens over de prevalentie en de diagnostiek van de aandoening. Literaturur werd systematisch verzameld via het MEDLINE databestand. 'Tevens werd de 'sneeuwbalmethode' gebruikt. Dit hoofdstuk geeft de stand van zaken weer van maart 1990.

De in de literatuur gerapporteerde prevalentie van perifeer arterieel vaatlijden varieert tussen 0.2 en $11.7 \%$, waarbij het aannemelijk is dat veel patiënten niet als zodanig bij de huisarts bekend zijn en dat de categorie patiënten zonder klachten ('asymptomatische gevallen') groot is.

De prognose van claudicatio intermittens als zodanig, wordt als relatief gunstig beschreven: slechts in een $k$ wart van de gevallen zouden symptomen verergeren. De prognose quod vitam van patiënten met claudicatio intermittens is relatief slecht, ten gevolge van een verhoogd risico op het ontwikkelen van manifest hart- en hersenvaatlijden. Dit verhoogde risico geldt mogelijk ook voor mensen met asymptomatisch perifeer arterieel vaatlijden.

Er blijkt weinig onderzoek gedaan te zijn naar de diagnostische warde van anamnese en lichamelijk onderzoek. Op basis van de gegevens uit de literatuur kan geconcludeerd worden dat de huisarts met de gangbare klinisch-diagnostische methoden perifeer arterieel vaatlijden goed kan uitsluiten, mat dat de diagnose veel minder zeker gesteld kan worden. Er is echter nauwelijks informatie voorhanden over de diagnostische waarde van gecombineerde gegevens uit anamnese en lichamelijk onderzoek.

In dit opzicht zou de bepaling van de enkel-arm-index (EA-index) in rust, met behulp van een pocket-Doppler-apparaat, een aanwinst kunnen zijn voor de huisartspraktijk. In boofdstuk 3 wordt de literatuur over de reproduceerbaarheid en 
de validiteit van deze methode besproken. Bovendien worden de mogelijkheden van het pocket-Doppler-apparaat vergeleken met de mogelijkheden die een vaatlaboratorium biedt. Literatuur werd systematisch verzameld via het MEDLINE databestand. Ook dit hoofdstuk geeft de stand van zaken weer van maart 1990.

Uit de literatuur blijkt dat de reproduceerbaarheid van de bepaling van de EA. index acceptabel is: het $95 \%$ voorspellingsinterval rond een gemeten waarde bedraagt \pm 0.14 tor \pm 0.20 .

Verder blijkt het goed mogelijk om mer behulp van de EA-index een onderscheid te maken tussen angiografisch 'gezonde vaten' en 'vaten met occlusies'. Het onderscheid tussen 'gezonde vaten' en 'vaten met stenosen' is minder scherp te trekken.

Omtrent de keuze van een afkappunt voor de EA-index, ergens in het gebied tussen 0.90 en 1.00 , blijkt geen consensus te bestaan. De meest valide onderzoeken vinden bij een affappunt van 0.90 een sensitiviteit variërend van 75 tot $100 \%$ en een specificiteit variërend van 80 tot $100 \%$. Bij een afkappunt van 1.0 varieert de sensitiviteit tussen 88 en $100 \%$ en de specificiteit tussen 60 en $80 \%$. Indien de gegevens van methodologisch vergelijkbare studies gepoold worden, bedraagt de gewogen gemiddelde sensitiviteit $82 \%$ en de gewogen gemiddelde specificiteit $98 \%$ bij een afkappunt van 0.90 ; deze cijfers zijn $88 \%$ respectievelijk $81 \%$ bij een aflkappunt wan 1.0.

Het vaatlaboratorium biedt diagnostische gegevens die harder en meer omvattend zijn dan de bepaling van de EA-index. Toch zou toepassing van de pocket-Doppler in de huisartspraktijk kunnen leiden tot een meer selectief behandel- en verwijsbeleid.

In boofdstuk 4 komen de vraagstellingen van dit onderzoek aan de orde. We wilden de volgende vragen beantwoorden:

1 Wat is de prevalentie van perifeer arterieel vaatijiden in een huisartsgeneeskundige populatie?

2 Wat is de diagnostische waarde van gegevens uit anamnese en lichamelijk onderzoek bij perifeer arterieel vaatlijden?

Daarnaast wilden we de volgende onderwerpen bestuderen:

- De teproduceerbaarheid van de bepaling van de EA-index.

- De diagnostische warde van de bepaling van de EA-index.

In hoofdstuk 5 behandelen we de algemene opzet, methodologie en variabelen van het (hoofd-)onderzoek naar de prevalentie en de klinische diagnostiek bij perifeer arterieel vaatlijden. De uiteindelijke onderzoekspopulatie werd geselecteerd door middel van een post-enquête uit de populatie patiënten, geboren tussen 1 november 1911 en 31 december 1946, van 18 huisartspraktijken. Na beantwoording van de post-enquête ( 5 vragen over klachten en risicofactoren) kon aan iedere patiënt een 'a priori risico-score' (kortweg 'score') worden toegekend; op grond hiervan werd de uiteindelijke onderzoekspopulatie geselecteerd.

De gegevensverzameling in de huisartspraktijken verliep volgens een dwarsdoorsnede-opzet en bestond uit twee onderdelen die onafhankelijk wan elkaar dienden plaats te vinden:

1 anamnestische gegevens werden verzameld door de patiënt een vragenlijst te laten invullen; gegevens met betrekking tot het lichamelijk onderzoek, medische 
voorgeschiedenis, medicatic-gebruik, co-morbiditeit en diagnose werden door de huisarts geleverd;

2 de bepaling van de EA-index met behulp van een pocket-Doppler apparaat werd bij woorkeur door de praktijkassistente uitgevoerd. Deze 'Dopplerbepaling" werd gebruikt als standaard-diagnosticum. Patiënten met een EA-index lager dan 0.95 bij twee opeenvolgende gelegenheden (interval: 1 week) werden beschouwd als patiënt met perifeer arterieel vaatlijden.

Alle gegevens werden anoniem en gecodeerd ingevoerd in de mainframe-computer van de Rijksuniversiteit Limburg. Personalia van patiënten werden apart opgeslagen in een gegevensbestand op een personal computer.

In boofdstuk 6 geven we een kwantitatief overzicht van het proces van selectie en uitval, dat uiteindelijk de samenstelling van de onderzoekspopulatie bepaalde.

De bron-populatie bestond uit 26620 patiënten, waarvan $52.5 \%$ vrouw was en waarvan de leeftijd varieerde van 40.3 tot 76.9 jaar (gemiddeld 56.5 jaar). De mate van respons op de post-enquête was $86.4 \%$. De gemiddelde respons per praktijlk bedroeg $85.7 \%$ (SD: $3.4 \%$ ). De non-respons veroorzaakte geen selectieve uitval met betrekking tot geslacht en leeftijd.

Er waren 9095 respondenten met een 'score' van nul en 13909 respondenten met een 'score' variërend tussen 1 en 5 . Uit de populatie respondenten werden twee steekproeven getrokken: uit de categorie met een 'score' van 0 (groep 1, 'geen risico', $\mathrm{n}=451$ ) en uit de categorie met een 'score' tussen 1 en 5 (groep 2, 'verhoogd risico', $n=897$ ). Beide steekproeven bleken representatief voor hun respectievelijke bron-populaties met betrekking tot leeftijd en geslacht. Van de overblijvende patiënten met een 'score' tussen 1 en 5, werden diegenen met de hoogste score geselecteerd (groep 3, 'hoogste risico', $\mathrm{n}=3953$ ).

Aldus werden 5301 mensen uitgenodigd voor een onderzoek in de praktijk van hun eigen huisarts. Deze uitnodiging werd aangenomen door $68.9 \%$ van de patienten. Het gemiddelde participatie-percentage per praktijk bedroeg $70.2 \%$ (SD: $11.9 \%)$. Patiënten deden niet mee om diverse redenen: een aantal patiënten was inmiddels gestorven, verhuisd, of langdurig opgenomen in ziekenhuis, psychiatrisch centrum of verpleeghuis (17.5\% van de uitvallers); een grote groep patiênten gaf aan 'niet geïnteresseerd' te zijn (48\%); soms besloot de huisarts dat een patiënt niet mee zou doen aan het onderzoek vanwege medische of praktische redenen (11\%). In de resterende gevallen bleef de reden van non-participatie onbekend $(23.5 \%)$.

Tot op zelkere hoogte was de uitval selectief met betrekking tot 'teeftijd' (oudere leefrijdsgroep), 'geslacht' (mannen) en 'score' (wisselend patroon). De uiteindelijke onderzoekspopulatie bestond uit 3654 patiënten (groep 1: 292; groep 2: 626; groep 3: 2736) met een leeftijd variërend van 40.7 tot 78.3 jaar (gemiddeld: 59.1 jaar), wharvan $53 \%$ vrouw was.

Aangezien we van plan waren de bepaling van de EA-index met een hand-Dopplerapparaat als 'standaard-diagnosticum' te gebruiken, verrichtten we onderzoek naar de reproduceerbaarheid en de validiteit van deze methode voor de huisartspraktijk.

In boofdstuk 7 worden de resultaten van ons onderzoek naar de reproduceerbaarheid van de bepaling van de EA-index beschreven. Vijfendertig huisartsen en 24 praktijkassistentes voerden 503 EA-index-bepalingen uit met een hand-Doppler bij 9 patiënten in een periode van 9 weken. Het aandeel van verschillende bronnen van 
meetwariabiliteit, van belang voor de huisartspraktijk en voor epidemiologisch onderzoke, werd geschat door middel van een "random effects analysis of variance". model.

We vonden dat als de EA-index gebruikt wordt met een diagnostisch doel, er rekening gehouden dient te worden met een $95 \%$ voorspellingsinterval rond de gemeten waarde van \pm 0.135 tot \pm 0.225 . Bovendien, als de EA-index gebruikt wordt bij het vervolgen van een patiënt met perifeer arterieel vaatlijden, dan dient het verschil tussen twee opeenvolgende metingen tenminste 0.16-0.19 te zijn om met $80 \%$ zekerheid te kunnen zeggen dat dit verschil niet te wijten is aan toevallige (intra-waarnemer)-meetvariatie.

We concludeerden dat de bepaling van de EA-index een reproduceerbare methode is, onder de voorwaarde dat een $95 \%$ voorspellingsinterval van \pm 0.15 à 0.20 wordt aangehouden. Het herhallen van de meting bevordert de betrouwbaarheid van de uitslag.

In hoofdstuk 8 wordt ons onderzoek van de diagnostische waarde van de bepaling van de EA-index beschreven. De diagnostische uitkomst van de EA-index-bepaling in drie gezondheidscentra werd vergeleken met de diagnostische conclusie van een vaatlaboratorium. Dit werd gedaan voor zowel enkelvoudige bepalingen van de EAindex (231 benen van 117 patiënten), als voor de uitkomst van het gemiddelde van bepalingen tijdens 3 opeenvolgende consulten (subgroep van 92 benen van 51 patiënten). We bepaalden het discriminerend vermogen en het optimale afkappunt voor de EA-index en berekenden drempelwarden waarbij perifeer arterieel vaatlijden met zekerheid kan worden uitgesloten respectievelijk kan worden aangetoond.

'Receiver operating characteristic' (ROC) analyse liet zien dat de diagnostische waarde van het gemiddelde van 3 opeenvolgende bepalingen van de EA-index, beter is dan die van een enkelvoudige bepaling van de EA-index. Het beste theoretisch optimale afkappunt voor het gemiddelde van 3 bepalingen was 0.92 (sensitiviteit $87 \%$, specificiteit $91 \%$, aannemelijkheids-coëfficiënt voor een positieve testuitslag 10 , aannemelijkheids-coëfficiënt voor een negatieve testuitslag 0.14). Het aantal correcte classificaties, gecorrigeerd voor prevalentie, bedroeg $90 \%$. We berekenden dat de voorspellende waarde van een positieve testuitslag $\geq 95 \%$ als het gemiddelde van 3 opeenvolgende bepalingen van de EA-index kleiner is dan 0.88 ; de voorspellende waarde van een negatieve testuitslag $\geq 99 \%$ als de gemiddelde $\mathbb{E} A$-index groter is dan 0.98 (in het prevalentiebereik $5 \times 33 \%$ ).

We concludeerden dat de bepaling van de EA-index met een pocket-Doppler* apparat een valide diagnostische methode voor de huisartspraktijk is. Om het diagnostisch vermogen van de bepaling te maximaliseren dient men de EA-index bij meerdere gelegenheden te bepalen alvorens een diagnostische conclusie te trekken.

In hoofdstuk $9 \mathrm{komt}$ het onderzoek naar de prevalentie van perifeer arterieel vaatlijden aan de orde. Het aantal gevallen van perifeer arterieel vaatlijden, inclusief asymptomatische gevallen en gevallen die niet bij de huisarts bekend waren, werd bepaald voor een populatie van 18884 patiënten, in leeftijd variërend tussen 45 en 75 jaar, ingeschreven bij 18 huisartspraktijken.

De onderzochte populatie $(\mathrm{n}=3171)$ bestond uit een selectie van de totale populatie. In de huisartspraktijken werden gegevens verzameld met betrekking tot claudicatio intermittens (CI), perifere pulsaties, vasculaire risicofactoren, hart-en 
hersenvaatlijden en de EA-index. De definitie van perifeer arterieel vaatlijden was tweemaal een EA-index $<0.95$ (interval: 1 week). De resultaten werden teruggerekend naar de totale populatie.

We vonden een prevalentie van perifeer arterieel vaatlijden van $6.9 \%$ (95\%bi 5.7 . $8.2 \%)$; een derde deel van de gevallen $(2.2 \%)$ had een EA-index $<0.75$. De prevalentie van CI was $6.6 \%$ (95\%bi 5.2-7.9\%), waarbij een vierde deel van de gevallen $(1.6 \%)$ voldeed aan de klassieke WHO-criteria voor Cl. De prevalentie van abnormale perifere pulsaties bedroeg $8 \%(95 \%$ bi; $6.5-9.5 \%)$. Perifeer arterieel vaatlijden kwam niet significant vaker voor bij mannen dan bij vrouwen, maar bij mannen was vaker sprake van een meer voortgeschreden vorm van perifeer arterieel vaatlijden. Bij een vijfde deel (22\%) van alle gevallen van perifeer arterieel vaatlijden was sprake van klachten van CI ("symptomatisch"). Deze proportie correleerde met leeftijd (ouder), geslacht (man) en EA-index (lager). In de groep asymptomatische gevallen van perifeer arterieel vaatlijen was de prevalentie van eveneens aanwezig hart- of hersenvaatijden 3 tor 4 mal zo hoog als in de groep zonder perifeer arterieel vaatlijden. Achtenzestig procent van alle gevallen van perifeer arterieel vaatlijden was niet als zodanig bij de huisarts bekend. Deze 'onbekende' groep bescond voornamelijk uit minder ernstige gevallen van perifeer arterieel vaatijden (meer vrouwen, jonger, minder lage EA-index, minder klachten). Toch bleek in de groep patiënten met een EA-index $<0.75$, nog $42 \%$ onbekend bij de huisarts.

We concludeerden dat huisartsen erin slagen de meest emstige gevallen van manifeste atherosclerose te selecteren voor begeleiding en behandeling, maar dat zij hun activiteiten op het gebied van secundaire preventie van hart- en vaatziekten nog kunnen aanscherpen.

In boofdstuk 10 wordt ons onderzoek naar de diagnostische betekenis van klachten en bevindingen bij perifeer arterieel vaatlijden besproken. Wij vergeleken klinische gegevens verzameld in 18 huisartsprakijken bij 1340 vrouwen en 1115 mannen in de leefujd van 40.7-78.4 jaar, met de uitkomst van de bepaling van de EA-index. perifeer arterieel vaatlijden werd aanwezig geacht als de EA-index bij twee opeenvolgende gelegenheden (interval: 1 week) lager dan 0.95 was (11.5\% van alle benen). De gegevens werden bivariaat en met behulp van multiple logistische regressie geanalyseerd.

We vonden dat de drie klassieke kenmerken wan perifeer arterieel vaatlijen de meest informatieve diagnostische 'testen' bleken te zijn: het affnemen van een anamnese naar claudicatio intermittens (bivariate diagnostische odds ratio 5.5, sensitiviteit $28 \%$, specificiteit $93 \%$ ), palpatie van beide voetarteriën (odds ratio 22.7 , sensitiviteit $66 \%$, specificiteit $80-92 \%$, beste enkelvoudige diagnostische procedure) en auscultatie van de arteria femoralis (odds ratio 7.7 , sensitiviteit $27 \%$, specificiteit $95 \%$ ). De multivariabele odds ratio's van deze variabelen waren respectievelijk 3.3 , 12.8 en 4.1 .

Echter ook andere kenmerken kunnen bijdragen tor een verhoogde kans op perifeer arterieel vaatlijden: mannelijk geslacht (odds ratio 1.3), leeftijd boven de 60 (odds ratio 2.2), eenzijdig koudere huidtemperatuur (odds ratio 2.1), hoge bloeddruk (odds ratio 1.5), roken (odds ratio 2.2) of de aanwezigheid van coronairlijden (odds ratio 1.8). Deze bevindingen zijn wooral van belang in die gevallen die niet voldoen aan het klassieke klinische patroon.

Onze multivariabele diagnostische modellen ondersteunen de intuitieve schatting 
van de kans op perifeer arterieel vaatlijden die een huisarts heeft na iedere fase van zijn klinische evaluatie van de patiënt. Bij veel patiënten zal hij ziekte kunnen uitsluiten met een hoge mate van zekerheid (60\% van alle benen in onze onderzoekspopulatie had een voorspelde kans op perifeer arterieel vaatlijden $<5 \%$ ). Bij een kleine groep patiënten kan hij een met een hoge mate van zekerheid de diagnose perifeer arterieel vaatijden stellen $(1.3 \%$ van alle benen in ons onderzoek had een voorspelde kans op perifeer arterieel vaatlijden $>80 \%$ ). Als de kans op perifeer arterieel vaatlijden niet laag genoeg is om de aandoening te mogen uitsluiten, maar niet hoog genoeg om de diagnose te kunnen stellen (in onze onderzoekspopulatie had $38 \%$ van alle benen een voorspelde kans op perifeer arterieel vaatlijden tussen 5 en $80 \%$ ), zou de huisarts het (laten) doen van niet-invasief vaatonderzoek kunnen overwegen om zijn diagnostische onzekerheid te verkleinen.

Samenvattend: onze analyse laat zien dat traditionele klinische diagnostiek de huisarts voldoende gegevens oplevert om een zinnige beslissing te kunnen nemen over de noodzaak van aanvullende diagnostiek of therapie bij patiënten met klachten verdacht voor perifeer arterieel vaatlijden. Het zou nuttig zijn als onze diagnostische modellen extern gevalideerd zouden worden door ze uit te testen in een vergelijkbare onderzoekspopulatie.

In hoofdstuk 11 worden de belangrijkste resultaten van ons onderzoek besproken in relatie tot onze vraagstellingen en recente literatuur. Ook wijden we een beschouwing an diverse methodologische aspecten, worden de consequenties van onze resultaten voor de huisartspraktijk besproken en worden enkele ideeën voor verder onderzoek gepresenteerd.

Ons onderzoek maakt duidelijk dat de huisarts in vele gevallen de hypothese dat perifeer arterieel vaarlijden aanwezig is kan verwerpen of bevestigen op basis van anamnese, lichamelijk onderzoek en groene kaartgegevens. Als dat niet met voldoende zekerheid mogelijk is, kan de huisarts het pocket-Doppler apparaat gebruiken om de EA-index te bepalen en zo zijn diagnostische onzekerheid te verminderen. De bepaling van de EA-index in de huisartspraktijk bleek reproduceerbaar en valide. We konden praktische beslisregels voor de bepaling en de interpretatie van de EA-index opstellen.

De resultaten van ons onderzoek kunnen een bijdrage leveren aan goede werkafspraken tussen huisartsen, vasculaire functie-afdelingen en vatspecialisten omtrent het gebruik van niet-invasief vaatonderzoek door de huisarts.

De notie dat perifeer arterieel vaatlijden een uiting is van gegeneraliseerde atherosclerose dient praktische consequenties te hebben voor de huisarts. Ons onderzoek laat zien dat de huisarts zijn feitelijk handelen met betrekking tot de secundaire preventie van thart- en vaatziekten nog kan aanscherpen.

In de nabije toekomst hopen we resultaten te kunnen publiceren over de conservav tieve behandeling van perifeer arterieel vaatlijden, over indicatoren met betrekking tot de prognose van de andoening en over de klinische relevantie van asymptomatisch perifeer arterieel vaatlijden. Ons huidige databestand kan gebruikt worden om een alternatieve analyse van diagnostische gegevens te testen.

$\mathrm{Er}$ is meer onderzoek nodig op het gebied van de "quality of life" van patiënten met perifeer arterieel vaatlijden. Ook zou het nuttig zijn onderzoek te doen naar het effect van het gebruik van het pocket-Doppler-apparaat door huisartsen op de hoeveelheid, de kwaliteit en het uiteindelijke resultaat van verwijzingen naar de 
vaatspecialist.

Voor toekomstig onderzoek naar perifeer arterieel vaatlijden vanuit de huisartspraktijk, is het noodzakelijk dat er consistente definities en codes voor deze aandoening komen. In zijn algemeenheid geldt dat epidemiologisch onderzoek van chronische aandoeningen vanuit de huisartspraktijk alleen mogelijk is, indien de klinische gegevens die huisartsen dag-in dag-uit verzamelen, voldoen aan wetenschappelijke normen (volledigheid, standaardisatie). Dit zal makkelijker zijn als geautomatiseerde protocollen, inpasbaar in de dagelijkse routines van de huisarts, beschikbaar komen. 


\section{Dankwoord (Acknowledgements)}

Aan dit onderzoek werkten velen mee. Ik wil allen bedanken voor hun bijdrage.

Cees de Geus, hoogleraar Huisartsgeneeskunde, en Paul förning, chirurg, leverden waardevolle bijdragen aan het op de rails zetten van het project. De laatste wierf ook patiënten woor de eerste "Doppler-reproduceerbaarheidsmeting". Ook Hubert Schouten, statisticus, speelde een belangrijke rol in de initiële fase van het project. Hij droeg tevens bij aan de opzet en de analyse van de "Doppler-reproduceerbaarheidsmeting" en leverde ad boc statistische adviezen.

Karin Aretz was de research-assistente uit de eerste jaren van het project. Zij heeft het project mee opgezet en gezorgd voor een degelijke administratieve infrastructuur. De coördinatie wan de informatiestromen tussen het 'projectbureau' en de praktijken was grotendeels haar werk.

De lay-out van de registratieformulieren werd verzorgd door Guns van Rooy (RL Design, destijds A.V.-dienst), het zetwerk door Martinus Maesen (Studio Zet). Deze registratieformulieren hebben andere onderzoekers van de vakgroep als voorbeeld gediend, toen desk top publishing tot de mogelijkheden van gewone tekstverwerkingsprogramma's ging behoren.

René Kocken voerde het financiële beheer over het project. Chris Bartels deed administratieve werkervaring op in de beginfase van het project toen zeer veel post verwerkt moest worden. Annie Lemmens-Sation, Helène Fey, Lidquine Boots, Nicolle Gerards, Marianne Bruystens en Paul Zavietering sprongen belangeloos in toen er eem keer acuut veel werk verzet moest worden bij het verzendklaar maken van de postenquêtes voor een praktijk. Monique Koekelkoren en Veron Scbrijnemakers fungeerden ieder een periode als waarnemend research-assistente voor het PAVProject. De datatypistes van 'de ponskamer' in het oude BMC (tegenwoordig: Memic, Data Entry Service) voerden de onderzoeksgegevens van het project in de 'VAX' in.

Paul Zwietering, huisarts-onderzoeker, droeg bij aan het tot stand komen van ons electronisch literatuurbestand. Boris Cox en Peter Ottengraf, student-assistenten, droegen hun steentje bij aan het verzamelen wan literatuur.

Jos Hamers, systeembeheerder van de vakgroep Huisartsgeneeskunde, reageerde altijd snel en adequat op mijn hard- en softwarevragen. Trudie Seegers, researchassistente vakgroep Epidemiologie, was behulpzaam bij BMDP- en VAX-problemen als andere deskundigen afwezig waren. Zij en Marion de Leeuw, statistisch analiste valkgroep Methodologie en Statistiek, maakten op basis van de in hoofdstuk 10 beschreven resultaten het computerprogramma LMMB.

Klaas Bonsema en Emiel Boutens, huisartsen, waren constructieve discussie-partners 
tijdens de bijeenkomsten van de werkgroep 'Standaard Perifeer Arterieel Vaatlijden' wan het Nederlands Huisartsen Genootschap in Utrecht.

We thank Gerry Fotukes, Director of the Wolfson Unit for Prevention of Peripheral Vascular Disease in Edinburgh, for inviting us to the Pfizer Foundation symposium in Edinburgh in 1991. It was a great opportunity to meet experts in the field of epidemiologic studies on peripheral arterial occlusive disease.

Bij de uitvoering van aandoeningsgericht patientgebonden onderzoek nemen de huisartsen en praktijkassistentes die de gegevens werzamelen een centrale plaats in. Aan dit onderzoek werd loyaal meegewerkt door: Piet Atbmer (Kerkrade); George Beusmans, Nandus Vierhout, Annemiek Franssen, Edith Dubislav (Maastricht); Ankie Westers, Marjo van Bommel, Tiny van Merode, Thelma l'Espoir (Maastricht); Frank Guldemond, Jeannie Spiertz (Ubachsberg); Paul Hulshof, Rudolf Panhwsen, Ytonne Guldemond-Hecker, Ingeborg Soomers, Yoonne Sintzen, Petra Senden, Geja Dialektopoulos-wan Patten, Sep Schmeets (Voerendaal); Bert ten Berge, Pieter van der Heyden, May van Bilsen (Roermond); Willem Niewedorp, Yoonne Draaisma, Marjo Neelis, Anja Savelkoul, Marina Gösgens, Marion Theunissen (Brunssum); They Lemmens", Paul Stalenboef, Bér Huynen, Pie Castermans, Lilian Claessens, Riet Hautrast, Lilian Wijnands, Linda van Laar (Maastricht); Henk Logister", Bert van de Werf, Mary Busscher, Anuschka. Westhoff, René Janssen (Heerlen); Geertje van Zanten, Jan Michels, Dirk van der Wissel, Giaconda Rutzerveld-Verspagen, Marina Oosterbuts, Hannie Drieman, Marjo Konings (Kerkrade); Bart Otten, Renate Trienes (Merkelbeek); Giel Peeters, Frans Vissers, Marion Frijns, Chris Grundlach, Marie-Louise de Bruyn (Maastricht); Erwin Vijgen, Resi Vijgen-Hamers, Lilian Otten (Geleen); Ton wan Dam, Chris Hanssen (Kerkrade); Harrie Eussen, Hans Ypma, Carla Stumman (Landgraal); Eef Hubbers (Kerkrade); Frank Soomers, Suzarne van Schijndel (Kerkrade); Pierre Passage, Jan Drenth, Gerda Salden (Kerkrade). Via hen wil ik ook alle patiënten die meededen bedanken.

Extra werkzaamheden werden verricht door de praktijkassistentes Edith Dubislav, Riet Hautvast, Linda van Ladr, Marion Frijns, Chris Grundlach en Marie-Lonise de Bruyn in verband met het 'Doppler-valideringsonderzoek'. Ingeborg Soomers en Marie-Lowise de Bruyn verzorgden Doppler-demonstraties tijdens het N.H.G.-congres van 1989 in Den Haag.

Ondanks de verhuizing van het Academisch Ziekenhuis Maastricht van Annadal naar Randwijck werd de uitvoering van het 'Doppler-valideringsonderzoek' een succes dankzii de enthousiaste medewerksters van "het vatlab": Ywonne Reijnders, secretaresse, Edith Ermers en Monique Kuypers, vaatlaborantes.

Jan Klerkx, tolk-vertaler, corrigeerde het Engels van hoofdstuk 7 en David Warn dorff, arts en native speaker, vertaalde in sneltreinvart de hoofdstukken 1 tot en met 6 in het Engels. Irene Korstjens gaf adviezen over de Nederlandstalige onderdelen van dit proefschrift.

Jan Ratuwerda, hoogleraar vaatchirurgie, Chris van Weel, hoogleraar huisartsgenceskunde, Pawl Knipschild, hoogleraar epidemiologie, Ton Gorgels, universitair hoofddocent cardiologie en Peter Pop, hoogleraar transmurale geneeskunde beoordeelden het concept-proefschrift.

Voor de vormgeving van het binnenwerk van het proefschrift ontwing ik gevraagde en ongevraagde tips van Jan Leewis, Micbiel Comel, Manuel Stoffers, Piet Portegijs, 
Rund Leliveld en Wendy Verbagen. Het omslag werd ontworpen door Wendy Verhagen (Datawyse).

Agnes Deckers (Hoechst) bood me de mogelijkheid het proefschrift een ruimere bekendheid te geven door verspreiding onder een groep geinteresseerde huisartsen financieel te ondersteunen.

Aan Victor Kaiser, Michiel Cornel, Saskia Mol en George Wolfs, mijn Maastrichtse collega's, had ik prima kamergenoten. Ik heb veel gehad aan de discussies met Michiel over de toepassing van multiple logistische regressie bij diagnostisch onderzoek.

Frank Soomers en Marianne Soomers-Turlings, mijn Kerkraadse collega's, hebben ervoor gezorgd dat ik meer huisarts ben geworden en dat ik nog steeds huisarts ben en denk te blijwen. 'Academisering' is in deze praktijk een werkbaar ontwikkelingsproces gebleken.

Peter Kitslaar, hoogleraar algemene heelkunde, was de opvolger van Paul Jörning in de projectgroep en mijn tweede promotor. Als toenmalig hoofd van het Vaatlaboratorium makte hij het 'Doppler-valideringsonderzoek' mogelijk. In de laatste jaren wan het project leverde hij met grote deskundigheid kritische en constructieve bijdragen aan de analyse en rapportage van het project.

Op Amold Kester, als statisticus bij het project betrokken, deed ik de afgelopen jaren nooit tevergeefs een beroep. Hij bedacht degelijke oplossingen voor niet-alledaagse analyse-problemen.

Pawla Rinkens was de research-assistente van dit deel van het PAV-Project. $\mathrm{Zij}$ was voortdurend een betrokken en creatieve gesprekspartner die met name in de analysefase van het onderzoek een ware rots in de branding bleek te zijn.

Victor Kaiser, huisarts-onderzoeker, was de 'eerste' onderzoeker van het PAVProject en mijn vaste kamergenoot in al die jaren. De voorbereiding van het project inclusief het werven van huisartsen voor dit onderzoek, is voor een belangrijk deel zijn werk geweest. Na de gemeenschappelijke fase van de gegevensverzameling bleef hiij als meedenker en co-auteur zijn bijdragen leveren aan mijn deel van het project. Zijn eigen dissertatie volgt binnenkort.

André Knottnerus, hoogleraar Huisartsgeneeskunde, was de projectleider van het onderzoek en mijn promotor. Hij gaf mij de ruimte en stuurde soepel bij. Ondanks het feit dat in de onderzoeksperiode extra velen een appél op hem deden, bleef hij een stimulerende en enthousiaste begeleider. 


\section{Curriculum Vitae}

Henri (Jelle') Stoffers was born on July 5th 1957 in Heerlen, the Netherlands. Eldest of five children of a teachers' couple he grew up in Hoensbroek and Schaesberg, villages in the former Limburg mining district. He finished his secon. dary education, Athenaeum- $B$, at the 'Eijkhagencollege' in Schaesberg in 1975 . He studied medicine at the Catholic University of Nijmegen from 1975 to 1983. As an alternative to military service he worked as a physician in the 'Humanitaskliniek', a nursing and revalidation hospital in Rotterdam (1984-1985).

During his vocational training (Nijmegen University Institute of Family Practice) he worked as GP trainee in the practice of Elbert van Ruller in Arnhem (19851986). During the year 1986-1987 he combined working as a general practitioner with the experimental GP research training of the University of Limburg in Maastricht. He received a grant from the Netherlands Organization for Scientific Research to work on the present study (1988-1991). In 1992 he became a staff member of the Department of General Practice, spending his time on research and undergraduate teaching. From 1989 he also works as a general practitioner in a group practice (with Frank Soomers and Marianne Soomers-Turlings) in Kerkrade. Jelle Stoffers lives in Maastricht, is married and has three children. 


\section{Appendices}

\section{Appendix chapter 3 The measurement of the ankle-brachial systolic pressure ratio (AB-ratio) by means of a pocket Doppler device}

Required are a pocket Doppler device with a transducer suitable for arteries (8 Mhz, possibly 5 $\mathrm{MH}(\mathrm{z})$, a calibrated mercury sphygmomanometer with a cuff of at least $12 \mathrm{~cm}$ and aqueous gel. The price of a pocket Doppler device varies from $f 700,-$ to $f 2000$,- depending on the type.

The measurement (of both legs and both arms) may be carried out by the general practitioner as well as by a practice assistant in approximately 10-20 minutes, depending on the experience of the investigator and the level of difficulty of the patient. The examination room should be properly heated. Prior to the actual measurement, the patient is asked to lie down as flat as possible on the examination couch. The sequence of the measurements is: arm-Lgother legother arm. Particular attention should be paid to proper fixation of the transducer and to slow release of the cuff pressure. After the measurements are made, the Doppler device is to be shut off and stored carefully: the transducer is extremely wulnerable!

The procedure for a leg is as follows:

1 Apply the sphygmomanometer just proximal to the malleoli of the leg, with the tubes in an upward position.

2 Palpate the posterior tibial artery dorsal to the medial malleolus.

3 Apply some aqueous gel at this location, even when the artery is impalpable.

4 Swith on the Doppler device and position the transducer in the gel at an angle of 30 to 60 degrees to the artery. Search for the best arterial signal.

5 In case no signal is obtained in this location, take the dorsalis pedis artery.

6 Keep the transducer well fixed and wse your other hand to inflate the cuff up to approximately $30 \mathrm{~mm} / \mathrm{g}$ higher than the reading at which the signal disappears.

7 Deflate the cuff very slowly; best is a rate of $2 \mathrm{mmHg}$ per second. Note the reading at which the artral signal is first audible. Never reinflate the cuff during the measurement. but deflate the curf completely if the transducer moves.

The procedure is repeated for the other leg (items 1-7).

The radial artery at the level of the wrist is used for the measurement of the systolic brachial pressure; the procedure is analogous to that for the legs (item $3,4,6,7$ ).

"The ABmatio is computed for each leg by dividing the systolic ankle pressure by the highest systolic brachial pressure. 


\section{Appendix Chapter 5}

\section{Appendix 5.1 Participating General Practice Centres}

1 Huisartspraktijk P. Athmer, Kerkrade

2 Gezondheidscentrum 'De Hohoek' (G.H.M.I. Beusmans, W.P.M. Vierhout), Maastricht

3 Huisartsprakrijk T. van Merode, M. van Bommel, Maastricht

5 Huisartspraktijk F.I. Guldemond, Ubachsberg

6 Huisartspraktikk P.B.N. Hulshof, R.A.M. Panhuysen, E.T.I.M. Guldemond-Hecker, Voerendaal

7 Gezondheidscentrum 'Maasniel' (A.A. ren Berge, P.F.M. wan der Heyden), Roermond

8 Huisartspraktijk W.M.H. Nieuwdorp, Brunssum

9 Gezondheidscentrum 'Dr. van Kleef' (Th.G.J. Lemmens?, P.A. Stalenhoef, L.G.J. Huynen, G.A.H.M. Castermans), Maastricht

10 Huisartspraktïk H. Logister ${ }^{\dagger}$, B.T.M.G. van der Werf, Heerlen

11 Gezondheidscentrum' De Maar' (G. van Zanten, J.J. Michels, H.A.W.J. van der Wissel), Kerkrade

12 Huisartspraktijk B.H.J.M. Otten, Merkelbeek

14 Gezondheidscentrum 'Heer' (M.P.J.M. Peeters, F.H.J.A. Vissers), Maastricht

15 Huisartspraktijk E.S.M. Viggen, T.A.H. Vigen-Hamers, Geleen

16 Huisartspraktijk A. van Dam, Ch. Hanssen, Kerkrade

17 Huisartspraktijk J.H.M. Eussen, J.A.M. Ypma, C. Stuurman, Landgraaf

18 Huisartspraktijk E.I.J.F. Hubbers, Kerkrade

19 Huisartspraktijk F.L.M. Soomers, J.M.S.J.G. Soomers-Turlings, Kerkade

20 Huisartspraktikk P.H.M. Passage, J.H.J. Drenth, Kerkrade

Appendix 5.2 "The Postal Questionnaire

- 'VRAGENLIST', 1 page

Appendix 5.3 Registration Forms

- "VRAGENLIJST PAV-PROJECT" LIMBURG', 11 pages

- 'PRAKTIK-ONDERZOEKSLIIST PAY-PROJECT LIMBURG', 8 pages 


\section{Rijksuniversiteit Limburg}

VRAGENLIJST

1. Kloppen de bovenstaande persoonsgegevens ?

0 ja

a nee

Indien nee, hoe luiden deze dan?

Naam

Adres

Postcode/woonplaats

2. Wat is uw geboortedatum ?

dag, maand, jaar $\quad$....................

Wat is uw geslacht?

man / vrouw (doorhalen wat niet van toepassing is)

3. Krijgt u pijn (kramp, lloom gevoel enz.) in de

o ja

o nee kuiten of benen bij het lopen?

4. Heeft u vaak last van koude voeten ?

0 ja

a nee

5. Plookt u meer dan 15 sigaretten gemiddeld per dag ?

0 ja

0 nee

6. Wordt $u$ behandeld voor hoge bloeddruk ?

0 ja

0 nee

7. Heeft u suikerzlekte?

0 ja

0 nee

8. Bent u ooit onder behandeling geweest woor een

0 ja

0 nee hartkwaal of beroerte?

9. Komen er in de familie mensen voor (broer, zus,

0 ja

0 nee vader, moeder, oom, tante, opa, oma) die eem

hartkwaal of een beroerte gehad hebben?

Controleer of $u$ geen vragen vergeten bent.

$\mathrm{U}$ wordt verzocht de vragentijst m.b.v. de bijgevaegde retourenveloppe (postzegell iniet nodig) binnen drie weken terug te sturen.

Bedankt voor uw medewerking. 


\section{VRAGENLIJST \\ PAV-PROJECT LIMBURG}

Diagnostiek van bloedvatvernauwing

in de benen

door de huisarts

Personalia

Zijh bovenstaande gegevens correct en volledig?

Zo nee, vul dan hier beneden de juiste of ontbrekende gegevens in.

naam:

voorletters:

adres:

postcode:

woonplaats:

Houdt de toelichting bij de hand. 
Vul in:

Datum (dag warop u de lijst invult): $-19$

Vul in:

Geboortedatum:

Kruis aan:

$\square$ Man $\square$ Vrouw

Vul in:

Wat is of was uw beroep?

Deze kollom niet invullen

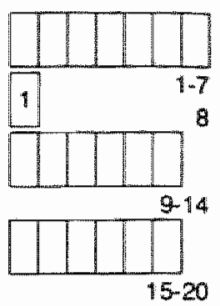

$\square$ 21

Doe nu het volgende:

- als u één of beide vragen me! "ja' beantwoord heeft, ga dén werder met vraag $3 \mathrm{t} / \mathrm{m} 14$

- anders gaat u verder met vraag 15 
Tijdens het iopen krijgt u dus, in meer of mindere mate, last van een of beide benen.

Ga verder met de volgende vragen. Lees eerst de "Toelichting".

Vul bij de vragen $3 \mathrm{t} / \mathrm{m} 6$ beide benen in. U mag bij deze vragen mér dan éen hokje per regel aankruisen.

3 Krijgt u last van kramp, en zo ja waar?

\begin{tabular}{|c|c|c|c|c|c|c|}
\hline & $\begin{array}{c}\text { geen } \\
\text { kramp }\end{array}$ & tenen & voet & kuil & $\begin{array}{l}\text { boven- } \\
\text { been }\end{array}$ & heup \\
\hline & 1 & 2 & 3 & 4 & 5 & 6 \\
\hline Linkerbeen: & $\square$ & $\square$ & $\square$ & $\square$ & $\square$ & $\square$ \\
\hline Rechterbeen: & $\square$ & $\square$ & $\square$ & $\square$ & $\square$ & $\square$ \\
\hline
\end{tabular}

4 Krilgt u last van pijn, en zo ja, waar?

\begin{tabular}{|c|c|c|c|c|c|c|}
\hline & $\begin{array}{c}\text { geen } \\
\text { piinn }\end{array}$ & tenen & voot & kuit & $\begin{array}{l}\text { boven- } \\
\text { been }\end{array}$ & heup \\
\hline & 1 & 2 & 3 & 4 & 5 & 6 \\
\hline & $\square$ & $\square$ & $\square$ & $\square$ & $\square$ & $\square$ \\
\hline lech & $\square$ & $\square$ & $\square$ & $\square$ & $\square$ & $\square$ \\
\hline
\end{tabular}

5 Krljgt u last van een moe of zwak gevoel, en zo ja waar?

geen last tenen veet kuit boven- heup bil
van moe
of zwak
gevoen

$\begin{array}{cccccccc} & 1 & 2 & 3 & 4 & 5 & 6 & 7 \\ \text { Linkerbeen: } & \square & \square & \square & \square & \square & \square & \square \\ \text { Rechterbeen: } & \square & \square & \square & \square & \square & \square & \square\end{array}$

6 Krijgt u last van een doof of tintelend gevoel, en zo ja, waar?

geenlast tenen voel kuit boven heup bil
van been
doof of
tintelend
gevoel

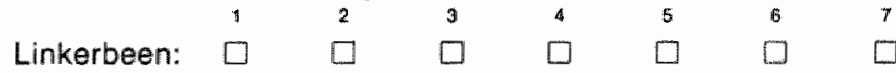

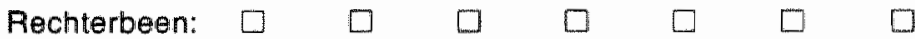

7 Krijgt u last van andere klachten in de benen tijdens het lopen, die we hierboven niet genoemd hebben?

$\square$, ja,

schriif dan hieronder in uw eigen woordlen wat u voelt:

$\square 2$ nee
Deze kolom

niet invullen
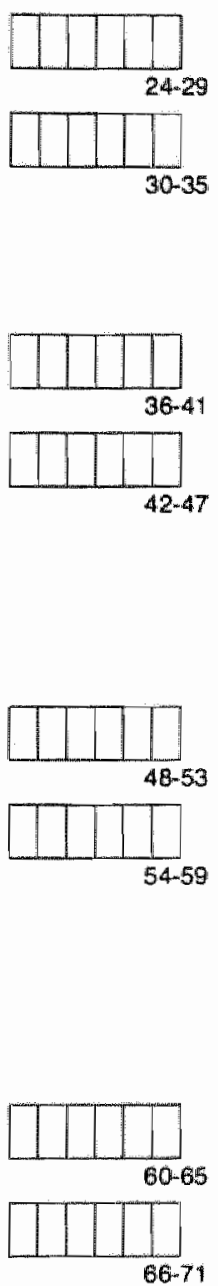

$66-71$ 
8 Als u last krijgt, wat doet u dan meestal?
[u, ik loop door in hetzelfde tempo
$\square z$ ik ga langzamer lopen
Dis ik stop

10 En wat gebeurt er als u niet doorloopt, maar stil gaat staan?

$\square$. meestal wordt het erger

$\square_{2}$ soms wordt het erger, soms blijft het hetzelfde

$\square$ meestal blijft het hetzelfde

$\square .4$ soms blift het hetzelfde, soms wordt het minder erg

$\square 5$ meestal wordt het minder erg of verdwijnt

11 En wat gebeurt er als u niet doorloopt, maar gaat ziften?

Q1 meestal wordt het erger

$\square_{2}$ soms wordt het erger, soms blijft het hetzelfde

$\square$ meestal blijt het hetzelfde

$\square$. soms blijft het hetzelfde, soms wordt het minder erg

$\square$ s meestal wordt het minder erg of verdwijnt

पo ik ga dan nooit zitten 
Tijdens het lopen krijgt $u$ in meer of mindere mate klachten in een of beide benen.

12 Hoeveel hinder ondervindt u daarvan bil de uitvoering van uw werkzaamheden (betaalde baan, huishoudelljk werk, vrljwilligerswerk, studie en dergeliljke)?
$\square$ zeer veel
$\square_{2}$ veel
$\square_{3}$ weinig
$\square_{4}$ geen

13. Hoeveel hinder ondervindt u daarvan bil] aktiviteiten dle u graag onderneemt in uw vrije Iljd (sport, hobbies, uitstaples, uitgaan, fillm- en theaterbezoek en dergellijke)?
口. zeer veel
$\square$ veel
$\square 3$ weinig
$\square$ geen

14 Hoeveel hinder ondervindt $u$ daarvan bil het onderhouden van uw sociale contacten (bezoek aan familie, vrienden, kennissen en dergelijkke)?

$D_{1}$ zeer veel

$\square 2$ veel

पlo weinig

口4 geen

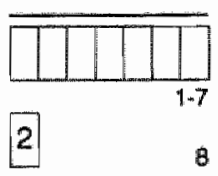

Ga verder met vraag 15 
Bil de vragen $15 \mathrm{t} / \mathrm{m} 17$ moet u beide benen invullen. Lees eerst de "Toelichting": U mag maar 1 hokje per regel aankruisen.

Deze kolom niet invulien

15 Als $u$ ('s nachts) in bed lig $t^{\text {, heeft }}$ u dan last van pifnlijke krampen in uw kuit?

\begin{tabular}{cccc} 
altijd & valik & soms nooit \\
\hline & 2 & 3 & 4
\end{tabular}

Linkerbeen: $\square \square \square$

Rechterbeen: $\square \quad \square \quad \square \quad \square$

Rechterbeen: $\square \quad \square \quad \square \quad \square$ uw voet of tenen?

altijo vaak soms nooit

17 Als u ('s nachts) in bed ligt, heeft $u$ dan last van pijn in uw voet of tenen?

$\begin{array}{rcccc} & \text { altijd } & \text { vaak } & \text { soms } & \text { nooit } \\ \text { Linkerbeen: } & \square & \square & 3 & 4 \\ \text { Rechterbeen: } & \square & \square & \square & \square \\ & \square & \square & \square\end{array}$

18. Als $u$ ('s nachts) in bed ligt, heeft $u$ dan last van andere klachten in een of beide benen (daarmee wordt alles van bil tot tenen bedoeld), dle we hierboven niet genoemd hebben?
$\square 1 \mathrm{ja}$, schrilf dan hieronder wät u voelt:
$\square:$ neo

19 Als u ('s nachts) in bed last heeft van een of belde benen, wat gebeurt er dan als u uw benen bulten bed laat bungelen?
D. het wordt erger
Q2 het bllijft hetzelfde
$\square$ s het wordt minder erg
$\square$ 4 ik heb dit nooit uitgeprobeerd
$\square$ s. ik heb nooit last van mijn benen als ik ('s nachts) in bed lig 
20 Heefl $u$ last van koude voeten?

Q

$\square_{2}$ nee

Zo nee, mannen: ga door naar vraag 24

vrouwen: ga door naar vraag 25
Deze kolom niet invulten maanden

Vraag 24 is alleen bedoeld voor mannen; vrouwen: ga door naar vraag 25

24 De volgende vraag zal u misschien verbazen. We stellen hem, omdat we duidelijk willen weten, welke klachten mensen met bloedvatvernauwing in de benen hebben. Het komt soms woor, dat man met bloedvatvernauwing geen stijf geslachtsorgaan kan krijgen, terwijl dat vroeger wel gebeurde. Overigens heeft deze klacht meestal een andere oorzaak dan bloedvatvernauwing I Onze vraag is: heeft u problemen gekregen met het stijf worden van uw geslachtsorgaan (terwill u daar vroeger of eerder geen problemen mee had)?

口. ja

$\square$ z nee 
Bif de vragen 25 um 29 moet 4 beide benen invillen. $U$ mag maar en hokje per regol aankruisen. Lees eerst de "Toelichting".

Deze kolom niet invullen

25 Als u een tijd lang zit krljgt u dán last van een of beide benen?

altijd vaak soms nooit

Linkerbeen: $\square \quad \square \quad \square \quad \square$

Rechterbeen: $\square \quad \square \quad \square \quad \square$

Linkerbeen: $\square \quad \square \quad \square \quad \square$

Rechterbeen: $\square \quad \square \quad \square \quad \square$

27 Krilgt u klachten In een of belde benen als $u$ achteroverbuigt met uw rug?

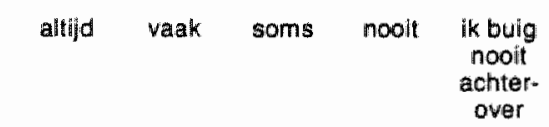

$\begin{array}{rccccc} & 4 & 2 & 3 & 4 & 5 \\ \text { Linkerbeen: } & \square & \square & \square & \square & \square\end{array}$

28 Krijgt u klachten in een of beide benen als u fletst?

altijd vaak soms nooit ikfiets

$\begin{array}{rccccc} & 1 & 2 & 3 & 4 & 5 \\ \text { Linkerbeen: } & \square & \square & \square & \square & \square \\ \text { Rechterbeen: } & \square & \square & \square & \square & \end{array}$

29 Krijgt $u$ last van een of belde benen als $u$ aan het joggen of trimmen bent?

$\begin{array}{rccccc} & \text { altijd } & \text { valk } & \text { soms } & \text { nooilt } & \begin{array}{c}\text { ik trim of } \\ \text { jog nooit }\end{array} \\ \text { Linkerbeen: } & \square & \square & 3 & 4 & 5 \\ \text { Rechterbeen: } & \square & \square & \square & \square & \square\end{array}$

Ga door met vraag 30 
Deze kolom niet invullen

30 Rookt u? (1 hokje aankruisen)

Di ja, ik rook

Ga door met vraag 31

$\square 2$ nee, maar ik heb wel gerookt

Ga door met vraag 32

$\square 3$ nee, en ik heb ook nooit gerookt

Ga door met vraag 33

31 Alleen invullen als u bij vraag 30 hokje " 1 " heeft aangekruist

Vul in (op alle regels een getal invullen):

ik rook:

jaar,

sigaretten (gemiddeld) per dag

sigaren (gemiddeld) per dag

pijpen (gemiddeld) per dag

Ga nu door met vraag 33

32 Alleen invullen als u bij vraag 30 hokje " 2 " heeft aangekruist

Vul in (op alle regels een getal invullen):

Ik ben ...........jaar geleden gestopt

Ik heb ............ jaar gerookt

ik rookte toen ............. sigaretten (gemiddeld) per dag

sigaren (gemiddeld) per dag

pijpen (gemiddeld) per dag

$39-40$

$41-42$

$43-44$

$45-46$

$47-48$

49-50

51.52

53-54

55-56

Ga nu door met vraag 33

33 Hebben een of meer van uw eigen familleleden (dus: oma's, opa's, vader, moeder, broer of zus van vader, broer of zus van moeder, uw elgen broer of zus, uw eigen zoon of dochter), een of meer van de volgende zlekten gehad:

- hartklachten, hartinfarct, hartverlamming; hersenbloeding, beroene, attaque, halfzljdige verlamming, bloedvatvernauwing in de hals, bloedvatvernauwing In de benen?

Dr ja

Wr nee 
34 Als u medicilnen in huis heett tegen pijn thoofdpiln, splerpinn, rugpiln, menstruatiepijn en dergelijke), griep of koorts, die u zonder recept bil de drogist of apotheek heeft gekocht, kunt u dan hleronder opschrijuen:

- de naam vain dat medicijn of die medicijnen (invullen), en

- hoe vaak u leder medicijn gemiddeld gebrulkt: dagelijks, wekelijks of nog minder vaak (aankrulsen)

(Zie de "Toelichting" bij vraag 34)

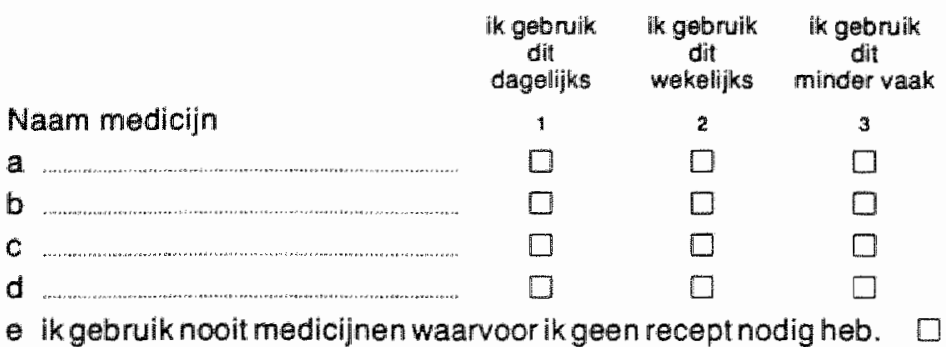

Ga door met de vragen 35,36 en 37.

In welke groep deelt $u$ uw werkzaamheden (betaalde baan, huishoudelljk werk, vrijwilligerswerk, studie en dergelljke) in, voor wat betreft lichaamsbeweging?

35 - Houding: (1 hokje aankruisen)

口. hoofdzakelijk lopend

$\square 2$ zittend en staand, soms lopend

$\square$ s hoofdzakelijk zittend

36 - Lichamelljke inspanning: (1 hokje aankruisen)

$\square$, zware lichamelijke inspanning

$\square 2$ matig zware lichamelijke inspanning

$\square$ s lichte lichamelijke inspanning

37 In walke groep deelt u uw bezlgheden in uw vrlje tljd (sport, hobbles, uitstapjes, uitgaan, film- en theaterbezoek en dergelljke) In, wat betreft llchaamsbeweging?

D. veel lichaamsbeweging

$\square_{2}$ niet weel, maar ook niet weinig lichaamsbeweging

$\square$ s weinig lichaamsbeweging

Ga door naar de volgende bladzijde. 
Vraag 37 was de laatste vraag.

Loopt $u$ alle vragen nog eens na?

Heeft $u$ alles ingevuld wat u in moest vullen?

Zijn uw naam, voorletters, adres, geboortedatum, geslacht en beroep correct ingevuld?

Heeft $u$ de datum van vandaag (boven op pagina 1) ingevuld?

Neem uw vragenlijst mee naar uw huisarts.

Uw hulsarts zal deze doorlezen.

Daarna gaat uw huisarts verder met het onderzoek.

HARTELIJK DANK! 


\section{PRAKTIJK-ONDERZOEKSLIJST PAV-PROJECT LIMBURG}

Diagnostiek van bloedvatvernauwing

in de benen

door de huisarts

Lichamelijk onderzoek

groene kaart

klinische diagnose

e-a-index I

e-a-index II

evaluatie

Personalla

Lees eerst de instructie en houdt deze bij de hand tijdens het invullen van deze formulieren. 


\section{Lichamelijk onderzoek}

Lees eerst de instructie

Datum

Onderzoekend huisarts

Onderzoeksnummer

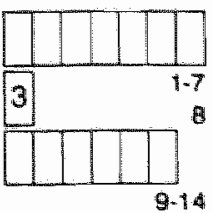

\section{ALGEMEEN}

1 Lengte $(\mathrm{cm})$ :

2 Gewicht (kg):

3 Pols (puls./min.)

4 Syst. tensie $(\mathrm{mm} \mathrm{Hg})$ :

5 Diast. tensie $(\mathrm{mm} \mathrm{Hg})$ :

6 Cor: ictus

$\square_{1}<\mathrm{mcl} \quad \square_{2}>\mathrm{mcl} \quad \square_{3}$ niet palpabel

7 Cor: regulair?

$\square$, ja

$\square 2$ nee

8 Cor: souffle?
Or ja
$\square_{2} \quad$ nee

Deze kolom

niet invullen

9.1.

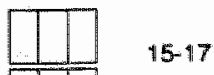

$18 \cdot 20$

$21 \cdot 23$

$24 \cdot 26$

27.29

BEHARINGSPATROON BENEN

9 Links-rechts-verschil?

$$
\begin{aligned}
& \square_{1} \quad \text { ja, links minder } \\
& \square_{2} \quad \text { ja, rechts minder } \\
& \square_{3} \text { nee, geen li-re-verschil }
\end{aligned}
$$

b Rechts

10 a Links

$\begin{array}{cc}\text { ja } & \text { nee } \\ \Downarrow & 2 \\ \square & \square \\ \square & \square\end{array}$

(n)

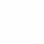

ULCERA AAN TENEN OF VOORVOET?

\section{ULCUS AAN HET ONDERBEEN?}

$\begin{array}{ccc}\text { ja, } & \text { ja, } & \\ \text { mediaal } & \text { lataraal } & \text { nee } \\ 1 & 2 & 3 \\ \square & \square & \square \\ \square & \square & \square\end{array}$

KLEUR VOET EN ONDERBEEN (liggend)

12

blaek rood blauw normal

1

2

b Rechts 
TEMPERATUUR VOETAUG

13 Links-rechts-temperatuurverschil?
口i ja, links kouder
$\square_{2}$ ja, rechts kouder
$\square$; nee, geen ll-re-verschil

\section{PALPATIE PERIFERE PULSATIES}

$$
\text { sterk }
$$

zwak

2

afwedg

3

14 A. Femoralis

a Liniks

b Rechts

15 A. Tib. Post.
a Links
$b$ Rechts

16 A. Dors. Ped.
a Links
b Rechts

$\square$

$\square$

$\square$

$\square \quad \square$

Deze kolom niet invullen

$\square$

40

41

42

43

44

45

46

47

48

a Links

$\begin{array}{ll}\square & \square \\ \square & \mathbb{\square}\end{array}$

b Rechts

Vul nu de groene-kaart-gegevens in op de volgende pagina. 
Lees eerst de instructie.

Deze kolom

\section{RISICOFACTOREN}

Geef aan, of de patient bij u bekend is met de volgende risicofactoren voor PAV:

19 angina pectoris

\begin{tabular}{|c|c|c|}
\hline D. ja & $\square_{z}$ & \\
\hline D. ja & $\square 2$ & \\
\hline D. ja & $\square_{2}$ & \\
\hline$Q_{1}$ ja & $\square 2$ & \\
\hline Dy ja & $\square_{2}$ & \\
\hline$\square i$ & $\square_{2}$ & \\
\hline ] ja & $\square_{2}$ & \\
\hline in & $\square z$ & \\
\hline
\end{tabular}

21 T.I.A.

22 C.V.A.

23 hypertensie

24 hypercholesterolemile

25 overgewicht

प. ja $\square_{2}$ nee

26 diabetes mellitus

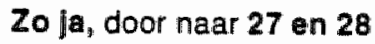

Zo nee, door naar 29

27 D.M.: welk type?

28 D.M.: goed gereguleerd?

$\square_{1} 1 \square_{2} \|$

$\square_{1}$ ja $\square_{2}$ nee

OPERATIE- EN AMPUTATIESTATUS

29 Operatie i.v.m. PAV

(m.u.v. amputatie)?

$\square$ ja $\square$ z nee

60

Zo ja, door met vraag 30

Zo nee, door met vraag 31

30 Welke operatie (z. n.

links-rechts vermelden)?

31 Amputatie i.v.m. PAV?

Zo ja, door met vraag 32

Zo nee door met vraag 33

$\square_{11}$ ja $\square_{2}$ nee

32 Geef het amputatie-nivo aan:

$\begin{array}{lcccccc} & \text { toen } & \begin{array}{c}\text { var- } \\ \text { voot }\end{array} & \text { enkel } & \begin{array}{c}\text { onder- } \\ \text { been }\end{array} & \begin{array}{c}\text { bowen- } \\ \text { been }\end{array} \\ \text { a Links } & 1 & 2 & 3 & 4 & 5 & 6 \\ \text { b Rechts } & \square & \square & \square & \square & \square & \square \\ & \square & \square & \square & \square & \square & \square\end{array}$

VOORGESCHREVEN ONDERHOUDSMEDICATIE

33 Naam

Dosering

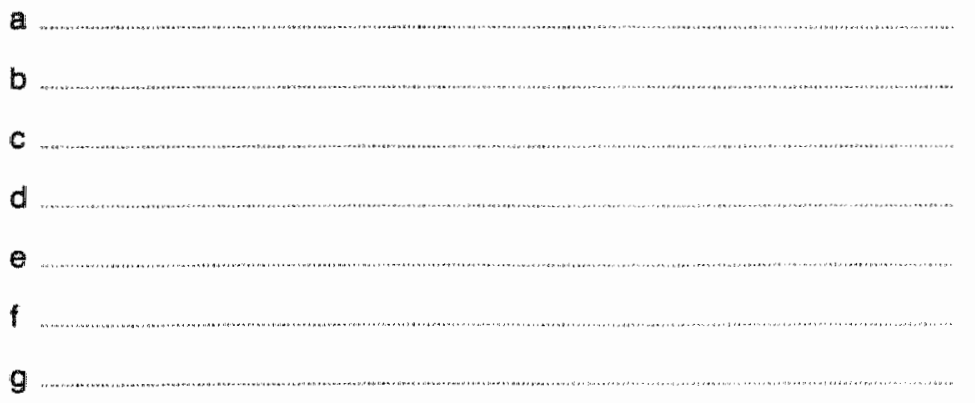

$66-67$

$68-69$

$70 \cdot 7$

$72 \cdot 73$

$74-75$

$70-87$

79.79 
Lees eerst de instructie.

34. Uw dlagnose op dit moment is:

Di deze pationt heeft hoogstwaarschijnlijk PAV (door met vraag 35)

Dz deze patient heeft mogelljk PAV (door met vraag 35)

$\square 3$ deze patient heeft waarschijnlijk geen PAV (door met vraag 36)

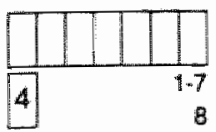

35 Deze patient heeft hoogstwaarschinnlijk of mogelijk PAV;

\section{a aan welk been?}

Q1 links

$\square_{2}$ rechts

$\square$ beide

b mate van emst?

$\square 1$ geen klachiten

प2 claudicatie, weinig invaliderend

$\square$. claudicatie, erg invaliderend

[.4 rustpijn / machtpijn / trofische stoornissen

Ds gangreen

c was patiënt (bij u) bekend met, of verdacht voor PAV, vóor dit onderzoek?

$\square 1$ ja

$\square 2$ nee

d lijdt deze patiënt daarnaast oók aan andere aandoeningen van zijn/haar been?

$\square_{i}$ ja (door met vraag e)

$\square$ nee

- om welke andere aandoeningen gaat het (max. 3)? 1

2

3

36 Deze patient heeft waarschijnlijk geen PAV. Hoe ziet uw differentiaaldiagnose er uit (max. 3)?

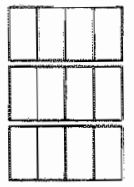

1

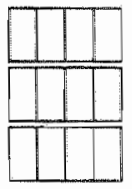

2

3 


\section{Enkel-Arm-Index; Eerste Doppler-Meting}

Lees eerst de instructie.

Datum $-19$

Onderzoeksnummer

Deze kolom niet invullen

1 Doppler-meting uitgevoerd door:

$\square$. praktijkassistente; naam:

De collega-arts; naam:

$\square 3$ huisarts die L.O. verricht heeft;

naam:

b Rechts

3 Systollische druk enkel
a Links
b Rechts

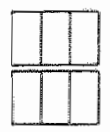

$45-47$

48.50

4 Index
a linker-enkel-druk
$\overline{\text { hoogste arm-druk }}=\square_{1}<95 \% \quad \square_{2} \geqslant 95 \%$
b rechter-enkel-druk

$$
\text { hoogste arm-druk }=\square_{1}<95 \% \quad \square_{2} \geqslant 95 \%
$$

Indien minimaal een van beide indexen kleiner is dan $95 \%$, wordt een afspraak gemaakt voor een $2 e$ meting, 1 week later (Zie formulier "Enkel-Arm-Index; Tweede Doppler-Meting").

Indien beide indexen groter dan of gelijk zijn aan $95 \%$, beschouwen we de patiënt als niet lijdend aan PAV. Hij/zij komt niet in aanmerking voor het interventieonderzoek.

HARTELIJK DANK VOOR UW MEDEWERKING 
Lees eerst de instructie.

Datum $-19$

Onderzoeksnummer

5 Doppler-meting uitgevoerd door:

Di praktijkassistente; naam:

$\square 2$ collega-arts; naam:

$\square$ * huisarts die L.O. verricht heeft;

naam:

6 Systollische druk arm

a Links

b Rechts

$7 \quad$ Systolische druk enkel
a Links
b Rechts

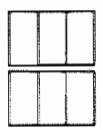

8 Index
a linker-enkel-druk
hoogste arm-druk $=\square_{1}<95 \%$
$\square_{2} \geqslant 95 \%$
b rechter-enkel-druk

$$
\text { hoogste arm-druk }=\square_{1}<95 \% \quad \square_{2} \geqslant 95 \%
$$

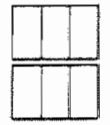

$60-62$

63-65

Indien minimaal een van beide E-A-indexen ook nu kleiner is dan $95 \%$, dan beschouwen we de patiënt als lijdend aan PAV. De patiënt komt dan in aanmerking voor opname in het interventie-onderzoek.

Indien de llaagste E-A.index gelijk is aan of groter ls dan $95 \%$, beschouwen we de patiènt als nlet lijdend aan PAV. De patiènt komt dan niet in aanmerking woor opname in het interventie-onderzoek.

De hulsarts die de patiënt klinisch onderzocht heeft, dient nu de vraag op de volgende pagina le beantwoorden: 


\section{Evaluatie}

Datum

Onderzoeksnummer

Volgens de criteria die we in het PAV-project Limburg gebruiken, heeft deze patiënt PAV, in meer of minder ernstige vorm.

9 Geef aan, wat voor u geldt in relatle tot deze patiënt:

$\square$. deze patiënt was (mij) bekend met PAV

$\square$ z deze patiënt was nlet bekend met $P A V$, maar ik verwachtte het wel op basis van mijn klinische diagnostiek in het kader van dit onderzoek

$\square 3$ deze patiënt was nlet bekend met PAV, en ik had het ook niet verwacht, gezien de resultaten van mijn klinische diagnostiek in het kader van dit onderzoek.

HARTELIJK DANK VOOR UW MEDEWERKING
Deze kolom niet invullen 


\section{DATENT QUESTIONNARE}

Date of completion and date of bith: age influences the atherosclerotic process, and therefore possibly also complaints, physical diagnosis and AB-rario.

The age of the patient at completion of the postal questionnaire is the difference berween the date of completion of the questionnare (questionnaire date) and the date of birth of the patient. The number of days of difference was divided by 365.25 in order to obtain the age in years. In case the questionnaire date was missing or the patient did not respond, the reference date taken was the median date of the period within which the postal inquiry was completed in the practice concerned. These data were necessary to demonstrate whether the responders formed an agedependent selection of the total population.

The patients were older at the time they were examined in the practice. The "age at examination' is the difference between the date on which the patient was examined (date of examination") and the date of birth. The number of days of difference was divided by 365.25 to obrain the age in years. In case the date of examination mas missing or the patient did not participate, the reference date taken was the median date of the period within which the examinations took place in the practice concerned. These data were necessary to demonstrate whether the participants formed an age-dependent selection of the population invited for examination.

The difference between the age at examination and the age at postal inquiry was due to the processing of the results of the postal inquiry and the final modification of the registration forms for the examination (investigation delay"). This shift of the age distribution to higher ages has implications for the categorization of the age distribution in the study population: the youngest age category (40-45) decreased whereas the oldest category ( $>75)$ increased in number.

Gender: gender influences the atherosclerotic process, and therefore possibly also complaints, physical diagnosis, and AB-ratio.

Occupation: imporant to obtain a global impression of the social status of the patient (analysis of risk factors), and to help assess the answers provided to the questions on physical exercise.

Quesions 1 and 2, complaints while walking. "These are the crucial opening questions: does the patient possibly have claudication or not?

Questions 3 to 7 : a specification of complaints while walking in terms of character and location. Not only are pain and cramps enquired after, but also less classic sensations and locations of complants in the leg. Question 7 offers the respondent the opportunity to indicate an aspecific complaint. These wariables an possibly refine the dinical diagnosis.

Questions 8 to 11: the influence of behaviow on the complaint. The purpose of these questions is to assess the probability of the patient having claudication. In questions 9 to 11, 5- or 6-point scales are used in order to ascertain whether less classic pain patterns occur.

Quentions 12 to 14: infuence of the walking complaints on daily life. These questions are intended to yield a view as to what extent the parient is encumbered by his leg complaints in social activities. In order to have the parient make a clear choice, a 4-point scale was selecred here. These questions may yeld data that could make it worth while to evaluate more closely the social consequences of intermittent claudication.

Questions 15 to 19: complaints at rest. These questions deal with complaints at night, both of possible claudicants and of non-claudicants. Question 18 is an open question, so that less classic complants may be reported also. Question 19 is a 'test question': in classic PAOD the patient should have less complaints on suspending the leg outside the bed.

Qmestions 20 to $23:$ cold feet. The literarure is equivocal in its judgenent as to whether cold feet are a symprom of PAOD or not. The trend seemed to be: "no, unless the complaint developed recently and is unilateral". 
Qwestion 24: erection problems. This question is considered important for the evaluation of the extent and consequences of PAOD. A pilot study among parients indicated that there were no major objections to this question.

Qmestions 25 to 29. some differential diagrostic questions. Sitring, standing, or bending back wards should not give complaints in classical PAOD, in contrast to cycling and running. "The answers may indicate to what extent other disorders possibly (also) contribute to the complaints of the patient, such as osteoarthritis, venous insufficiency, spinal stonosis, atc.

Questions 30 to 32: moking. This is an important risk factor. Presumably, the data provided by the patient himself are more reliable and complete than those of the general practitioner.

Question 33: atherosclerosis in the famly. A risk factor of which the patient possibly has a different view than the general practitioner.

Question 74: selfmedication. The goal of this question is to identify the use of salicylic acid derivatives. This could infuence both the pattern of complaints and the AB-ratio.

Qwestions 35 to 37: physical exercise. The purpose of these questions was to gaim a global view of the extent of physical exercise of the patient. Much exercise may have a protective infuence, while litte exercise may have a masking effect. Much exercise also can have a provoking effect on complaints. Depending on the outcome, a more detailed study in this area could be worthwile.

\section{THE GENERAL PRACTITIONER 'S FORM}

The physical examiration (itens 1-18) was carried out by the general practitioner according to protocol.

Jems 1 to 8: general: obesity (burden for the legs, risk factort) and a number of basic vascular data

Items 9 to 13: inspection for trophic skin changes. There is no consensus in the literature on the significance of the pattern of hair growth, ulcers, and the skin colour of the legs in relation to PAOD.

Items 14 to 18 : peripheral pulsations. The palpation of peripheral arterial pulsations, is well as the auscultation of the femoral arteries, are traditional aspects of the physical examination. Nonetheless, the literature gives reason to doubt the signilicance of these procedures with regard to diagnosing $P A O D$.

The dependency test of Ratschow-Burger was not investigated. Considering that this test is presumably only rarely applied in general practice, and that its inclusion in the study would have demanded extra time from the general practitioners, it was decided not to examine this wariable.

Data frow the patient recond (items 19 to 33) were copied onto the registration fom by the general practioner.

Items 19 to 28: risk factors. Concerned were risk factors as they were known to the general practitioner. In view of the present uncertainties in the literature one might have wished, in hindsight, that serum cholesterol (and triglyceride) levels were also assessed. The reasons for not including these assessments were the following:

- the primary purpose of including items 19 to 28 was to establish in how far data from the patient record - i.e. risk factors known to the general practitioner - can contribute to the general practitioner's diagnostic judgement

- a higher drop-out rate was expected if the parients were to be subjected to an invasive cest (in hospital or health centre)

Items 29 to 33: exclusion criteria for the course G intervention study".

- vascular surgery (items 29 to 33 ) use of salicylic acid derivatives and oral anticoagulants (item 33)

Lem 33: wasoactive medication. Item 33 also served to establish which drugs the patient uses. Especially important are ergotamine preparations, betablockers, calcium antagonists, and other 
vasodilators. These could be confounding variables with respect to the pattern of complants and the $A B$ ratio.

Clinical diagnosis, differential diagnosis, and other leg problems (items 34 to 36 ):

Clinical diagnosis and differential diagnosis: here the general practitioner gave his own opinion on the parient, based on the pattern of complaints (questionnaire), the findings of the physical examination, and the data from the patient record, against the background of his knowledge of the patient and of the latter's (illness) behaviour. It was considered important to compare the summational judgement of the general practitioner with the diagnostic models resulting from the multiwariable analysis.

Other leg complaints: in order to identify diagnostic relationships in the study population, it is essential to know what effect the selection process had on disorders other than PAOD which can cause leg complants. Moreover, the extent of the PAOD problem can thus be compared to the extent of other leg problems in the study population. The 'other leg complaints' were categorized as follows:

- Raynaud's discase, Bürger's discase, chillblained teer

- varicose veins, venous insufficiency, venous ulcer

- osteoarthritis hip, knee, ankle, leg n..o.s

- peripheral neuropathy, lumbar disc lesion, sciatic pain, neuralgia

- restless legs, paraesthesia, muscular cramps

pain and other complaints of legs n.o.d.

- no leg problems

Evaluation: filled in by the general practitioner after the AB-ratio was assessed. For each patient considered no have PAOD on the basis of two consecutive AB-ratio measurements yielding $<0.95$, the general practitioner had to indicate whether the subject was already known as such. The literature suggests that there are many unknown parients wirh PAOD.

\section{Appendix Chapter 6 Additional tables}

Abbreviations: $S$ source population, $\mathbb{R}$ responders (postal inquiry), NR non-responders, I invited population, P participants, study population, NP non-participants

Appendix 6.1 Age distribution in the source, response and non-response population

\begin{tabular}{lccc} 
& $\mathrm{S}$ & $\mathrm{R}$ & $\mathrm{NR}$ \\
\hline Total & 26620 & 23004 & 3616 \\
Missingags & 975 & 66 & 909 \\
$\mathrm{~N}$ & 25654 & 22938 & 2707 \\
\hline Range $(\mathrm{yr})$ & $40.3-76.9$ & $40.3-76.9$ & $40.3-76.7$ \\
$\mathrm{SD}(\mathrm{yr})$ & 9.8 & 9.8 & 10.0 \\
Mean $(y \mathrm{r})$ & 56.5 & 56.5 & 56.5 \\
Median $(y \mathrm{r})$ & 56.1 & 56.1 & 56.0 \\
\hline
\end{tabular}


Appendix 6.2 Proportion of non-responders in different age-categories

\begin{tabular}{llcll} 
Age category & $S$ & $\mathrm{NR}$ & $\% \mathrm{NR}$ & $95 \% \mathrm{Cl}$ \%RR \\
\hline $40 \leq 45$ & 3989 & 424 & 10.6 & 9.6711 .6 \\
$45 \leq 55$ & 7919 & 852 & 10.7 & $10.1-11.4$ \\
$55 \leq 65$ & 7915 & 797 & 10.1 & $9.41-10.7$ \\
$65 \leq 75$ & 5266 & 556 & 10.6 & $9.73-11.4$ \\
$>75$ & 556 & 79 & 14.2 & $11.3-17.1$ \\
\hline $\mathrm{N}$ & 25645 & 2707 & 10.6 & $10.2-10.9$ \\
\hline
\end{tabular}

$p=0.0377$

Appendix 6.3a Distribution of gender in the source, response and non-response population. Crude data.

\begin{tabular}{|c|c|c|c|}
\hline & S & R & NR \\
\hline Total & 26620 & 23004 & 3616 \\
\hline Missing gyedater & 18 & 18 & 0 \\
\hline $\mathrm{N} \quad(\%)$ & $26602(100.0)$ & $22986(100.0)$ & $3616(100.0)$ \\
\hline Male $(\%)$ & $12563(47.2)$ & $10911(47.5)$ & $1652(45.7)$ \\
\hline Female $(\%)$ & $13866(52.1)$ & $12075(52.5)$ & $1791(49.5)$ \\
\hline Unknown $(\%)$ & $173(0.7)$ & $0(0)$ & $173(4.8)$ \\
\hline
\end{tabular}

When the dara on gender that were either not filled in (18) or unknown (173) would be divided according to the observed gender distribution in $S_{3}$ the result would be 91 men and 100 women. These figures are incorporated in appendix $6.3 \mathrm{~b}$, in which the $95 \%$ confidence intervals of the percentages are also given.

Appendix 6.3b Distribution of gender in the source, response and non-response-population. Data adjusted for 'missing' and 'unknown'

\begin{tabular}{|c|c|c|c|}
\hline & $s$ & $R$ & $N R$ \\
\hline Male $(\%)$ & $12654(47.5)$ & $10920(47.5)$ & $1734(48.0)$ \\
\hline 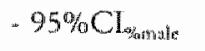 & $46.9-48.1$ & $46.9-4.8 .1$ & $46.4-49.6$ \\
\hline Female $(\%)$ & $13966(52.5)$ & $12084(52.5)$ & $1882(52.0)$ \\
\hline 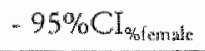 & $51.9-53.1$ & $51.9-53.1$ & $50.4-53.6$ \\
\hline Total $(\%)$ & $26620(100.0)$ & $23004(100.0)$ & $3616(100.0)$ \\
\hline
\end{tabular}

$\mathrm{p}=0.588$

Appendix 6.4 Proportion of non-responders by gender. Based on table 6.3b.

\begin{tabular}{lll} 
Gender & 95\%-confidence interval \\
\hline Male & 13.7 & $13.1-14.3$ \\
Female & 13.5 & $12.9-14.1$ \\
\hline Total & 13.6 & $13.2-14.0$
\end{tabular}


Appendix 6.5 Representatiweness, for age and gender, of both random samples from the response population

\begin{tabular}{|c|c|c|c|c|c|c|c|}
\hline \multicolumn{2}{|c|}{ Category } & $\begin{array}{l}\text { I } \\
\text { group } 1\end{array}$ & $\begin{array}{l}R, \\
\text { scote } 0\end{array}$ & 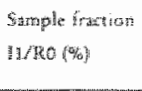 & $\begin{array}{l}I_{y} \\
\text { group } 2\end{array}$ & $\begin{array}{l}\mathrm{R}_{3} \\
\text { scone } 1-5\end{array}$ & 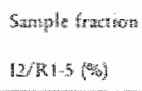 \\
\hline \multirow[t]{5}{*}{ Age } & $40 \leq 45$ & 94 & 1778 & 5.29 & 118 & 1787 & 6.60 \\
\hline & $45 \leq 55$ & 137 & 2997 & 4.57 & 248 & 4071 & 6.09 \\
\hline & $55 \leq 65$ & 132 & 2666 & 4.95 & 296 & 4452 & 6.65 \\
\hline & $65 \leq 75$ & 81 & 1491 & 5.43 & 214 & 3219 & 6.65 \\
\hline & $>75$ & 6 & 124 & 4.84 & 18 & 353 & 5.10 \\
\hline \multicolumn{2}{|l|}{$N_{i g k e}$} & 450 & 9056 & 4.97 & 894 & 13882 & 6.44 \\
\hline \multicolumn{2}{|c|}{ Missingage } & $\mathbb{1}$ & 39 & & 3 & 27 & \\
\hline \multirow[t]{2}{*}{ Gender } & Male & 206 & 4282 & 4.81 & 412 & 6629 & 6.22 \\
\hline & Female & 245 & 4807 & 5.10 & 485 & 7268 & 6.67 \\
\hline \multicolumn{2}{|l|}{$N_{\text {zignder }}$} & 451 & 9089 & 4.96 & 897 & 13897 & 6.45 \\
\hline \multicolumn{2}{|c|}{ Missing grepder } & 0 & 6 & & o & 12 & \\
\hline
\end{tabular}

Pearson chi-squares: age: sample II/RO: $p=0.706$, sample I2/R1-5: $p=0.644$; gerder: sample I1/RO: $\mathrm{p}=0.531$, sample $\mathrm{I} 2 / \mathrm{R} 1-5: \mathrm{p}=0.272$

Appendix 6.6 Age distribution in the invited, study, and non-participant population (age at time of postal inquiry)

\begin{tabular}{lccc} 
& $\mathrm{I}$ & $\mathrm{P}$ & $\mathrm{NP}$ \\
\hline Total & 5301 & 3654 & 1647 \\
Missingag & 6 & 0 & 6 \\
$\mathrm{~N}$ & 5295 & 3654 & 1641 \\
\hline Range $(\mathrm{yr})$ & $40.3-76.9$ & $40.3-76.9$ & $40.5-76.8$ \\
$\mathrm{SD}(\mathrm{yr})$ & 9.8 & 9.6 & 10.2 \\
Mean $(\mathrm{yr})$ & 58.7 & 58.1 & 60.0 \\
$-95 \% C I_{\text {meai }}$ & $58.4-59.0$ & $57.8-58.4$ & $59.5-60.5$ \\
Median $(\mathrm{yr})$ & 59.1 & 58.3 & 61.1 \\
\hline
\end{tabular}

Appendix 6.7 Proportion of non-participants in different age-categories lage at time of postal inquiry) of the invited population

\begin{tabular}{|c|c|c|c|c|}
\hline Age category & I & $\mathrm{NP}$ & $\% N P$ & $95^{\circ} \mathrm{Cl}_{\%_{k} \mathrm{NP}^{*}}$ \\
\hline $40 \leq 45$ & 594 & 178 & 30.0 & 26.3 .33 .7 \\
\hline $45 \leq 55$ & 1387 & 371 & 26.7 & $24.4-29.1$ \\
\hline $55 \leq 65$ & 1713 & 464 & 27.1 & $25.0-29.2$ \\
\hline $65 \leq 75$ & 1436 & 553 & 38.5 & 36.041 .0 \\
\hline$>75$ & 165 & 75 & 45.5 & $37.9-51.1$ \\
\hline$N$ & 5295 & 1641 & 31.0 & $29.7-32.2$ \\
\hline
\end{tabular}

$p<<0.0001$. 
Appendix 6.8 Distribution of gender in the invited, study, and non-participant population

\begin{tabular}{|c|c|c|c|}
\hline & I & $\mathrm{p}$ & $\mathrm{NP}$ \\
\hline Total & 5301 & 3654 & 1647 \\
\hline Missing gyender & 2 & 0 & 2 \\
\hline $\mathbb{N} \quad(\%)$ & $5299(100.0)$ & $3654(100.0)$ & $1645(100.0)$ \\
\hline Male $(\%)$ & $2535(47.8)$ & $1719(47.0)$ & $816(49.6)$ \\
\hline 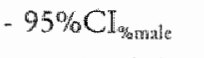 & $46.5-49.1$ & $45,4-48.6$ & 47.2 .52 .0 \\
\hline Female $(\%)$ & $2764(52.5)$ & $1935(53.0)$ & $829(50.4)$ \\
\hline$-95 \% \mathrm{Cl}_{\text {oibermale }}$ & $50.9-53.5$ & $51.4-54.6$ & $48.0-52.8$ \\
\hline
\end{tabular}

$p=0.084$

Appendix 6.9 Proportion of non-participants by gender

\begin{tabular}{lll} 
Gender & $\%$ NP & $95 \%$ confidence inverval \\
\hline Male & 32.2 & $30.4-34.0$ \\
Female & 30.0 & $28.3-31.7$ \\
\hline$N$ & 31.1 & $29.9-32.3$ \\
\hline
\end{tabular}

Appendix 6.10 Distribution of "score" in the invited, study, and non-participant population and proportion of non-participants in each category of "score".

\begin{tabular}{|c|c|c|c|c|c|}
\hline Score & $\mathbb{I}$ & $\mathrm{P}$ & $\mathrm{NP}$ & $\% \mathrm{NP}^{2}$ & $95 \% \mathrm{Cl}_{\text {wan }}$ \\
\hline 0 & 451 & 292 & 159 & 35.3 & $30.8-39.7$ \\
\hline 1 & 562 & 389 & 173 & 30.8 & $27.0-34.6$ \\
\hline 2 & 2614 & 1869 & 745 & 28.5 & $26.8-30.2$ \\
\hline 3 & 1166 & 776 & 390 & 33.4 & $30.7-36.2$ \\
\hline 4 & 384 & 244 & 140 & 36.5 & $31.6-41.3$ \\
\hline 5 & 124 & 84 & 40 & 32.3 & $24.0-40.5$ \\
\hline Total & 5301 & 3654 & 1647 & 311 & $29.8 \times 32.3$ \\
\hline
\end{tabular}

$p=0.0012$

Appendix 6.11 Distribution of 'group' in the invited, study, and non-participant population and proportion of non-participants in each category of 'group'.

\begin{tabular}{lccccc} 
Group & I & P & NP & $\% N P$ & $95 \% C I_{\% N P}$ \\
\hline 1 ("no risk) & 451 & 292 & 159 & 35.3 & $30.8-39.7$ \\
2 ("increased risk") & 897 & 626 & 271 & 30.2 & $27.2-33.2$ \\
3 ("high risk") & 3953 & 2736 & 1217 & 30.8 & $29.3-32.2$ \\
\hline Total & 5301 & 3654 & 1647 & 31.1 & $29.8-32.3$ \\
\hline
\end{tabular}

$\mathrm{p}=0.126$ 
Appendix Chapter 8 Comparison of ROC-curves (for the GPC AB-ratio): confidence intervals, optimum cutoff values.

\author{
Anold DM Kester, Henri EIH Sroffers
}

A $95 \%$ confidence interval for the optimal cutolf value was obtained by resting for each possible cutoff watue the hypothesis that chere is no difference in walidity (= the sum of sensitivity and specificicy) between the optimum cutoff value and that specific cutoff value (chi-square test). The most extreme values for which the hypothesis was not rejected were taken as the limits of the interwal.

The equality of the optimum cutof values in the ROC curves of both sexes was analyzed by testing this hypothesis in the "male" and in the "female" curve; the tests were combined using the MantelHaenszel technique. The difference was non-significant $(p=0.3)$. The equality of the maximum validity in both curves was tested by division of the difference of the estimated maximum walidities by rhe estimated s.e. of that difference $(p=0.27)$.

Parametric comparison of ROC curves is usually done under the assumption of a normal distribution in both groups, possibly after a suitable transformation. However, in our data a satisfactory fit to the raw curve was not obtained that way. Therefore the ROC curve was smoothed. Using logistic regression the probability of $\mathrm{PAOD}$ at each value $X$ for the $\mathrm{AB}$-ratio was estimated. "The formula gives these probabilities assuming estimated parameters $a$ and $b$ from a linear logistic model:

$$
\operatorname{Prob}(P A O D \mid X)=\frac{\exp (a+b \cdot X)}{1+\exp (a+b \cdot X)}
$$

Subsequently, the sensitivity and specificity at each possible cutoff $C$ according to this model are calculated as

$$
\text { sens }_{\text {manilell }}(C)=\frac{\sum \operatorname{Prob}(P A O D \mid X)}{\sum \operatorname{Prob}(P A O D \mid X)} \text { and } \operatorname{spec}_{\text {modal }}(C)=\frac{\sum_{x>C} 1-\operatorname{Prob}(P A O D \mid X)}{\sum 1-\operatorname{Prob}(P A O D \mid X)}
$$

The smoothed ROC curve was obtained by plotting sens model against 1-spec model. Using a third degree logistic model for the probabilities, a close fit was obtained. For the means of 3 consecutive AB-ratio measurements, a linear logistic model was used.

For each of these techniques a method was used which allowed for the dependence of left and right legs of each patient (generalized estimating equations). 2,3 "The correlation coefficient of left and right legs was approximately 0.35.

\title{
References
}

1 Goddard MJ, Hinberg 1. Receiver operator characteristic (roc) curves and non-normal data: an empirical study. Statist in Medicine 1990; 9: 325 37.

2 Zeger SL, Liang KY. Longitudinal data analysis for discrete and continuous outcomes. Bionetrics 1986; $42: 121-30$.

3 Karn MR, Zeget SL. GEE: a SAS macro for longitudinall data analysis. Baltimore: John Hopkins University, 1988.

4 Gebski V, Lenng O, MoNeil D, Lunn D. SPIDA version 6. Eastwood: Statistical Laboratory Maquarie Unuersity, 1992. 


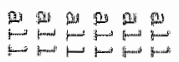
(1) (1) th of of to

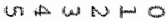

in 2 a the

UE

on wh n w

000 w or $-100 \mathrm{w}$ an on 4 a $y$ in an on un in ent

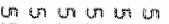
mi un un en का मी दो को

15. in ax

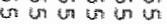

क w 0 का I t $N$ is o
4. W क v 0 un and on w 1 is w mon w $\infty \mathrm{NO} 0$

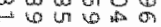

is

w the in w on 000000 (1) क 6 w 4 0 in $\rightarrow \infty$ is o 0000 080900 898998 NWNOB Now on w w b.0000 in on 0 a 00 w on 4000

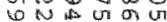
000000 ONMGO 6 他

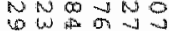
w w in is NNF 000000 800 ha w w o w on w o) $\mathrm{N}$ w 0 or w on 0
Nos 00000 ow w w o o vi wh 0 . . . जा 00 o 00 i Un un $\omega$ d 000000 80000 000090 $N$ woro

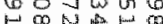
$\rightarrow \infty \begin{array}{ll}1 \\ 4\end{array}$ 100001

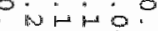
o U日 un w 0 แ and जi 000000

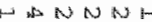
an wo no - vin w w w w a 40 on 00 000000 - No is us (9. 0 is 4 列 di wo a

$\frac{5}{3}$

w

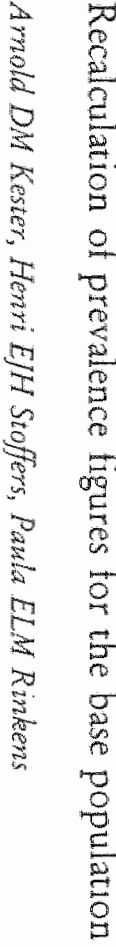

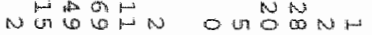

000000

0000

$9+1400$

an

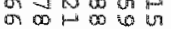

a g w w o

000000

989980

No 000

ow

$\$ 6$, Un

10000.

- ondo.

0 w w w

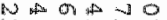

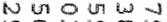

Un of the to no

000000

w N N i

ज的 $N$ wit w om

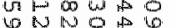

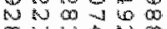

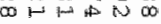

000000

000 in w

On w on w w w o o s u

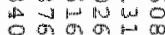
wo 00 in 0 oा 400 - 0 w w ด. 0000 0808 90908 Ont w th क o Doll "8.0 a in the

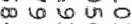
it un $N$ on 0 is w w is 00000 in a on 1 w कू to Un $\forall N N$ N 0 जu: 0 in 00000 $0001 \omega x$ OH:

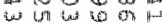

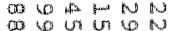




\section{Formulas}

score prior risk score on postal inquiry

study $n_{i}$ number of subjects with a specific score in the study popularion

resp. $\mathrm{N}_{i}$ number of subjects with a specific score in the base population

PAOD number of patients with wariale of interest (here: PAOD) in the study population

$P_{3} \quad$ prevalence of variable in each category of 'score' in the study population $=(P A O D / \mathrm{m})$

var $\left(\mathrm{p}_{\mathrm{i}}\right) \quad$ variance of $\mathrm{p}_{\mathrm{i}}=\left\{P A O D \times\left(n_{1}-P A O D\right)\right\} / n^{3}$

ci L(p) left side of $95 \%$ confidence interval for $\left.\mathrm{p}_{\mathrm{i}}=p_{\mathrm{i}}-1.96 \sqrt{\mathrm{var}} \mathrm{p}\right)$

ci $R(p)$ right side of $95 \%$ confidence interval for $\mathrm{P}_{i}=p_{i}+1.96 \sqrt{ }$ var $(p)$

$\mathrm{C}^{-} \quad=N_{i} / \mathrm{LN}$

$\mathrm{P}$ prevalence of variable in the base population $=\Sigma\left(\mathrm{C}_{i} \times p_{i}\right)$

Vart $(P) \quad$ variance of $P=\Sigma / C_{i}^{2} \times$ atar $\left.(p)\right)$

ci $L(P) \quad$ left side of $95 \%$ confidence interval for $P=P-1.96 \sqrt{ } \operatorname{Var}(P)$

ci $R(P)$ right side of $95 \%$ confidence interval to $P=P+1.96 \sqrt{ } \mathrm{Var}(P)$

\section{Appendix Chapter 10 Calculation of the predicted probability of PAOD using} the multivariable logistic regression models

The probability of PAOD being present can be estimated according to the formula

$$
P=1 /\left\{1+e^{-m}\right\}
$$

where $g=\left(a+b_{1} x_{1}+b_{2} x_{2}+\ldots b_{i} x_{i}\right) a$ is the coefficient of the constant in the model, and $b_{x}, b_{3}, b_{\text {; }}$ are the coefficients of the wariables in the model.

For our most comprehensive model (4) the coefficients are given in table 10.4. The values of the $x_{i} s$ is $O$ if the test has a negative (normal) outcome, and 1 if the test has a positive (abnormal) outcome. Below the calculations are given for the examples given in the section "Results" of chapter 10 (model 4).

Example 1: at woman, 62 years old, with intermitent claudication, abnormal pedal pulses, and all other 'tests' negative has a probability of

$$
1 /\left\{1+a^{-1-5.06+0.88+1.18+2.59}\right\}=0.37
$$

to have PAOD in this leg.

Example 2: a man, 75 years old, with intermittent claudication, abnormal pedal pulses, a femoral bruit, who snokes and other tests negative, has a probability of

$$
1 /\left\{1+e^{-\{-9.04+0.25+0.78+1.18+2.55+1.40+0.804\}}\right\}=0.87
$$

to have $P A O D$ in this leg.

In the same way less differentiated predictions an be made usirng the less extensive models (13). The coefficients of these models can be recalculated from the odds ratios (OR), using the Comula

$$
b_{s}=m(O R)
$$

where $m$ is the natural logarithm. 